LA-14259-T

Thesis

Approved for public release;

distribution is unlimited.

\title{
Heat Transfer Analysis and Assessment of Kinetics Systems for PBX 9501
}


This thesis was accepted by the Department of Mechanical Engineering, Colorado State University, Fort Collins, Colorado, in partial fulfillment of the requirements for the degree of Master of Science.

Los Alamos National Laboratory, an affirmative action/ equal opportunity employer, is operated by Los Alamos National Security, LLC, for the National Nuclear Security Administration of the U.S. Department of Energy under contract DE-AC52-06NA25396.

This report was prepared as an account of work sponsored by an agency of the U.S. Government. Neither Los Alamos National Security, LLC, the U.S. Government nor any agency thereof, nor any of their employees make any warranty, express or implied, or assume any legal liability or responsibility for the accuracy, completeness, or usefulness of any information, apparatus, product, or process disclosed, or represent that its use would not infringe privately owned rights. Reference herein to any specific commercial product, process, or service by trade name, trademark, manufacturer, or otherwise does not necessarily constitute or imply its endorsement, recommendation, or favoring by Los Alamos National, LLC, the U.S. Government, or any agency thereof. The views and opinions of authors expressed herein do not necessarily state or reflect those of Los Alamos National Security, LLC, the U.S. Government, or any agency thereof. Los Alamos National Laboratory strongly supports academic freedom and a researcher's right to publish; as an institution, however, the Laboratory does not endorse the viewpoint of a publication or guarantee its technical correctness. 
LA-14259-T

Thesis

Issued: July 2006

Heat Transfer Analysis and Assessment

of Kinetics Systems for PBX 9501

Jeffrey W. Jorenby 


\section{Acknowledgments}

The author would especially like to recognize his advisors, many of whom sacrificed countless hours for the success of this research: Dr. Fred W. Smith (Advisor and Professor of Mechanical Engineering), Dr. Snezana Konecni (Mentor at Los Alamos National Laboratory), and Dr. Robert Meroney (Professor of Mechanical Engineering, working as a member of the Department of Civil Engineering). The author extends special thanks to Armando Vigil (employee of Los Alamos National Laboratory with over 28 years of experience in high explosives research).

The author would also like to recognize the following agencies: Los Alamos National Laboratory for the graduate research position, the Weapon Response Group (WR) from the Engineering Sciences and Applications Division (ESA) for guidance and direction, and the Department of Energy for research funding. 


\title{
COLORADO STATE UNIVERSITY \\ Committee on Graduate Work
}

Fall 2005

\begin{abstract}
WE HEREBY RECOMMEND THAT THE THESIS PREPARED UNDER OUR SUPERVISION BY JEFF W. JORENBY, ENTITLED HEAT TRANSFER ANALYSIS AND ASSESMENT OF KINETICS MODELS FOR PBX 9501, BE ACCEPTED AS FULFILLING IN PART REQUIREMENTS FOR THE DEGREE OF MASTER OF SCIENCE.
\end{abstract}

\author{
Dr. Fred Smith, Advisor \\ Dr. Robert Meroney, Committee Member \\ Dr. Snezana Konecni, Committee Member \\ Dr. Allan Kirkpatrick, Mechanical Engineering Department Head
}





\section{TABLE OF CONTENTS}

LIST OF FIGURES.

LIST OF TABLES.

NOMENCLATURE

ABSTRACT

1.0 INTRODUCTION: BACKGROUND AND STATE OF THE ART ……..................................

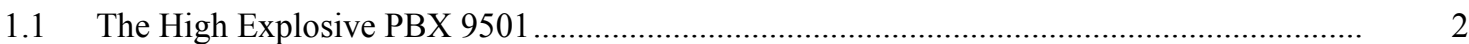

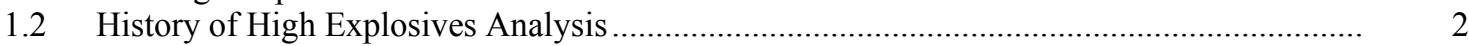

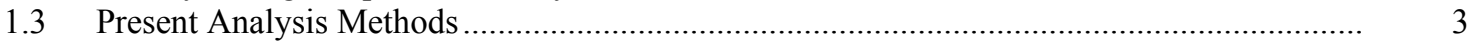

2.0 PURPOSE: ASSESSMENT OF KINETICS SYSTEMS TO PREDICT THE TIME TO

IGNITION AND LOCATION OF THE IGNITION POINT …….......................................

$2.1 \quad$ The Three Kinetics Systems.........................................................................

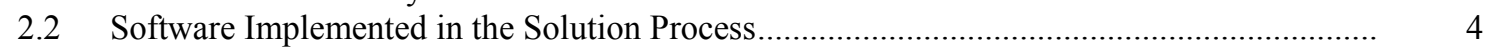

2.3 The Four Experiments......................................................................................................... 5

2.4 Comparison of the Simulation Results with the Four Experiments ....................................... 5

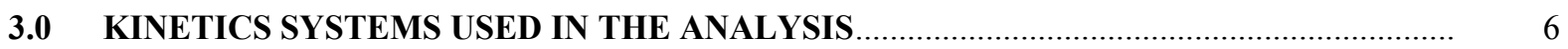

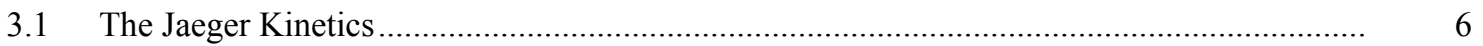

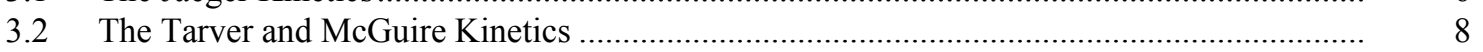

3.3 Dickson et al. Kinetics ...................................................................................... 10

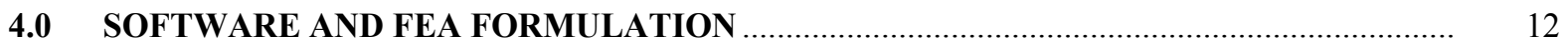

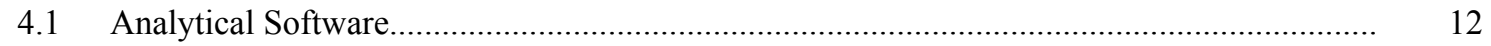

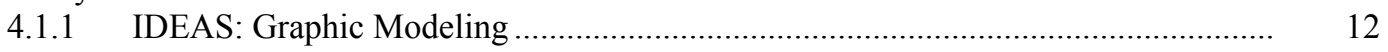

4.1.2 EnSight: Pre-Process and Post-Process Visualization ........................................... 13

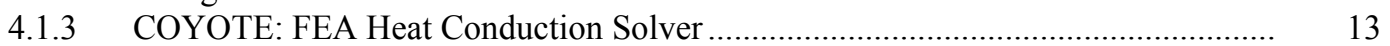

4.1.4 Excel: Analysis Compilation ........................................................................ 13

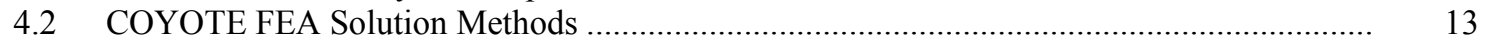

4.2.1 The Heat Conduction Equation....................................................................... 14

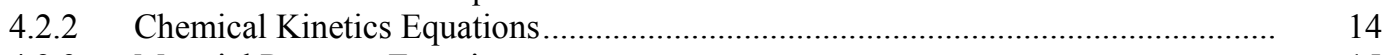

4.2.3 Material Property Equations ......................................................................... 15

5.0 THE FOUR EXPERIMENTS USED IN THE KINETICS ASSESSMENT ……….................. 15

5.1 The LLNL Scaled Thermal Explosion Experiment (STEX) for Confined Cylinders ............ 16

5.2 The LLNL One-Dimensional Time to Explosion (ODTX) Experiments for Spheres .............. 19

5.3 The LANL Unconfined One-Dimensional Experiments for Spheres ................................. 24

5.4 The Naval Air Warfare Center Weapons Division Experiments at China Lake for Confined Cylinders

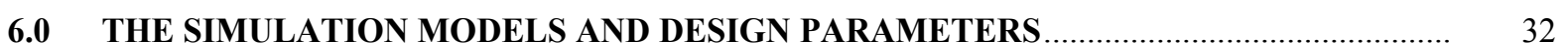

6.1 The LLNL Scaled Thermal Explosion Experiment (STEX) for Confined Cylinders ............. 33

6.2 The LLNL One-Dimensional Time-to-Explosion (ODTX) Experiments for Spheres............ 36

6.3 The LANL Unconfined One-Dimensional Experiments for Spheres ................................... 40

6.4 The Naval Air Warfare Center Weapons Division Experiments at China Lake for Confined Cylinders

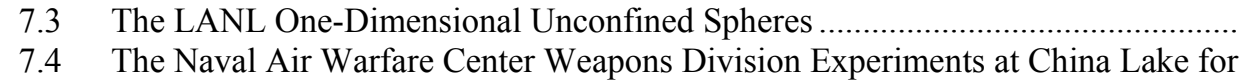
Confined Cylinders 
APPENDIX A

A-1

A.1. Example of an Input File for the STEX Model Using the Dickson et al. Kinetics................. A-1

A.2. Example of an Input File for the STEX Model Using the Jaeger Kinetics ......................... A-9

A.3. Example of an Input File for the STEX Model Using the Tarver and McGuire Kinetics...... A-16

A.4. User-Defined Conductivity, USRCON, for the Dickson et al. Kinetics ........................... A-24

A.5. User-Defined Specific Heat, USRCP, for the Dickson et al. Kinetics ............................. A-27

APPENDIX B

B-1

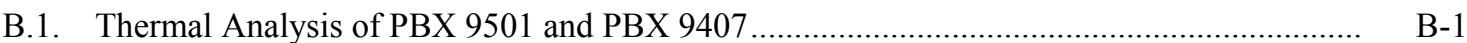

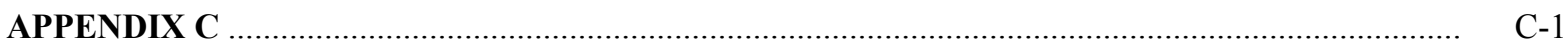

C.1. STEX Data from the Dickson et al. Kinetics ............................................................. C-1

C.2. STEX Data from the Jaeger Kinetics .............................................................................. C-4

C.3. STEX Data from the Tarver and McGuire Kinetics........................................................... C-6

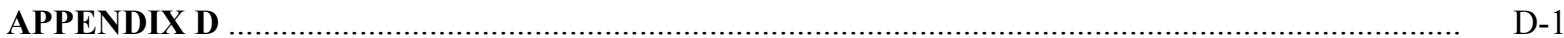

D.1. Results Using the Dickson et al. Kinetics System....................................................... D-1

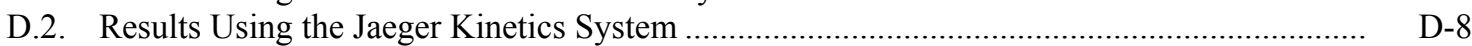

D.3. Results Using the Tarver \& McGuire Kinetics System.............................................. D-15

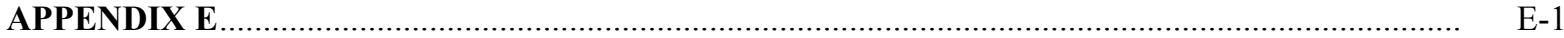

E.1. Unconfined Sphere Data Using the Dickson et al. Kinetics.......................................... E-1

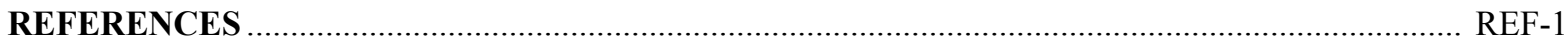




\section{LIST OF FIGURES}

Figure 5.1: $\quad$ Rendition of STEX preliminary design vessel …............................................................. 16

Figure 5.2: $\quad$ STEX vessel mounted with thermocouples................................................................... 17

Figure 5.3: Side and top views of the STEX vessel shown in a blast containment chamber...................... 18

Figure 5.4: Thermocouple profile of the PBX 9501 in the LLNL STEX experiment. ........................... 19

Figure 5.5: Rendition of the ODTX aluminum anvils ........................................................................ 20

Figure 5.6: The ODTX experimental test device............................................................................. 21

Figure 5.7: Cross-sections showing the thermocouple locations highlighted in pink for the

2.54-cm-diameter and 7.62-cm-diameter unconfined spheres ............................................ 25

Figure 5.8: Critical-temperature test chamber for unconfined spheres up to $8.0 \mathrm{~cm}$ in diameter........... 26

Figure 5.9: $\quad$ Unconfined spherical data from Test 1..................................................................... 27

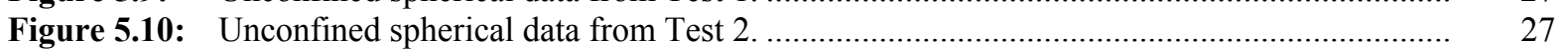

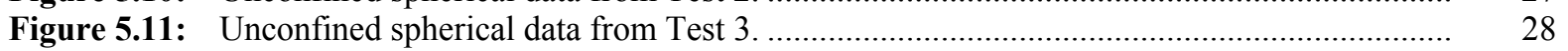

Figure 5.12: $\quad$ Unconfined spherical data from Test 4......................................................................... 28

Figure 5.13: Thermocouple locations on the Navy cookoff cylinder. ...................................................... 30

Figure 5.14: Navy cookoff cylinder wrapped in flexible heating tape. ................................................ 30

Figure 5.15: Cross-sectional schematic of the Navy cookoff experiment. ................................................ 31

Figure 5.16: Heating profile for the Navy cookoff experiment ............................................................... 31

Figure 6.1: Cross-sectional view of the STEX vessel with a green box outlining the area modeled...... $\quad 34$

Figure 6.2: $\quad$ Meshed axisymmetric model of the STEX test vessel. ........................................................

Figure 6.3: The 1.0-mm mesh and the finer $0.5-\mathrm{mm}$ mesh for the STEX model. ..................................... 36

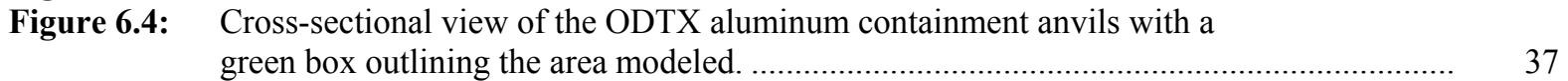

Figure 6.5: Meshed axisymmetric model of the ODTX experiment. ..................................................... 38

Figure 6.6: The 1.0-mm mesh and 0.5 - $\mathrm{mm}$ mesh for the ODTX models............................................... 39

Figure 6.7: Cross-sectional view of the 2.54-cm-diameter and 7.62-cm-diameter spheres with a green box outlining the areas modeled............................................................................. 40

Figure 6.8: $\quad$ Meshed axisymmetric models of the unconfined spherical experiments. ............................ $\quad 41$

Figure 6.9: The 1.0-mm mesh and $0.5-\mathrm{mm}$ mesh for the 2.54-cm unconfined spherical section........... $\quad 42$

Figure 6.10: The $1.0-\mathrm{mm}$ mesh and $0.5-\mathrm{mm}$ mesh for the $7.62-\mathrm{cm}$ unconfined spherical section........... $\quad 42$

Figure 6.11: Cross-sectional view of the Navy cookoff vessel with a green box outlining 43

Figure 6.12: $\quad$ Meshed axisymmetric model of the Navy cookoff experiment..................................................

Figure 7.1: STEX comparison between the thermocouple data and numerical results............................ 48

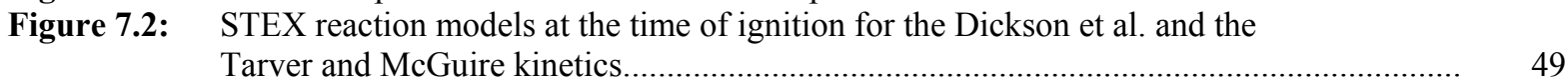

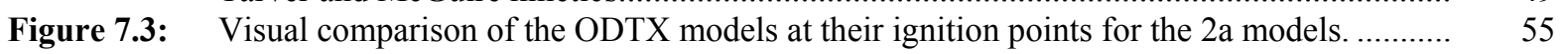

Figure 7.4: Comparison between the unconfined thermocouple data and numerical results for Experiment 3........................................................................................................... 57

Figure 7.5: Comparison of the reaction times for the unconfined spheres in Experiment 3................ 62

Figure 7.6: Navy cookoff comparison between the input data and numerical results. .......................... $\quad 64$

Figure 7.7: Visual comparisons of the reaction times for the three kinetics systems. ............................. 65

Figure C.1: Comparison between STEX thermocouple data and numerical results from the

Dickson et al. kinetics. .................................................................................................. C- C 1

Figure C.2: Close-up comparison of the thermal runaway location for the Dickson et al. kinetics. ......... C C-2

Figure C.3: A comparison of the endothermic phase change seen in the use of the

Dickson et al. kinetics. ............................................................................................. C- C-3

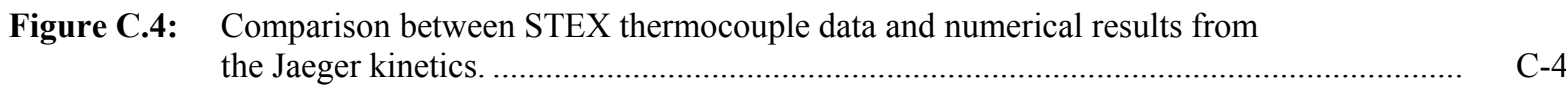

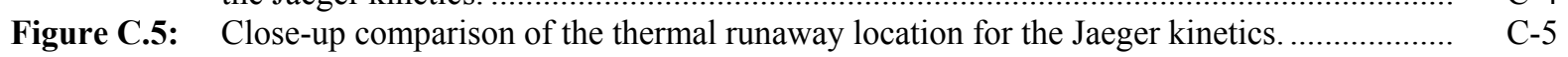

Figure C.6: Comparison between STEX thermocouple data and numerical results from the
Tarver kinetics. .......................................................................................................... C-6 
Figure C.7: Close-up comparison of the thermal runaway location for the Tarver kinetics.

Figure E.1: Comparison of the thermocouple data and the numerical results of the

Dickson et al. kinetics for Experiment 1.

Figure E.2: Comparison of the thermocouple data and the numerical results of the Dickson et al. kinetics for Experiment 3.

Figure E.3: Comparison of the thermocouple data and the numerical results of the

Dickson et al. kinetics for Experiment 4.

Figure E.4: Comparison of the thermocouple data and the numerical results of the Jaeger kinetics for Experiment 1

Figure E.5: Comparison of the thermocouple data and the numerical results of the Jaeger kinetics for Experiment 2

Figure E.6: Comparison of the thermocouple data and the numerical results of the Jaeger kinetics for Experiment 3

Comparison of the thermocouple data and the numerical results of the

Figure E.7: Comparison of the thermocouple

Figure E.8: Comparison of the thermocouple data and the numerical results of the Tarver kinetics for Experiment 1

Figure E.9: Comparison of the thermocouple data and the numerical results of the Tarver kinetics for Experiment 2

Figure E.10: Comparison of the thermocouple data and the numerical results of the Tarver kinetics for Experiment 3

Figure E.11: Comparison of the thermocouple data and the numerical results of the Tarver kinetics for Experiment $4 .$. 


\section{LIST OF TABLES}

Table 3.1: $\quad$ Kinetic and thermal properties that are used in the Jaeger heat flow calculations ...............

Table 3.2: $\quad$ Kinetic and thermal properties that are used in the Tarver and McGuire heat flow calculations .......................................................................................................... 9

Table 3.3: $\quad$ Kinetic and thermal properties that are used in the Dickson et al. heat flow calculations . 12

Table 5.1: $\quad$ Test data for sixteen confined ODTX experiments .......................................................... 22

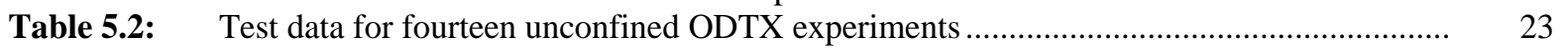

Table 5.3: $\quad$ Test data for ten aged ODTX experiments........................................................................ 24

Table 7.1: $\quad$ STEX results from the various models..................................................................................... 47

Table 7.2: $\quad$ ODTX results for the confined models using the Dickson et al. kinetics system................. 51

Table 7.3: $\quad$ ODTX results for the confined models using the Jaeger kinetics system ............................ 52

Table 7.4: $\quad$ ODTX results for the confined models using the Tarver and McGuire kinetics system..... 53

Table 7.5: $\quad$ Unconfined sphere results using Dickson et al. kinetics .................................................... 58

Table 7.6: $\quad$ Unconfined sphere results using Jaeger kinetics ............................................................... 59

Table 7.7: $\quad$ Unconfined sphere results using Tarver and McGuire kinetics............................................ 60

Table 7.8: $\quad$ Comparison between the Navy cookoff data and the numerical results................................. 63

Table B.1: $\quad$ Thermal Analysis Results for PBX 9501 and PBX 9407 ………........................................ B-1

Table D.1: $\quad$ ODTX results for the 16 confined experiments using Dickson et al. kinetics....................... $\quad$ D-1

Table D.2: $\quad$ ODTX results for the 14 unconfined experiments using Dickson et al. kinetics................... D D-4

Table D.4: $\quad$ ODTX results for the 16 confined experiments using Jaeger kinetics ................................. D D-8

Table D.5: $\quad$ ODTX results for the 14 unconfined experiments using Jaeger kinetics ............................. D $\quad$-11

Table D.6: $\quad$ ODTX results for the 10 aged experiments using Jaeger kinetics ........................................ D-13

Table D.7: $\quad$ ODTX results for the 16 confined experiments using Tarver \& McGuire kinetics............... D-15

Table D.8: $\quad$ ODTX results for the 14 unconfined experiments using Tarver \& McGuire kinetics........... D-18

Table D.9: $\quad$ ODTX results for the 10 aged experiments using Tarver \& McGuire kinetics ..................... D-20 


\section{NOMENCLATURE}

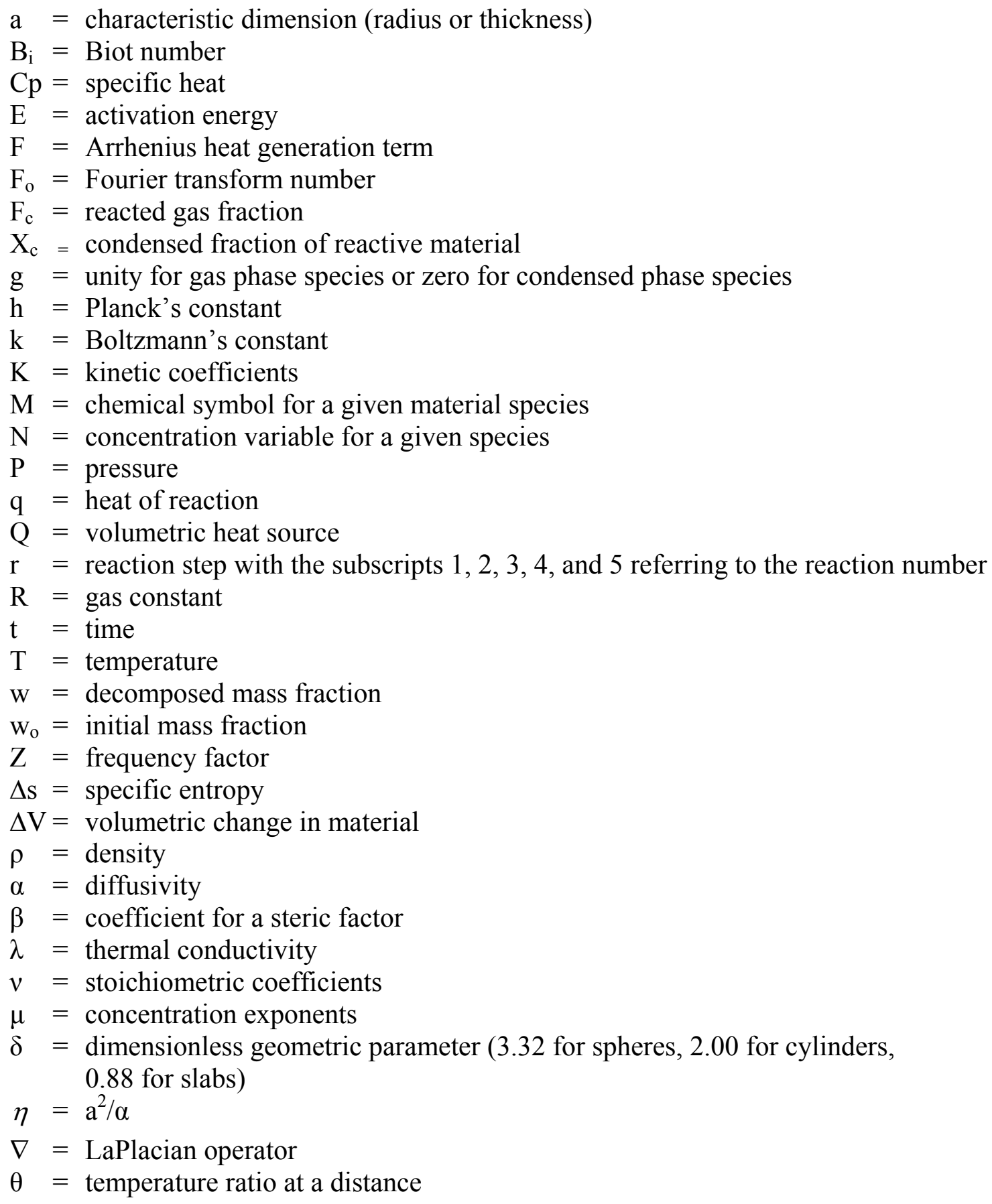




\title{
Heat Transfer Analysis and Assessment of Kinetics Models for PBX 9501
}

\author{
by
}

Jeffrey W. Jorenby

\begin{abstract}
The study of thermal decomposition in high explosive (HE) charges has been an ongoing process since the early 1900s. This work is specifically directed towards the analysis of PBX 9501. In the early 1970s, Dwight Jaeger of Los Alamos National Laboratory (LANL) developed a single-step, two-species kinetics system that was used in the development of one of the first finite element codes for thermal analyses known as EXPLO. Jaeger's research focused on unconfined spherical samples of HE charges to determine if varied heating ramps would cause detonation or deflagration. Tarver and McGuire of Lawrence Livermore National Laboratory (LLNL) followed soon after with a three-step, four-species kinetics system that was developed for confined spheres under relatively fast heating conditions. Peter Dickson et al. of LANL then introduced a kinetics system with four steps and five species that included bimolecular products to capture the effects of the endothermic phase change that the HE undergoes.
\end{abstract}

The results of four experiments are examined to study the effectiveness of these kinetics systems. The experiments are

1. The LLNL scaled thermal explosion (STEX) experiments on confined cylindrical charges with long heating ramps in the range of 90 hours.

2. The LLNL one-dimensional time to explosion (ODTX) experiments on spherical charges that include confined, partially confined, and aged HE experiments.

3. The LANL unconfined one-dimensional experiments for small spheres.

4. The Naval Air Warfare Center Weapons Division at China Lake experiments on small confined cylinders.

The three kinetics systems are applied to each of the four experiments with the use of the finite element analysis (FEA) heat conduction solver COYOTE. The numerical results using the kinetics systems are compared to each other and to the experimental data to determine which kinetics systems are best suited for analyzing conditions such as time to ignition, containment, heating time, and location of ignition. 


\subsection{INTRODUCTION: BACKGROUND AND STATE OF THE ART}

The process of thermal decomposition in high explosive (HE) materials has been of interest since the early 1900s. This chapter details the composition and thermal reactivity of the HE PBX 9501. The history of HE analysis is also reviewed, and its progression leads to the state of the art in thermal analysis methods being used to date. The importance of this type of research is evident in the necessity to compute the ignition characteristics of HE charges with confidence in all aspects of operational safety, including manufacture, storage, and delivery of explosive ordnances.

\subsection{The High Explosive PBX 9501}

The plastic bonded explosive, PBX 9501 is made of $95 \%$ by weight octa-hydro-1,3,5,7tetranitro-1,3,5,7-tetrazine (HMX), 2.5\% Estane, and 2.5\% bis(2,2-dinitropropyl) acetal/bis(2,2-dinitropropyl) formal (50/50), commonly referred to as BDNPA/F. It is a metastable material that decomposes exothermally at all temperatures. Its decomposition is generally thought to occur according to the Arrhenius Law of Kinetics. If the kinetic constants of the PBX 9501 are known, then it should be possible to accurately compute the temperatures and time to ignition as a function of the time-dependent boundary conditions.

\subsection{History of High Explosives Analysis}

In 1948, A. J. B. Robertson published the results of tests on the decomposition of nitroglycerin, ammonium nitrate, pentaerythritol tetranitrate, and ethylenediamine dinitrate [1]. It was observed that the time-pressure curves at elevated temperatures showed a very nearly constant rate of gas evolution over the first half of the decomposition and that the decomposition diminished in accordance with the unimolecular equation. It was also observed that at higher gas pressures, autocatalytic self-heating occurred. Results published by Henkin and McGill in 1952 [2] furthered Robertson's decomposition theory. The results of Robertson's decomposition theory determined that it is unlikely that there were two competing decomposition mechanisms. The results showed two activation energies for certain explosives thought to be due the heat absorption through vaporization above the material's boiling point. Thus, the decomposition of high explosives should still be defined by the unimolecular equation with temperature-dependent variances in the values for the activation energies applied.

In 1960, Zinn and Mader [3] ran tests to study the effects of heating rates, initial temperature and shape effects. Experiments showed that, if the surface temperature is kept below the critical temperature, $\mathrm{T}_{\mathrm{m}}$, a thermal explosion will not occur as the dimensions of the explosive charge are increased, but the value of $\mathrm{T}_{\mathrm{m}}$ decreases. It was also determined that, at relatively low temperatures, the geometry has an important influence on induction times. However, these effects diminished as temperature increased. Further research published by Zinn and Rogers in 1962 [4] correlated geometric effects and investigated material composition changes. In order to interpret the experimental data, the theoretical model used 
in the solution process was extended to take into account pressure effects and the depletion of reactants as the reactions proceeded.

Rogers continued his research into high explosive analysis, and in 1967, Rogers and Smith authored an article [5] that introduced a simple method of estimating the pre-exponential factor used to solve the first-order decomposition in the reactant. Realizing the difficulties in measuring the decomposition energies of reactions involving gaseous products, Rogers published a paper in 1972 [6] on a method of simplifying the determination of the rate constants. He observed that the differential scanning calorimeter (DSC) deflection above a determined baseline, $b$, is directly proportional to the rate of energy evolution or absorption of the sample. From this work, a deflection as a function of time graph that gives a simplified, accurate method was created. These results led to a quick method of obtaining the rate constants for decomposition.

After many years of research and experiments, these aforementioned methods were utilized and updated into the analysis methods that are currently being used today.

\subsection{Present Analysis Methods}

Researchers at Los Alamos National Laboratory (LANL), Lawrence Livermore National Laboratory (LLNL), Sandia National Laboratories (SNL), the Naval Air Warfare Center Weapons Division at China Lake (China Lake), and other Department of Energy (DOE) and Department of Defense (DoD) facilities — as well as in academia - have performed cookoff experiments of PBX 9501. The initial empirical data were generated as the result of smallscale, milligram tests to establish first approximation parameters for future HE experiments. Data in the form of thermal and mechanical response are now being used to validate and refine computational models of the events. In these experiments, temperature and pressure traces were collected and recorded for varying confinement, geometries, and applied heating ramps. These data were used to determine the reactions, products, and the activation energies that are used in the Arrhenius equations.

From the early tests in the 1960s and 1970s, Dwight L. Jaeger of LANL developed one-step kinetics that he introduced in 1980 [7], based on the unconfined cookoff experiments of PBX 9501 spheres. Then in 1981, Tarver and McGuire of LLNL [8] followed with a reduced three-step, four-species Arrhenius system to describe the thermal decomposition of HMX. This decomposition system is a multi-parameter curve fit for the time-to-explosion data from one-dimensional time to explosion experiments (ODTX). Dickson et al. from LANL [9] performed another set of experiments in 1999 on 1-in.-diameter PBX 9501 cylinders confined in a copper liner. That data was used to develop a modified reduced kinetics system that more accurately defines the simulation process for the small radial cookoff tests. The extra bimolecular step creates a better representation of the exothermic phase change and also helps to better define the location of the thermal runaway. The Dickson et al. kinetics is a four-step, five-species system. 


\subsection{PURPOSE: ASSESSMENT OF KINETICS SYSTEMS TO PREDICT THE TIME TO IGNITION AND LOCATION OF THE IGNITION POINT}

This chapter is an overview of the research that was performed and outlines the kinetics systems, the software incorporated, the experiments that the systems are derived from, and the results of these assessments.

\subsection{The Three Kinetics Systems}

The following three Arrhenius thermal-decomposition kinetics systems are currently being used to solve thermal decomposition analysis at LANL, LLNL, and SNL. Updated versions and variations of these systems are also being examined; however, the kinetics systems used in this assessment are the currently accepted methods of choice. The Jaeger kinetics system was developed in the early 1970 s as a method for looking at the decomposition of high explosive materials from reactants to products and was originally used for unconfined spherical charges. In this simplest case, the solution process is based on a single-step, two-species reaction. The Tarver and McGuire kinetics system was created in the late 1970s, and it is a reduced three-step, four-species thermal decomposition that is characterized by the Arrhenius equation. A reactive intermediary step in the thermal decomposition process was included in the development of this system. The Dickson et al. kinetics system was designed in the late 1990s, and it is a four-step, five-species kinetics system for thermal decomposition. This system is, in fact, a refinement of the Tarver and McGuire system that includes a bimolecular intermediate step to approximate nucleation, growth, and the endothermic phase change occurring in the high explosive material.

\subsection{Software Implemented in the Solution Process}

To evaluate the kinetics systems, the graphics software IDEAS is used to create axisymmetric, two-dimensional drawings of four experiments. The drawings are then meshed, and the appropriate boundary conditions are applied to create the finite element analysis (FEA) model. The FEA thermal solver COYOTE is used to simulate the conditions present in each of the four experiments. EnSight is used as the visual interface for preprocessing and post-processing of the FEA model and is used to create the output data file. These outputs files are then modified from text files into an Excel spreadsheet for analysis.

COYOTE is FEA software used for solving heat conduction models [10]. This code was written at SNL and created for use in multi-dimensional analysis of nonlinear heat conduction problems. A comprehensive description of the software used in this analysis and the mathematical solution methods for the COYOTE FEA code are described in Chapter 4. An example of the COYOTE input file for all three kinetics systems from one of the ODTX analyses can be found in Appendix A. The Dickson et al. kinetics system also requires two subroutines: USRCON for user-defined conductivity and USRCP for user-defined specific heat. 


\subsection{The Four Experiments}

In these studies, prediction of time to ignition and the location of the ignition point are compared with test data from experiments performed by personnel at LANL, LLNL, and China Lake. The accuracy of the FEA models is examined by creating and comparing the analysis from the following four experiments:

- The Lawrence Livermore National Laboratory scaled thermal explosion experiments (STEX) for confined cylinders [11] were developed in the late 1990s to provide a database to develop, calibrate, and validate predictive capabilities for computer simulation codes. The tests were performed with the goal of well-defined boundary conditions, physical confinement, and a predefined ignition location and with the ability to quantitatively measure reaction violence.

- The Lawrence Livermore National Laboratory one-dimensional time to explosion (ODTX) experiments for spheres [12] were designed in the late 1970s for the purpose of creating consistent temperature boundary conditions. These experiments also looked at different levels of pressure confinement, material density, and aging effects.

- The Los Alamos National Laboratory unconfined one-dimensional experiments [13] were performed on spheres in the late 1970s and early 1980s, and used as the experimental data to calibrate the FEA software EXPLO. These tests also produced data that gave insight into how confinement affects decomposition rates and thermal runaway.

- The Naval Air Warfare Center Weapons Division Experiments at China Lake for confined cylinders [14] are another series of experiments developed in the 2000s that attempted to create uniform temperature boundary conditions, physical confinement, and a predefined ignition location.

\subsection{Comparison of the Simulation Results with the Four Experiments}

Each experiment is modeled with the three different kinetics systems and analyzed using the COYOTE FEA thermal solver. The results from these analytical models are then compared with each other to determine which model is best suited for the individual conditions present in that experiment. This comparison of the three kinetics systems helps determine where each model is most appropriate and what the limitations are of each model.

The time to ignition and the location of ignition are tabulated and compared with data from the experiments. The accuracy of these kinetics systems, when compared to the experimental data from each of the four experiments, is of great concern. Variances in time to ignition, location of ignition points, and the ability to accurately simulate the thermocouple temperature traces are vital in the overall assessment of usability. The results from the four analysis models are recorded, compared, and assessed in Chapter 7. 


\subsection{KINETICS SYSTEMS USED IN THE ANALYSIS}

The necessity for the assessment of these three kinetics systems is driven by the need to create a consistent and reliable method of predicting the handling and testing of $\mathrm{HE}$ materials. As such, the ability of these kinetics packages to accurately simulate the different types of heating conditions and confinement situations is very crucial. The intention of this chapter is to get an understanding of the background and derivation of each of the three kinetics systems.

\subsection{The Jaeger Kinetics}

The Jaeger kinetics [7] is a single-step, two-species kinetics system. This system is developed to look at the decomposition of high explosive $(\mathrm{HE})$ materials from reactants to products. In this simplest form, there are two phases of the material: $\mathrm{A}=$ reactants and $\mathrm{B}=$ products.

$$
\mathrm{A} \rightarrow \mathrm{B}
$$

When a reactive material is heated or cooled, it decomposes by a single $\mathrm{n}^{\text {th }}$ order rate process. Then the variation in temperature is defined by the equation

$$
\frac{\partial T}{\partial t}=\alpha \nabla^{2} T+\frac{q Z}{C p}\left(w_{o}-w\right)^{N} e^{-\frac{E}{R T}}
$$

and the variation in concentration is defined by the equation

$$
\frac{\partial w}{\partial t}=-Z\left(w_{o}-w\right)^{N} e^{-\frac{E}{R T}} .
$$

These two equations are then combined into the following single Arrhenius heat generation equation used in the Jaeger solution:

$$
F=-\rho Q(1-w)^{N} Z e^{-\frac{E}{R T}} .
$$

The kinetic and thermal properties used for the solution to the heat generation calculations in the Jaeger system are displayed in Table 3.1. 
Table 3.1: Kinetic and thermal properties that are used in the Jaeger heat flow calculations [7]

\begin{tabular}{|l|l|}
\hline \multicolumn{1}{|c|}{ Explosive Properties } & PBX 9501 \\
\hline \hline$\rho\left(\mathrm{g} / \mathrm{cm}^{3}\right)$ & 1.84 \\
\hline $\mathrm{q}(\mathrm{cal} / \mathrm{g})$ & 505 \\
\hline $\ln \mathrm{Z}$ & 45.363 \\
\hline $\mathrm{E}(\mathrm{kcal} / \mathrm{mol})$ & 52.700 \\
\hline$\lambda(\mathrm{cal} / \mathrm{cm}-\mathrm{s}-\mathrm{K})$ at $293 \mathrm{~K}$ & $1.08 \mathrm{E}-03$ \\
\hline$\lambda(\mathrm{cal} / \mathrm{cm}-\mathrm{s}-\mathrm{K})$ at $446 \mathrm{~K}$ & $7.30 \mathrm{E}-04$ \\
\hline $\mathrm{Cp}(\mathrm{cal} / \mathrm{g}-\mathrm{K})$ at $293 \mathrm{~K}$ & 0.238 \\
\hline $\mathrm{Cp}(\mathrm{cal} / \mathrm{g}-\mathrm{K})$ at $446 \mathrm{~K}$ & 0.359 \\
\hline $\mathrm{Cp}(\mathrm{cal} / \mathrm{g}-\mathrm{K})$ at $554 \mathrm{~K}$ & 0.441 \\
\hline
\end{tabular}

This kinetics system was originally developed to numerically simulate the ignition process of an unconfined explosive. It is well documented that the ignition response is extremely dependent upon whether the system is confined or unconfined. Confinement usually entails a metal container into which a charge of HE is tightly fit or pressed. Ideally, this container will be able to withstand high pressures and temperatures so that none of the decomposition gases will escape before the reaction goes to completion.

Jaeger's experimental data showed that if the surface temperature, $T_{s}$, is above the critical temperature, $T_{m}$, then the center of the charge ignites shortly after the center equilibrates with the surface. $T_{m}$ is defined as the surface temperature at which the internal energy generated by chemical decomposition is greater than that which can be removed through the surface by conduction and radiation. However, if the surface temperature never reaches the $T_{m}$ point, then the center of the charge decomposes instead of igniting. Most significantly, the HE charge undergoes an induction process that is controlled by an energy function that is both time and temperature dependent.

In the early 1970s, a new finite difference heat transfer program known as EXPLO was developed using the Jaeger kinetics to calculate the temperature as a function of time and space in a conductive medium. The energy source term in EXPLO was designed to handle first-order kinetics with up to five separate energy-generating materials. This software was also designed to handle either free or forced convection, which allowed the code to be quite useful as a predictive analysis method to estimate the ignition under conditions of slow heating or exposure of the material to temperatures near the critical temperature $T_{m}$. 
This kinetics system was derived under the assumption of steady state, constant material properties, and a zero order reaction of the form

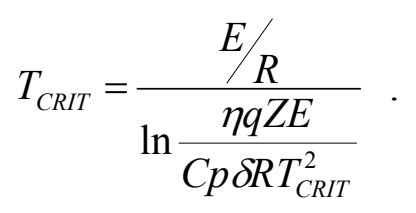

Equations (2), (3), and (4) drive the solution for the Jaeger kinetics. However, experimental results published in 1979 [13] demonstrate that the amount of confinement has a large impact on the thermal decomposition. In an unconfined condition, the loss of product gases often led to the consumption of the explosive material without a detonation. Also, when applying the kinetics to a confined system at low temperature and long-term heating, the kinetics reduced to a quasi-steady state and never achieved a detonation.

\subsection{The Tarver and McGuire Kinetics}

The Tarver and McGuire [8] three-step, four-species kinetics system was developed at Lawrence Livermore National Laboratory. It was the first multi-step solution method employed for thermal analysis, following the modest success of the Jaeger kinetics incorporated in the EXPLO finite difference code. The development of this new kinetics system included a reactive intermediary step in the thermal decomposition process. In this system, $\mathrm{A}=$ energetic material, $\mathrm{B}=$ reactive intermediate, $\mathrm{C}=$ secondary intermediates, and $\mathrm{D}=$ final products. For these specific experiments of PBX 9501, A represents HMX, B represents the chemical chain $\left(\mathrm{H}_{2} \mathrm{C}=\mathrm{N}-\mathrm{NO}_{2}\right), \mathrm{C}$ represents the chemical chain $\left(\mathrm{CH}_{2} \mathrm{O}+\mathrm{N}_{2} \mathrm{O}\right)$ or $\left(\mathrm{HCN}+\mathrm{HNO}_{2}\right)$ and $\mathrm{D}$ represents the final products. This is an autocatalytic process that has the following three reaction processes:

$$
\begin{aligned}
& \mathrm{A} \rightarrow \mathrm{B}, \\
& \mathrm{B} \rightarrow 2 \mathrm{C}, \text { and } \\
& 2 \mathrm{C} \rightarrow \mathrm{D} .
\end{aligned}
$$

The heat flow equation used to define the thermal decomposition process is

$$
-\lambda \nabla^{2} T+\rho C p \frac{\partial T}{\partial t}=N_{A} q_{1} Z_{1} e^{-\frac{E_{1}}{R T}}+N_{B} q_{2} Z_{2} e^{-\frac{E_{2}}{R T}}+N_{C} q_{3} Z_{3} e^{-\frac{E_{3}}{R T}},
$$

where $\mathrm{N}_{\mathrm{A}, \mathrm{B}, \mathrm{C}}=$ mole fractions such that $\mathrm{N}_{\mathrm{A}}+\mathrm{N}_{\mathrm{B}}+\mathrm{N}_{\mathrm{C}}=1$. The kinetic and thermal properties used for the solution to the heat-generation calculations in the Tarver and McGuire system are given in the following table. 
Table 3.2: Kinetic and thermal properties that are used in the Tarver and McGuire heat flow calculations [8]

\begin{tabular}{|l|l|}
\hline \multicolumn{1}{|c|}{ Explosive Properties } & HMX \\
\hline \hline $\mathrm{q}_{1}(\mathrm{cal} / \mathrm{g})$ & -100 \\
\hline $\ln \mathrm{Z}_{1}$ & 48.7 \\
\hline $\mathrm{E}_{1}(\mathrm{kcal} / \mathrm{mol})$ & 52.7 \\
\hline $\mathrm{q}_{2}(\mathrm{cal} / \mathrm{g})$ & 300 \\
\hline $\ln \mathrm{Z}_{2}$ & 37.5 \\
\hline $\mathrm{E}_{2}(\mathrm{kcal} / \mathrm{mol})$ & 44.1 \\
\hline $\mathrm{q}_{3}(\mathrm{cal} / \mathrm{g})$ & 1200 \\
\hline $\ln \mathrm{Z}_{3}$ & 28.1 \\
\hline $\mathrm{E}_{3}(\mathrm{kcal} / \mathrm{mol})$ & 34.1 \\
\hline $\mathrm{Cp}(\mathrm{cal} / \mathrm{g}-\mathrm{K})$ at $293 \mathrm{~K}$ & 0.24 \\
\hline $\mathrm{Cp}(\mathrm{cal} / \mathrm{g}-\mathrm{K})$ at $623 \mathrm{~K}$ & 0.42 \\
\hline$\lambda(\mathrm{cal} / \mathrm{cm}-\mathrm{s}-\mathrm{K})$ at $293 \mathrm{~K}$ & $1.23 \mathrm{E}-03$ \\
\hline$\lambda(\mathrm{cal} / \mathrm{cm}-\mathrm{s}-\mathrm{K})$ at $433 \mathrm{~K}$ & $9.70 \mathrm{E}-04$ \\
\hline
\end{tabular}

This kinetics system was originally developed to simulate the time to ignition in the LLNL one-dimensional time to ignition (ODTX) experiments. Ideally, this kinetics system was designed to analyze confined experiments, where the gaseous phase is part of the thermal decomposition. With an appropriate description of the principal energy rate processes and an understanding of the thermal diffusion of an explosive as a function of temperature, the time to explosion for the ODTX experiments was more accurately calculated. When no product gases were allowed to escape, the results of this kinetics system correlated very well with experimental data published by LLNL.

Also included in the development of this kinetics system are temperature dependencies for material properties and activation energies. Along with the chemical kinetics parameters, the thermal conductivity and heat capacity of the explosives as a function of temperature are vital inputs for the time-to-ignition solutions. Of note is the fact that the product gases have thermal conductivities up to an order of magnitude lower than their solid-phase values. This kinetics system assumes a linear decrease in the thermal conductivity as a function of the mass fraction until the gas-phase conductivity value is achieved.

A major component of this new kinetics system included the formation of an endothermic, reactive intermediate. These kinetics equations were the first system to include an autocatalytic process in which a reactive intermediate is formed. This intermediate then reacts with the solid phase of the explosive to produce gaseous reaction products. 
The chemical reaction involved in the thermal decomposition of HMX and other explosives of similar composition suggest that the energy deposition can be described by three relatively slow processes. The first step is the endothermic breaking of $\mathrm{C}-\mathrm{N}$ bonds from the $\mathrm{H}_{2} \mathrm{C}=$ $\mathrm{N}-\mathrm{NO}_{2}$ ring. The second step is a slightly exothermic rearrangement of the $\mathrm{H}_{2} \mathrm{C}=\mathrm{N}-\mathrm{NO}_{2}$ ring into either $\mathrm{CH}_{2} \mathrm{O}$ and $\mathrm{N}_{2} \mathrm{O}$ or $\mathrm{HCN}$ and $\mathrm{HNO}_{2}$ that lead to $\mathrm{NO}_{2}$ radicals. The third and final step is a very exothermic gas phase decomposition of $\mathrm{CH}_{2} \mathrm{O}+\mathrm{N}_{2} \mathrm{O}$ into multiple stable gaseous products.

\subsection{Dickson et al. Kinetics}

The Dickson et al. kinetics [9] is a four-step, five-species kinetics system. This kinetics system is a refinement of the Tarver and McGuire system, where the first two steps approximate nucleation and an additional growth step is incorporated using the Arrhenius method. The remaining two steps are empirical and still undergoing validation. The four-step process is as follows:

(A) $\operatorname{HMX}(\beta) \rightarrow$ (B) $\operatorname{HMX}(\delta)$

(A) $\operatorname{HMX}(\beta)+(\mathrm{B}) \operatorname{HMX}(\delta) \rightarrow(\mathrm{B}) \operatorname{HMX}(\delta)$ (bimolecular endothermic)

(B) HMX ( $\delta) \rightarrow(C)$ Intermediates $\left(1^{\text {st }}\right.$ order endothermic)

(B) $\operatorname{HMX}(\delta)+(\mathrm{D})$ Intermediates $\left(2^{\text {nd }}\right.$ order exothermic)

$\rightarrow$ (E) Final Products

The rate equations associated with these reactions are as follows:

$$
\begin{aligned}
& r_{1}=N_{A} \frac{k T}{h} \exp \left\{\frac{T \Delta s_{1}-E_{1}-P \Delta V}{R T}\right\} \\
& r_{2}=N_{A} N_{B} \frac{k T}{h} \exp \left\{\frac{T \Delta s_{2}-E_{2}-P \Delta V}{R T}\right\} \\
& r_{3}=N_{B} Z_{3} \exp \left\{\frac{-E_{3}}{R T}\right\} \\
& r_{4}=N_{B} N_{C} Z_{4} \exp \left\{\frac{-E_{4}}{R T}\right\} \\
& r_{5}=N_{D}^{2} Z_{5} \exp \left\{\frac{-E_{5}}{R T}\right\}
\end{aligned}
$$


$\mathrm{N}_{\mathrm{A}, \mathrm{B}, \mathrm{C}, \mathrm{D}}=$ mole fractions such that $\mathrm{N}_{\mathrm{A}}+\mathrm{N}_{\mathrm{B}}+\mathrm{N}_{\mathrm{C}}+\mathrm{N}_{\mathrm{D}}=1$. The reaction rates from Equations (14)-(18) are then combined into three differential equations that are balanced as follows:

$$
\begin{aligned}
& \frac{d M_{A}}{d t}=-r_{1}-r_{2}, \\
& \frac{d M_{B}}{d t}=-r_{1}+r_{2}-r_{3}-r_{4}, \text { and } \\
& \frac{d M_{B}}{d t}=-r_{3}+r_{4} .
\end{aligned}
$$

This kinetics system assumes a coupling to the heat conduction equation through the following volumetric heat generation term:

$$
Q(T)=\rho \sum_{j}^{4} q_{j}^{*} r_{j} .
$$

The kinetic and thermal properties used for the solution to the heat generation calculations in the Dickson et al. system can be found in the Table 3.3.

The Tarver and McGuire system did an adequate job of predicting the temperature of the runaway reaction and gave a reasonable time-to-ignition approximation. However, it could not accurately predict the location of the first runaway exotherm. The Dickson et al. kinetics system was developed to predict the location of ignition for the LANL small radial cookoff experiments. Also, the Tarver and McGuire kinetics had some inadequacies in capturing the detailed behavior of the thermochemistry involved in decomposition. The Dickson et al. kinetics includes a fourth thermal decomposition step and a fifth bimolecular species. This new kinetics system resulted in analytical results that closely followed the thermocouple data and the location of thermal runaway in the LANL small, radial cookoff experiments [9].

In a manner similar to the Tarver and McGuire equations, this kinetics system also includes temperature dependencies for the material properties and activation energies. Additionally, Dickson et al. includes the chemical kinetics parameters, the thermal conductivity and the heat capacity of the explosives as a function of temperature. This kinetics system also requires two user subroutines that are temperature dependent and reliant on the material decomposition and reformation. The two subroutines are USRCON for user-defined conductivity and USRCP for user-defined specific heat. In the small, radial cookoff analysis, this kinetics system more accurately simulates the thermocouple traces and the location of thermal runaway in the HE material. 
Table 3.3: Kinetic and thermal properties that are used in the Dickson et al. heat flow calculations [9]

\begin{tabular}{|c|c|c|c|c|c|}
\hline $\begin{array}{c}\text { Reaction } \\
\text { Number }\end{array}$ & $\mathbf{q}(\mathbf{k J} / \mathbf{k g})$ & $\mathbf{E}(\mathbf{J} / \mathbf{k g})$ & $\mathbf{Z}$ & $\mathbf{\Delta s}(\mathbf{J} / \mathbf{k g}-\mathrm{K})$ & $\mathbf{\Delta \mathbf { V } ( \mathbf { m } ^ { 3 } / \mathbf { k g } )}$ \\
\hline \hline $\mathbf{1}$ & -111 & - & - & 460 & $4.73 \mathrm{E}-05$ \\
\hline $\mathbf{2}$ & -111 & - & - & 2130 & $1.22 \mathrm{E}-05$ \\
\hline $\mathbf{3}$ & -1000 & $2.00 \mathrm{E}+05$ & $1.582 \mathrm{E}+16$ & - & - \\
\hline $\mathbf{4}$ & 100 & $1.73 \mathrm{E}+05$ & $3.582 \mathrm{E}+16$ & - & - \\
\hline $\mathbf{5}$ & 5000 & $1.43 \mathrm{E}+06$ & $1.598 \mathrm{E}+12$ & - & - \\
\hline
\end{tabular}

Inclusion of the bimolecular, endothermic material formation is a key component in representing the phase change and ultimately creating a more accurate kinetics system. This system includes the endothermic transformation seen in the small radial experiments, where the material goes through its $\beta$ to $\delta$ transition at around $170^{\circ} \mathrm{C}$. A combination of first-order and bimolecular forms of the thermodynamic process are used to define the transition state theory kinetics used to represent nucleation and the growth process in the explosive material. The material decomposition is then represented by a slow-moving, first-order Arrhenius reaction. These bimolecular and second-order exothermic reactions are incorporated until thermal runaway occurs.

\subsection{SOFTWARE AND FEA FORMULATION}

This chapter looks at the software used in the modeling of the four experiments. It is divided into two major sections: the first section is an overview of all the software used in this research, and the second section gives a more definitive description of the mathematical solution methods used in the FEA thermal solver COYOTE.

\subsection{Analytical Software}

This section will provide a list and description of the software packages incorporated into the design, solution, and visualization of the three kinetics systems.

\subsubsection{IDEAS: Graphic Modeling}

The Integrated Data Evaluation and Analysis System (IDEAS) is the solid modeling package employed to draw the two-dimensional axisymmetric representations of the four experiments. This standard drawing software allows the individual parts to be created about the center axis and then combined into a single assembly. Once the assembly is properly dimensioned, it is then partitioned, and elemental grids are 
created. Each section is then separated into the appropriate grouping where predefined material properties are assigned to them. Next, boundary conditions are applied to the model, and nodes associated with thermocouple locations are notated and set aside into groups to create the analytical temperature traces.

\subsubsection{EnSight: Pre-Process and Post-Process Visualization}

The meshed model is then exported into EnSight using the Exodus format. As part of the pre-process operation, the model is viewed, and all the associating element blocks are redefined by material properties and the new element and node numbering is recorded. This step allows for a final inspection of the model to ensure all the proper dimensions, materials, and boundary conditions are applied before being analyzed with the FEA solver.

The output file created by COYOTE in the post-process phase is used to visualize the step-by-step heat transfer through the model. The node where thermal runaway occurs is located, and a time-versus-temperature plot is recorded for some of the experiments. For other experiments, the nodes used to represent thermocouple locations are used to create similar time-versus-temperature plots. These plots are then saved as text files for future analysis.

\subsubsection{COYOTE: FEA Heat Conduction Solver}

This is the FEA heat conduction solver chosen to analyze the different kinetics in each of the experimental models. Section 4.2 will provide in-depth details on how this solution process is derived. After the model has run to completion in COYOTE, two files are created: one file is a text file, listing all of the steps in the solution process and the reason for completion, and the second is an output file that can be imported into various visualization programs.

\subsubsection{Excel: Analysis Compilation}

The text files created in EnSight are then opened and formatted into Excel spreadsheets. The data is then organized into a folder for each experiment, with a separate sheet for each kinetics system. The Excel software allows all the data to be compared and contrasted in terms of each different kinetics system. Furthermore, it is used to compare the kinetics systems with each other and with the experimental data.

\subsection{COYOTE FEA Solution Methods}

The COYOTE finite element analysis computer program for nonlinear heat conduction problems had its first version released by Sandia National Laboratory in Albuquerque (SNLA) in mid-1978 [10]. The software used in this analysis is Version 4.25.05.

The species equations must be solved for each reactive material and its phase and composition at the same time as the thermal diffusion for the process is solved. 
This type of solution requires that multiple nonlinear conservation equations are solving for the chemical species in conjunction with the temperature-driven variances. The mathematical nature (stiffness) of the kinetic equations requires that the chemistry and thermal diffusion equations be solved independently. Thus, for a given time step, the chemistry solution is solved first using a fixed temperature field. Then, the temperature field is subsequently solved over the same time interval with the new chemical value, which is held fixed. The inherent stiffness of this equation system led to the incorporation of the ordinary differential equation (ODE) solvers CHEMEQ and CHEMEQ2. For this solution method, the rate equation for the most restrictive chemistry time step is used to regulate the choice of the thermal diffusion time step.

The following systems of equations are the used by COYOTE to solve the heat conduction assessment for this research.

\subsubsection{The Heat Conduction Equation}

The primary driver for thermal transfer in these analytical models is heat conduction. The heat conduction equation used to describe the thermal process within a single homogeneous material is given as follows:

$$
\rho * c_{p} \frac{\partial T}{\partial t}=\frac{\partial}{\partial x_{i}}\left(\lambda_{i j} \frac{\partial T}{\partial x_{j}}\right)+Q .
$$

\subsubsection{Chemical Kinetics Equations}

The thermal diffusion for a chemically reacting material uses the following equations to describe the stoichiometry, reaction kinetics, and material property behavior [10].

The equation for the stoichiometry in relation to the material behavior is given by

$$
\sum_{i=1}^{I} v_{i j}^{\prime} M_{i} \rightarrow \sum_{i=1}^{I} v_{i j}^{\prime \prime} M_{i} \text { for } \mathrm{j}=1,2, \ldots, \mathrm{J} .
$$

For each step of the reaction process, the reaction rate equation is defined as follows:

$$
r_{j}=K_{j}(T) \coprod_{i=1}^{I}\left[N_{i}\right]^{\mu a j} \text { for } \mathrm{j}=1,2, \ldots, \mathrm{J} .
$$

The kinetic coefficients in the Arrhenius form are defined by

$$
K_{j}(T)=T^{\beta j} Z_{j} \exp \left(-E_{j} / R T\right) .
$$


The rate change for the species involved in the reaction is defined by

$$
\frac{d}{d t}\left[N_{i}\right]=\sum_{j=1}^{J} v_{i j} r_{j}, \text { for } \mathrm{i}=1,2, \ldots, \mathrm{I} \text {. }
$$

The chemical reaction equation for the using a volumetric source code coupled with thermal diffusion is

$$
Q_{r}=\sum_{j=1}^{J} q_{j} r_{j}
$$

\subsubsection{Material Property Equations}

The material properties are determined in terms of mole-fraction-weighted averages as defined by the following equations:

$$
\begin{aligned}
& (\rho C)_{i}=\sum_{i=1}^{I}\left[N_{i}\right](\rho C)_{i}, \text { and } \\
& \left(K_{j k}\right)_{m i x}=\sum_{i=1}^{I}\left[N_{i}\right]\left(K_{j k}\right)_{m i x} .
\end{aligned}
$$

The parameter for the reacted gas fraction existing in the material is shown as follows:

$$
F_{c}=\frac{\left(1.0-X_{c}\right) \sum_{i=1}^{I}\left[N_{i}\right]^{*}(g)_{i}}{\sum_{i=1}^{I}\left[N_{i}\right]}
$$

\subsection{THE FOUR EXPERIMENTS USED IN THE KINETICS ASSESSMENT}

This chapter elaborates on each of the four experiments upon which the design models and analytical assessments are based. First, a justification for the need of each particular experiment is given, and then explanations of the setup, materials, equipment, and simulation conditions present in each test are provided. 


\subsection{The LLNL Scaled Thermal Explosion Experiment (STEX) for Confined Cylinders}

The STEX tests performed and documented at LLNL [15] were developed to provide a database of reaction violence from thermal explosions for selected explosives. These tests had the following goals: uniform heating for well-defined boundary conditions: well-defined physical confinement, pre-determined reaction location away from the end effects; a range of physical scales, quantitative measurements of reaction violence, and a design to allow accurate simulation of the model while avoiding physical features that are difficult to model. The reaction location for this test initiates in the axially center region of the test cylinder [11]. The illustration seen in Figure 5.1 is a representation of the STEX test vessel.

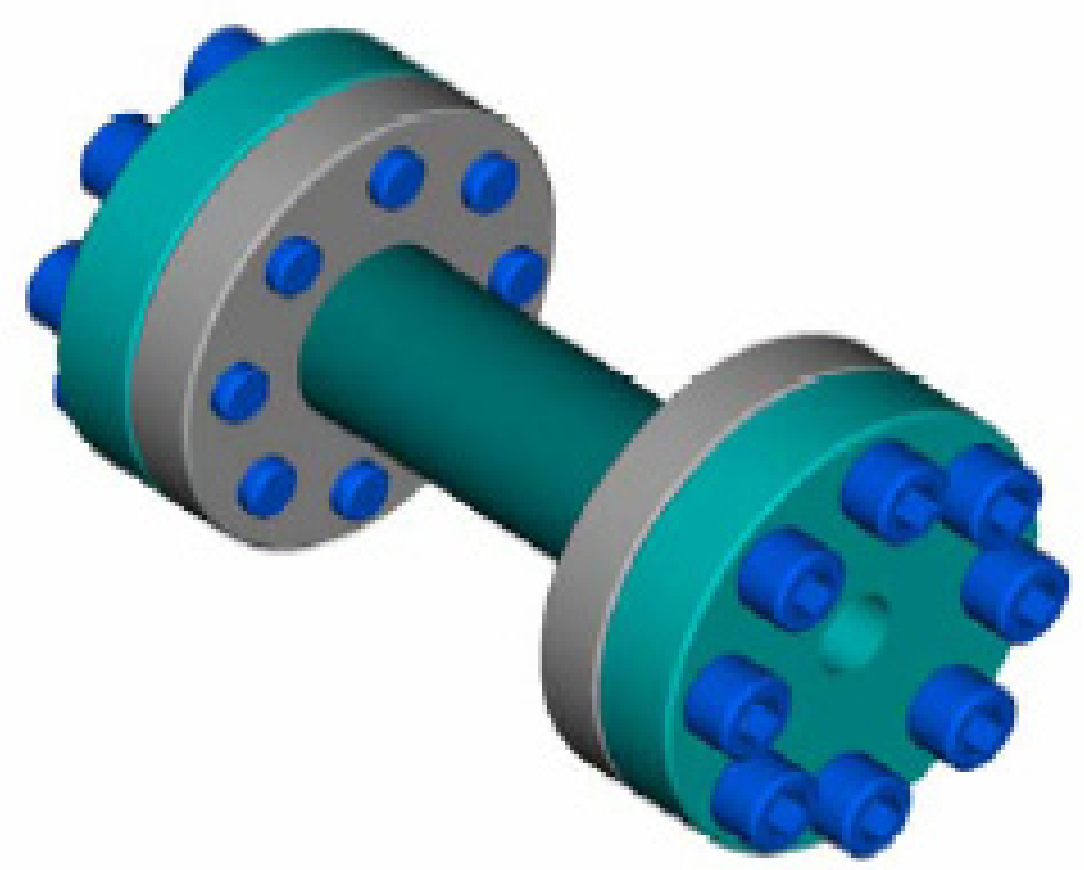

Figure 5.1: Rendition of STEX preliminary design vessel [11].

The STEX experiment is a cylindrical vessel made of 4130 steel hardened to a Rockwell 32C. A flange $152.0 \mathrm{~mm}$ in diameter by $25.4 \mathrm{~mm}$ thick is brazed onto each end of the vessel and sealed with an end cap $152.0 \mathrm{~mm}$ in diameter by $28.4 \mathrm{~mm}$ thick. During the development of this design, the researchers at LLNL extensively analyzed the mechanical response of the system to anticipated stresses and ensured that the weak point in the system was the cylinder wall and not the end caps. A constant length-to-diameter ratio of 4:1 was used for all the STEX experiments. Figure 5.2 is a picture of the STEX setup and thermocouple locations in a completed assembly that is ready for the cookoff experiment to commence. 


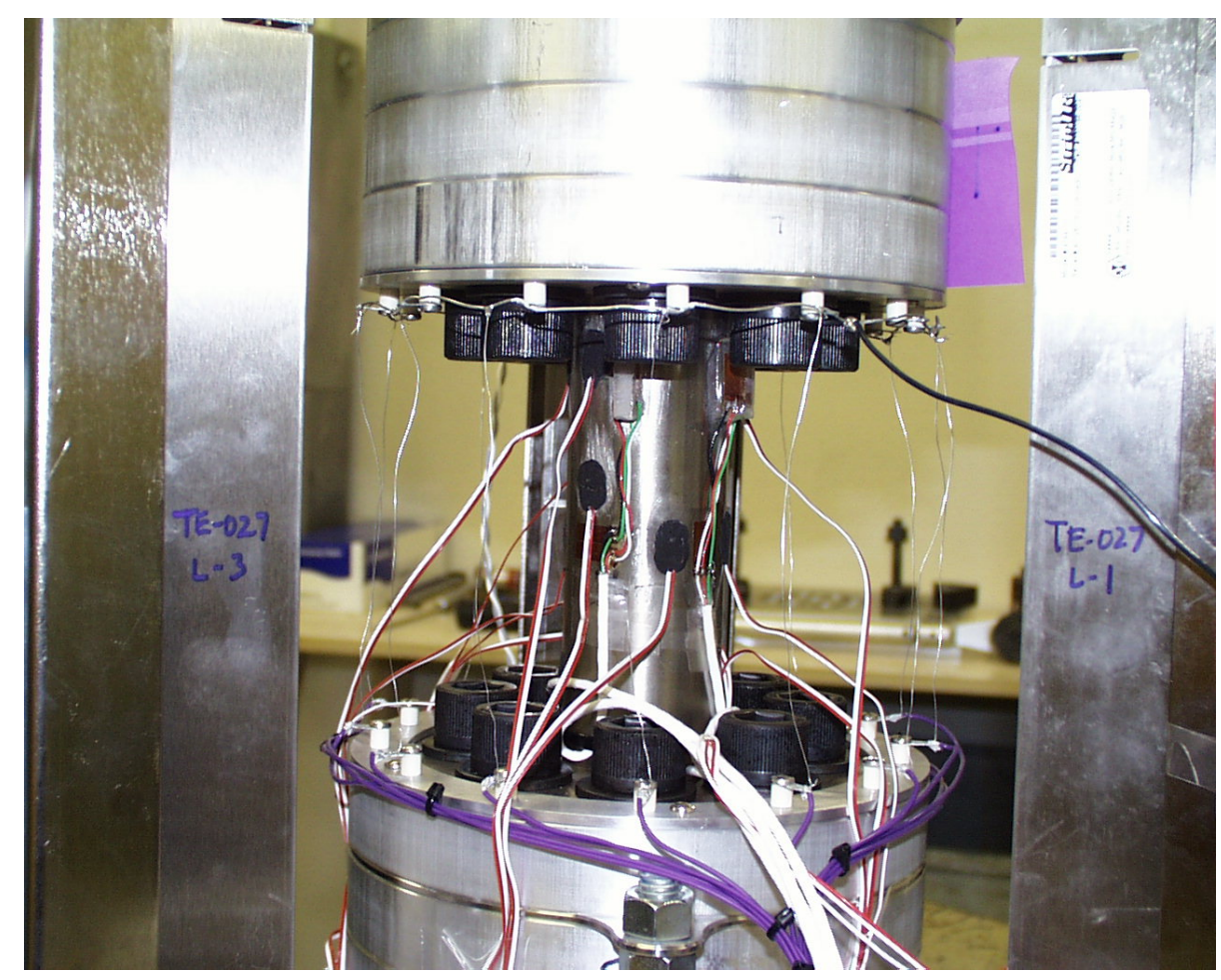

Figure 5.2: STEX vessel mounted with thermocouples [15].

There are three non-contact radiant heater elements positioned $140.0 \mathrm{~mm}$ from the containment vessel used to heat the cylinder wall. These heaters were chosen to reduce temperature gradients that are typically present with heater bands and to eliminate the nonquantifiable extra confinement that heater bands provide. The three heaters are controlled by one temperature controller monitoring a resistance temperature detector (RTD) that is located at the center of the vessel between two of the heaters. Each end cap is heated with a separately controlled heating element. These heater elements are attached to an aluminum plate and an assembly of rings that enclose the end cap and vessel flange to provide more uniform end heating conditions.

The experimental configuration is shown in Figure 5.3, where the drawing on the left is a side view and the drawing on the right is a top view of the STEX experiment in its containment chamber. The blast containment vessel used in the experiment serves many purposes. First, it is very well insulated to help negate the effect of convection and radiation. Secondly, it is also a protective container in the event of ignition. Finally, it acts as a collection container for visual analysis of all the blast fragments. As seen below the STEX vessel, the radiant heaters and radar horns are all supported in the center of the container in order to ensure uniform heating on all sides and the top and bottom.

The external temperature is controlled by three RTDs (one for the cylindrical vessel and one for each end cap) and monitored by twelve additional RTDs placed at locations at 60-degree intervals $1 / 4,1 / 2$, and $3 / 4$ of the way up the vessel wall; these RTDs are calibrated to $\pm 0.1^{\circ} \mathrm{C}$. 
The RTDs are attached to the outside diameter of the vessel wall with a high-temperature, two-part epoxy system. An internal thermocouple sheath is placed on the axis of the cylinder in the explosive, with thermocouples at each end of the vessel and at $1 / 4,1 / 2$, and $3 / 4$ height locations.

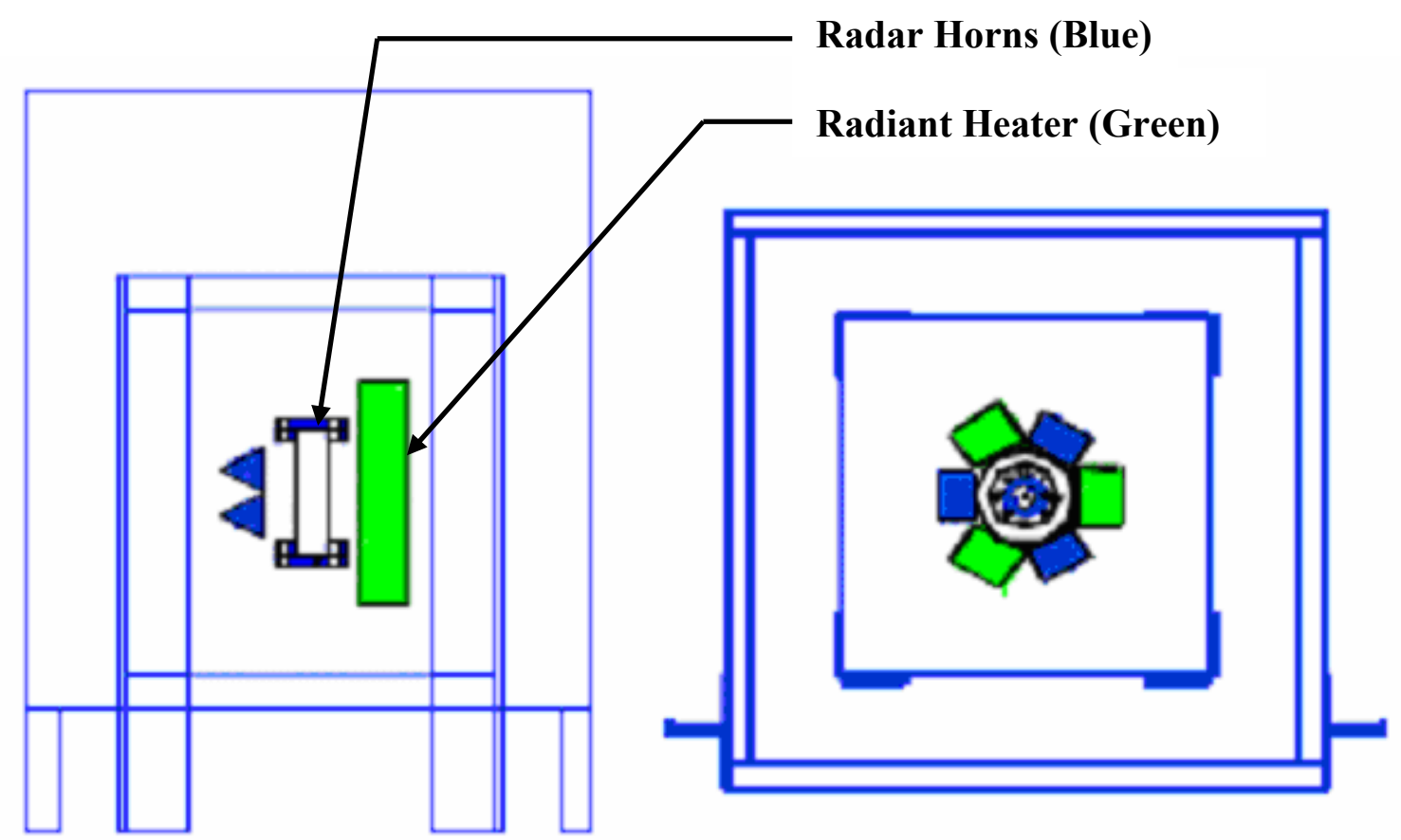

Figure 5.3: Side and top views of the STEX vessel shown in a blast containment chamber [11].

The containment vessel is fabricated from type 304 stainless steel (1.6-mm OD, 0.4-mm wall thickness) with a welded end plug. This vessel was designed to withstand a pressure of 200 $\mathrm{MPa}$, which is the maximum that should be seen before the final explosion. Type $\mathrm{K}$ thermocouples calibrated to $\pm 0.5^{\circ} \mathrm{C}$ are inserted into the sheath to measure the temperature at the positions given above. Thermocouples were placed on the outside of the STEX vessel at 60-degree radial increments to track the heat applied to it at the following locations: the mid-plane, halfway between the mid-plane and end caps, and on both end caps.

A full set of hardware technical drawings, sketches, and data sheets for all the equipment used in the experiment was made available from correspondence with Jeffrey Wardell at LLNL [15]. A CD containing a detailed outline of the STEX experiment from January 2003 is the basis for the analytical analysis presented in this article.

The experiment started out at $296.5 \mathrm{~K}$ and was heated to $323 \mathrm{~K}$ over a 4-hour heating ramp before being allowed to soak for a 2-hour period at $323 \mathrm{~K}$. Then the experiment was heated to $403 \mathrm{~K}$ with a 29 -hour ramp and again allowed to soak at the desired temperature at $403 \mathrm{~K}$ for 14 hours. Finally, a 1-K/hour heating ramp was applied until ignition occurred. For this 
experiment the final time to ignition was 358,872 seconds or 99.6 hours. Figure 5.4 shows a time-versus-temperature recording of the thermocouple data from the STEX experiment.

The thermocouples were all placed horizontally along the y-axis and located at the mid-plane of the x-axis (Middle), half way between the center and the ends (Upper), and at the ends of the HE charge (End). This test procedure is considered a long test in that it took over 90 hours for a reaction to occur.

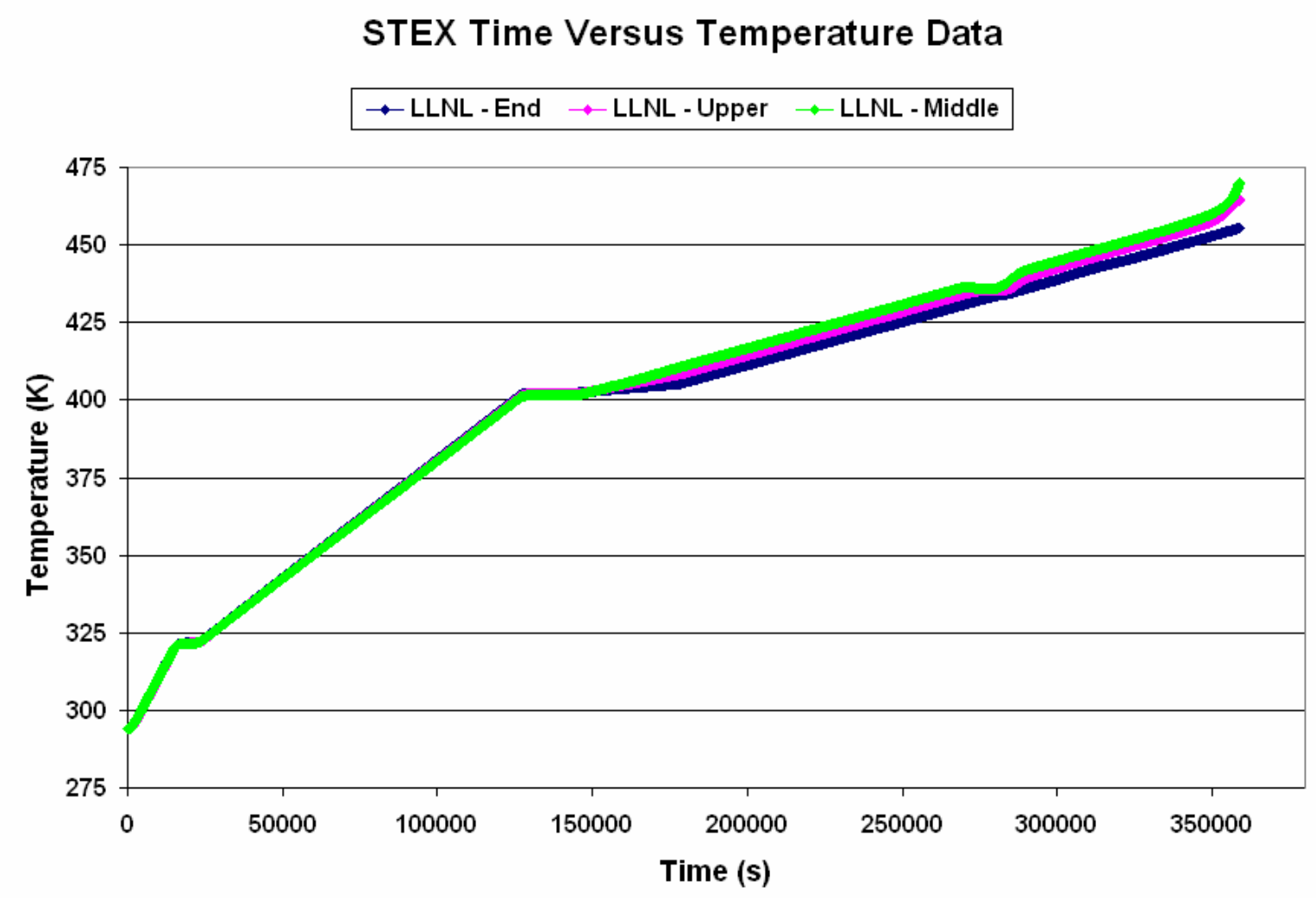

Figure 5.4: Thermocouple profile of the PBX 9501 in the LLNL STEX experiment [15].

\subsection{The LLNL One-Dimensional Time to Explosion (ODTX) Experiments for Spheres}

The objective of the ODTX experiments was to accurately determine the time interval required to produce a reactive event in confined explosives that were subjected to temperatures that will cause decomposition [12]. The necessity of using experimental data generated to define reactive source terms in heat flow computer codes dictated that the experimental setup be one-dimensional so as to simplify geometric effects in the calculation on heat flow. The initial temperature of the HE charges for all the experiments was approximately $298 \mathrm{~K}$.

The key component of the ODTX experiment was the design of cylindrical aluminum anvils, which were preheated and then the temperature was held at the desired operating temperature. The two anvils were $7.62 \mathrm{~cm}$ in diameter and $5.08-\mathrm{cm}$ high each. A 
hemispherical cavity was machined into the face of each anvil so that, when closed, the setup could accept a spherical charge of HE. Likewise, recessed knife edges were machined into each face. These knife edges pressed together on a copper sealing ring during the experimental runs. For reasons of safety in the laboratory environment, the sample sizes and the hemispherical cavities were limited to $1.27 \mathrm{~cm}$ in diameter, which resulted in experiments using approximately 22 grams of the desired HE. Figure 5.5 is a graphical illustration of the ODTX assembly.

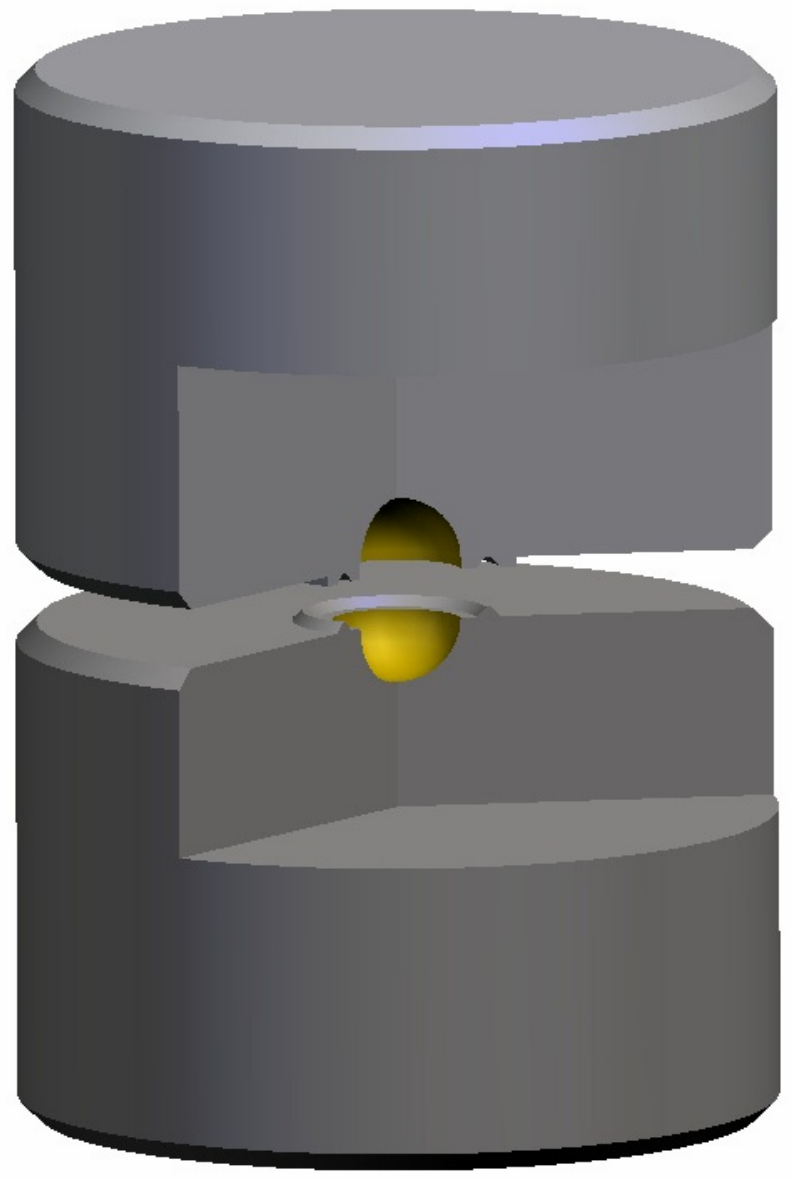

Figure 5.5: Rendition of the ODTX aluminum anvils.

The anvils are electrically heated, and the temperature is controlled to $\pm 0.2 \mathrm{~K}$ by thermocouples. When the operating temperature is achieved, the HE sample is placed in a vacuum chuck that is then remotely controlled. The chuck places the HE sample in the lower hemispherical cavity. The upper anvil is then driven downward by a preloaded pressure accumulator, thus sealing the cavity. The entire process takes approximately 0.6 seconds. Both the closing and confinement pressures (the pressure required to keep the anvils sealed during the experiment) are adjustable by the experimental operator. The ODTX experimental configuration is shown below in Figure 5.6. 


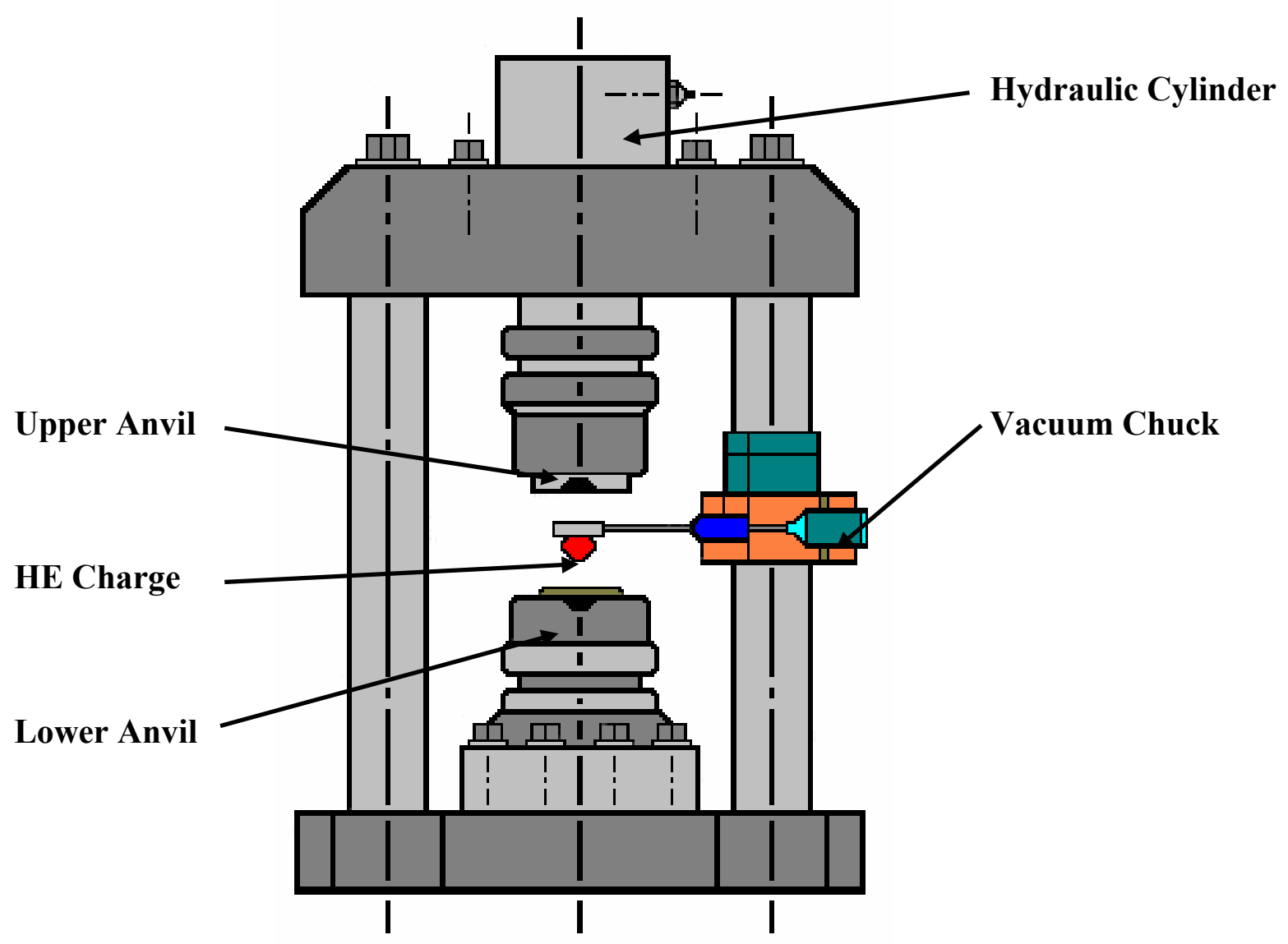

Figure 5.6: The ODTX experimental test device [7].

This unique and rather simple system provides a spherically symmetric, well-characterized, nearly isothermal boundary and a well-defined, variable confinement. The main purpose of this experimental approach was to allow the utilization of the experimental results to set various parameters in the chemical reaction model so that calculated, predictive models could be applied more widely and with a greater measure of confidence. These tests are considered to be fast tests, where even the longest time to reaction occurred in less than 10,000 seconds or about 3 hours.

There were many ODTX experiments performed using PBX 9501. The first 16 tests that were chosen for modeling were completely confined. The initial temperature of the PBX 9501 charge $(300 \mathrm{~K})$, the preset temperature of the aluminum anvils, and the time to an occurrence of a reactive event were recorded, and those results can be seen in Table 5.1.

No temperature profiles were recorded for this series of tests. No thermocouples were imbedded in the HE charges, thus the exact point of ignition was never located or recorded. 
Table 5.1: Test data for sixteen confined ODTX experiments

\begin{tabular}{|c|c|c|c|c|c|}
\hline \multicolumn{5}{|c|}{ PBX 9501 Confined Data, Aug 2000} \\
\hline \hline \multirow{2}{*}{ Experiment } & Weight & Density & Temp & Temp & Time \\
\cline { 2 - 6 } & $\mathbf{g}$ & $\mathbf{g} / \mathbf{c m}^{\mathbf{3}}$ & ${ }^{\circ} \mathbf{C}$ & K & s \\
\hline \hline $\mathbf{1}$ & 1.9971 & 1.8620444 & 280.4 & 553.55 & 9.30 \\
\hline $\mathbf{2}$ & 1.9944 & 1.859527 & 268.0 & 541.15 & 28.50 \\
\hline $\mathbf{3}$ & 1.9946 & 1.8597134 & 250.0 & 523.15 & 226.20 \\
\hline $\mathbf{4}$ & 1.9946 & 1.8597134 & 231.8 & 504.95 & 517.80 \\
\hline $\mathbf{5}$ & 1.8954 & 1.7672219 & 299.2 & 572.35 & 4.80 \\
\hline $\mathbf{6}$ & 1.9049 & 1.7760795 & 275.7 & 548.85 & 18.60 \\
\hline $\mathbf{7}$ & 1.8962 & 1.7679678 & 249.6 & 522.75 & 175.80 \\
\hline $\mathbf{8}$ & 1.8997 & 1.7712311 & 224.8 & 497.95 & 643.50 \\
\hline $\mathbf{9}$ & 1.8953 & 1.7671287 & 200.6 & 473.75 & 4351.80 \\
\hline $\mathbf{1 0}$ & 1.8959 & 1.7676881 & 210.5 & 483.65 & 1950.60 \\
\hline $\mathbf{1 1}$ & 1.8990 & 1.7705785 & 231.2 & 504.35 & 413.10 \\
\hline $\mathbf{1 2}$ & 1.8002 & 1.6784599 & 240.8 & 513.95 & 249.60 \\
\hline $\mathbf{1 3}$ & 1.8958 & 1.7675949 & 190.4 & 463.55 & 9369.60 \\
\hline $\mathbf{1 4}$ & 1.8973 & 1.7689934 & 266.4 & 539.55 & 47.40 \\
\hline $\mathbf{1 5}$ & 1.8956 & 1.7674084 & 280.7 & 553.85 & 12.60 \\
\hline $\mathbf{1 6}$ & 1.9024 & 1.7737485 & 289.4 & 562.55 & 6.60 \\
\hline
\end{tabular}

Fourteen experiments denoted as partially confined were tested. These partially confined tests were run with decreased closing and holding pressures allowing some product gases to escape. Ten sets of data referred to as aged samples were also examined. Table 5.2 and Table 5.3 show the recorded experimental results of those tests. 
Table 5.2: Test data for fourteen unconfined ODTX experiments

\begin{tabular}{|c|c|c|c|c|c|}
\hline \multicolumn{6}{|c|}{ PBX 9501 Unconfined Data, Jul/Aug 2000} \\
\hline & Weight & Density & Temp & Temp & Time \\
\hline Experiment & g & $\mathrm{g} / \mathrm{cm}^{3}$ & ${ }^{\circ} \mathrm{C}$ & $\mathbf{K}$ & $\mathbf{s}$ \\
\hline 17 & 2.00 & 1.86 & 268.50 & 541.65 & 149.70 \\
\hline 18 & 1.99 & 1.86 & 281.50 & 554.65 & 111.00 \\
\hline 19 & 1.90 & 1.77 & 249.90 & 523.05 & 208.50 \\
\hline 20 & 2.00 & 1.86 & 231.10 & 504.25 & 577.20 \\
\hline 21 & 2.00 & 1.86 & 210.10 & 483.25 & 2620.80 \\
\hline 22 & 1.90 & 1.77 & 219.50 & 492.65 & 1061.40 \\
\hline 23 & 1.90 & 1.77 & 200.40 & 473.55 & 4990.20 \\
\hline 24 & 1.90 & 1.77 & 239.40 & 512.55 & 301.20 \\
\hline 25 & 1.90 & 1.77 & 259.60 & 532.75 & 176.10 \\
\hline 26 & 1.90 & 1.77 & 191.80 & 464.95 & 9950.10 \\
\hline 27 & 1.90 & 1.77 & 274.60 & 547.75 & 90.90 \\
\hline 28 & 1.90 & 1.78 & 272.60 & 545.75 & 99.90 \\
\hline 29 & 1.90 & 1.77 & 281.00 & 554.15 & 95.10 \\
\hline 30 & 1.90 & 1.77 & 298.20 & 571.35 & 12.90 \\
\hline
\end{tabular}


Table 5.3: Test data for ten aged ODTX experiments

\begin{tabular}{|c|c|c|c|c|c|}
\hline \multicolumn{7}{|c|}{ PBX 9501 Aged Data, Sept 1999 } \\
\hline \multirow{2}{*}{ Experiment } & Weight & Density & Temp. & Temp. & Time \\
\cline { 2 - 6 } & $\mathbf{g}$ & $\mathbf{g} / \mathbf{c m}^{\mathbf{3}}$ & ${ }^{\circ} \mathbf{C}$ & $\mathbf{K}$ & $\mathbf{s}$ \\
\hline \hline $\mathbf{3 1}$ & 1.97 & 1.84 & 240.90 & 514.05 & 294.60 \\
\hline $\mathbf{3 2}$ & 1.98 & 1.84 & 260.40 & 533.55 & 126.60 \\
\hline $\mathbf{3 3}$ & 1.97 & 1.83 & 280.40 & 553.55 & 14.10 \\
\hline $\mathbf{3 4}$ & 1.97 & 1.84 & 220.20 & 493.35 & 824.70 \\
\hline $\mathbf{3 5}$ & 1.95 & 1.82 & 209.60 & 482.75 & 1885.80 \\
\hline $\mathbf{3 6}$ & 1.98 & 1.84 & 204.40 & 477.55 & 2909.10 \\
\hline $\mathbf{3 7}$ & 1.98 & 1.84 & 200.20 & 473.35 & 3896.10 \\
\hline $\mathbf{3 8}$ & 1.97 & 1.84 & 210.40 & 483.55 & 1584.30 \\
\hline $\mathbf{3 9}$ & 1.97 & 1.83 & 181.00 & 454.15 & 21255.60 \\
\hline $\mathbf{4 0}$ & 1.97 & 1.84 & 189.90 & 463.05 & 9345.60 \\
\hline
\end{tabular}

\subsection{The LANL Unconfined One-Dimensional Experiments for Spheres}

A series of one-dimensional heating experiments was performed with selected HEs in unconfined spherical geometries [7]. The purpose of these tests was to experimentally determine the thermal behavior of HE specimens near their ignition temperatures. Also of importance was an examination of the accuracy of simulation models using Arrhenius kinetics.

All chemical high explosives are metastable chemicals; thus, they decompose exothermically at all temperatures [13]. It should be possible to calculate the temperatures and times to ignition as functions of geometry and time-dependent boundary conditions if the thermal decomposition kinetics is known.

The goal of this experimental program was to theoretically and experimentally study the response of selected high explosives to predetermined boundary conditions. A spherically shaped charge was chosen for these tests in order to promote a one-dimensional analysis to simplify both the experiment and the calculations. 
Four unconfined spherical tests were conducted at Los Alamos, where three of the tests used a $2.54-\mathrm{cm}$-diameter sphere and one of the tests used a $7.62-\mathrm{cm}$-diameter sphere. The HE test samples were fabricated as hemispheres by either pressing or machining. The $0.125-\mathrm{mm}-$ diameter thermocouples were glued along the mid-plane of one hemisphere, and the second hemisphere was then glued to the first. Five thermocouple wires were adhered to the smaller spheres, and seven thermocouple wires were adhered to the larger sphere. The locations of the thermocouple recording points are denoted in pink in Figure 5.7.
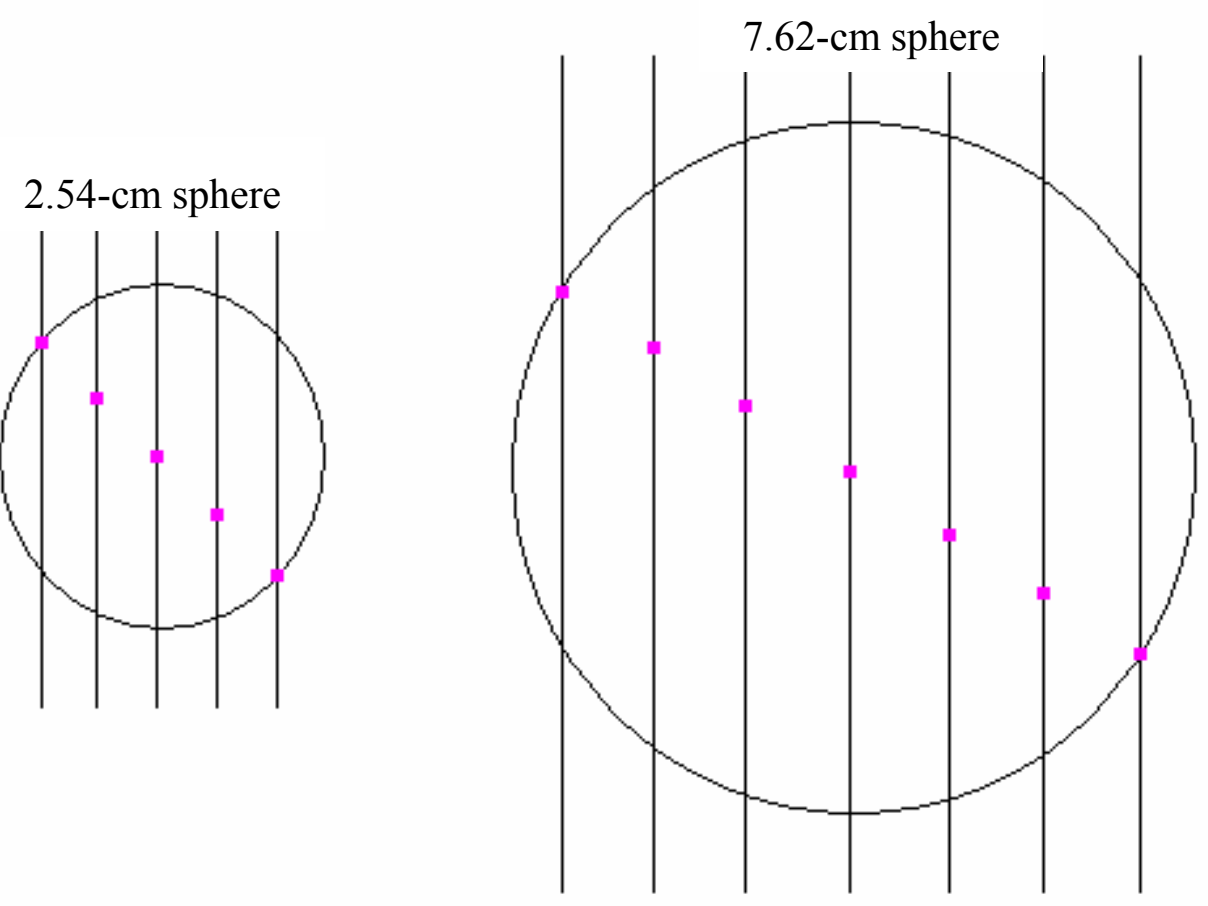

Figure 5.7: Cross-sections showing the thermocouple locations highlighted in pink for the $2.54-\mathrm{cm}$-diameter and 7.62-cm-diameter unconfined spheres [7].

The test chamber for the unconfined spheres was designed to be relatively inexpensive and easily rebuilt. The frame was constructed of angle iron, with the base and back wall being made of steel, which was then surrounded by $5.0-\mathrm{cm}$-thick glass foam insulation. The spherical HE specimens were suspended in the chamber and were heated by forced circulation of heated air, and the internal ducting was designed to insure uniform surface temperatures by providing turbulent mixing of the boundary layer air on the surface of the spheres. Electric heaters capable of producing 4,500 W of power were located in the duct and controlled by a Honeywell time-proportioning temperature controller. Figure 5.8 is a top view representation of the test chamber configuration.

Four different heating ramps were implemented in the unconfined experiments. The heating ramp from the April 4, 1979, test (labeled Test 1) had the following heating conditions: for a 2.54-cm-diameter unconfined sphere, the initial temperature was $288 \mathrm{~K}$, which was raised to $475 \mathrm{~K}$ over the first 3,600 seconds (about 2 hours) of the test. The spherical HE charge was 


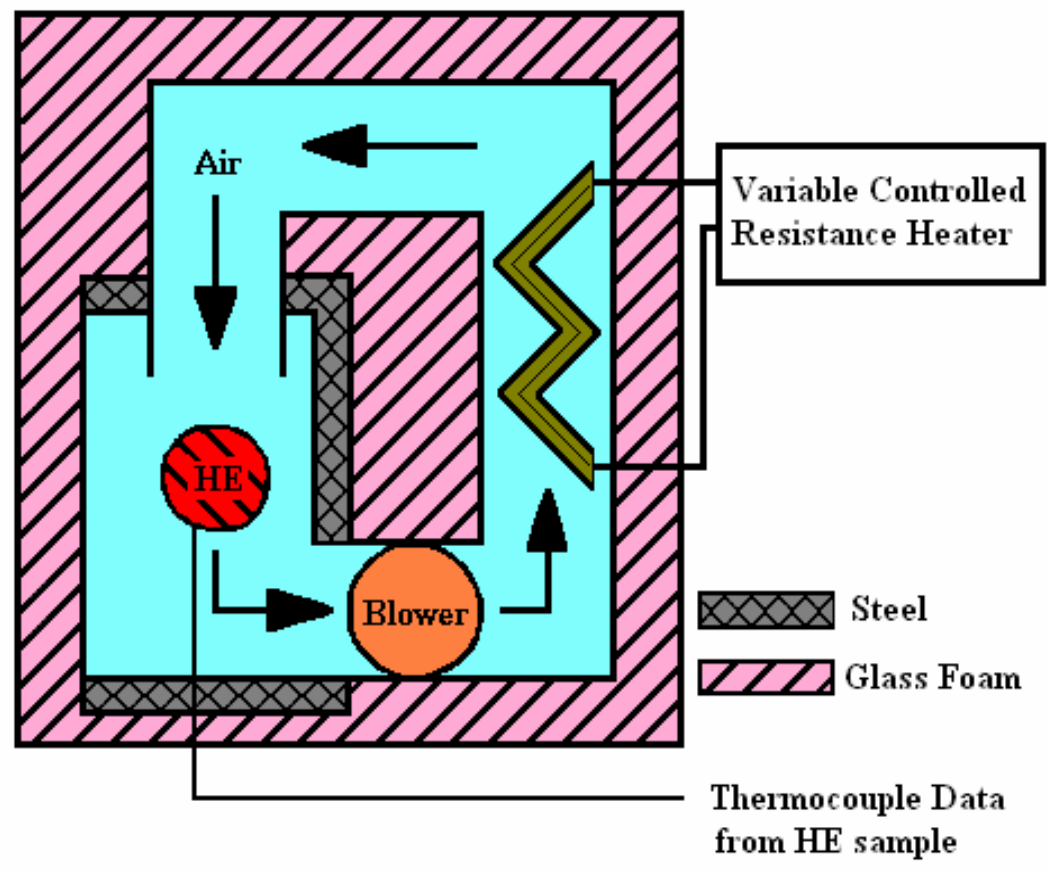

Figure 5.8: Critical-temperature test chamber for unconfined spheres up to $8.0 \mathrm{~cm}$ in diameter [7].

then allowed to soak at this temperature, and after approximately 8 hours, a reaction occurred. The results are shown in Figure 5.9.

The 7.62-cm-diameter unconfined sphere test from April 6, 1979, has been assigned as Test 2. This test started out at an initial temperature of $312 \mathrm{~K}$ and was raised to approximately $450 \mathrm{~K}$ in over 2 hours. It was allowed to soak at this temperature for around 11 hours. Then the temperature was gradually increased to $475 \mathrm{~K}$ over an 8 -hour period. A thermal reaction occurred at 78,600 seconds. Figure 5.10 traces the temperature profile for this test. Test 3 was performed on September 6, 1978. It was another 2.54-cm-diameter unconfined sphere with the following heating conditions: the initial temperature of the experiment started out at $310 \mathrm{~K}$ and was raised to $450 \mathrm{~K}$ in about 15 minutes. Instead of a soak temperature, the experiment was allowed to gradually rise to $500 \mathrm{~K}$ over a 2-hour period, at which time a thermal reaction was recorded. See Figure 5.11 for the recorded temperature traces. Test 4 was also conducted on September 6, 1978, and it too was a 2.54-cm-diameter unconfined sphere. This test started out at an initial temperature of $308 \mathrm{~K}$. It was raised to $470 \mathrm{~K}$ in about 45 minutes, and then the temperature was reduced over the next 3 hours to $450 \mathrm{~K}$, at which point the HE burned non-violently. The temperature traces for this test can be seen in Figure 5.12.

The unconfined experiments went through an induction process that created outgassing into the test chamber. Because of this unconfined state, the kinetics analysis performed on this experiment did not accurately predict the reaction time. 


\section{Test 1 Thermocouple Data [04/04/79]}

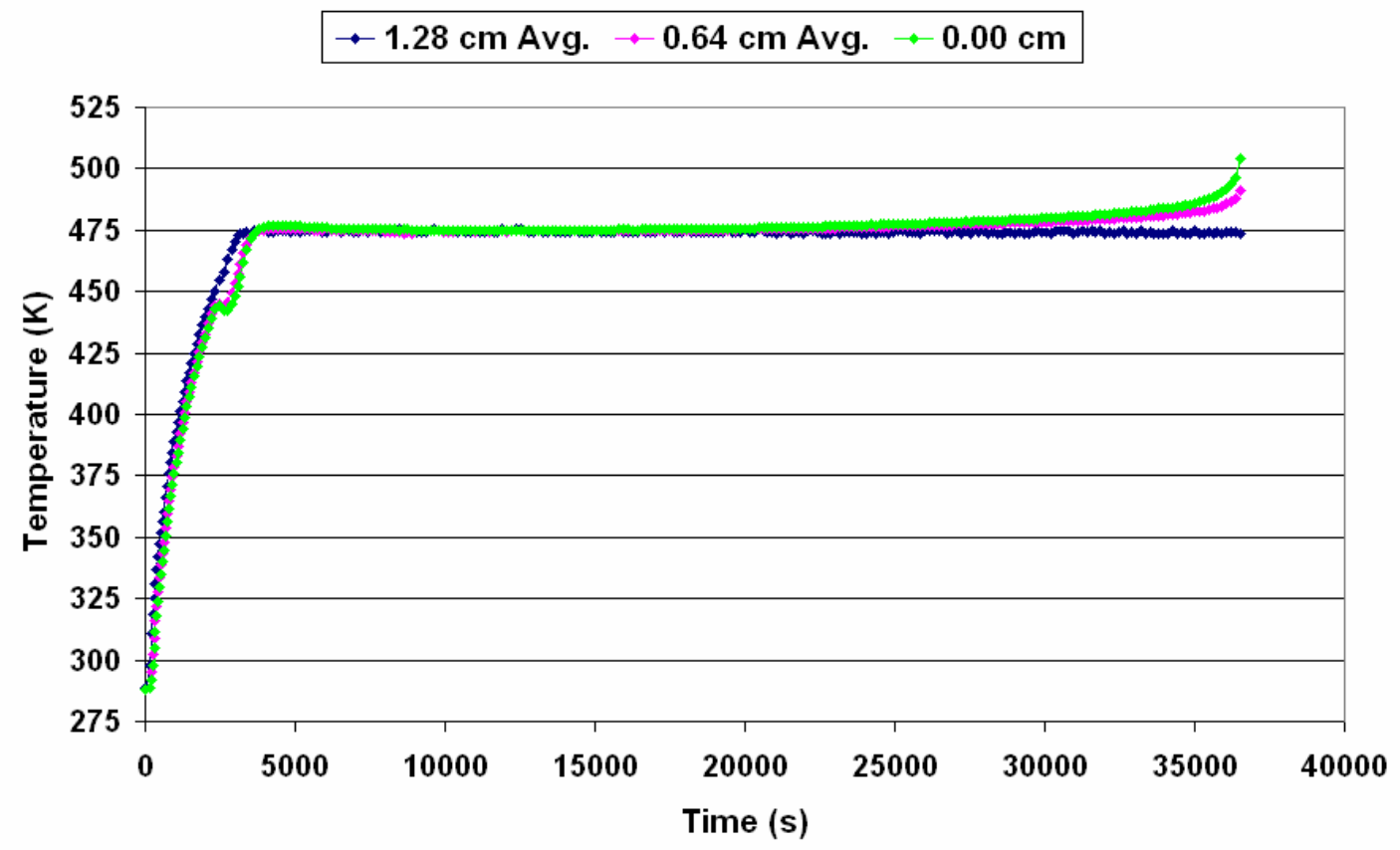

Figure 5.9: Unconfined spherical data from Test 1.

Test 2 Thermocouple Data [04/06/79]

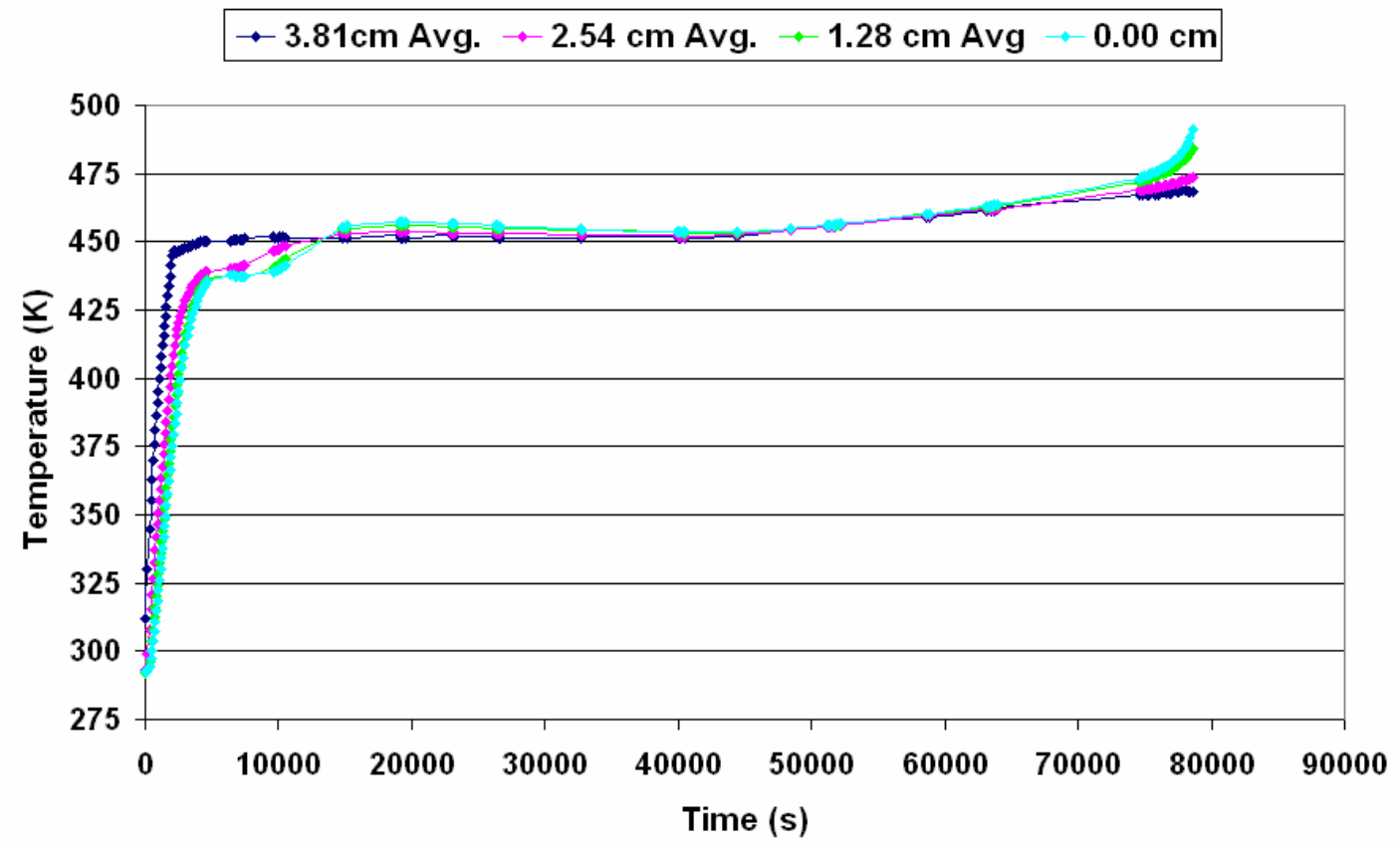

Figure 5.10: Unconfined spherical data from Test 2. 
Test 3 Thermocouple Data [09/06/78 - 1st]

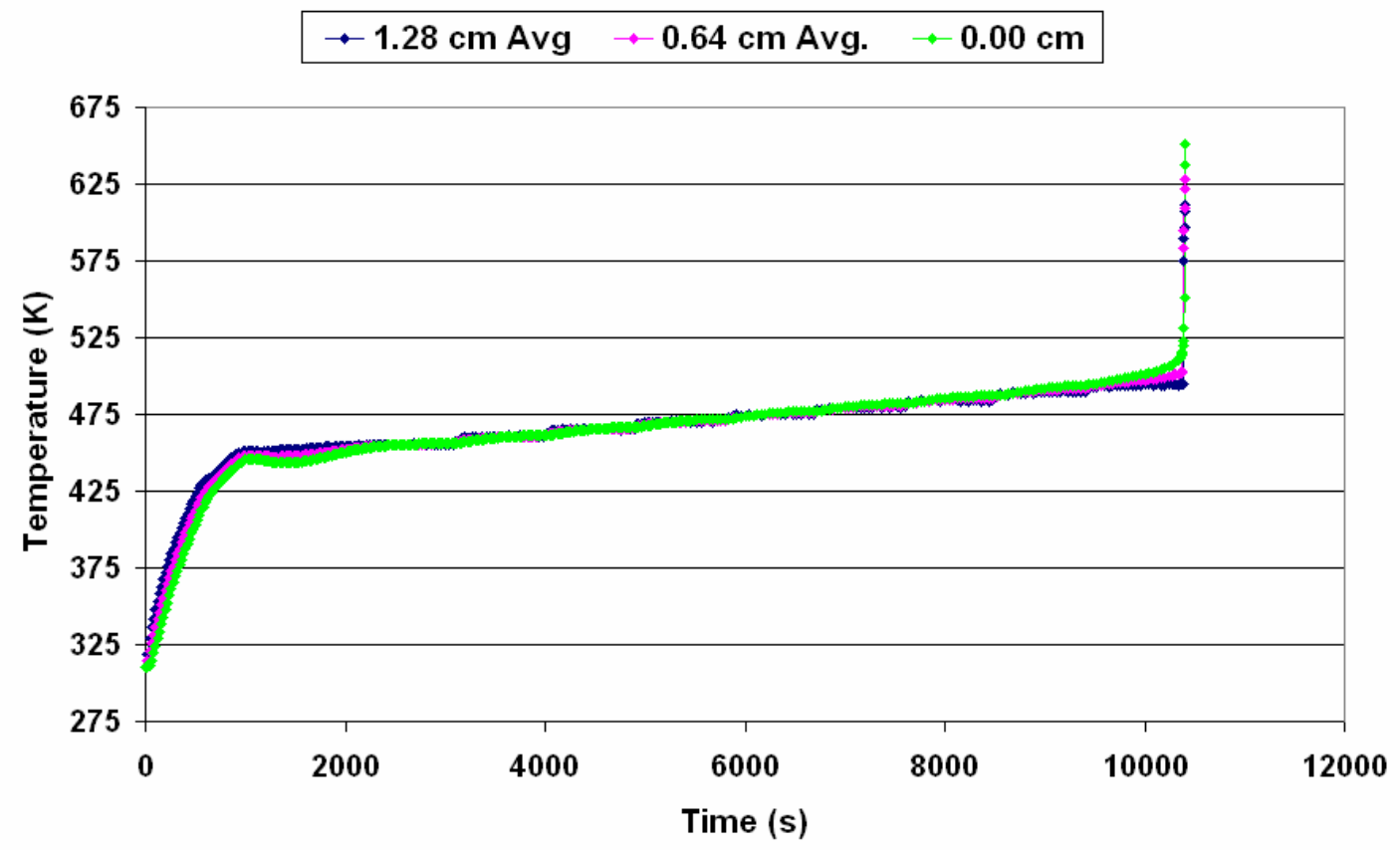

Figure 5.11: Unconfined spherical data from Test 3.

Test 4 Thermocouple Data [09/06/78 - 2nd]

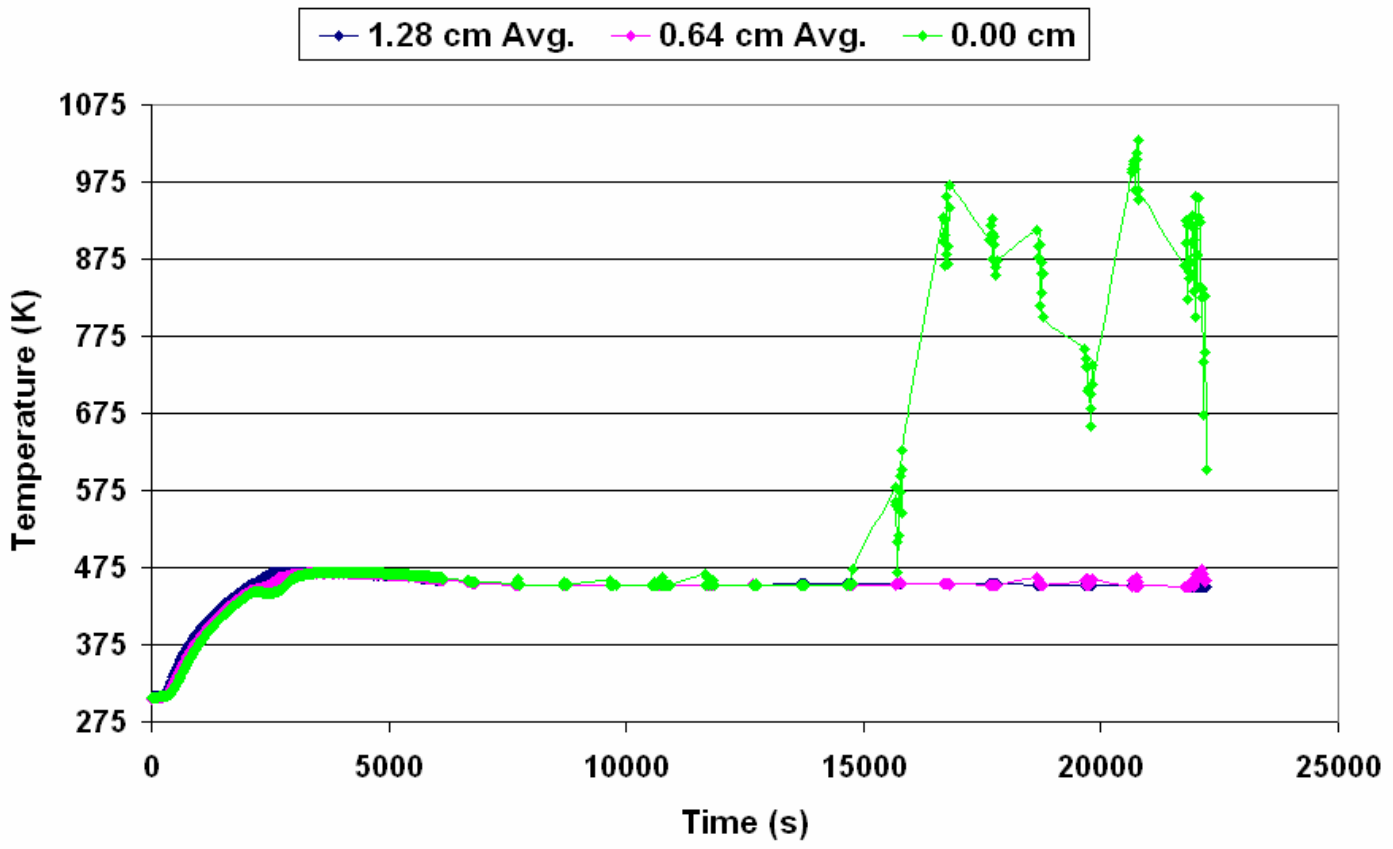

Figure 5.12: Unconfined spherical data from Test 4. 


\subsection{The Naval Air Warfare Center Weapons Division Experiments at China Lake for Confined Cylinders}

The Navy's cookoff experiments are part of a three-year study of slow cookoff conditions [14]. These experiments were developed to validate the cookoff models currently under development by the Department of Energy (DOE).

Cookoff is a serious and costly hazard over a large range of fields impacting the Navy. Of major concern to the Navy is the fear of shipboard fires that can ignite other weapons in an area already very susceptible to fire. Other concerns are handling, munitions design, testing, transportation, and storage.

Once a cylindrical design was chosen, calculations indicated that temperature uniformity increased as the sample length increased and that the optimum conditions occurred at the sample length-to-diameter ratio (L/D) of 4 . These experiments used cylinders that were sealed with a commercially available high-pressure plug manufactured by Torq N' Seal. Models that are vented or leaked cannot be accurately defined by the current mathematical solution models. The cylinder used in this experiment was a cold drawn, seamless 1018 steel tube with an outer diameter of $3.175 \mathrm{~cm}$ and a wall thickness of $0.478 \mathrm{~cm}$.

As many as 10 type-K thermocouples were externally mounted along the length of the cookoff tube. Four of the thermocouples were mounted at 90-degree radial intervals about the mid-plane of the test vessel. Two more thermocouples were evenly spaced in line between the mid-plane and end cap on both sides of the cylinder for a total of four more data points. The last two thermocouples were positioned at each end of the cylinder and in line with the others. This configuration can be seen in Figure 5.13. Next, a 110-volt, flexible heating cord was wrapped about the entire length cylinder. This was added to maximize the amount of PBX 9501 material involved in the thermal reaction process. This is the final step before the heating process is applied to the cookoff vessel and can be seen in Figure 5.14.

Three pieces of PBX 9501 were machined to the proper dimensions and then pressed into the cylinder to the appropriate depth. Next a $0.31-\mathrm{cm}$ disc of insulating board and a $0.51-\mathrm{cm}$ steel disk were pressed into each end of the tube leaving a $0.51-\mathrm{cm}$ air gap between the $\mathrm{HE}$ charges and the insulation at both ends of the cylinder. This gap was referred to as "ullage" by the experimentalists. Finally, the Torq N' Seal plugs were inserted into each end and tightened to ensure no leakage of gas from the material during the cookoff process. A crosssectional schematic view of the cookoff experiment is shown in Figure 5.15. 


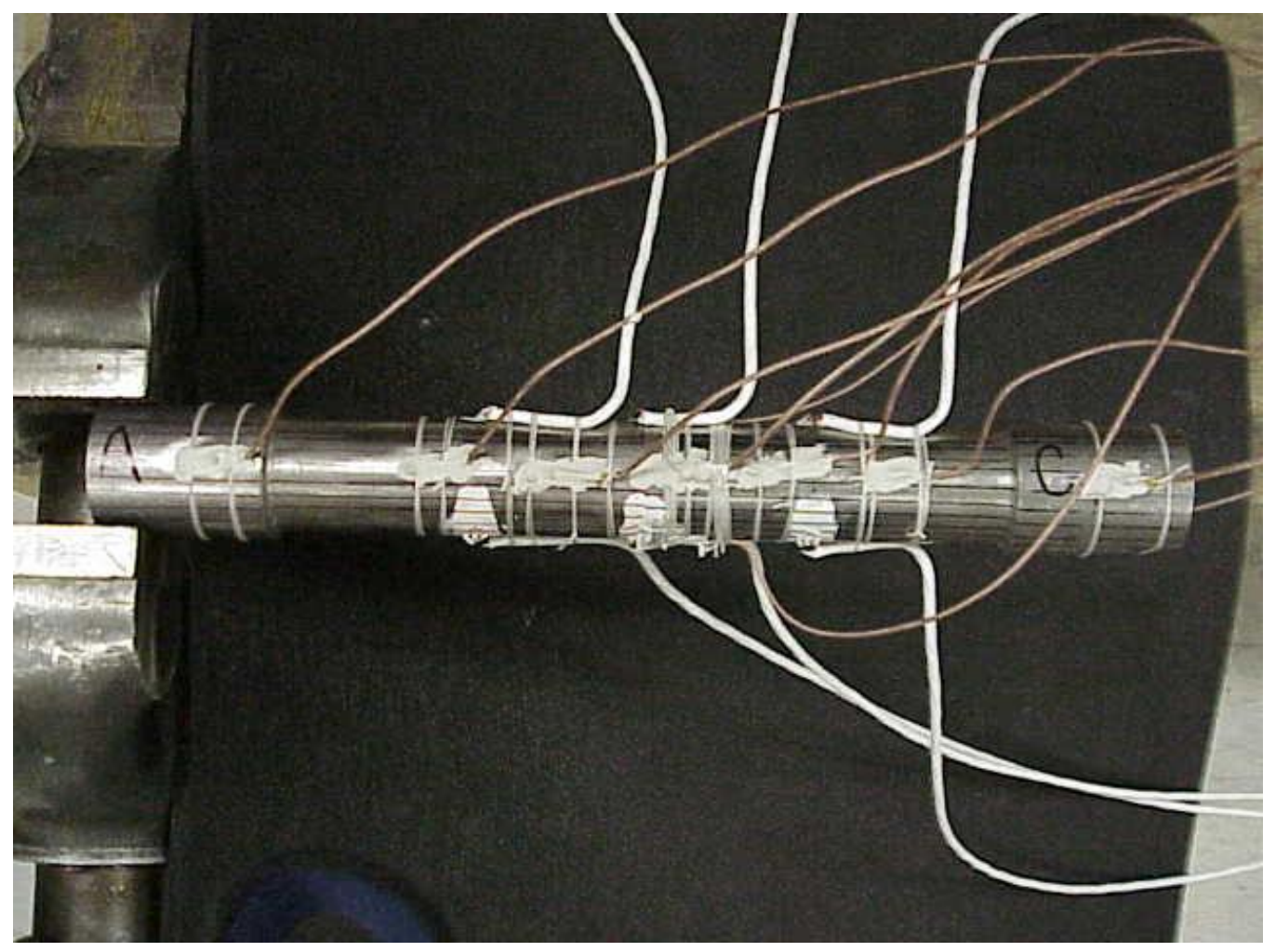

Figure 5.13: Thermocouple locations on the Navy cookoff cylinder.

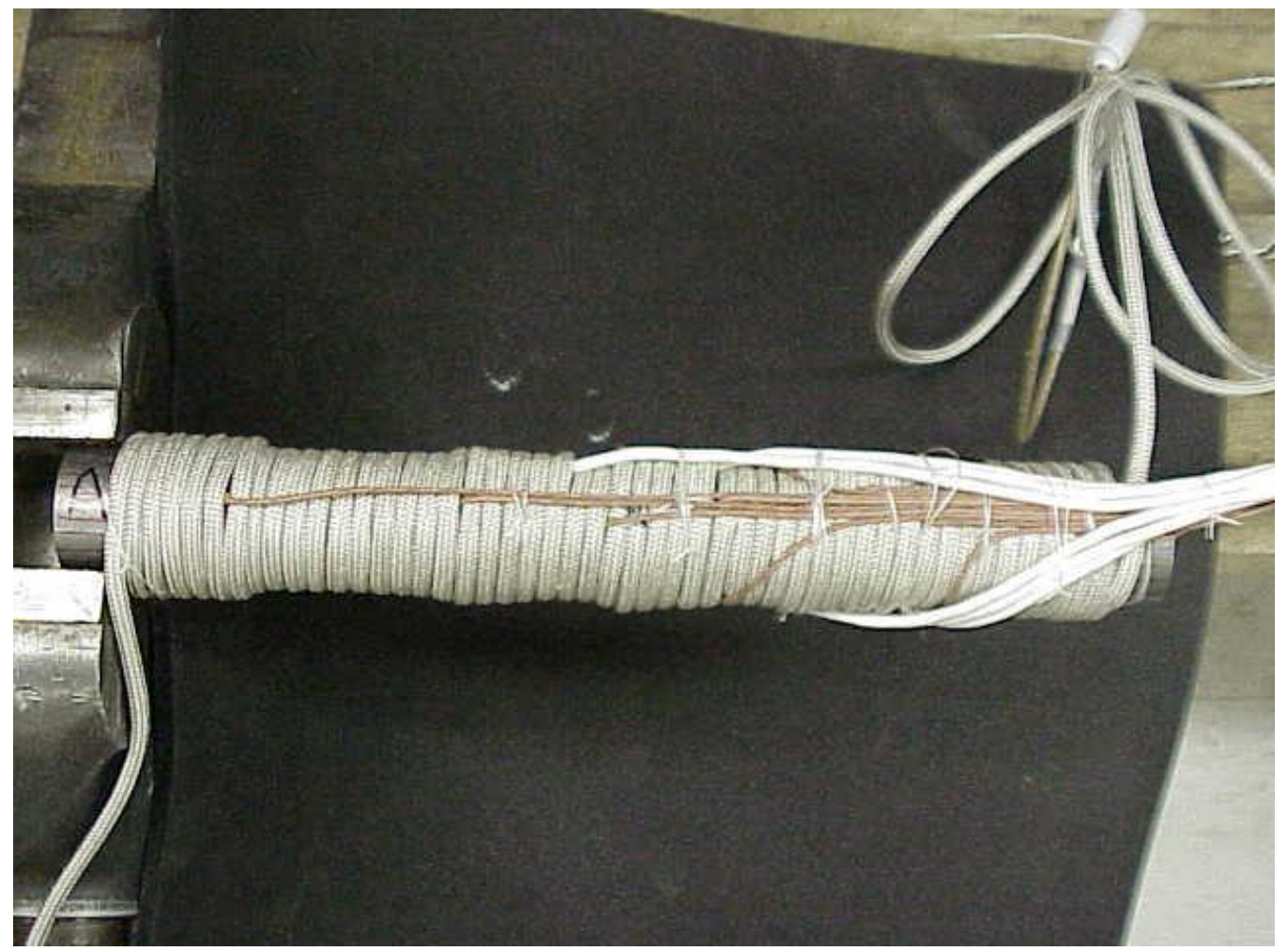

Figure 5.14: Navy cookoff cylinder wrapped in flexible heating tape. 
$\square$ Torq N' Seal Plug $\quad \square$ Thermal Banier

$\square$ Torq N' Seal Anchor $\square$ Energetic Material

$\square 1018$ Steel Cover $\quad \square 1018$ Steel Tube

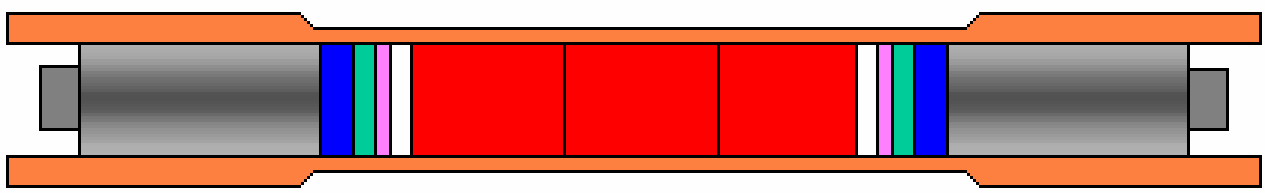

$\mathrm{ID}=22 \mathrm{~mm}$

Center Wall $=2.54 \mathrm{~mm}$
Tube Length $=250 \mathrm{~mm}$

Explosive Length $=102 \mathrm{~mm}$

Figure 5.15: Cross-sectional schematic of the Navy cookoff experiment.

Pat Curran from the Naval Air Warfare Center Weapons Division at China Lake supplied the heating conditions used in the Navy cookoff experiment [16]. The experiment started off at an initial temperature of $293 \mathrm{~K}$, was then heated up to $180 \mathrm{~K}$ over a 16-minute time interval, and held at this temperature for a 3-hour soak. The next heat addition raised the temperature $15 \mathrm{~K}$ to $195 \mathrm{~K}$ over a 15 -minute interval. The experiment was then allowed to soak at $195 \mathrm{~K}$. A reaction occurred during this cycle after having soaked for 18.57 minutes. Figure 5.16 shows the applied heat ramp used for the Navy cookoff experiment.

\section{Naval Cookoff Data}

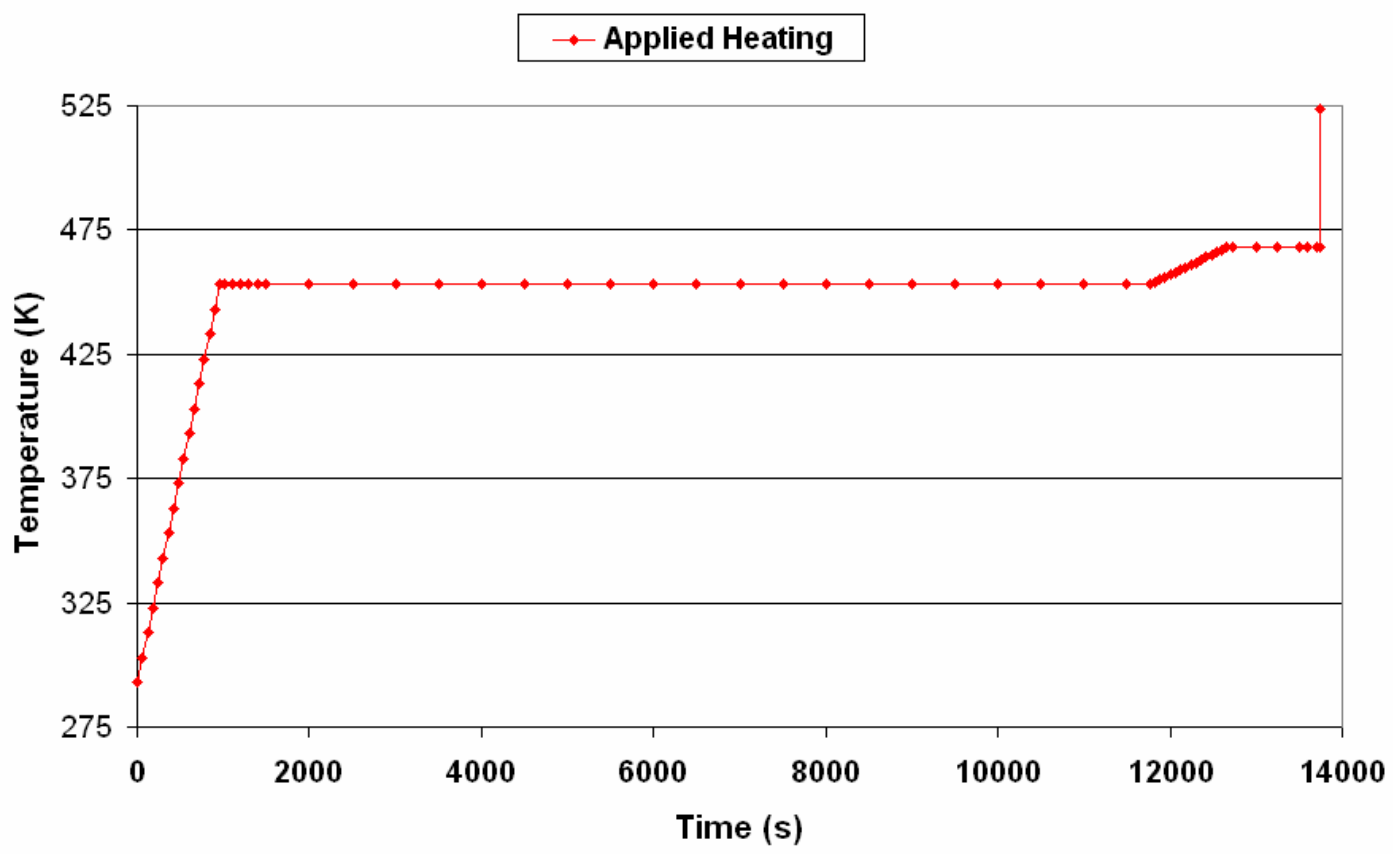

Figure 5.16: Heating profile for the Navy cookoff experiment [16]. 


\subsection{THE SIMULATION MODELS AND DESIGN PARAMETERS}

This chapter provides the geometry, confinement details, boundary conditions, mesh refinement, and time increment studies for each of the four experiments with the models using each of the three kinetics systems.

The modeling process consists of two major components. First, a representative region from each of the four experiments is chosen. A model is then drawn, meshed, and boundary conditions are applied. Second, a COYOTE input file is created, and the following five fields are updated with the appropriate data and solution parameters: material definitions, geometry, boundary conditions, variable functions, and data output.

IDEAS design software is used to create graphical models for each of the four experiments, using dimensions supplied on the engineering prints. After each model is drawn, it is then partitioned into sections such that the interfaces of the different material regions will have shared nodes.

Next, the finite element mesh (FEM) is created, using the mapped option that allows the user to define the number of nodes per side. Quadrilateral elements were used for all the models in the anticipation of future research. This includes using other FEA solvers to study the effects of tied thermal and mechanical processes such as fracture and deformation. The mesh sections are applied to each partitioned region according to its corresponding material type.

For all four models, the initial mesh size for the elements is approximately $1.0 \mathrm{~mm}$ by $1.0 \mathrm{~mm}$ in size. All four models also have FEMs with $0.5-\mathrm{mm}$ - by $0.5-\mathrm{mm}$-length element sides; thus, these meshes have four times as many total elements. The refined $(0.5-\mathrm{mm}) \mathrm{mesh}$ is created to check mesh convergence, i.e., is the result different with finer mesh. If there is no discernable differences between the two mesh solutions, with everything else being kept the same, then the initial mesh size is determined to be accurate.

Once the mesh is created, the boundary conditions are applied. The boundary conditions are applied to the nodes along the appropriate edges of the model. Temperature, as a function of time, is applied on the outside surfaces of the model to represent uniform heating created by heat tape or radiant lamps. Thermocouple values measured on the outside surfaces of the experiments are used to define these heat transfer boundary conditions.

All of the COYOTE input files used in the four models are based on the same generic format with each of the three previously described kinetics systems used for the solution process as heat generated in the HE during chemical decomposition.

All four models are solved using automatically changing time steps. An initial time step of 0.1 seconds is chosen for all the calculations. The chemical solver CHEMEQ has its one time solver that solves the ordinary differential equations (ODEs) within each time step in the heat transfer process. A time step sensitivity study is also performed. The purpose of these reduced time step models of 0.01 seconds is to see if there is a change in the time to reaction 
or the location of reaction. This method is very time consuming but allows the user the opportunity to gauge the effect that the time step has on the solution.

Before the model is drawn, certain conditions and assumptions need to be established. None of the models incorporate friction effects that occur between the different material contact surfaces. Also, changes in the HE material, including material expansion and crack propagation, are not solved for in any of the models. Furthermore, no pressure or deformation effects are represented in the modeling or involved in the solution process. Finally, these models only solve for heat conduction using the three versions of Arrhenius decomposition kinetics defined earlier as the heat source. It is determined that, for these experiments, convection and radiation effects are considered negligible and thus not included in the solution process.

\subsection{The LLNL Scaled Thermal Explosion Experiment (STEX) for Confined Cylinders}

The purpose of this experiment was to very slowly heat the STEX vessel in such a manner that the ignition point would be ideally located at the mid-plane and in the center of the cylindrical PBX 9501 charge. Since the geometry is radially uniform throughout the entire 360 degrees of the vessel, a two-dimensional axisymmetric section of the top half is chosen as the representative area to be modeled. A cross-sectional view of the STEX vessel is shown in Figure 6.1, and the area being modeled is outlined with a green box. The STEX experiment was considered to be perfectly sealed, thus no gas losses were expected and no products, intermediates, or reactants were lost in the decomposition process.

A graphical model was designed using the dimensions acquired from the engineering prints provided by Jeffrey Wardell from LLNL [15]. To represent the six bolts used to seal the top cap to the vessel, a percentage of the bolt area with respect to its radial location is computed - that calculated thickness is centered at the bolt-hole location and is used to represent the bolt and its material properties - and is shown in Figure 6.2.

A temperature as a function of time boundary condition is applied to the nodes along the appropriate outer edges of the model. Figure 6.2 shows the location of the temperature boundary conditions applied to the outside edges of this model. Thermocouples placed on the outside of the confinement vessel measured non-uniform axial temperature in the experiments. The outside of the cylinder is divided into zones 1 through 7 . These zones are used to apply variable axial temperature to see the effect of a non-uniform heating profile along the outside edge of the containment cylinder and compare these results with the uniform heating model. Another version of the model divides the top cap of the cylinder into two sections and those data are also compared with the uniform heating model. 


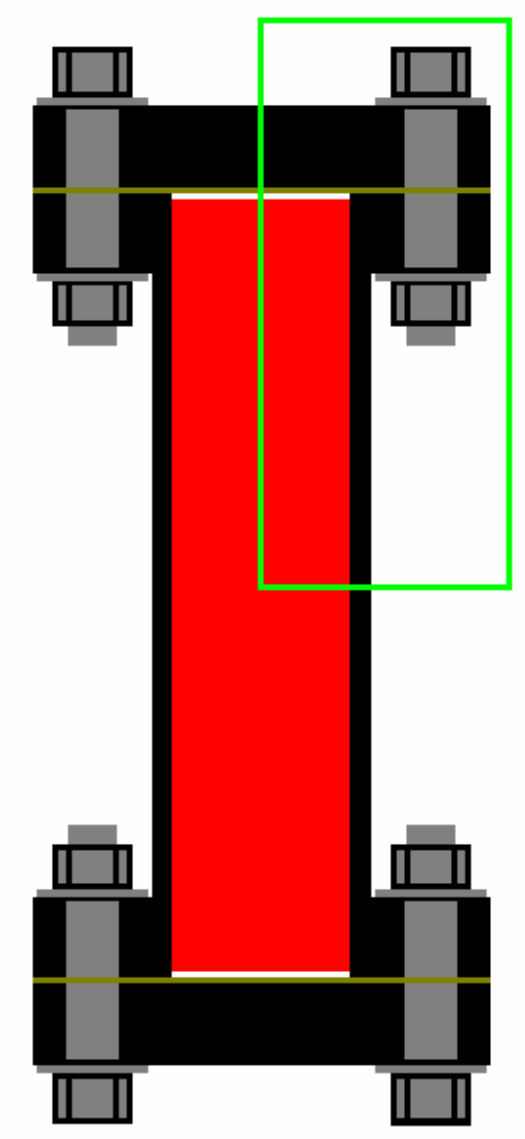

Figure 6.1: Cross-sectional view of the STEX vessel with a green box outlining the area modeled [11].

The STEX models also incorporate the use of 'gap' elements that are represented by yellow and green meshes in Figure 6.2. The gap elements represent the thermal resistance between two materials, and in this case, it is the air gap between the metal liner and the HE charge. A gap element is a fictitious material that is $0.5 \mathrm{~mm}$ in width or less, and it is located at the interface of two materials that have vastly different specific heat and conductivity rates [17]. The interface conditions for these elements are continuity of temperature and heat flux for the materials to either side of the gap elements. Many FEA solvers have problems with nodes that are not tied, so the use of gap elements is a way to bypass this problem. A version of this model was also run without the gap elements and again compared with the results from the other models.

One of the STEX experiments conducted by researchers at LLNL is modeled and assessed using all three kinetics systems. Multiple versions of this single model are run with varied heating conditions, activation energies, material definitions, and mesh size. All three kinetics systems are also run with both the initial time step value of 0.1 seconds and with the reduced time step of 0.01 seconds. 


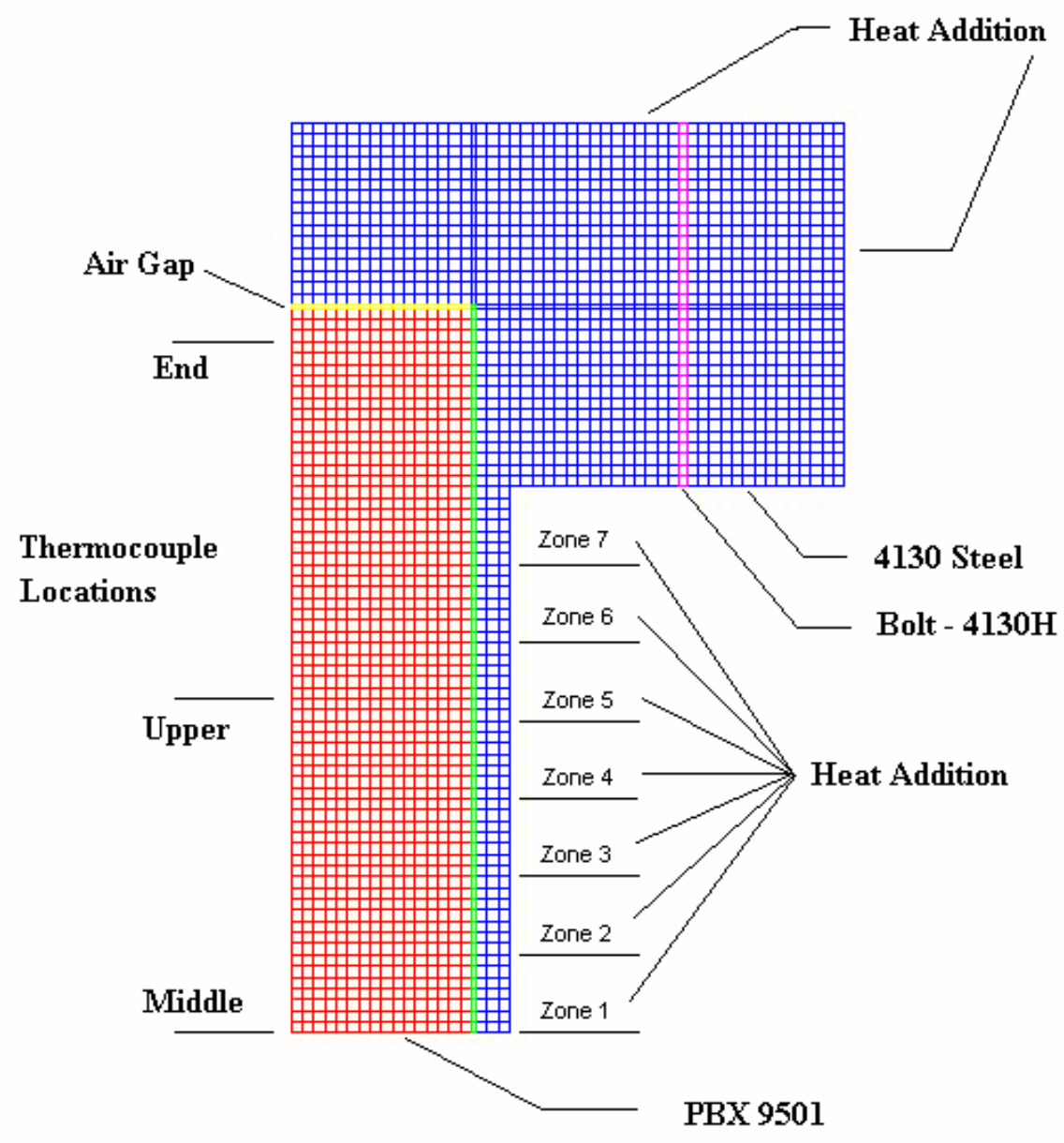

Figure 6.2: Meshed axisymmetric model of the STEX test vessel.

The different combinations of variables result in 8 data sets using the Dickson et al. kinetics. The Jaeger kinetics has 6 data sets, and the Tarver and McGuire kinetics has 10 data sets from the various versions of the models. This adds up to a total of 24 data sets being assessed from the different variations in the STEX model.

Each of the three kinetics systems is also run with both the standard 1.0-mm mesh and the finer $0.5-\mathrm{mm}$ mesh. The number of elements and material type of theses elements are shown in Figure 6.3. For the standard mesh, there are 1040 elements of PBX 9501 shown in red, 82 elements of air gap displayed in yellow and green, 33 elements of bolt material denoted in pink, and 1475 elements of steel represented in blue. For the fine mesh, there are 4160 elements of PBX 9501 shown in red, 328 elements of air gap displayed in yellow and green, 132 elements of bolt material denoted in pink, and 5900 elements of steel represented in blue. 

1.0-mm Mesh
0.5-mm Mesh

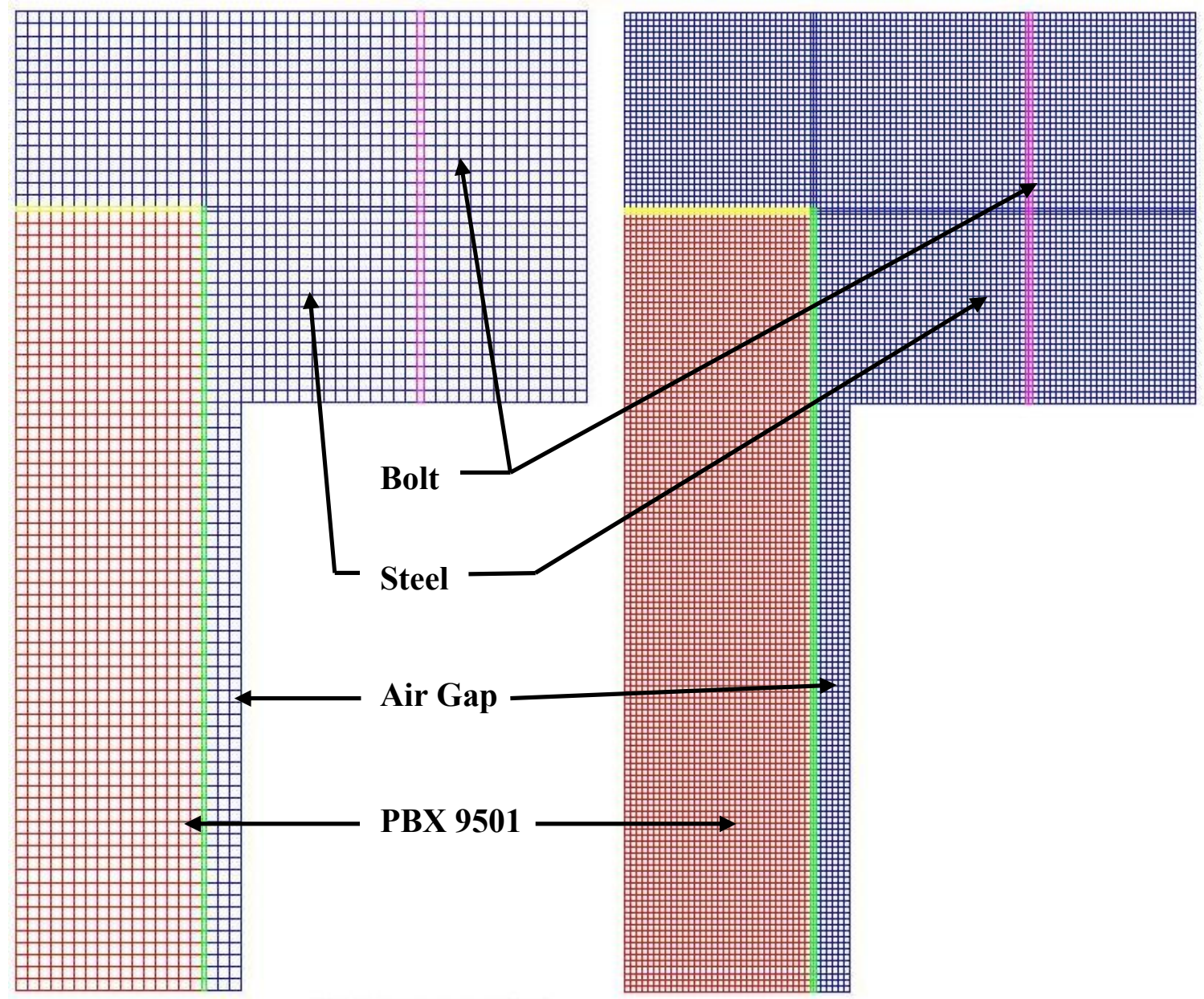

Figure 6.3: The 1.0-mm mesh and the finer 0.5-mm mesh for the STEX model.

\subsection{The LLNL One-Dimensional Time-to-Explosion (ODTX) Experiments for Spheres}

The purpose of the ODTX experimental series was to have a constant temperature boundary condition applied to a spherical charge of PBX 9501. Due to design conditions, it is assumed that each half of the aluminum containment anvils is identical, which leads to the heattransfer process being identical in the top and bottom sections.

The minimum radial length of the aluminum anvil is five times greater than the radius of the PBX 9501 sphere used in the experiments. Because the shape of the HE charge is spherical and the anvils are cylindrical, a two-dimensional axisymmetric section of the top half is chosen as the representative area that was to be modeled. A cross-sectional view of the 
ODTX containment anvils is shown in Figure 6.4, and the area being modeled is outlined with a green box.

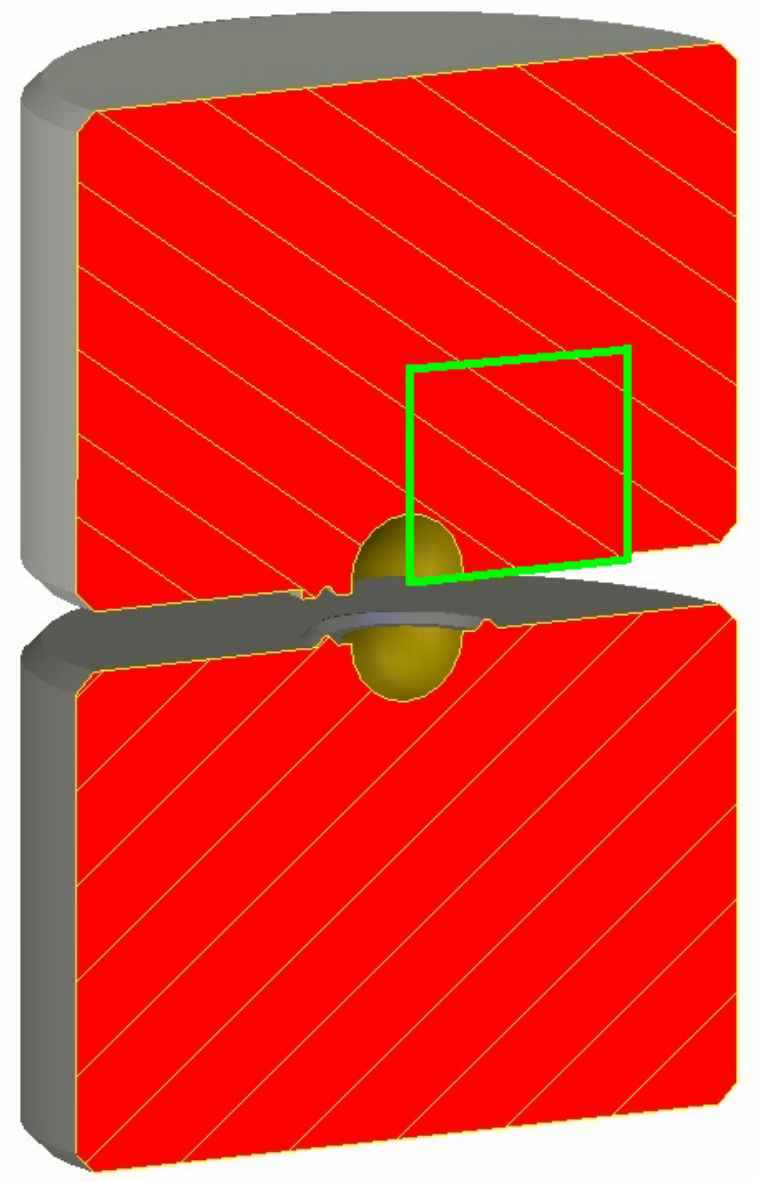

Figure 6.4: Cross-sectional view of the ODTX aluminum containment anvils with a green box outlining the area modeled.

The ODTX experiments were performed at LLNL with two different confinement conditions. For one series of tests, the experiments are considered confined, and for another series of tests, the experiments are considered partially confined. For the confined experiments, no gas losses were expected and no products, intermediates, or reactants are lost in the decomposition process. For the partially confined experiments, no records of the amount or types of losses were recorded. A series of tests was also performed on what is referred to as aged samples of PBX 9501.

The ODTX model is drawn as a square section with 3.0-cm-long sides. The aluminum anvils are preheated and maintained at a constant temperature. The assumption for this model was that since the anvil area was so much larger than the spherical charge, a control volume consisting of a section of the anvil and sphere will give an accurate thermal solution for the conduction process. A representation of the meshed model is shown in Figure 6.5. 


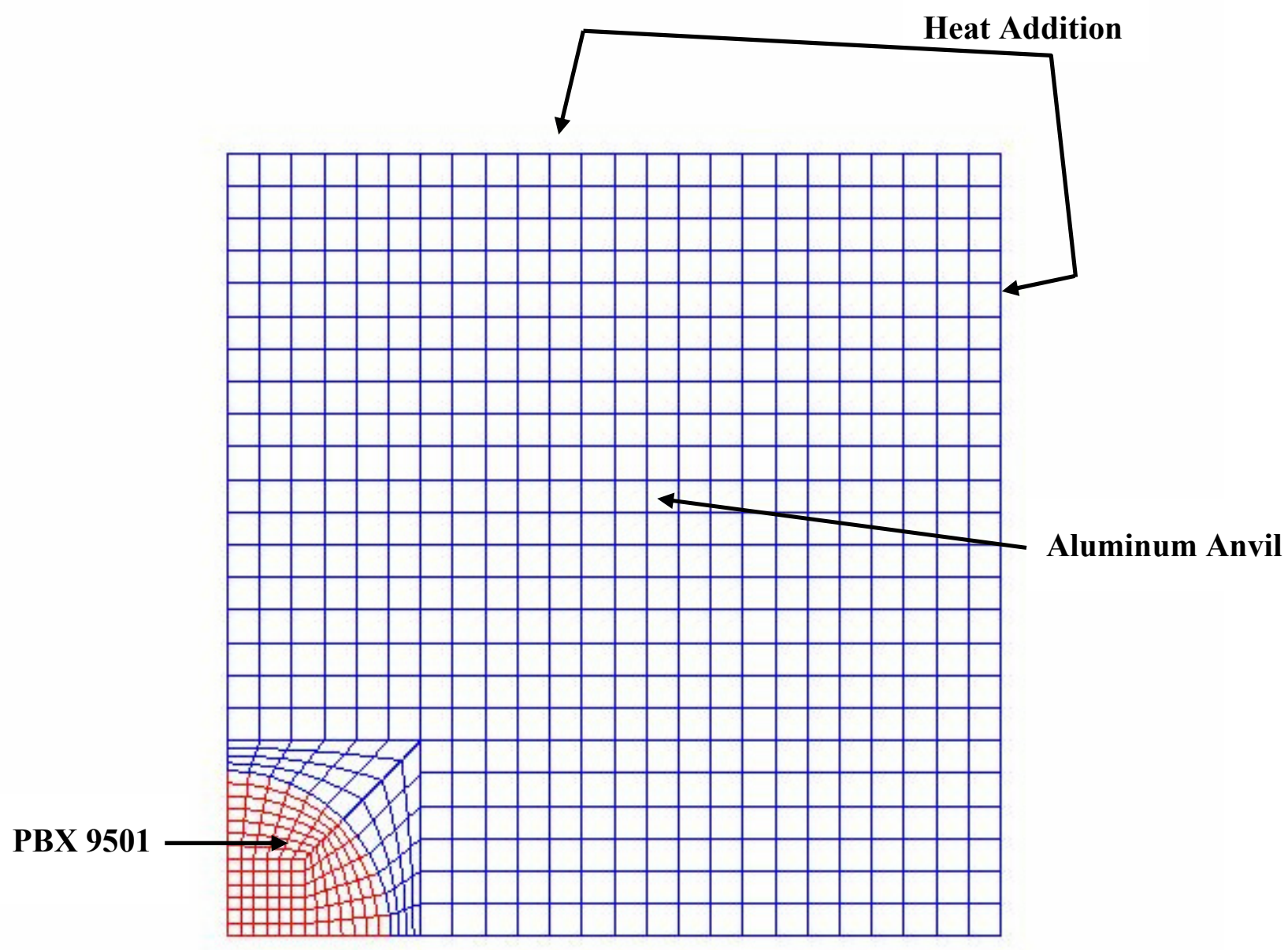

Figure 6.5: Meshed axisymmetric model of the ODTX experiment.

A constant temperature boundary condition is applied to the nodes along the outer edge of the aluminum anvil, and Figure 6.5 shows this location. The initial time step value of 0.1 seconds was used to begin the analysis of the 40 experiments using each of the three kinetics systems for a total of 120 results. The same process was performed with the reduced time step of 0.01 seconds for another 120 data sets.

All 40 experiments were analyzed with the 1.0-mm mesh using the three kinetics systems. An additional set of models using the first four confined experiments and incorporating the $0.5-\mathrm{mm}$ mesh were also analyzed giving another 12 sets of data. A total of 252 data sets were created and assessed using the ODTX models.

When utilizing COYOTE to solve heat transfer problems [18], the rate of heat addition, the size of the mesh, and the size of the initial time step become interdependent factors. As the heating rate increases so does the local temperature ratio $\theta$, which in turn increases the local Biot number, $\mathrm{B}_{\mathrm{i}}$. This relation in turn increases the local Fourier transform number $\mathrm{F}_{\mathrm{o}}$. 
The three equations defining these three local values combine to give a direct relationship between the initial time step and the characteristic length of an element. The mathematical relationship for these variables is defined by the following equations:

$$
\begin{aligned}
& \theta=T(\Delta x) / T_{\text {surface }}, \\
& B_{i}=h \Delta x / k, \\
& F_{o}=\alpha \Delta t / \Delta x^{2}, \text { and } \\
& \Delta t=\frac{\left(F_{o}\right)\left(\Delta x^{2}\right)}{(\alpha)} .
\end{aligned}
$$

From these equations, it was determined that, for the fast heating rates used in the ODTX experiments, an initial time step of 0.01 seconds is required for a mesh with elements having a characteristic length of $1.0 \mathrm{~mm} .0 .50 \mathrm{~mm}$.

The number of elements and material type of these elements are shown in Figure 6.6. For the 1.0-mm mesh, there are 120 elements of PBX 9501 shown in red, and 1475 elements of aluminum displayed blue. For the $0.5-\mathrm{mm}$ mesh, there are 480 elements of PBX 9501 shown in red, and 5900 elements of aluminum represented in blue.

\section{0-mm Mesh}

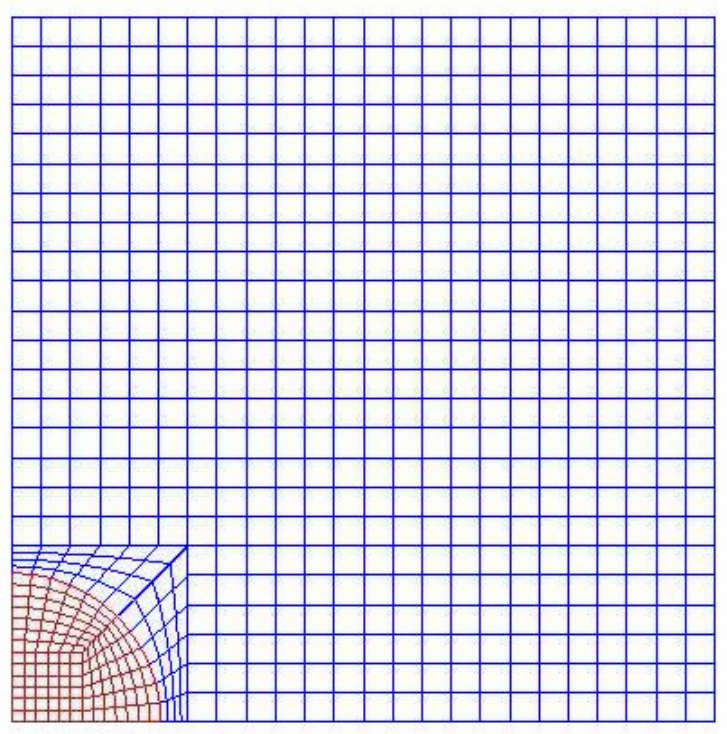

\section{5-mm Mesh}

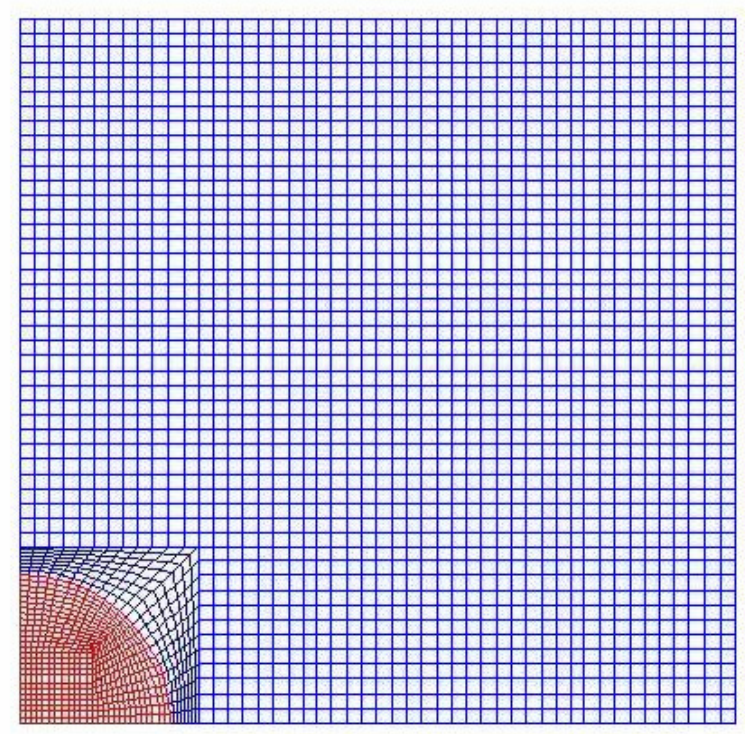

Figure 6.6: The 1.0-mm mesh and 0.5-mm mesh for the ODTX models. 


\subsection{The LANL Unconfined One-Dimensional Experiments for Spheres}

The purpose of the unconfined spherical experiments was to have a constant heat boundary condition applied to a spherical charge of PBX 9501. Due to the spherical shape and the slow heating process, the point of ignition was supposed to be at the center of the PBX 9501 charge. Even if a reaction occurred somewhere other than the center of the sphere, that reaction should occur at the same radial distance inward along any path inward from the spheres surface. The unconfined experiments, as is obvious from the name, had no type of containment and no method for recording the amount or types of gas (product) losses that occurred.

The green boxes shown in Figure 6.7 represent a cross-sectional view of the areas that were modeled for assessment of the unconfined spherical experiments. Graphical models of both sizes of spheres used in the experiments were designed using dimensions supplied on the engineering prints from the experiments conducted by Dwight Jaeger at LANL [7] and representations of the models are shown in Figure 6.8.

A constant temperature boundary condition was applied to the nodes along the circumferential edges on both the $2.54-\mathrm{cm}$ and the $7.62-\mathrm{cm}$ unconfined PBX 9501 spheres, as shown in Figure 6.8.

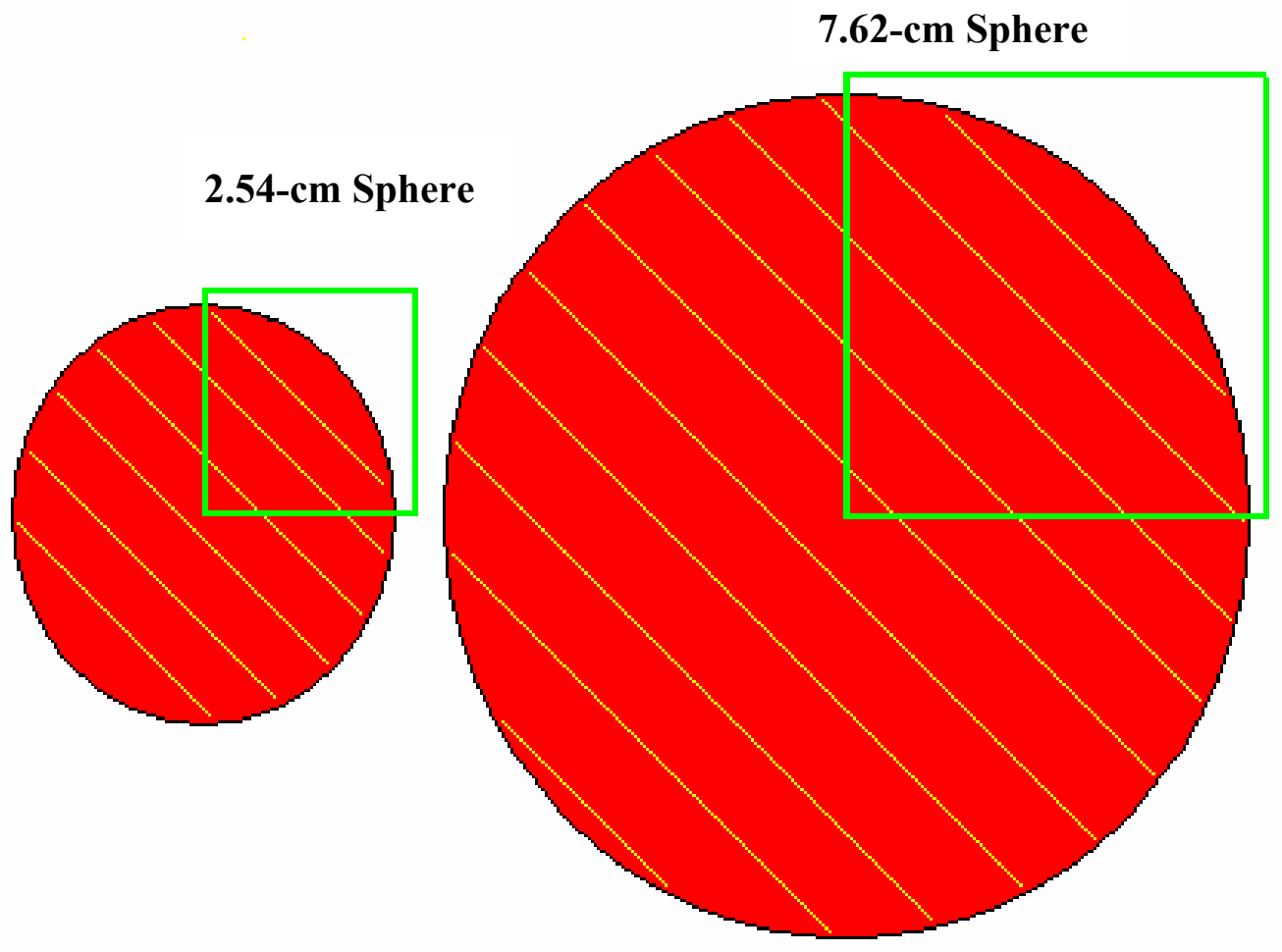

Figure 6.7: Cross-sectional view of the 2.54-cm-diameter and 7.62-cm-diameter spheres with a green box outlining the areas modeled. 


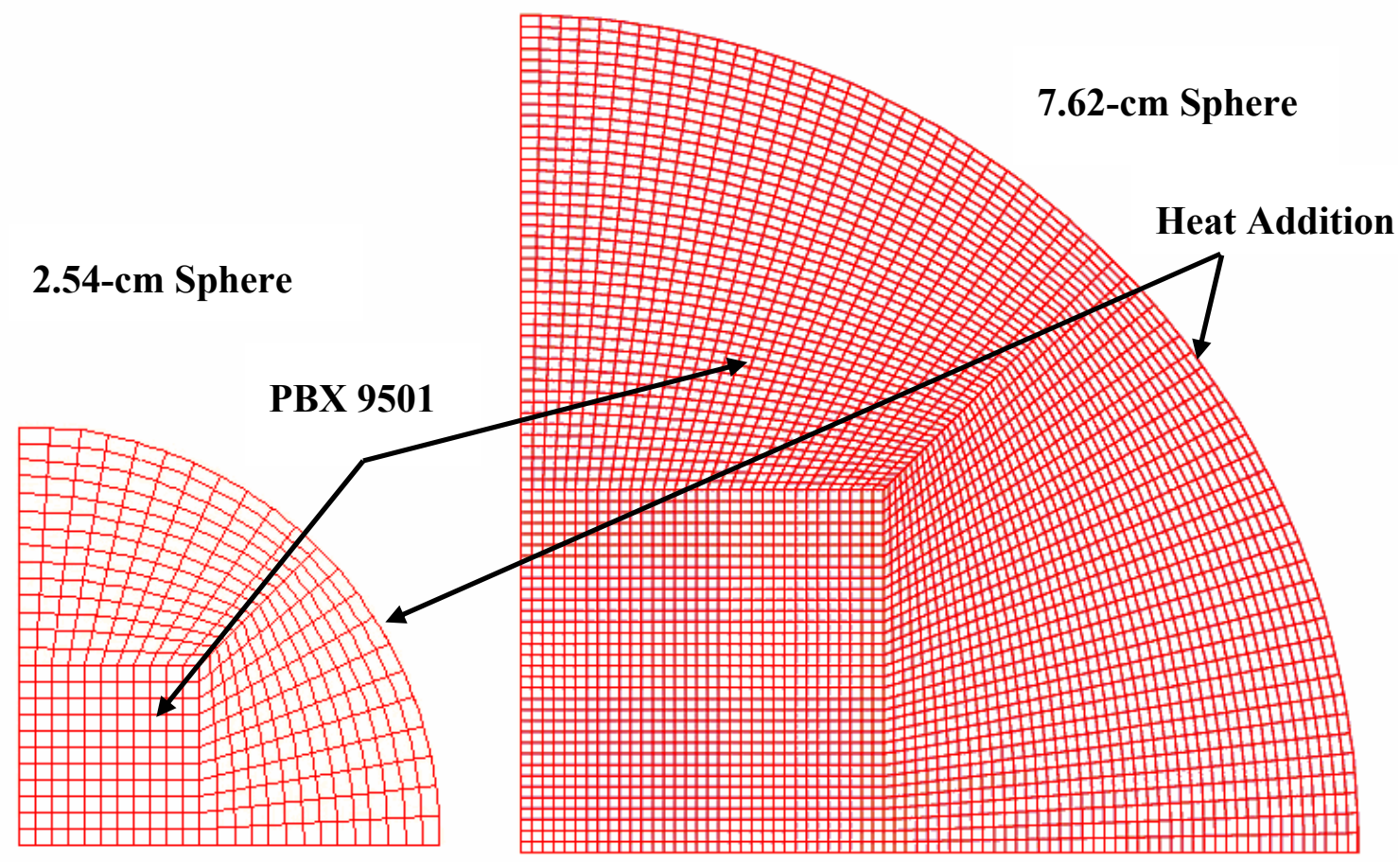

Figure 6.8: Meshed axisymmetric models of the unconfined spherical experiments.

Four unconfined spherical experiments were preformed at LANL in the 1970s, and in turn, these experiments were modeled and assessed using all three kinetics systems. Three of the four experiments were conducted using the 2.54- $\mathrm{cm}$ spheres and are labeled as models 1, 3, and 4. Model 2 was based on the 7.62-cm unconfined sphere.

The three kinetics systems were run with the initial time step of 0.1 seconds and the reduced time step of 0.01 seconds, resulting in 24 sets of data. Each of the kinetics systems was also run with both the $1.0-\mathrm{mm}$ and $0.5-\mathrm{mm}$ mesh, resulting in another 24 data sets. For the unconfined analysis, a total of 48 data sets were assessed.

The only material modeled in the unconfined experiment was PBX 9501. The number of elements in the 2.54-cm spherical section is shown Figure 6.9. For the 1.0-mm mesh, there are 429 elements of PBX 9501, and for the 0.5-mm mesh, there are 1716 elements of PBX 9501.

The number of elements in the 7.62-cm spherical section is shown in Figure 6.10. For the 1.0-mm mesh, there are 3927 elements of PBX 9501, and for the $0.5-\mathrm{mm}$ mesh, there are 15708 elements of PBX 9501. 

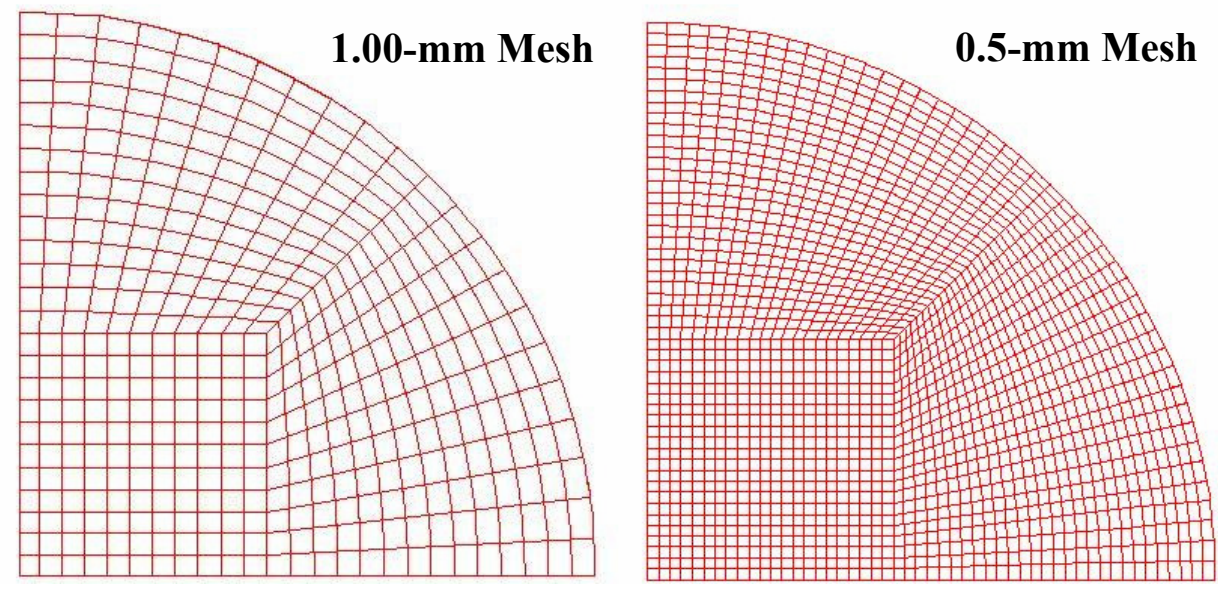

Figure 6.9: The 1.0-mm mesh and $0.5-\mathrm{mm}$ mesh for the $2.54-\mathrm{cm}$ unconfined spherical section.
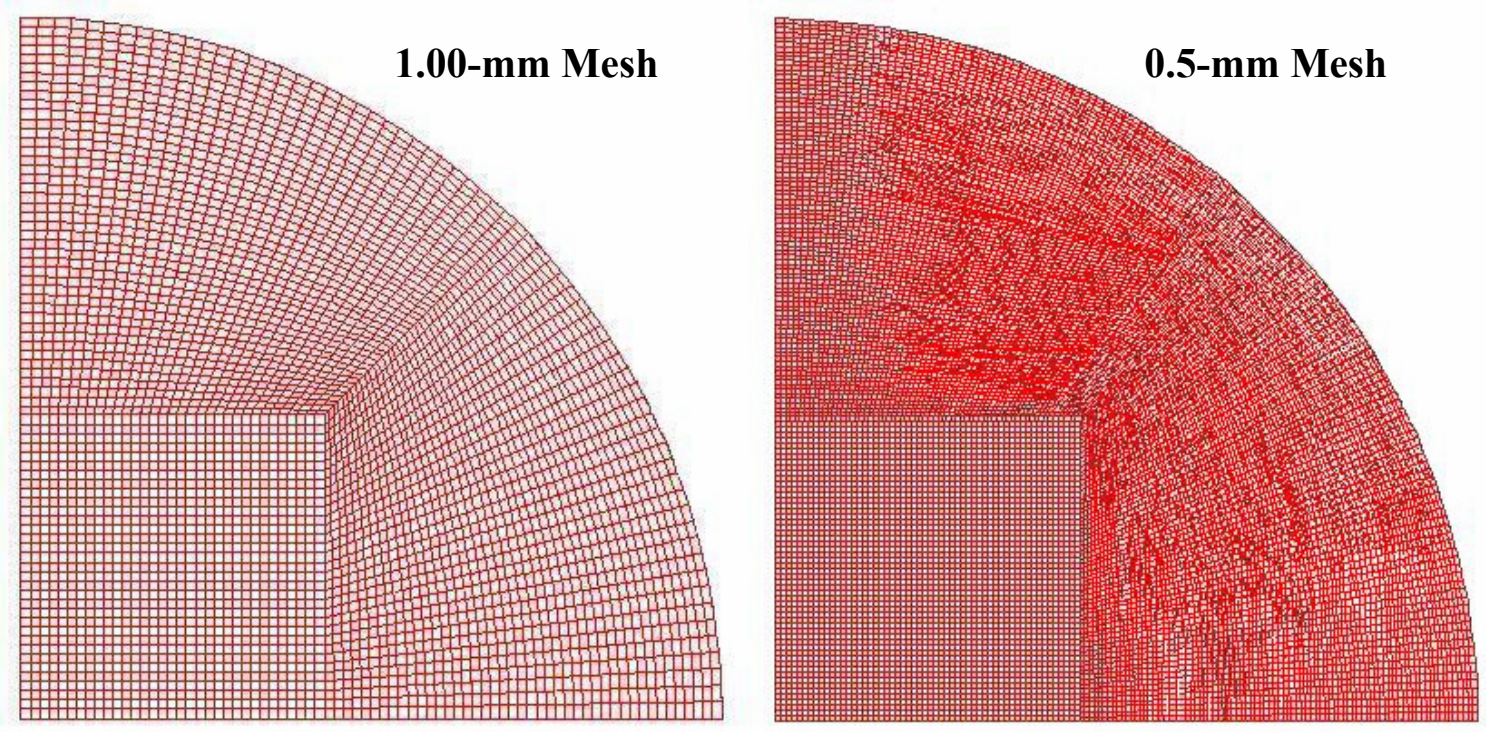

Figure 6.10: The $1.0-\mathrm{mm}$ mesh and $0.5-\mathrm{mm}$ mesh for the $7.62-\mathrm{cm}$ unconfined spherical section. 


\subsection{The Naval Air Warfare Center Weapons Division Experiments at China Lake for Confined Cylinders}

The purpose of the Navy cookoff experiment was to heat a cylindrical PBX 9501 charge in a containment vessel in such a manner that the ignition point would be located at the mid-plane and in the center of the HE charge. Using the same assumptions that were used in the STEX model, it was assumed that if the cylinder is cut in half, the heat transfer process in the top and bottom sections of the vessel will be identical.

Again, since the geometry is radially uniform throughout the entire 360 degrees of the cookoff vessel, like the STEX model, a two-dimensional axisymmetric section of the top half was chosen as the representative area that was to be modeled. A cross-sectional view of the Navy cookoff vessel is shown in Figure 6.11, and the area modeled is outlined with a green box. The Navy cookoff experiment is considered to be perfectly sealed, thus no gas losses are expected and no products, intermediates, or reactants are lost in the decomposition process.

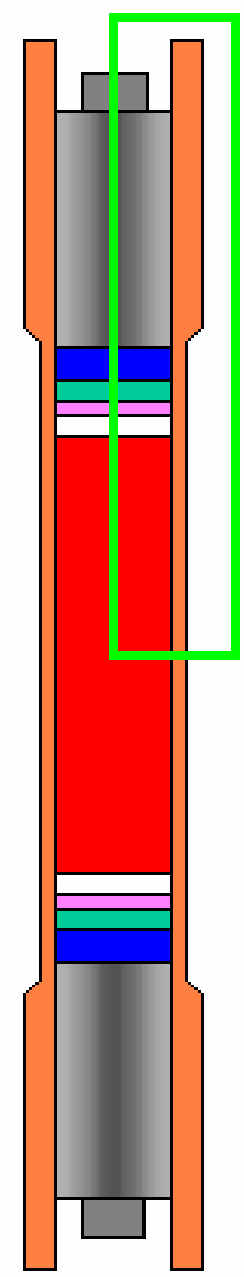

Figure 6.11: Cross-sectional view of the Navy cookoff vessel with a green box outlining the area modeled. 
A graphical representation of the model was designed using dimensions obtained from engineering prints and from correspondence with Pat Curran from China Lake [16]. This model is shown, and its materials are defined in Figure 6.12. Figure 6.12 also shows the constant temperature boundary condition applied to the nodes along the outside (right) and top edges of the model.

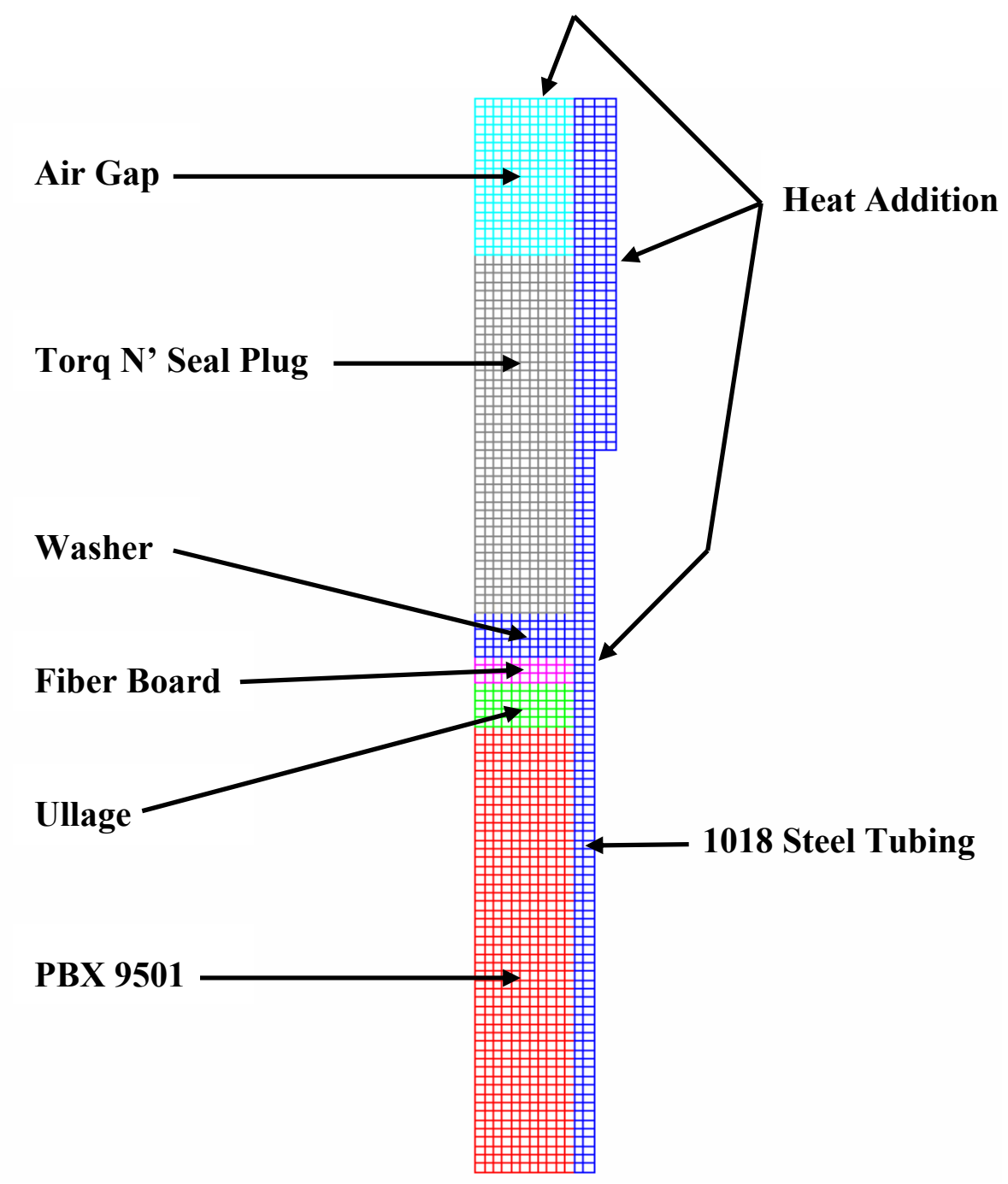

Figure 6.12: Meshed axisymmetric model of the Navy cookoff experiment.

The Naval Air Warfare Center Weapons Division at China Lake conducted the cookoff experiments, and one of those cookoff experiments was modeled and assessed using all three kinetics systems. Each model was run with both the initial time step of 0.1 seconds and the reduced time step of 0.01 seconds. The models used the $1.0-\mathrm{mm}$ mesh, and there were 6 sets of data created and tabulated. For the 1.0-mm mesh, there are 561 elements of PBX 9501 shown in red, 55 elements of ullage (air gap) displayed in green, 55 elements of fiber board 
represented in pink, 33 elements of a steel washer represented in dark blue, 334 elements of the steel cylinder also represented in dark blue, 451 elements of the Torq N' Seal denoted in gray, and 198 elements of the top air gap shown in light blue.

\subsection{RESULTS}

This chapter gives a complete summary of the numerical results recorded for all of the various iterations of the four experimental models. Numerical results for each of the three kinetics systems used in the models are compared with one another. The results of the mesh study for the $1.0-\mathrm{mm}$ and $0.5-\mathrm{mm}$ mesh are compared. The results for the models with initial time steps of 0.1 seconds and 0.01 seconds are also compared. Finally, the results from each model are compared with the experimental data.

HE materials have many variable parameters, including the temperature at which thermal runaway occurs. An internal memo at Los Alamos National Laboratory from Lloyd Davis defines the onset of thermal runaway for different high explosive charges subjected to different heating rates [19]. Onset of thermal reaction is an important part of the results process because reaction temperature is subjective to the analysts' definition of when a reaction occurs. The memorandum by Mr. Davis is included in Appendix B as a reference for defining detonation temperature. After discussing these issues with Zana Konecni, Armando Vigil, and Peter Dickson (technical staff members at Los Alamos National Laboratory), it was decided that the time of thermal reaction would be determined on a case-by-case analysis, based on the design and operating condition of each experiment. Thus, the ignition time is not precisely determined by objective criteria, but rather, it is based on the engineering judgment of the author with the extensive experience of LANL staff members Dr. Konecni, Mr. Vigil, and Dr. Dickson.

\subsection{The LLNL Scaled Thermal Explosion Experiment (STEX) for Confined Cylinders}

Various iterations of the STEX models were assessed and recorded. Definitions of the variables used to define the different COYOTE input files are listed below.

- 'DH' refers to the Dickson et al. kinetics model

- 'JV' refers to the Jaeger and Vigil kinetics model

- 'TM' refers to the Tarver and McGuire kinetics model

- ' 1 ' refers to a constant average temperature profile applied to the outer edge of the cylinder with gap element used in the solution

- ' 2 ' refers to a varied temperature profile applied to the outer edge of the cylinder with gap element used in the solution

- ' $a$ ' refers to the initial integration time step reduced from 0.1 to 0.01 seconds

- 'c' refers to no gap elements used in the solution 
- ' $d$ ' refers to the heat addition being $1^{\circ}$ cooler on the outer edge of the top flange for the applied heating ramp

- ' $h$ ' refers to the activation energy $\mathrm{E}_{4}$ being changed from $41,371.89293 \mathrm{cal} / \mathrm{mol}$ to $41,586.99808 \mathrm{cal} / \mathrm{mol}$ based on the Dickson et al. $\mathrm{E}_{4}$ value for a reversible reaction

- ' $i$ ' refers to the activation energy $\mathrm{E}_{4}$ being changed from $41,371.89293 \mathrm{cal} / \mathrm{mol}$ to $40,646.49613 \mathrm{cal} / \mathrm{mol}$ based on an average of $\mathrm{E}_{4}$ values from Table 5 of Temo Aviles-Ramos's paper [17].

- 'Fine' refers to a mesh with 0.5 -mm elements

All three kinetics systems are used in the assessment; however, even though the Jaeger kinetics system is allowed to run 100,000 seconds longer than the experimental time, none of the various Jaeger FEA models induced thermal runaway. The results of these STEX models are recorded below in Table 7.1, and the results column shows the experimental data in red and the numerical results in black. The delta time is the amount of time that the numerical analysis varies from the experimental data, and the percent error is a measure of how far the numerical results of the kinetics systems vary from the experimental data.

The STEX experiment took approximately 90 hours to attain a reaction; as such, a temperature of $500 \mathrm{~K}$ and a heating rate of greater than $1 \mathrm{~K} / \mathrm{s}$ were chosen as the parameters to define thermal ignition. Because of the slow heating process, the data from the experiment recorded the hottest point to be at the thermocouple located in the middle of the HE charge. After comparing the data from the various models, it was apparent that the initial model with a constant heat addition and no gap elements was an accurate assessment model for this analysis. In fact, the numerical results for all three kinetics systems are within $2 \mathrm{~K}$ of the experimental data, which is less than a $1.0 \%$ deviation, up to about 345,000 seconds. At that point, the Dickson et al. kinetics system shows thermal runaway, whereas the Tarver and McGuire kinetics system displays thermal runaway at around 361,000 seconds and the Jaeger kinetics system never achieves thermal runaway even after an additional 50,000 seconds of analysis time. The reason that each kinetics systems varies so much at ignition is that the individual kinetics use slightly different thermal conductivities, activation energies, material properties, and temperature dependencies.

Results of the analysis from the model that used seven heating zones along the cylinder wall and the model that has varied heating on the top edge of the end cap are almost the same as the results from the initial model. The model using an averaged activation energy value results in a less accurate solution. The model using the activation energy value from the reversible Dickson et al. kinetics is slightly more accurate; however, it is not valid for these models because it is an ideal value that is never achieved in a real experiment. The models solved with the altered activation energies are useful because they give an analytical look at the effect that this energy has on the solution process. The results from the $1.0-\mathrm{mm}$ mesh and the $0.5-\mathrm{mm}$ mesh are almost identical; thus, the $1.0-\mathrm{mm}$ mesh is appropriate as the basis for the different input files for this experiment, which is good because it is more economical in that it takes about half as much time to solve. The solutions generated from the initial time steps of 0.1 seconds and 0.01 seconds are also very close in value, and subsequently, the 
model with the initial time step of 0.1 seconds is sufficiently accurate. Furthermore, the use of the initial time step value is approximately twice as fast in the solution process.

Table 7.1: STEX results from the various models

\begin{tabular}{|l|c|c|c|}
\hline \multicolumn{2}{|c|}{ Time-to-Ignition Results for LLNL STEX Cylinder } \\
\hline \hline & Results & $\Delta$ time & $\%$ Error \\
\hline \hline STEX Experiment & 358912.0 & & \\
\hline STEX - DH1 & 345724.0 & -13188.0 & -3.6744 \\
\hline STEX Fine - DH1 & 345724.0 & -13188.0 & -3.6744 \\
\hline STEX - DH1a & 345719.0 & -13193.0 & -3.6758 \\
\hline STEX - DH1c & 345740.0 & -13172.0 & -3.6700 \\
\hline STEX - DH1h & 351706.0 & -7206.0 & -2.0077 \\
\hline STEX - DH1i & 325907.0 & -33005.0 & -9.1958 \\
\hline STEX - DH2 & 337236.0 & -21676.0 & -6.0394 \\
\hline STEX - DH2c & 337042.0 & -21870.0 & -6.0934 \\
\hline STEX - TM1 & 361529.0 & 2617.0 & 0.7291 \\
\hline STEX Fine - TM1 & 361520.0 & 2608.0 & 0.7266 \\
\hline STEX - TM1a & 361531.0 & 2619.0 & 0.7297 \\
\hline STEX - TM1c & 362529.0 & 3617.0 & 1.0078 \\
\hline STEX - TM1d & 361563.0 & 2651.0 & 0.7386 \\
\hline STEX - TM2 & 354636.0 & -4276.0 & -1.1914 \\
\hline STEX - TM2c & 355561.0 & -3351.0 & -0.9337 \\
\hline STEX - TM2d & 354637.0 & -4275.0 & -1.1911 \\
\hline STEX - JV & & No solution found & \\
\hline
\end{tabular}


There are three separate thermocouple recordings from the STEX experiment, and Appendix $\mathrm{C}$ shows the graphical comparisons for each kinetics system prediction and how these results compare to the three thermocouple records. These thermocouples are denoted as 'END' for the one nearest the end cap, 'UPPER' for the one halfway between the end cap and the center of the charge, and 'MID' for the thermocouple in the center of the HE charge. Figure 7.1 compares the experimental data to each of the three kinetics systems for the 'MID' thermocouple location.

\section{Comparison of Numerical Results with Experimental Data}

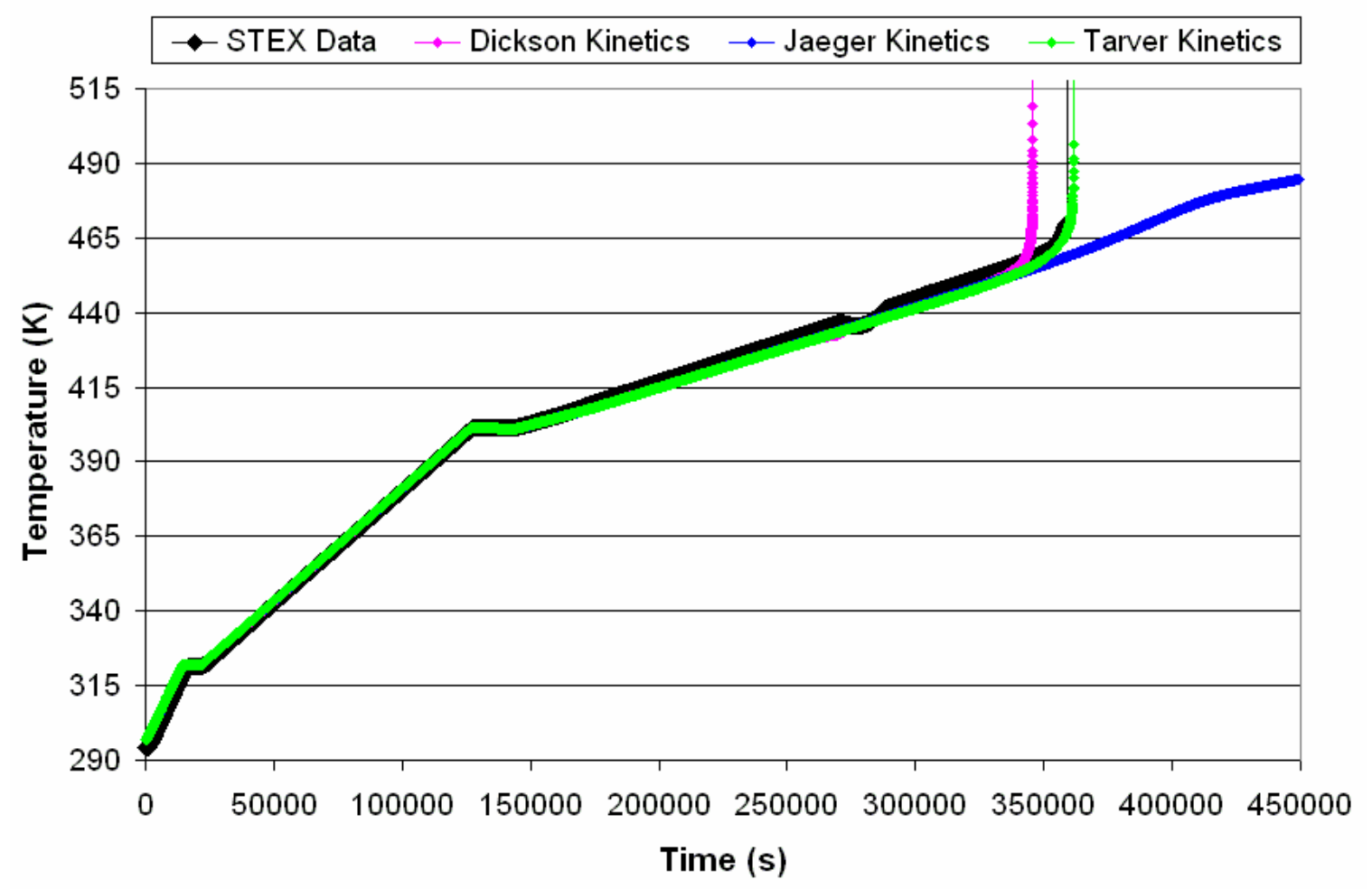

Figure 7.1: STEX comparison between the thermocouple data and numerical results.

The graphs in Appendix C are time-versus-temperature data recorded from the nodes that represent the location of the thermocouples in the experiment. Figure C.1 shows that the Dickson et al. kinetics system (DH) slightly under-predicts the actual time to ignition, but that it is still within 13,188 seconds, or $4 \%$ of the actual experimental data. Figure C. 2 gives a closer look at the last heat ramp and the reaction region showing how the kinetics system compares with the experimental data. Figure C.3 shows the occurrence of an endothermic phase change, which is seen as a dip in the thermocouple data at about 27,000 seconds. The Dickson et al. kinetics shows similar results that occur earlier in the process, that is, are shorter in duration and do not decline as deeply. Figure C.4 shows the three thermocouple comparisons using the Jaeger kinetics, and the fact that, even after an additional 100,000 seconds, no thermal runaway occurs. Figure C.5 shows the thermocouple data in comparison to the Tarver and McGuire kinetics system, and Figure C.6 is a close-up of the ignition 
region. The Tarver and McGuire system is the most accurate of the three kinetics systems for the conditions present in the STEX experiment and, in fact, it only over-predicts the actual experiment by 2,617 seconds, or $0.73 \%$.

After solutions were resolved in the FEA heat conduction solver COYOTE, a graphical representation of the thermal process was viewed in EnSight 7 to observe the location of the reaction areas and the temperature gradients created in the model by the different kinetics systems. Figure 7.2 shows visual representations of the heat gradient and the ignition location at the time of ignition for the Dickson et al. and the Tarver kinetics systems. There is no visual Jaeger system since the kinetics never induced self-heating in the HE charge, and thus, thermal runaway never occurred.

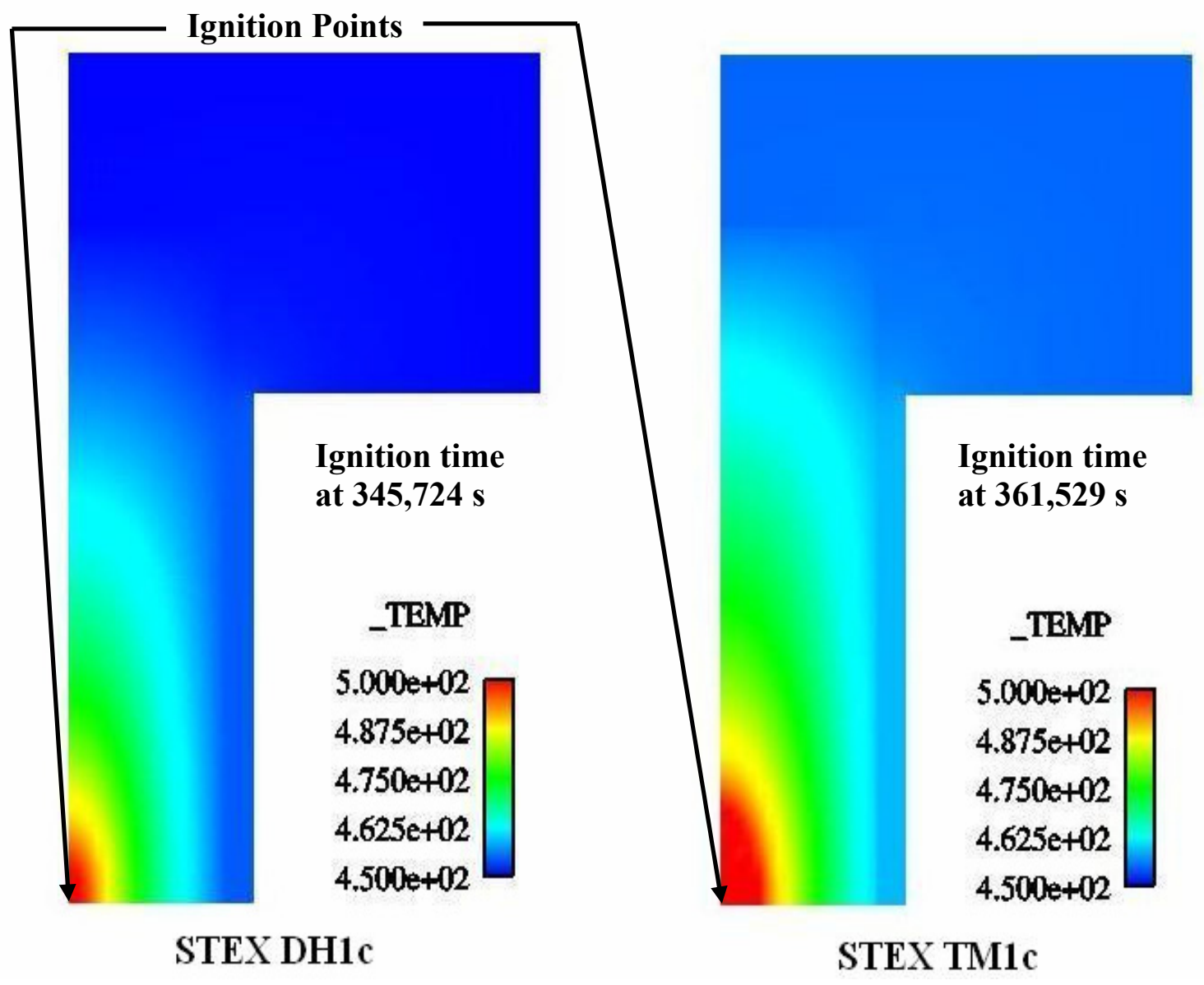

Figure 7.2: STEX reaction models at the time of ignition for the Dickson et al. and the Tarver and McGuire kinetics. 
The location of ignition for both models is at node 50 (the node in the lower-left corner of the model that represents the exact center of the cylindrical HE charge). A visual inspection of the DH1 and TM1 models shows a distinct difference in the temperature gradients at their individual ignition times. The Dickson et al. model shows a much more localized ignition point at the center with most of the rest of the model being a lot cooler. The Tarver model represents a more uniform heat distribution throughout. For the Tarver model, there is a large area of the explosive material that is at or near the ignition point.

\subsection{The LLNL One-Dimensional Time-to-Explosion (ODTX) Experiments for Spheres}

Forty different ODTX experiments using the three kinetics systems were created from a single FEA model with 1.0-mm elements. Additionally, each of the COYOTE input files was modified to run with initial time steps of both 0.1 seconds and 0.01 seconds, bringing the total to 240 data sets. An additional FEM model with $0.5-\mathrm{mm}$ elements was created and applied to the first four experiments, using the initial time step of 0.1 seconds and giving 12 more sets of data. The results of the 252 variations of the ODTX models were run to completion, and their data were recoded and organized into spreadsheets. The following definitions apply to the variations in each of the different COYOTE input files.

- 'DH' refers to the Dickson et al. kinetics model

- 'JV' refers to the Jaeger and Vigil kinetics model

- 'TM' refers to the Tarver and McGuire kinetics model

- Numbers 01 through 40 are assigned to the forty experiments modeled

- 'Confined' refers to experiments 01-16

- 'Unconfined' refers to experiments 17-30

- 'Aged' refers to experiments 31-40

- ' $\mathrm{a}$ ' refers to the initial integration time step reduced from 0.1 to 0.01 seconds

- 'Fine' refers to a mesh with 0.5-mm elements

The results of the first four confined ODTX experiments are shown in Table 7.2, which uses the Dickson et al. kinetics (DH); Table 7.3, which uses the Jaeger kinetics (JV); and Table 7.4, which uses the Tarver and McGuire kinetics (TM). Each of these four experiments $(01-04)$ was solved using the $1.0-\mathrm{mm}$ mesh with the initial time step of 0.1 seconds, the $1.0-\mathrm{mm}$ mesh with the initial time step of 0.01 seconds (a), and the $0.5-\mathrm{mm}$ mesh (Fine) with the initial time step of 0.1 seconds. The results shown in the three tables below follow the same format as defined for Table 7.1. 
Table 7.2: ODTX results for the confined models using the Dickson et al. kinetics system

\begin{tabular}{|l|c|c|c|}
\hline \multicolumn{3}{|c|}{ Time to Ignition for LLNL ODTX - Confined } \\
\hline \hline & Results & $\Delta$ time & \% Error \\
\hline ODTX 01 Data & 9.30 & & \\
\hline ODTX - DH01 & 18.94 & 9.6 & 103.66 \\
\hline ODTX - DH01a & 19.09 & 9.8 & 105.27 \\
\hline ODTX Fine - DH01 & 8.86 & -0.4 & -4.73 \\
\hline ODTX 02 Data & 28.50 & & \\
\hline ODTX - DH02 & 37.92 & 9.4 & 33.05 \\
\hline ODTX - DH02a & 36.39 & 7.9 & 27.68 \\
\hline ODTX Fine - DH02 & 36.58 & 8.1 & 28.35 \\
\hline ODTX 03 Data & 226.20 & & \\
\hline ODTX - DH03 & 117.85 & -108.4 & -47.90 \\
\hline ODTX - DH03a & 114.73 & -111.5 & -49.28 \\
\hline ODTX Fine - DH03 & 90.25 & -136.0 & -60.10 \\
\hline ODTX 04 Data & 517.80 & & \\
\hline ODTX - DH04 & 348.98 & -168.8 & -32.60 \\
\hline ODTX - DH04a & 353.28 & -164.5 & -31.77 \\
\hline ODTX Fine - DH04 & 353.96 & -163.8 & -31.64 \\
\hline
\end{tabular}


Table 7.3: ODTX results for the confined models using the Jaeger kinetics system

\begin{tabular}{|l|c|c|c|}
\hline \multicolumn{4}{|c|}{ Time to Ignition for LLNL ODTX - Confined } \\
\hline \hline & Results & $\Delta$ time & \% Error \\
\hline ODTX 01 Data & 9.30 & & \\
\hline ODTX - JV01 & 30.53 & 21.2 & 228.28 \\
\hline ODTX - JV01a & 30.98 & 21.7 & 233.12 \\
\hline ODTX Fine - JV01 & 28.03 & 18.7 & 201.40 \\
\hline ODTX 02 Data & 28.50 & & \\
\hline ODTX - JV02 & 25.32 & -3.2 & -11.16 \\
\hline ODTX - JV02a & 25.45 & -3.1 & -10.70 \\
\hline ODTX Fine - JV02 & 21.09 & -7.4 & -26.00 \\
\hline ODTX 03 Data & 226.20 & & \\
\hline ODTX - JV03 & 67.02 & -159.2 & -70.37 \\
\hline ODTX - JV03a & 85.02 & -141.2 & -62.41 \\
\hline ODTX Fine - JV03 & 64.34 & -161.9 & -71.56 \\
\hline ODTX 04 Data & 517.80 & & \\
\hline ODTX - JV04 & 128.30 & -389.5 & -75.22 \\
\hline ODTX - JV04a & 132.06 & -385.7 & -74.50 \\
\hline ODTX Fine - JV04 & 131.69 & -386.1 & -74.57 \\
\hline
\end{tabular}


Table 7.4: ODTX results for the confined models using the Tarver and McGuire kinetics system

\begin{tabular}{|l|c|c|c|}
\hline \multicolumn{4}{|c|}{ Time to Ignition for LLNL ODTX - Confined } \\
\hline \hline & Results & $\Delta$ time & \% Error \\
\hline ODTX 01 Data & 9.30 & & \\
\hline ODTX - TM01 & 9.34 & 0.0 & 0.43 \\
\hline ODTX - TM01a & 9.41 & 0.1 & 1.18 \\
\hline ODTX Fine - TM01 & 5.54 & -3.8 & -40.43 \\
\hline ODTX 02 Data & 28.50 & & \\
\hline ODTX - TM02 & 31.35 & 2.9 & 10.00 \\
\hline ODTX - DTM2a & 26.56 & -1.9 & -6.81 \\
\hline ODTX Fine - TM02 & 6.15 & -22.4 & -78.42 \\
\hline ODTX 03 Data & 226.20 & & \\
\hline ODTX - TM03 & 40.34 & -185.9 & -82.17 \\
\hline ODTX - TM03a & 123.60 & -102.6 & -45.36 \\
\hline ODTX Fine - TM03 & 7.98 & -218.2 & -96.47 \\
\hline ODTX 04 Data & 517.80 & & \\
\hline ODTX - TM04 & 218.57 & -299.2 & -57.79 \\
\hline ODTX - TM04a & 424.31 & -93.5 & -18.06 \\
\hline ODTX Fine - TM04 & 27.68 & -490.1 & -94.65 \\
\hline
\end{tabular}

The ODTX experiments took anywhere from approximately 4 seconds to 22,000 seconds for a reaction to occur. As was discussed earlier, the heating rate is an important determinant in defining the ignition temperature. For these models, a temperature of $525 \mathrm{~K}$ and a heating rate of greater than $1 \mathrm{~K} / \mathrm{s}$ are chosen as the parameters to define thermal ignition. 
For these analyses, only the Dickson et al. kinetics system worked for all 40 experimental models and their variations. The models using the Jaeger kinetics system did not solve for experiments that took longer than 2,900 seconds. The models using the Tarver and McGuire kinetics system did not solve for experiments that took longer than 9,000 seconds.

In Appendix D, there are data tables for each of the kinetics systems, using both the initial time steps of 0.1 seconds and 0.01 seconds for all 40 experiments. The 16 models defined as confined experiments are the only tests that are defined well enough to be assessed. The 14 partially confined models are analyzed, and the data is recorded with the analytical results showing no trends. Since there is no way to know the rate of material loss (product gases) for each model, this data was not assessed. The reason these data sets were modeled was to see if it is possible to track a consistent rate of material loss so that the models could provide some useful properties or correlations, but the inconsistency of the results makes it unacceptable for consideration. The last 10 experiments are from a series of aged explosive charges, and as with the partially confined experiments, there are no trends or tendencies that are of use in aiding in the assessment process. Thus, the results from the aged models were not analyzed either, but the results of all the models are still reported.

The three results tables for the confined models are organized in ascending order based on the times of ignition reported in the experiments. The Tables D.1, D.4, and D.7 are compared and contrasted with each other and the experimental results. Table D.1 contains the results from the Dickson et al. kinetics system, and it substantially over-predicts the ignition time for the experiments that reacted in less than 30 seconds. After 30 seconds, the Dickson et al. kinetics then under predict all of the ignition times up until the final experiment which has a reaction that occurs at over 9,000 seconds. The 9 models that have reactions between time ranges of 47.9 seconds and 4,351.9 seconds under-predict the reaction time with a percent error range of $12 \%$ to $50 \%$. This assessment shows that the Dickson et al. kinetics system is unpredictable at very fast reaction times and then the results becomes relatively consistent with conservative solutions for the mid-time experiments $(30 \mathrm{~s}>\mathrm{t}<9,000 \mathrm{~s})$.

The results shown in Table D.4 are the product of the Jaeger kinetics system, and this kinetics system creates results that are inconsistent for the experiments that react in under 30 seconds. The 8 experiments ranging in time from 47.90 to $1,950.60$ seconds have reaction times that under predict ignition by $58 \%$ to $84 \%$, with the error having a tendency to get larger as the time to ignition increases. Also, the Jaeger kinetics system does not solve for ignition times above 4,000 seconds.

Table D.7 has analytical data that is created from the Tarver and McGuire kinetics system. The Tarver and McGuire kinetics system is in fact based on the results of a series of ODTX experiments from the early 1980s. The initial models using the initial time step of 0.1 seconds had inconsistent results, but the models with an initial time step of 0.01 seconds show very good agreement with the experimental data. In fact, with the exception of experiment 03 , this kinetics system has results that are within $20 \%$ of the experimental values. This kinetics system even gives inconsistent results for the experiments that ignite in less than 30 seconds. The Tarver and McGuire kinetics system is again the most consistent system for the modeled ODTX experiments. 
After comparing the data from the various models, it is clear that the initial model using the $1.0-\mathrm{mm}$ mesh and an initial time step of 0.1 seconds produces an accurate assessment model for the Dickson et al. and Jaeger kinetics systems. The finer mesh of $0.5 \mathrm{~mm}$ and the reduced time step of 0.01 seconds did not significantly improve or change the results for any of the various models that incorporated either the Dickson et al. or the Jaeger kinetics systems.

The time step and the mesh size have a major affect on the solution process. The smaller time steps produce significantly more accurate and consistent results, whereas the application of the finer, $0.5-\mathrm{mm}$ mesh results in unrealistically short times to ignition for all the models. The initial time step value is a function of the change in distance squared, times a local Fourier number, divided by the thermal diffusivity (Equations 32-35). The local Fourier number is derived from the temperature change as a function of the elemental distance between nodes. This means that, for large temperature changes over small element lengths, the initial time step value needs to be very small — in the range of 0.005 seconds.

When creating the results tables, a graphical representation of the heating process was viewed for all 252 ODTX models, which allowed the location of the reaction areas to be observed and the differences in the temperature gradients caused by the variations in each kinetics system to be visualized. Figure 7.3 gives a visual comparison of the reaction results and the temperature gradients produced by the three kinetics systems in the solution process for experiment 02 .

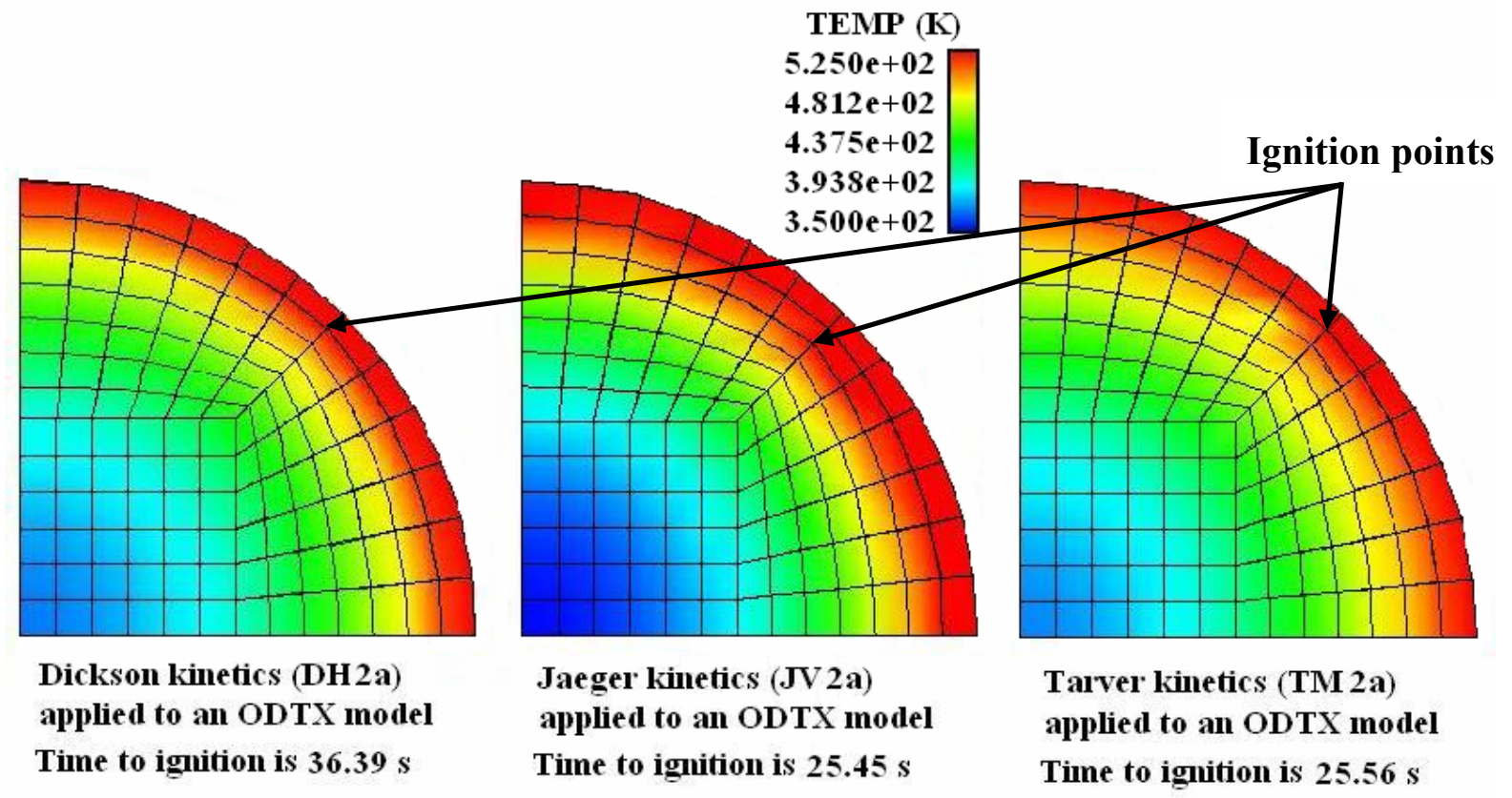

Figure 7.3: Visual comparison of the ODTX models at their ignition points for the 2a models. 
The model with the initial time step of 0.01 seconds is being used in this comparison because the Tarver and McGuire models require the smaller time step for an accurate analysis, while the smaller time step has a negligible effect on the results for the Dickson et al. and Jaeger models. For experiment 02, the ignition point is located 2 elements in from the outer edge of the FEA model at node 55 for the Jaeger kinetics system. The ignition points for both the Dickson et al. and the Tarver and McGuire kinetics systems occur at node 56, one element in from the outer edge.

\subsection{The LANL One-Dimensional Unconfined Spheres}

For this assessment, four different unconfined experiments were modeled from two spheres, one having a $2.54-\mathrm{cm}$-diameter sphere and the other with a $7.62-\mathrm{cm}$-diameter sphere. Experiments 1, 3, and 4 used the 2.54-cm-diameter sphere, and experiment 2 used the 7.62-cm-diameter sphere. Each of the four unconfined spherical models is solved using a 1.0-mm mesh, a $0.5-\mathrm{mm}$ mesh, an initial time step of 0.1 second, and a time step of 0.01 second. There are 64 models, and the following notations define the variations in each of the different FEA input files.

- 'DH' refers to the Dickson et al. kinetics model

- 'JV' refers to the Jaeger \& Vigil kinetics model

- 'TM' refers to the Tarver \& McGuire kinetics model

- ' $\mathrm{a}$ ' refers to the initial integration time step reduced from 0.1 to 0.01 seconds

- 'Fine' refers to a mesh with 0.5-mm elements

All four experiments were suspended by wires in a well-insulated test chamber and had no type of confinement to keep the reaction gases from escaping. The time to ignition in the four experiments ranged from about 10,000 to about 80,000 seconds. These were considered to be slow tests, and the intention was to have the HE charge heat up in a uniform manner. The 2.54-cm-diameter experiments had five thermocouples recording the temperature, and two of them were located directly across from each on the outer edge of the sphere. There were also two more located half way to the center and one located in the very center. The $7.62-\mathrm{cm}-$ diameter sphere had a center thermocouple, two at one-third of the way out from the center, two at two-thirds of the way out from the center, and two directly across from each other on the outside surface of the sphere. This provided a method for tracking the movement of heat

through the explosive material, a way to record the endothermic phase change, and the ability to locate the ignition region.

Since the minimum time to runaway for these experiments was 10,000 seconds, a temperature of $500 \mathrm{~K}$ and a heating rate of greater than $1 \mathrm{~K} / \mathrm{s}$ were chosen as the parameters to define thermal runaway. The thermocouple data from all four experiments showed that the hottest location was always in the center of the sphere; however, none of the three kinetics systems predicted ignition at the very center of the model. 
Figure 7.4 shows a full time-and-temperature comparison for the three sets of kinetics results in comparison to the recorded thermocouple value at the center of the sphere in experiment 3. All of the time-versus-temperature graphs are based on data collected from the nodes that correspond to the thermocouple location in the spherical models and not necessarily the hottest node in the model. In Figure 7.4, TC_0.00-cm refers to the thermocouple data recorded at the center of the sphere in experiment 3. Appendix E contains full graphical records of each of the initial kinetics systems for all four experiments and how they compare with the thermocouple data.

\section{Comparison of Numerical Results and Unconfined Data for Experiment 3}

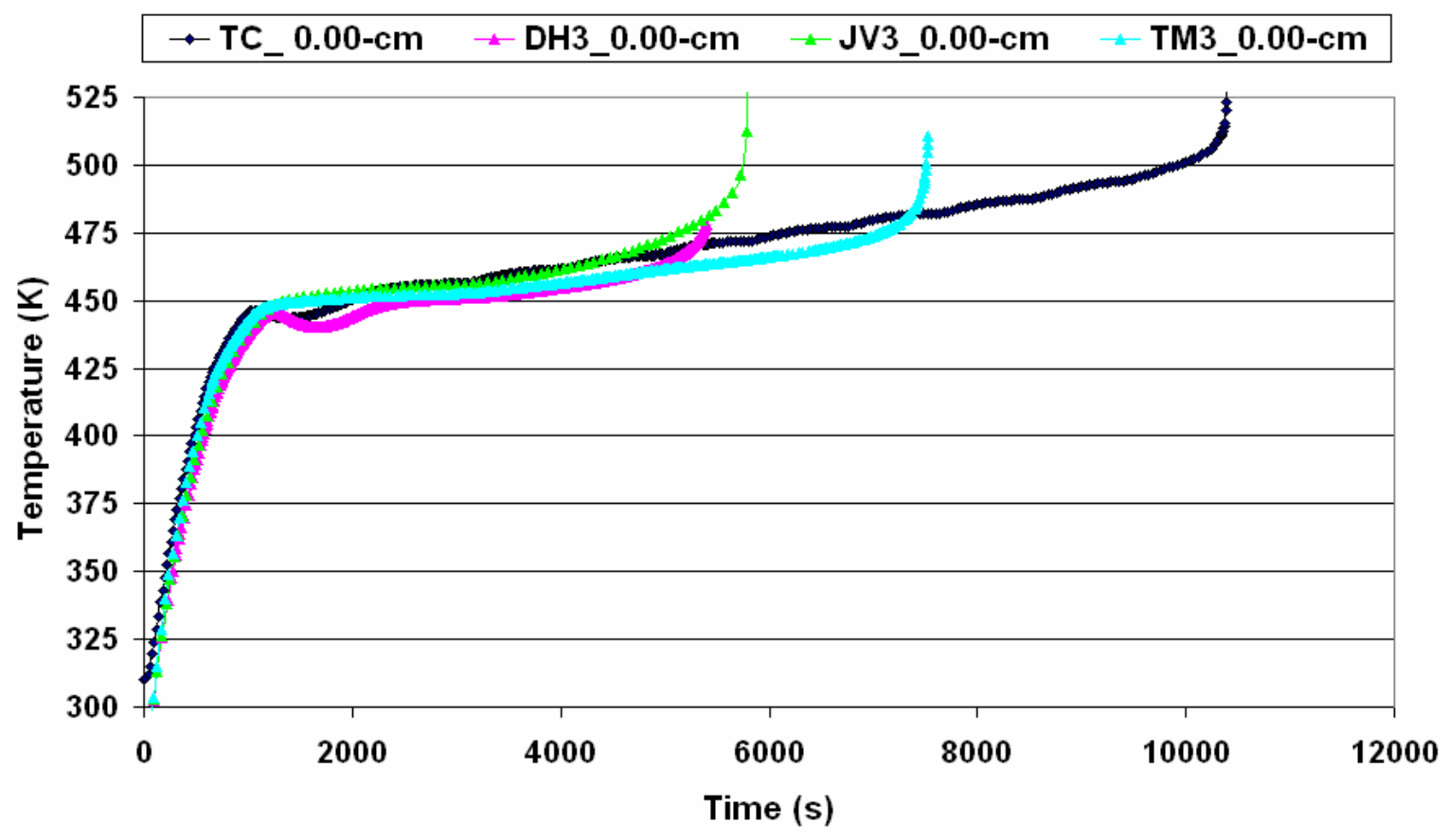

Figure 7.4: Comparison between the unconfined thermocouple data and numerical results for Experiment 3.

The data analysis shows that the kinetics systems have varying reaction locations, so the node with the greatest temperature change is used to define thermal runaway, and those results are used to define time to thermal runaway. This means that the results tables are not based on thermocouple data but rather the initiation of a thermal ignition point. Table 7.5 compares the various models using Dickson et al. kinetics, Table 7.6 shows the Jaeger kinetics applied to the differing models, and Table 7.7 analyzes the effect of the Tarver and McGuire kinetics on the models. The results recorded in each of these tables follow the same format as explained in the results section for Figure 7.1. 
Table 7.5: Unconfined sphere results using Dickson et al. kinetics

Time to Ignition for LANL Unconfined Spheres

\begin{tabular}{|c|c|c|c|}
\hline & Results & $\Delta$ time & $\%$ Error \\
\hline Unconfined 1 Data & 36507.00 & & \\
\hline Unconfined - DH1 & 4388.80 & -32118.20 & -87.98 \\
\hline Unconfined - DH1a & 4400.30 & -32106.70 & -87.95 \\
\hline Unconfined Fine - DH1 & 4369.33 & -32137.67 & -88.03 \\
\hline Unconfined Fine - DH1a & 4395.00 & -32112.00 & -87.96 \\
\hline Unconfined 2 Data & 78600.00 & & \\
\hline Unconfined - DH2 & N/A & $\mathrm{N} / \mathrm{A}$ & N/A \\
\hline fined - DH2a & 18800.40 & -59799.60 & -76.08 \\
\hline Unconfined Fine - DH2 & N/A & $\mathrm{N} / \mathrm{A}$ & $\mathrm{N} / \mathrm{A}$ \\
\hline Unconfined Fine - DH2a & 18800.10 & -59799.90 & -76.08 \\
\hline Unconfined 3 Data & 10418.00 & & \\
\hline Unconfined - DH3 & 5393.45 & -5024.55 & -48.23 \\
\hline Unconfined - DH3a & 5405.34 & -5012.66 & -48.12 \\
\hline Unconfined Fine - DH3 & 5401.28 & -5016.72 & -48.15 \\
\hline Unconfined Fine - DH3a & 5405.43 & -5012.57 & -48.11 \\
\hline Unconfined4 Data & 22215.00 & & \\
\hline Unconfined - DH4 & 4697.78 & -17517.22 & -78.85 \\
\hline Unconfined - DH4a & 4710.23 & -17504.77 & -78.80 \\
\hline Unconfined Fine - DH4 & 4701.90 & -17513.10 & -78.83 \\
\hline Unconfined Fine - DH4a & 4710.11 & -17504.89 & -78.80 \\
\hline
\end{tabular}


Table 7.6: Unconfined sphere results using Jaeger kinetics

\begin{tabular}{|c|c|c|c|}
\hline \multicolumn{4}{|c|}{ Time to Ignition for LANL Unconfined Spheres } \\
\hline & Results & $\Delta$ time & $\%$ Error \\
\hline Unconfined 1 Data & 36507.00 & & \\
\hline Unconfined - JV1 & 3593.14 & -32913.86 & -90.16 \\
\hline Unconfined - JV1a & 3655.01 & -32851.99 & -89.99 \\
\hline Unconfined Fine - JV1 & 3677.94 & -32829.06 & -89.93 \\
\hline Unconfined Fine - JV1a & 3655.09 & -32851.91 & -89.99 \\
\hline Unconfined 2 Data & 78600.00 & & \\
\hline Unconfined - JV2 & 48685.50 & -29914.50 & -38.06 \\
\hline Unconfined - JV2a & 48560.50 & -30039.50 & -38.22 \\
\hline Unconfined Fine - JV2 & 48600.10 & -29999.90 & -38.17 \\
\hline Unconfined Fine - JV2a & 48555.90 & -30044.10 & -38.22 \\
\hline Unconfined 3 Data & 10418.00 & & \\
\hline Unconfined - JV3 & 5804.14 & -4613.86 & -44.29 \\
\hline Unconfined - JV3a & 5755.00 & -4663.00 & -44.76 \\
\hline Unconfined Fine - JV3 & 5770.22 & -4647.78 & -44.61 \\
\hline Unconfined Fine - JV3a & 5755.42 & -4662.58 & -44.76 \\
\hline Unconfined 4 Data & 22215.00 & & \\
\hline Unconfined - JV4 & $\mathrm{N} / \mathrm{A}$ & $\mathrm{N} / \mathrm{A}$ & $\mathrm{N} / \mathrm{A}$ \\
\hline Unconfined - JV4a & $\mathrm{N} / \mathrm{A}$ & $\mathrm{N} / \mathrm{A}$ & $\mathrm{N} / \mathrm{A}$ \\
\hline Unconfined Fine - JV4 & $\mathrm{N} / \mathrm{A}$ & $\mathrm{N} / \mathrm{A}$ & $\mathrm{N} / \mathrm{A}$ \\
\hline Unconfined Fine - JV4a & N/A & $\mathrm{N} / \mathrm{A}$ & N/A \\
\hline
\end{tabular}


Table 7.7: Unconfined sphere results using Tarver and McGuire kinetics

\begin{tabular}{|c|c|c|c|}
\hline \multicolumn{4}{|c|}{ Time to Ignition for LANL Unconfined Spheres } \\
\hline & Results & $\Delta$ time & $\%$ Error \\
\hline Unconfined 1 Data & 36507.00 & & \\
\hline Unconfined - TM1 & 7301.45 & -29205.55 & -80.00 \\
\hline Unconfined - TM1a & 7415.93 & -29091.07 & -79.69 \\
\hline Unconfined Fine - TM1 & 7357.18 & -29149.82 & -79.85 \\
\hline Unconfined Fine - TM1a & 7420.25 & -29086.75 & -79.67 \\
\hline Unconfined 2 Data & 78600.00 & & \\
\hline Unconfined - TM2 & 49437.80 & -29162.20 & -37.10 \\
\hline Unconfined - TM2a & 49655.40 & -28944.60 & -36.83 \\
\hline Unconfined Fine - TM2 & $\mathrm{N} / \mathrm{A}$ & $\mathrm{N} / \mathrm{A}$ & $\mathrm{N} / \mathrm{A}$ \\
\hline Unconfined Fine - TM2a & 49655.80 & -28944.20 & -36.82 \\
\hline Unconfined 3 Data & 10418.00 & & \\
\hline Unconfined - TM3 & 7519.43 & -2898.57 & -27.82 \\
\hline Unconfined - TM3a & 7545.32 & -2872.68 & -27.57 \\
\hline Unconfined Fine - TM3 & 7525.32 & -2892.68 & -27.77 \\
\hline Unconfined Fine - TM3a & 7545.14 & -2872.86 & -27.58 \\
\hline Unconfined 4 Data & 22215.00 & & \\
\hline Unconfined - TM4 & $\mathrm{N} / \mathrm{A}$ & $\mathrm{N} / \mathrm{A}$ & $\mathrm{N} / \mathrm{A}$ \\
\hline Unconfined - TM4a & $\mathrm{N} / \mathrm{A}$ & $\mathrm{N} / \mathrm{A}$ & $\mathrm{N} / \mathrm{A}$ \\
\hline Unconfined Fine - TM4 & $\mathrm{N} / \mathrm{A}$ & $\mathrm{N} / \mathrm{A}$ & $\mathrm{N} / \mathrm{A}$ \\
\hline Unconfined Fine - TM4a & $\mathrm{N} / \mathrm{A}$ & $\mathrm{N} / \mathrm{A}$ & $\mathrm{N} / \mathrm{A}$ \\
\hline
\end{tabular}


There are five thermocouple recordings for Experiments 1, 3, and 4, and there are seven thermocouple recordings from the Experiment 2. Appendix E shows the graphical comparisons for each kinetics system in comparison to the thermocouple records. For this analysis, the two thermocouples that are the same radial distance from the center and 180 degrees from each other are averaged to create the $0.65-\mathrm{cm}$, the $1.27-\mathrm{cm}$, the $2.54-\mathrm{cm}$, and 3.81-cm experimental data points.

Figures E.1, E.2, and E.3, located in Appendix E, show comparisons between the Dickson et al. kinetics system and the recorded thermocouple data for the unconfined sphere Experiments 1, 3, and 4. The Dickson et al. kinetics fails to work for Experiment 2 because of a convergence error that occurs due to the inability of the kinetics solver to resolve a value for the internal energy in the PBX 9501 at a particular element. Figures E.4, E.5, E.6, and E.7 compare the Jaeger kinetics system with the thermocouple traces for all four experiments. The Tarver and McGuire kinetics system is compared with the thermocouple data from the four experiments and the results are graphed in Figures E.8, E.9, E.10, and E.11. All three kinetics systems under-predict the ignition time for all the experiments. In addition, the Dickson et al. kinetics that used a time step of 0.1 seconds failed to converge for experiment 2, and the Jaeger and Tarver and McGuire kinetics ran to 50,000 seconds, which is twice the ignition time, without initiating a thermal runaway.

Analyzing the data from the various models made it apparent that none of the kinetics systems used can accurately predict unconfined heating conditions. For these models, the analytical results for the $1.0-\mathrm{mm}$ mesh and the $0.5-\mathrm{mm}$ mesh are almost identical. That implies that it is appropriate to use the $1.0-\mathrm{mm}$ mesh as the standard mesh for the different input files. The results of the analysis using the initial time step of 0.1 seconds and the reduced time step of 0.01 seconds are also almost identical for all three kinetics and for all four models. This indicates that the initial time step of 0.1 seconds is satisfactorily accurate for all the various iterations of the models.

For each of the unconfined experimental models, the kinetics systems produced results that varied greatly in the locations and times of ignition. Visual analyses of the Dickson et al. system, the Jaeger system and the Tarver and McGuire system for Experiment 3 are shown in Figure 7.5.

For the Dickson et al. kinetics, ignition occurs at node 164, which is 10 elements in from the outer edge, and that puts the hottest zone at approximately two-thirds of the way out from the center of the sphere. The results for the Jaeger kinetics put the point of ignition at node 105, which is located 3 elements up the y-axis and 3 elements to the right. This location is in referenced from the node at the lower-left corner, which represents the center of the spherical HE charge. Roughly one-third of the Jaeger kinetics is at or near the thermal runaway point and is shown as the red zone at the center of the model. The Tarver and McGuire kinetics shows almost the whole model being at or near the ignition temperature. Node 73 is given as the initiation location for this model and it is located 11 elements up and 5 elements to the right of the corner node. This places the ignition really close to half-way between the center and the edge of the model, with over half of the model at or near the ignition point. 


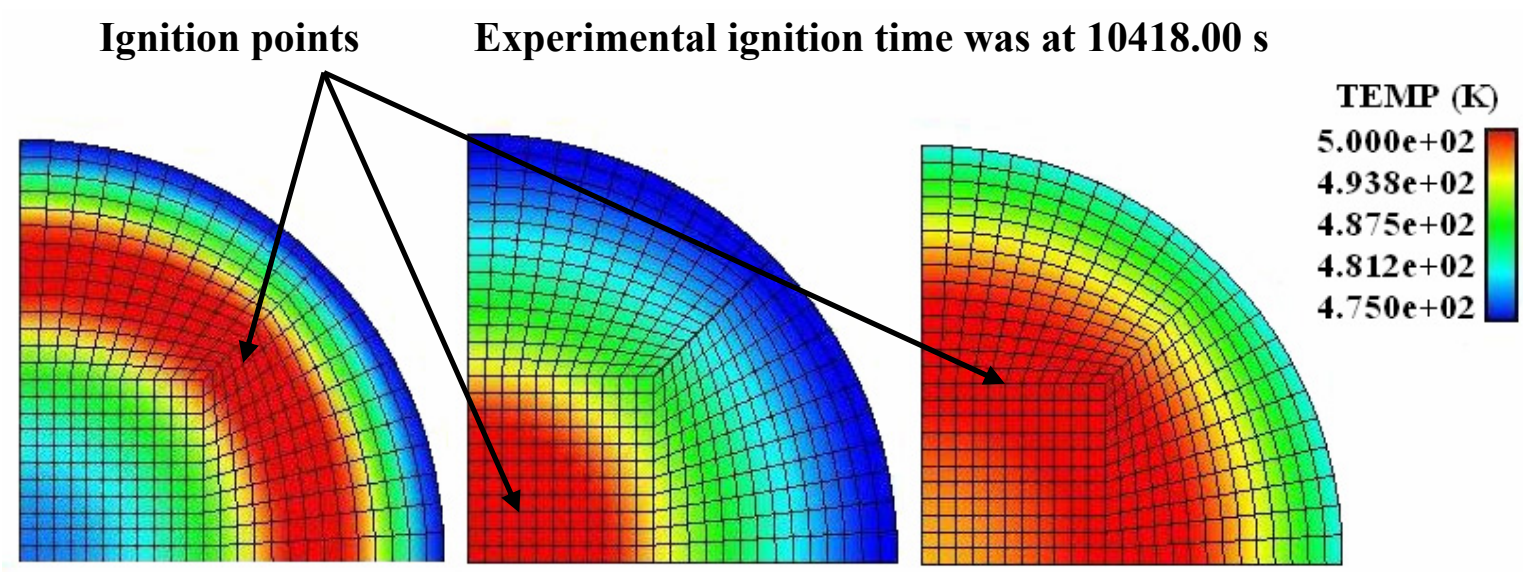

Dickson kinetics (DH3) applied to the unconfined spherical models Ignition at $5393.45 \mathrm{~s}$
Jaeger kinetics (JV3) applied to the unconfined spherical models Ignition at $5804.14 \mathrm{~s}$
Tarver kinetics (TM3) applied to the unconfined spherical models Ignition at $7519.43 \mathrm{~s}$

Figure 7.5: Comparison of the reaction times for the unconfined spheres in Experiment 3.

The recorded ignition time for Experiment 3 was 10,418.00 seconds, whereas the ignition times for both the Dickson et al. and Jaeger kinetics systems are premature by about $45 \%$ at $5,393.45$ seconds and at 5,804.14 seconds, respectively. The ignition value for the Tarver and McGuire kinetics is 7,519.43 seconds and that is less than $30 \%$ short of the experimental value. Once again, the Tarver and McGuire kinetics system is the most accurate of the three kinetics systems.

\subsection{The Naval Air Warfare Center Weapons Division Experiments at China Lake for Confined Cylinders}

The Navy cookoff experiment is a single test that is modeled with three kinetics systems and includes a reduced time step analysis of 0.01 seconds for each model. There are six models being analyzed and assessed. The following definitions are used in the cookoff models to denote the different COYOTE input files.

- 'DH' refers to the Dickson et al. kinetics model

- 'JV' refers to the Jaeger and Vigil kinetics model

- 'TM' refers to the Tarver and McGuire kinetics model

- ' 'a' refers to the initial integration time step reduced from 0.1 to 0.01 seconds

The Navy cookoff experiment is characterized as a slow time-to-ignition study because of the fact that the process includes long heat soaks at a constant temperature to ensure the explosive material is heated evenly and completely. The cookoff experiment was heated for approximately 4 hours when a reaction occurred. For this analysis, the thermal runaway time is defined as the time when the temperature at a particular location in the HE exceeds $510 \mathrm{~K}$ 
and has an internal heating rate of greater than $1 \mathrm{~K} / \mathrm{s}$. The results for each of the Navy cookoff models are shown in Table 7.8. As with the previous results, the Navy cookoff table follows the same format used in Table. 7.1.

Table 7.8: Comparison between the Navy cookoff data and the numerical results

\begin{tabular}{|l|c|c|c|}
\hline \multicolumn{4}{|c|}{ Time to Reaction for Navy Cookoff } \\
\hline & Results & $\boldsymbol{\Delta}$ time & \% Error \\
\hline \hline Navy Data & 13774.20 & & \\
\hline Navy - DH1 & 14607.70 & 833.5 & 6.05 \\
\hline Navy - DH1a & 14610.70 & 836.5 & 6.07 \\
\hline Navy - JV1 & 13607.20 & -167.0 & -1.21 \\
\hline Navy - JV1a & 13594.50 & -179.7 & -1.30 \\
\hline Navy - TM1 & 16833.40 & 3059.2 & 22.21 \\
\hline Navy - TM1a & 16854.60 & 3080.4 & 22.36 \\
\hline
\end{tabular}

The experimental time to ignition for the Navy cookoff was recorded as 13,774.20 seconds. The Jaeger kinetics under-predicts ignition by only about $1.5 \%$, with a value of $13,607.20$, and the Dickson et al. kinetics is within $6 \%$ of the experimental values, with an ignition time of 14,607.70 seconds. For the analysis of this experiment the Tarver and McGuire model was the least accurate model with an ignition time of 16,833.40 seconds which translates into an over-prediction of around $22 \%$.

Only the Dickson et al. model predicted an ignition at the center of the model. Both the Jaeger and Tarver models predicted ignition higher up but still along the axisymmetric $\mathrm{y}$-axis. The heat ramp data recorded on the graph in Figure 7.6 is created from the parameters described in the literature provided by Pat Curran [16]. All of the analytical temperature traces in Figure 7.6 are created from the analysis of the ignition nodes from each of the different kinetics systems. As Figure 7.6 shows, the results from the Jaeger and Dickson et al. models do a very good job of matching the experimental results. 


\section{Comparison of Numerical Results with Navy Cookoff Data}

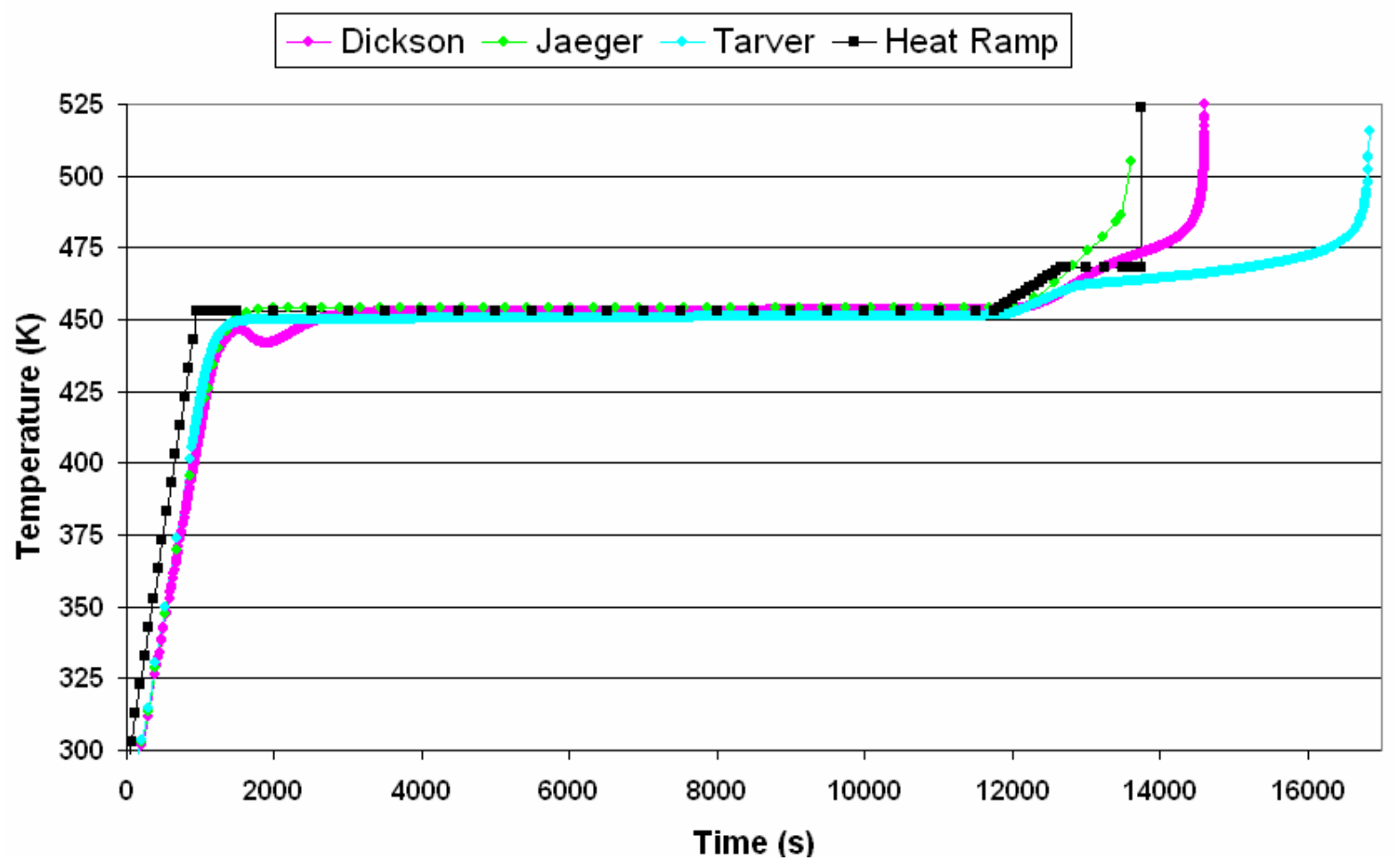

Figure 7.6: Navy cookoff comparison between the input data and numerical results.

A comparison and assessment of the data from the various models of this experiment reveal that the results from the initial time step of 0.1 seconds and the reduced time step of 0.01 seconds are relatively the same for each of the kinetic systems. This in turn indicates that the 0.1 second time step is adequate for all the kinetics systems.

Figure 7.7 displays a graphical representation of the three kinetics systems at their ignition times. All of the materials except the HE charge are shown as a mesh. This is displayed to delineate the exact location and size of the HE region in the model. The HE is displayed as the shaded region in the lower-left corner, with black lines representing the elements and the nodes in the explosive.

The location of the thermal runaway for the Dickson et al. kinetics system is at node 613, which is at the lower-left corner of the FEA model and at the center of the cookoff vessel. The Jaeger kinetics systems ignition point is located two-thirds of the way up the HE charge at node 182, which is 36 elements up from the corner and 1 element in from the y-axis. The ignition point for Tarver and McGuire kinetics system is 16 elements up from the bottom left corner and on the y-axis at node 421, which is approximately one-third the distance up the HE charge. 


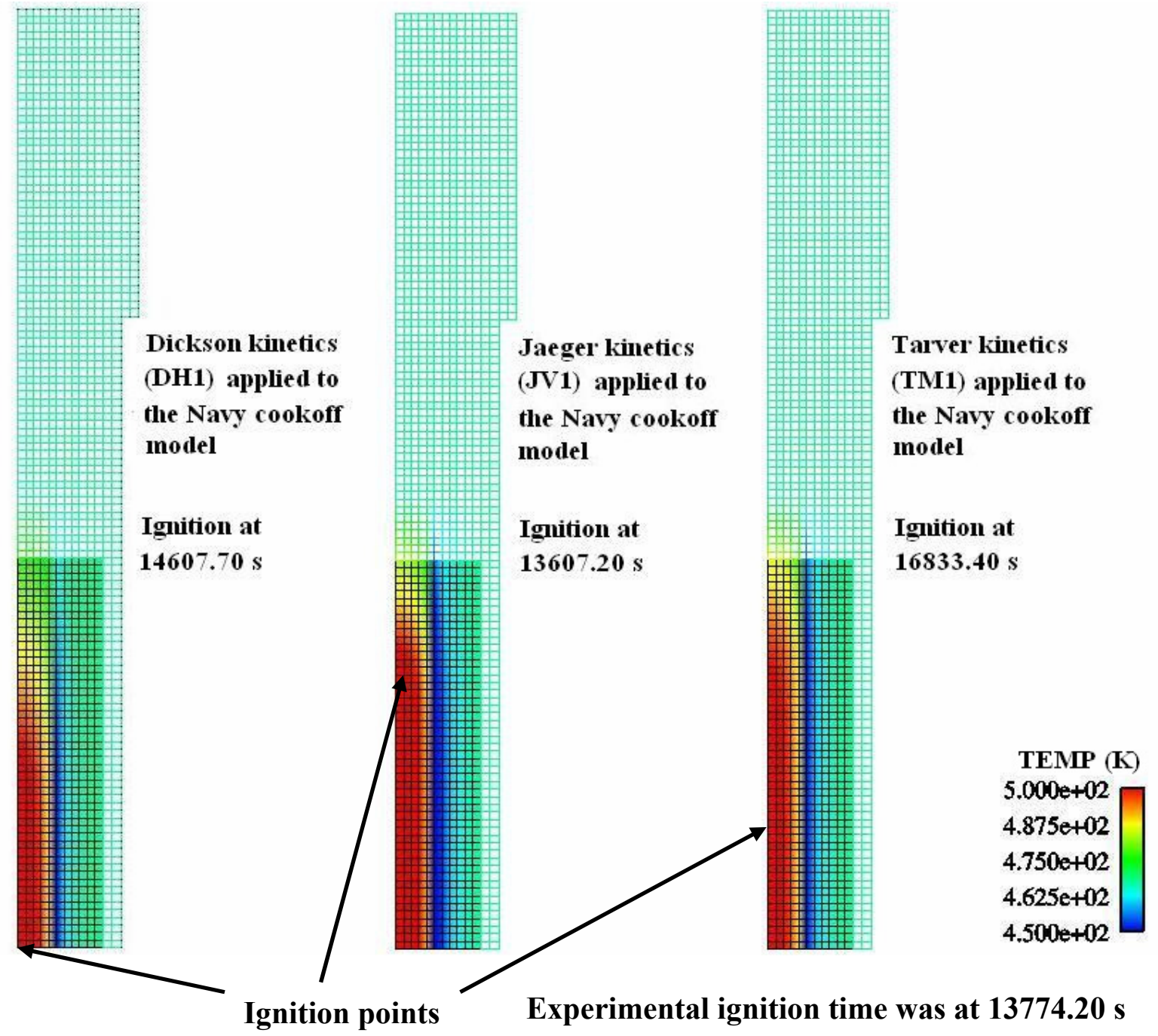

Figure 7.7: Visual comparisons of the reaction times for the three kinetics systems.

The Dickson et al. kinetics system shows a smaller region of the HE material that is near the ignition temperature, but the entire model has a more uniform temperature distribution. The Jaeger model exhibits a region where about half of the HE charge is at or near the ignition temperature. The Tarver and McGuire model has temperature gradients that are not as extreme as those in the Jaeger model but are still more pronounced than those shown in the Dickson et al. model. All three models show a narrow band of colder material that is directly adjacent to the ignition zone. 


\subsection{CONCLUSIONS}

The importance of this type of research is to assess the current capability to accurately predict the ignition time, temperature, and location in PBX 9501 for varying induced temperatures, heating rates, configurations, and confinements. The predictive capabilities assessed by this research are critical in all aspects of operational safety, including manufacture, delivery, handling, and processing of explosive ordnances.

The STEX experiment was extremely well sealed, and it was heated up to ignition very slowly. The three kinetics systems create numerical results that closely match (to within $1.0 \%$ ) the thermocouple data of the experiment up to about 345,000 seconds. The ignition time for the Dickson et al. model is within $4.0 \%$ of the experimental data, and this kinetics system reproduces the endothermic phase change that is brought about by the heating process, as can be seen graphically as a temperature dip at around 270,000 seconds. The Jaeger model also represents the heating process of the experiment to within $1.0 \%$ of the experimental data, but it is not capable of producing thermal runaway even after an additional 50,000 seconds of analysis time. The Jaeger kinetics requires a faster heating rate to induce thermal runaway. The Tarver and McGuire model predicts the time to ignition within $1.0 \%$ of the test data. None of the models show significantly different results when the initial time step is reduced from 0.1 seconds to 0.01 seconds or when the mesh size is reduced from $1.0-\mathrm{mm}$ to $0.5-\mathrm{mm}$. Thus, there is no mesh size sensitivity or time step sensitivity for the analyses of the LLNL STEX kinetics models.

The ODTX experiments were fast-heating tests that only recorded the ignition time and the temperature of the preheated containment vessel. No temperature was recorded anywhere on or in the HE charge. All three kinetics systems produce inconsistent numerical results for the experiments that have reaction times of less than 30 seconds. The Dickson et al. model predicts ignition at $20 \%$ to $50 \%$ earlier than the test data for tests that take over 30 seconds to react. The results of the Jaeger models are premature by at least $50 \%$ and show a trend of getting less accurate as the ignition time increases and do not show any reaction for reaction times greater than about 3000 seconds. Mesh size and time step variations affect the time to ignition only slightly in the Dickson et al. and Jaeger models. The Tarver and McGuire models are very dependent on time step and mesh size for the ODTX analysis. The Tarver and McGuire results are much more accurate when using the smaller initial time step of 0.01 seconds. With the smaller initial time step, the analytical results are within about $20 \%$ of the test data. However, models of the experiments that took more than 9,000 seconds to react showed no thermal reactions.

None of the kinetics systems reasonably predict the time to ignition for the partially confined experiments or the aged experiments. The kinetics systems are not able to create numerical results that accurately predict the unconfined experiments. None of the kinetics systems have a way to model the loss of product gases. 
None of the kinetics systems predict the time to ignition for the LANL unconfined experiments. The gas losses are not included in the kinetics systems, and this makes an accurate analysis impossible. Each kinetics system solves consistently for changes in mesh size and initial time step results for their individual analysis. Each kinetics system solves ignition time and location quite differently from each other and from the experimental results.

The Navy experiment was slowly heated and took almost four hours to initiate a reaction. There was no thermocouple data recorded from inside or on the surface of the HE material. The Dickson et al. models over-predict by about $6.0 \%$, as compared to the test data. The results of the Jaeger models are premature but with less than $2.0 \%$ difference from the test data. The results of the Tarver and McGuire models are over-predicting by about $22.0 \%$, as compared to the test values.

The Dickson et al. kinetics system does an adequate modeling all four experiments. This system incorporates the endothermic phase change in its results, and for most of the analyses it under-predicts the ignition time. This kinetics system is not greatly influenced by varying the time step, the mesh size, or the heating rate.

The Jaeger kinetics system is not able to solve slow heating experiments like the STEX test. The Jaeger kinetics does very well for experiments that have a fast heating ramp near the ignition temperature, as seen in the Navy cookoff model. This kinetics system has a rate dependency. If the heating ramp is too slow, the kinetics for the HE do not initiate the selfheating process that is needed to produce thermal runaway.

The Tarver and McGuire kinetics system does a good job of modeling all four experiments. For three of the four experimental models, the Tarver and McGuire kinetics are the most accurate. This kinetics system is greatly influenced by the time step used in the FEA solver, as is the case with the ODTX results. For fast reaction models, the Tarver kinetics is more accurate when a smaller time step is used because it produces more solution iterations at a particular temperature.

Overall, none of the kinetics systems produce reliable predictions of thermal runaway for experiments that react in under 30 seconds. All three kinetics systems are very good at modeling the thermal reaction process in experiments that react in the 30-second-to-3-hour range. For slow heating experiments where the PBX 9501 is held close to the ignition temperature and slowly heated, both the Dickson et al. and the Tarver and McGuire models are very accurate at predicting the time to ignition. However, the Dickson et al. kinetics predicts the location of the ignition point, as seen graphically by comparisons with the thermocouple data. For experiments with faster heating rates, all three kinetics systems compare well, but as was shown, the characteristic length of the mesh and the initial time step value become more important factors in accurately predicting ignition times and locations. 



\section{APPENDIX A}

\section{A.1. Example of an Input File for the STEX Model Using the Dickson et al. Kinetics}

TITLE

STEX with Dickson-Henson Kinetics

END

$\$$

\$Modified for August 24, 2004 bc

$\$$

$\${ }^{* * *}$ This is DH1 that has constant heating on the outer cylinder

$\$$

$\$ * * * *$ MATERIAL DEFINITION****

$\$$

\$ This file for PBX 9501: 95\% HMX, 2.5\% Estane, 2.5\% BDNPA/F

\$ Assembled by: W. W. Erikson 9116 2002/01/24

$\$$ This mechanism is the LANL (Peter Dickson) version

\$ Units are cal-cm-s-k

$\$$

$\$ \quad \mathrm{~A}<-------->\mathrm{B} \quad(\mathrm{RXNS} 1 \& 2)$

$\$ \quad \mathrm{~A}+\mathrm{B}<--->2 \mathrm{~B} \quad(\mathrm{RXNS} 3 \& 4)$

$\$ \quad \mathrm{~B}------>\mathrm{C} \quad(\mathrm{RXN} 5)$

$\$ \quad \mathrm{~B}+\mathrm{C}---->2 \mathrm{C} \quad(\mathrm{RXN} 6)$

$\$$

$\$ \mathrm{KOH}=2.08145 \mathrm{e}+10$

$\$$ units are $[1 / \mathrm{s}-\mathrm{K}]$ (boltzmann/planck)

$\$$ Heat Release Calculations

\$ Q1=-5.975143403 cal $/ \mathrm{g}$

$\$$ Q2 $=5.975143403 \mathrm{cal} / \mathrm{g}$

$\$ \mathrm{Q} 3=-5.975143403 \mathrm{cal} / \mathrm{g}$

$\$$ Q4 $=5.975143403 \mathrm{cal} / \mathrm{g}$

\$ Q5=-286.8068834 cal $/ \mathrm{g}$

\$ Q6=764.8183556 cal/g

$\$$ R9501 $=1.865$

$\$ \mathrm{H} 1=-11.14364245 \mathrm{cal} / \mathrm{cc}$

$\$ \mathrm{H} 2=11.14364245 \mathrm{cal} / \mathrm{cc}$

$\$ \mathrm{H} 3=-11.14364245 \mathrm{cal} / \mathrm{cc}$

$\$ \mathrm{H} 4=11.14364245 \mathrm{cal} / \mathrm{cc}$ 


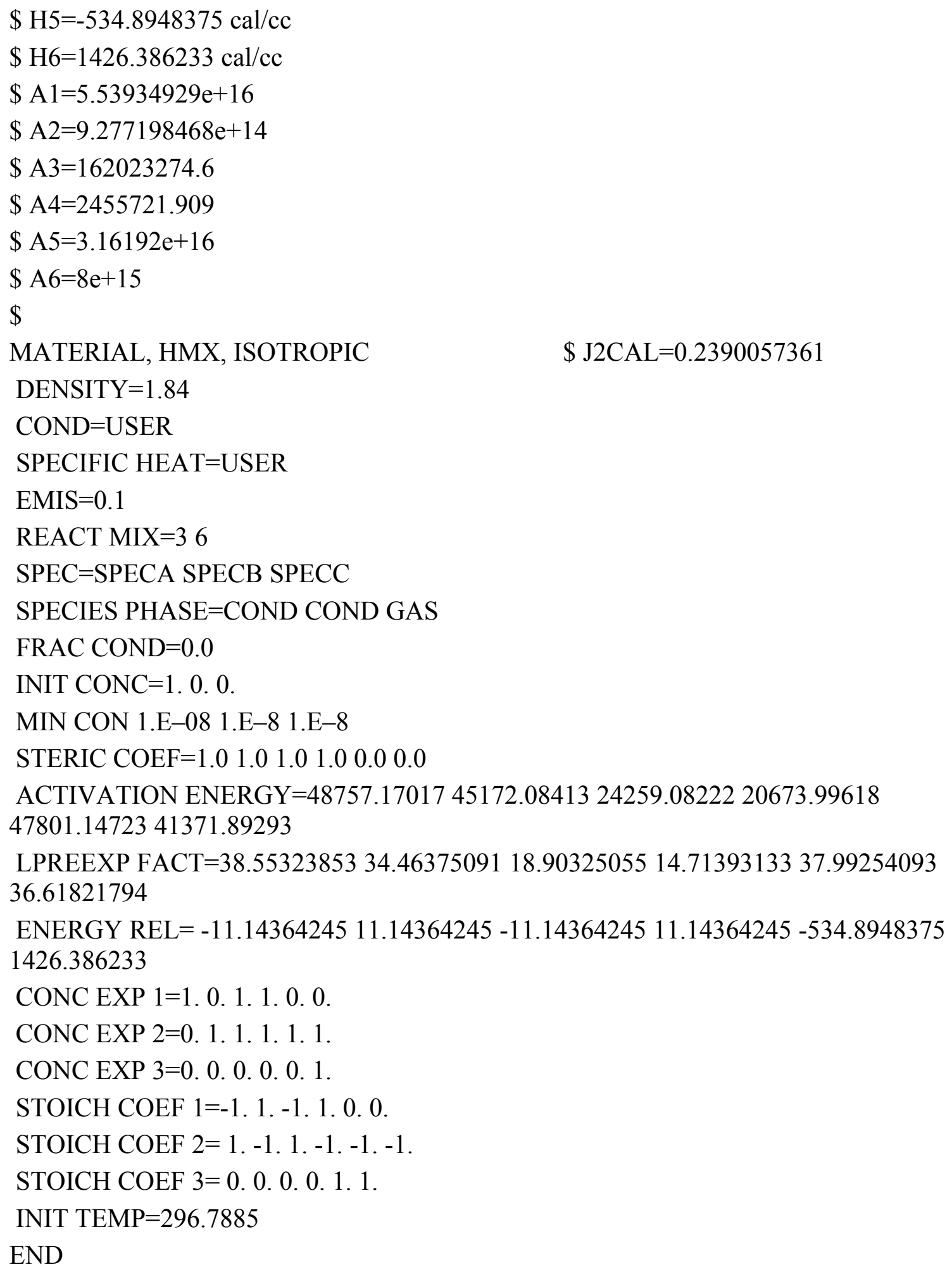


USER CONSTANTS

USER REAL=101 236.0

\$ LANL Cp a for spec A

USER REAL $=1022.7$

USER REAL $=103236.0$

\$ LANL Cp b (*T) for spec A

USER REAL $=1042.7$

$\$$ LANL Cp a for spec B

USER REAL $=105721.0$

\$ LANL Cp b (*T) for spec B

USER REAL $=1060.952$

\$ LANL Cp a for spec C

USER REAL $=1210.750$

USER REAL $=122-1.1 \mathrm{e}-3$

\$ LANL Cp b (*T) for spec C

$\$$ LANL $\mathrm{k}$ a for spec $\mathrm{A}$

$\$$ LANL $k$ b (*T) for spec A

USER REAL $=1230.160$

USER REAL $=1240.0$

USER REAL $=125$ 4.20e-2

$\$$ LANL $\mathrm{k}$ a for spec $\mathrm{B}$

$\$$ LANL k b (*T) for spec B

$\$$ LANL $k$ a for spec C

USER REAL $=1260.0$

USER INTEGER=10 3

$\$$ LANL k b (*T) for spec C

$\$$ USRCP/CON flag (1=erg,g,cm 2=J,kg,m

$3=$ cal,g,cm)

END

$\$$

MATERIAL, STEEL, ISOTROPIC

$\$$ carbon steel 4130 cylinder

DENSITY $=7.865$

$\mathrm{COND}=\mathrm{VFUNC}, 11$

$\$ \mathrm{~g} / \mathrm{cc}$, Touloukian, EXPLO

$\$ \mathrm{cal} / \mathrm{cm}-\mathrm{s}-\mathrm{K}$

SPECIFIC HEAT=VFUNC, 12

$\$ \mathrm{cal} / \mathrm{g}-\mathrm{K}$

INIT TEMP $=296.7885$

$\$ \mathrm{~K}$

$\mathrm{EMIS}=0.1$

\$ Emissivity

END

$\$$

MATERIAL, BOLT, ISOTROPIC

\$ ASTM 571 Bolts

DENSITY $=7.865$

$\mathrm{COND}=\mathrm{VFUNC}, 21$

$\$ \mathrm{~g} / \mathrm{cc}$, Touloukian, EXPLO

$\$ \mathrm{cal} / \mathrm{cm}-\mathrm{s}-\mathrm{K}$

SPECIFIC HEAT=VFUNC, 22

INIT TEMP $=296.7885$

$\$ \mathrm{cal} / \mathrm{g}-\mathrm{K}$

$\$ \mathrm{~K}$

$\mathrm{EMIS}=0.1$

\$ Emissivity,

END

$\$$

MATERIAL, GAP_TOP, ISOTROPIC

DENSITY $=$ VFUNC, 30

\$ Air gap on top

$\mathrm{COND}=\mathrm{VFUNC}, 31$

$\$$ g/cc, Touloukian, EXPLO

SPECIFIC HEAT $=1.433 \mathrm{E}-6$

$\$ \mathrm{cal} / \mathrm{cm}-\mathrm{s}-\mathrm{K}$

$\$ \mathrm{cal} / \mathrm{g}-\mathrm{K}$ 


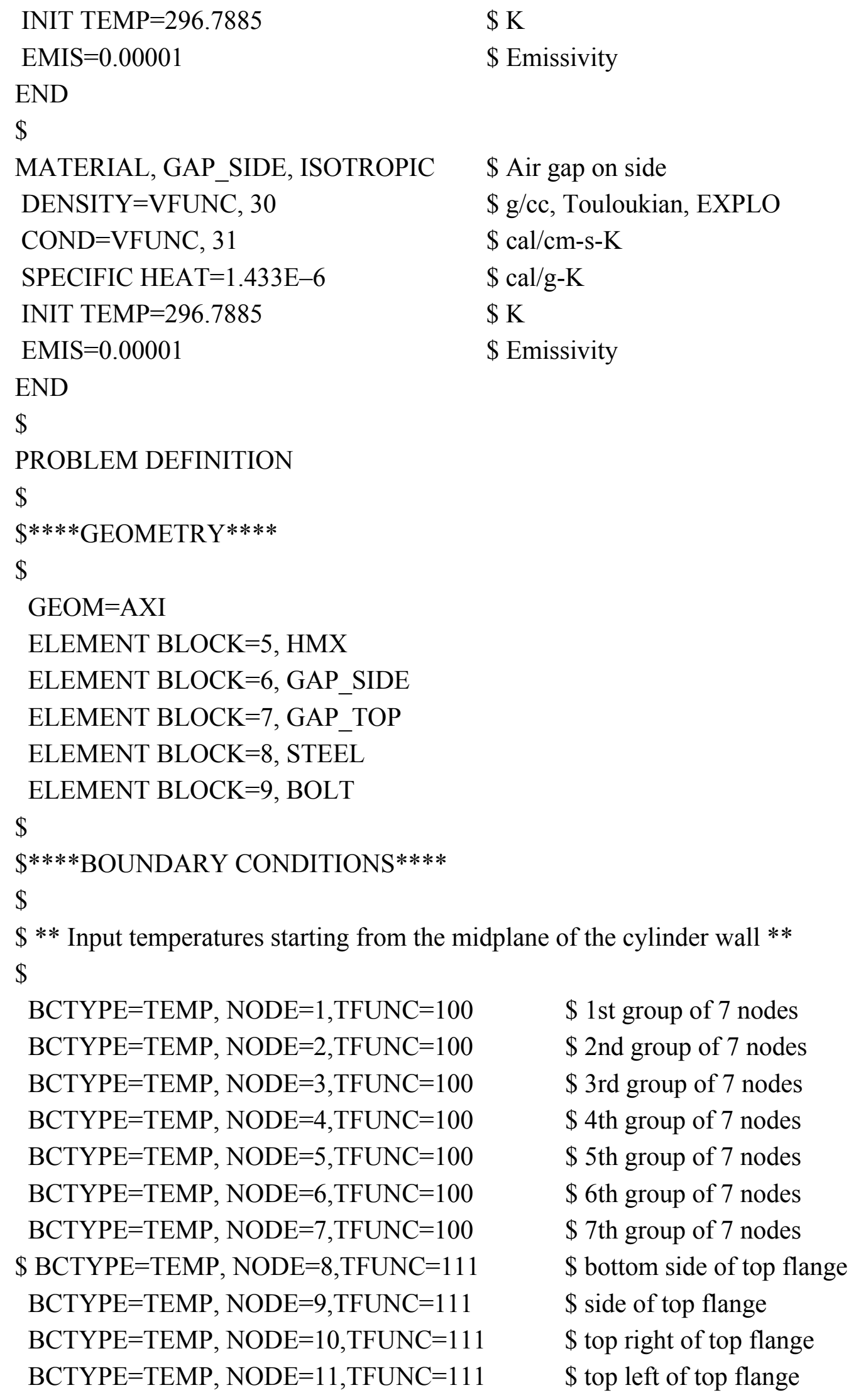


$\$$ BCTYPE $=$ MP CONS, SIDE $=3$, SIDE $=10$, PEN $=100.0$, CAP DIS $=0.0001$

$\$$ BCTYPE $=$ RAD, $\mathrm{SIDE}=2, \mathrm{COEFF}=0.5, \mathrm{TREF}=295$.

$\$$ BCTYPE $=$ RAD, $\mathrm{SIDE}=8, \mathrm{COEFF}=0.5, \mathrm{TREF}=300$.

$\$$ BCTYPE $=$ CONV, SIDE $=2$, COEFF $=0.0018$, TREF $=295$.

SIGMA $=2.3742 \mathrm{E}-11$

GAS CONSTANT $=1.987$

END

$\$$

SOLUTION, 1, TIME DEPENDENT

$\$$

INT METH=TRAPEZOID

MATR SOL $=$ CG

TIME STEP OPTION=AUTO

$\$$ TIME STEP OPTION=FIXED

TIME STEP $=0.1$

INIT TIME $=0.0$

FINAL TIME $=500000$

CONV TOL $=1 . E-8$

NUM TIME STEP $=50000000$

MAX MATRIX ITER $=10000$

ABS TEMP LIMIT $=700.0$

END

$\$$

$\$$ ****FUNCTIONS****

$\$$

VAR FUNCTION=11

$\$$ Conductivity of 4130 steel

273.0, 0.101989

$\$ \mathrm{cal} / \mathrm{cm}-\mathrm{s}-\mathrm{K}$

373.0, 0.101989

\$ www.eFunda.com

573.0, 0.096973

773.0, 0.089091

973.0, 0.074044

$1273.0,0.067117$

1473.0, 0.071894

END

$\$$

VAR FUNCTION $=12$

$\$$ Specific heat of 4130 steel

273.0, 0.113929

$\$ \mathrm{cal} / \mathrm{g}-\mathrm{K}$

358.0, 0.113929

\$ www.eFunda.com

A-5 


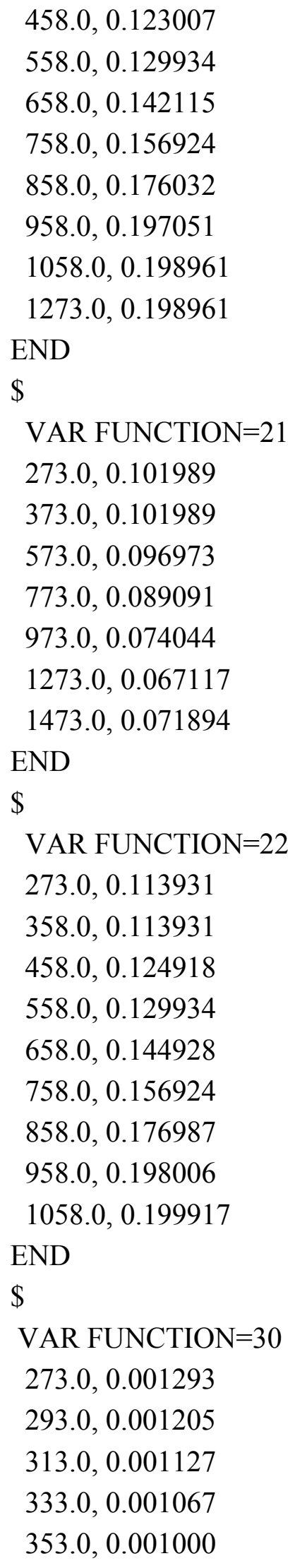

$\$$ Conductivity of $4130 \mathrm{H}$ bolt $\$ \mathrm{cal} / \mathrm{cm}-\mathrm{s}-\mathrm{K}$

\$ www.eFunda.com
$\$$ Specific heat of $4130 \mathrm{H}$ bolt $\$ \mathrm{cal} / \mathrm{g}-\mathrm{K}$

\$ www.eFunda.com
\$ Density of air gap

$\$ \mathrm{cal} / \mathrm{cm}-\mathrm{s}-\mathrm{K}$

\$ www.eFunda.com 


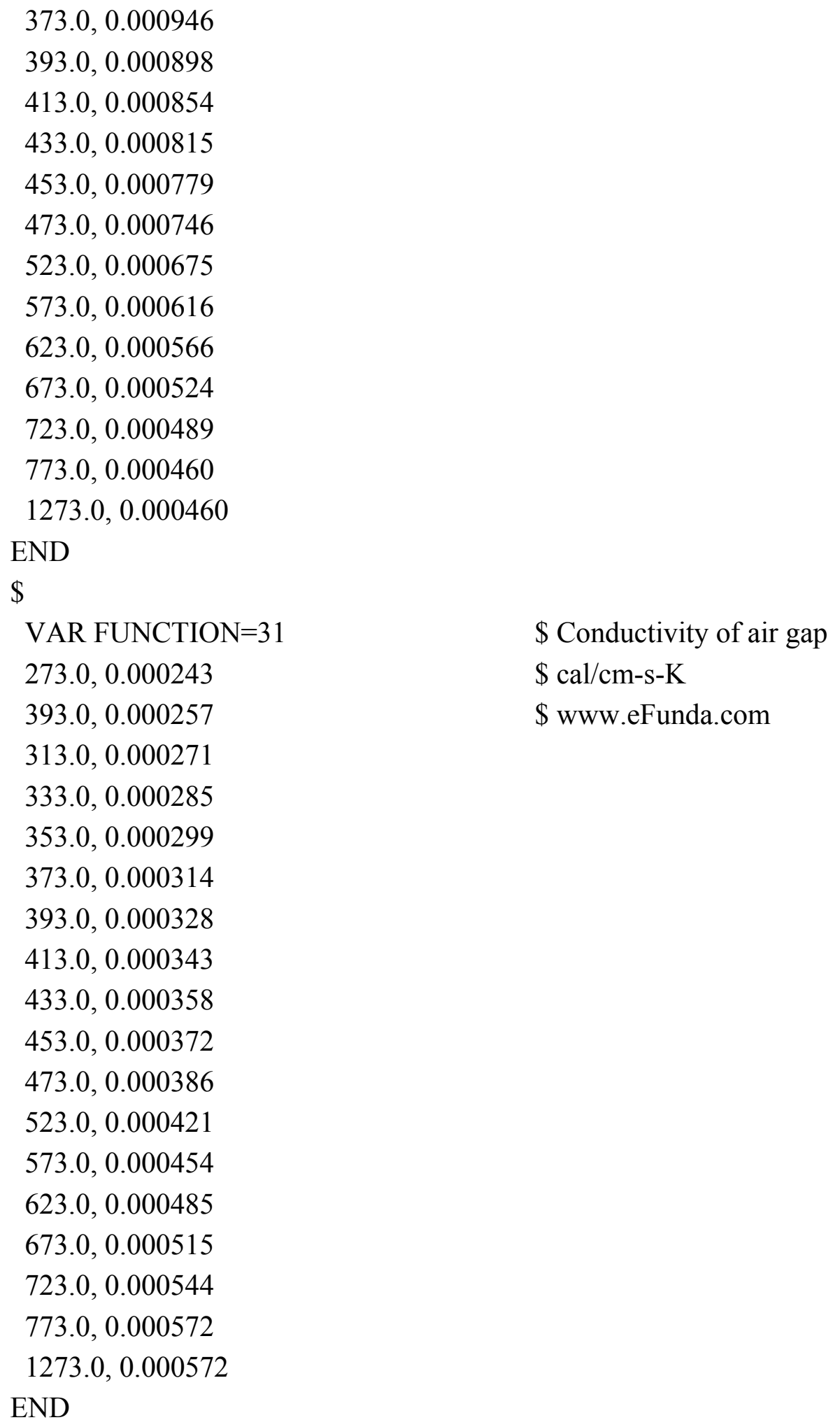

\$ Conductivity of air gap $\$ \mathrm{cal} / \mathrm{cm}-\mathrm{s}-\mathrm{K}$

\$ www.eFunda.com 


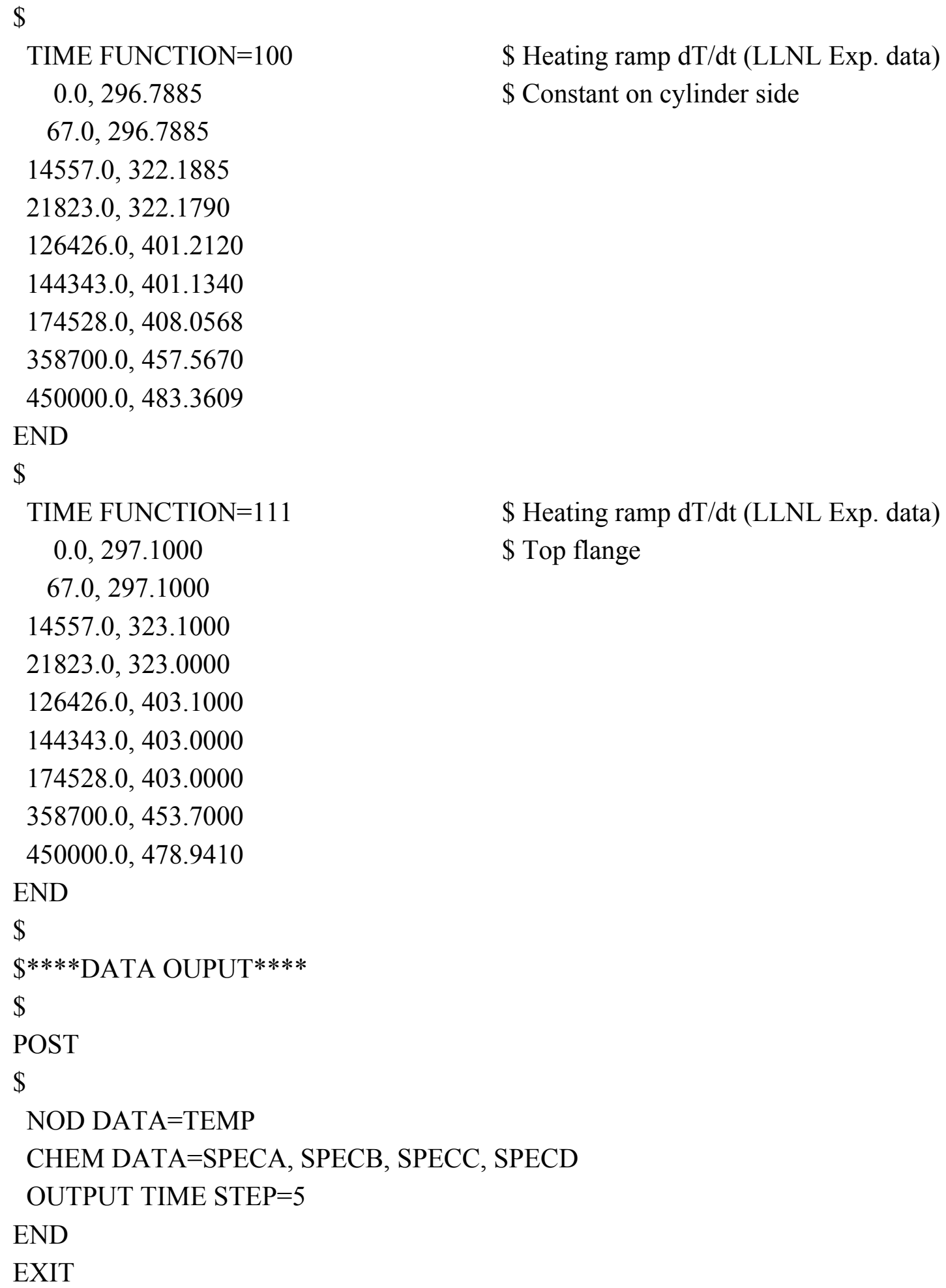




\section{A.2. Example of an Input File for the STEX Model Using the Jaeger Kinetics}

TITLE

STEX with Jaeger-Vigil Kinetics

END

$\$$

$\${ }^{* * *}$ This is JV1 that has constant heating on the outer cylinder

$\$$

$\$ * * * *$ MATERIAL DEFINITIONS****

$\$$

MATERIAL, HMX, ISOTROPIC

\$ HMX used for PBX 9501

DENSITY $=1.84$

$\$ \mathrm{~g} / \mathrm{cc}$

COND $=$ VFUNC, 5

$\$ \mathrm{cal} / \mathrm{cm}-\mathrm{s}-\mathrm{K}$

SPECIFIC HEAT $=$ VFUNC, 6

$\$ \mathrm{cal} / \mathrm{g}-\mathrm{K}$

INIT TEMP $=296.7885$

$\$ \mathrm{~K}$

LAT HEAT $=50.0$

$\$ \mathrm{cal} / \mathrm{g}$

SOL TEMP $=519.0$

$\$ \mathrm{~K}$

LIQ TEMP $=521.0$

$\$ \mathrm{~K}$

PHASE CHANGE

$\$$ delta-HMX to gas products

REACT MIX=2,1,,

SPEC $=$ SPECA, SPECD

$\$ 2$ species, 1 reaction,

$\$$ species in Jaeger and Vigil reaction

SPEC PHASE, COND, GAS

$\$$ Assumed phase of species

FRAC COND $=0.0$

$\$$ Fraction condensed not used

INIT $\mathrm{CONC}=1.0,0.0$

$\$$ Initial conc.

MIN CON, 1.E-08, 1.E-08

$\$$ Minimum conc.

STERIC COEF $=0$.

$\$$ Steric factors

ACTIVATION ENERGY $=52700$.

$\$ \mathrm{cal} / \mathrm{mol}$, Act. Energy, (Jaeger 1980, pg 6)

LPREEX FACT $=45.3625$

$\$$ Ln of pre-exponential, (Jaeger 1980, pg 6)

ENERGY REL $=929.2$

$\$ \mathrm{cal} / \mathrm{cc}$, heat of reaction, (Jaeger 1980, pg 6)

CONC EXP, $1=1.0$

$\$ \mathrm{~A} \rightarrow \mathrm{B}$

a 1

CONC EXP, $2=0.0$

$\$ \mathrm{~B}->$ A matrix --> b 0

STOICH COEF, $1=-1.0$

$\$ \mathrm{dA} / \mathrm{dt}=-\mathrm{r} 1$

STOICH COEF, $2=+1.0$

$\$ \mathrm{dD} / \mathrm{dt}=+\mathrm{r} 1$

END

$\$$

MATERIAL, STEEL, ISOTROPIC

DENSITY $=7.865$

\$ carbon steel 4130 cylinder

$\$ \mathrm{~g} / \mathrm{cc}$, Touloukian, EXPLO

A-9 
$\mathrm{COND}=\mathrm{VFUNC}, 11$

SPECIFIC HEAT=VFUNC, 12

INIT TEMP $=296.7885$

EMIS $=0.1$

END

$\$$

MATERIAL, BOLT, ISOTROPIC

DENSITY $=7.865$

COND=VFUNC, 21

SPECIFIC HEAT $=$ VFUNC, 22

INIT TEMP $=296.7885$

$\mathrm{EMIS}=0.1$

END

$\$$

MATERIAL, GAP_TOP, ISOTROPIC

DENSITY $=$ VFUNC, 30

COND $=$ VFUNC, 31

SPECIFIC HEAT $=1.433 \mathrm{E}-6$

INIT TEMP $=296.7885$

EMIS $=0.00001$

END

$\$$

MATERIAL, GAP_SIDE, ISOTROPIC

DENSITY $=$ VFUNC, 30

COND=VFUNC, 31

SPECIFIC HEAT $=1.433 \mathrm{E}-6$

INIT TEMP $=296.7885$

EMIS $=0.00001$

END

$\$$

PROBLEM DEFINITION

$\$$

$\$ * * * *$ GEOMETRY $* * * *$

$\$$

GEOM=AXI

ELEMENT BLOCK $=5$, HMX

ELEMENT BLOCK $=6$, GAP_SIDE

ELEMENT BLOCK $=7$, GAP_TOP
$\$ \mathrm{cal} / \mathrm{cm}-\mathrm{s}-\mathrm{K}$

$\$ \mathrm{cal} / \mathrm{g}-\mathrm{K}$

$\$ \mathrm{~K}$

\$ Emissivity

\$ ASTM 571 Bolts

$\$ \mathrm{~g} / \mathrm{cc}$, Touloukian, EXPLO

$\$ \mathrm{cal} / \mathrm{cm}-\mathrm{s}-\mathrm{K}$

$\$ \mathrm{cal} / \mathrm{g}-\mathrm{K}$

$\$ \mathrm{~K}$

\$ Emissivity

\$ Air gap on top

$\$ \mathrm{~g} / \mathrm{cc}$, Touloukian, EXPLO

$\$ \mathrm{cal} / \mathrm{cm}-\mathrm{s}-\mathrm{K}$

$\$ \mathrm{cal} / \mathrm{g}-\mathrm{K}$

$\$ \mathrm{~K}$

\$ Emissivity,

\$ Air gap on side

$\$ \mathrm{~g} / \mathrm{cc}$, Touloukian, EXPLO

$\$ \mathrm{cal} / \mathrm{cm}-\mathrm{s}-\mathrm{K}$

$\$ \mathrm{cal} / \mathrm{g}-\mathrm{K}$

$\$ \mathrm{~K}$

\$ Emissivity, 


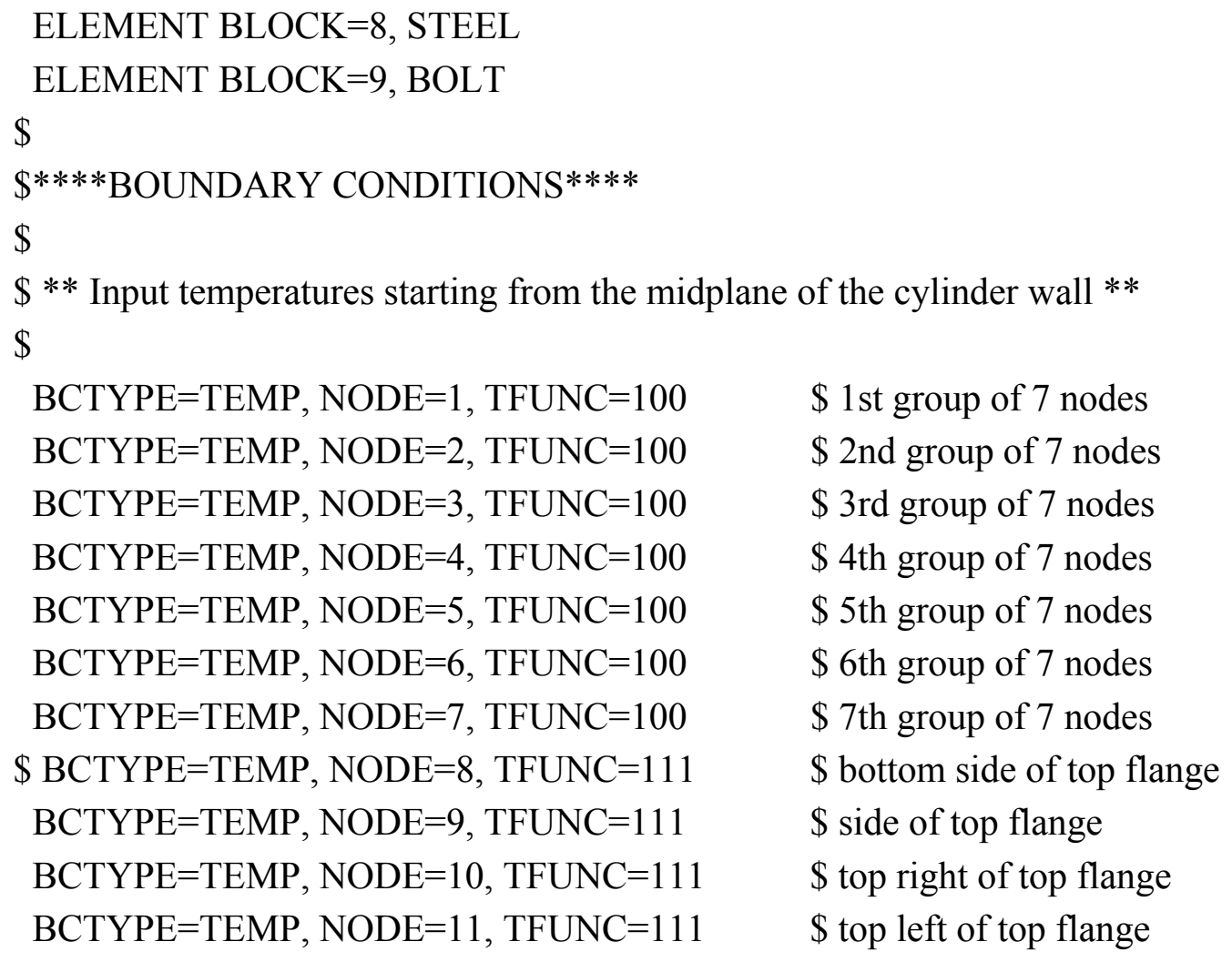




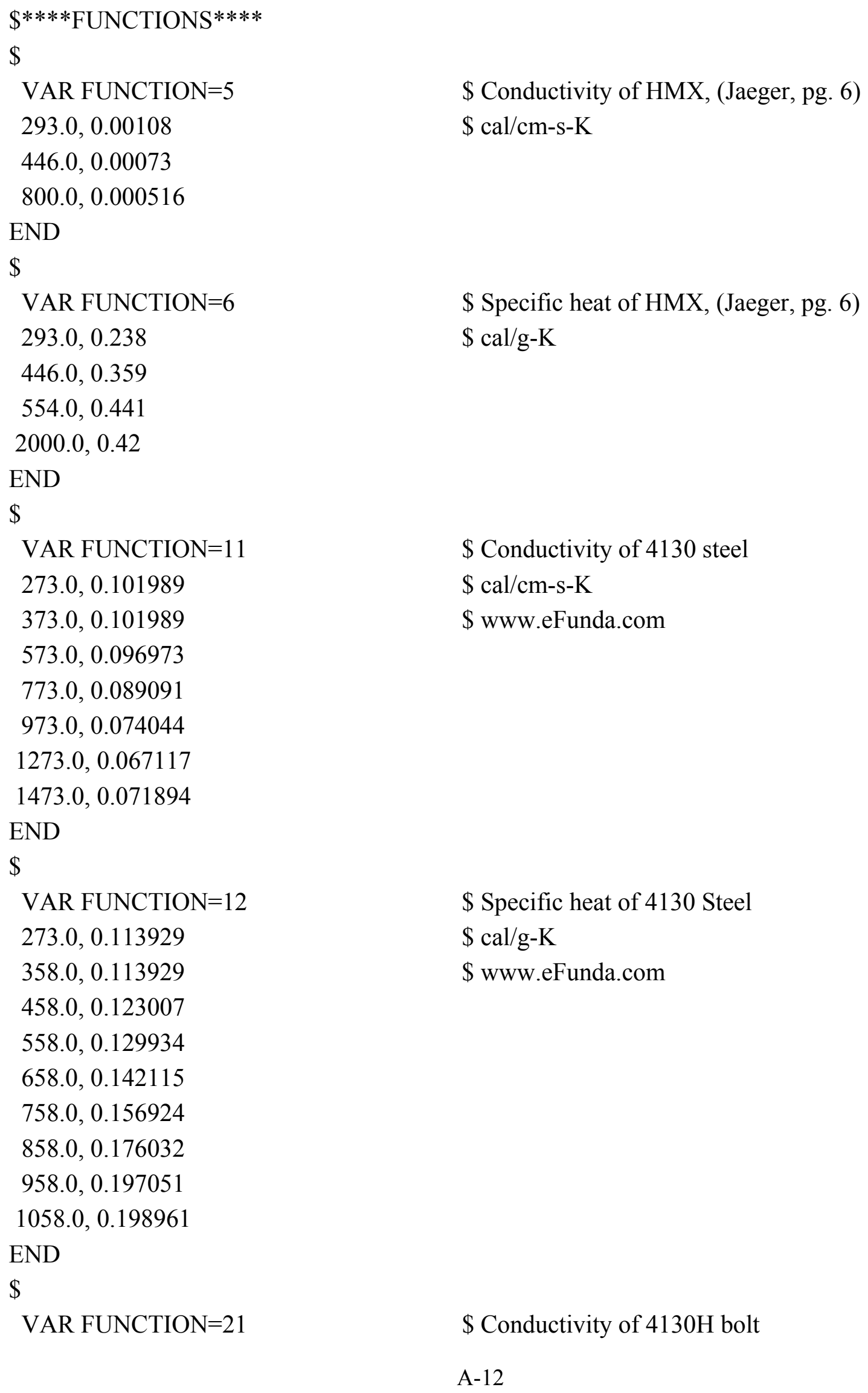

\$ Conductivity of $4130 \mathrm{H}$ bolt 


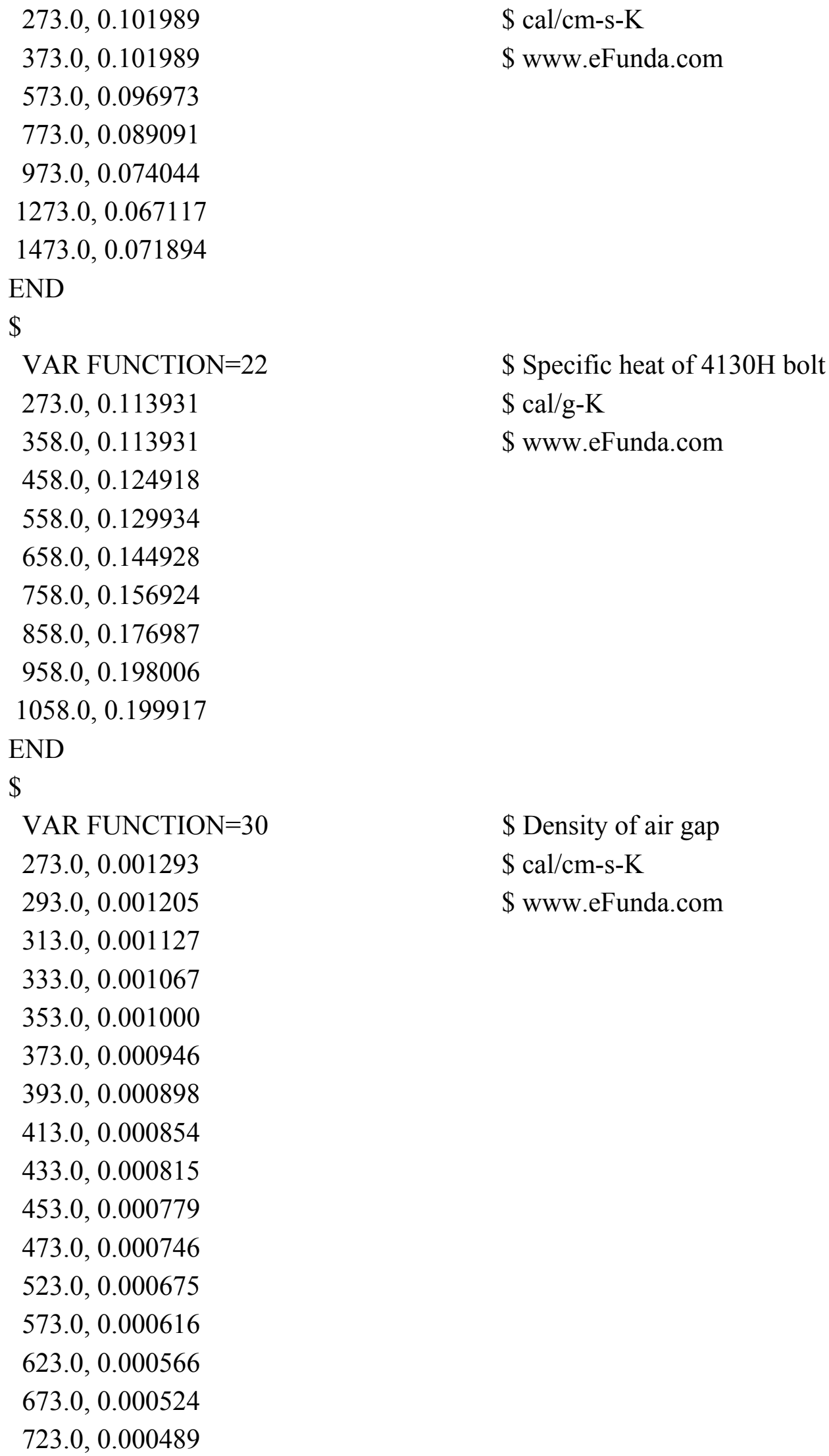

$\$ \mathrm{cal} / \mathrm{cm}-\mathrm{s}-\mathrm{K}$

\$ www.eFunda.com

$\$$ Specific heat of $4130 \mathrm{H}$ bolt $\$ \mathrm{cal} / \mathrm{g}-\mathrm{K}$

\$ www.eFunda.com

\$ Density of air gap $\$ \mathrm{cal} / \mathrm{cm}-\mathrm{s}-\mathrm{K}$

\$ www.eFunda.com 
773.0, 0.000460

\section{END}

$\$$

VAR FUNCTION=31

273.0, 0.000243

$393.0,0.000257$

313.0, 0.000271

$333.0,0.000285$

$353.0,0.000299$

373.0, 0.000314

393.0, 0.000328

413.0, 0.000343

433.0, 0.000358

453.0, 0.000372

473.0, 0.000386

523.0, 0.000421

$573.0,0.000454$

$623.0,0.000485$

673.0, 0.000515

$723.0,0.000544$

$773.0,0.000572$

END

$\$$

VAR FUNCTION=32

273.0, 0.240044

293.0, 0.240044

$313.0,0.240044$

$333.0,0.240999$

353.0, 0.240999

373.0, 0.240999

$393.0,0.241954$

413.0, 0.241954

$433.0,0.242910$

$453.0,0.244104$

$473.0,0.245059$

$523.0,0.246970$

$573.0,0.250075$

$623.0,0.251986$
$\$$ Conductivity of air gap

$\$ \mathrm{cal} / \mathrm{cm}-\mathrm{s}-\mathrm{K}$

\$ www.eFunda.com
$\$$ Specific heat of air gap

$\$ \mathrm{cal} / \mathrm{g}-\mathrm{K}$

\$ www.eFunda.com 


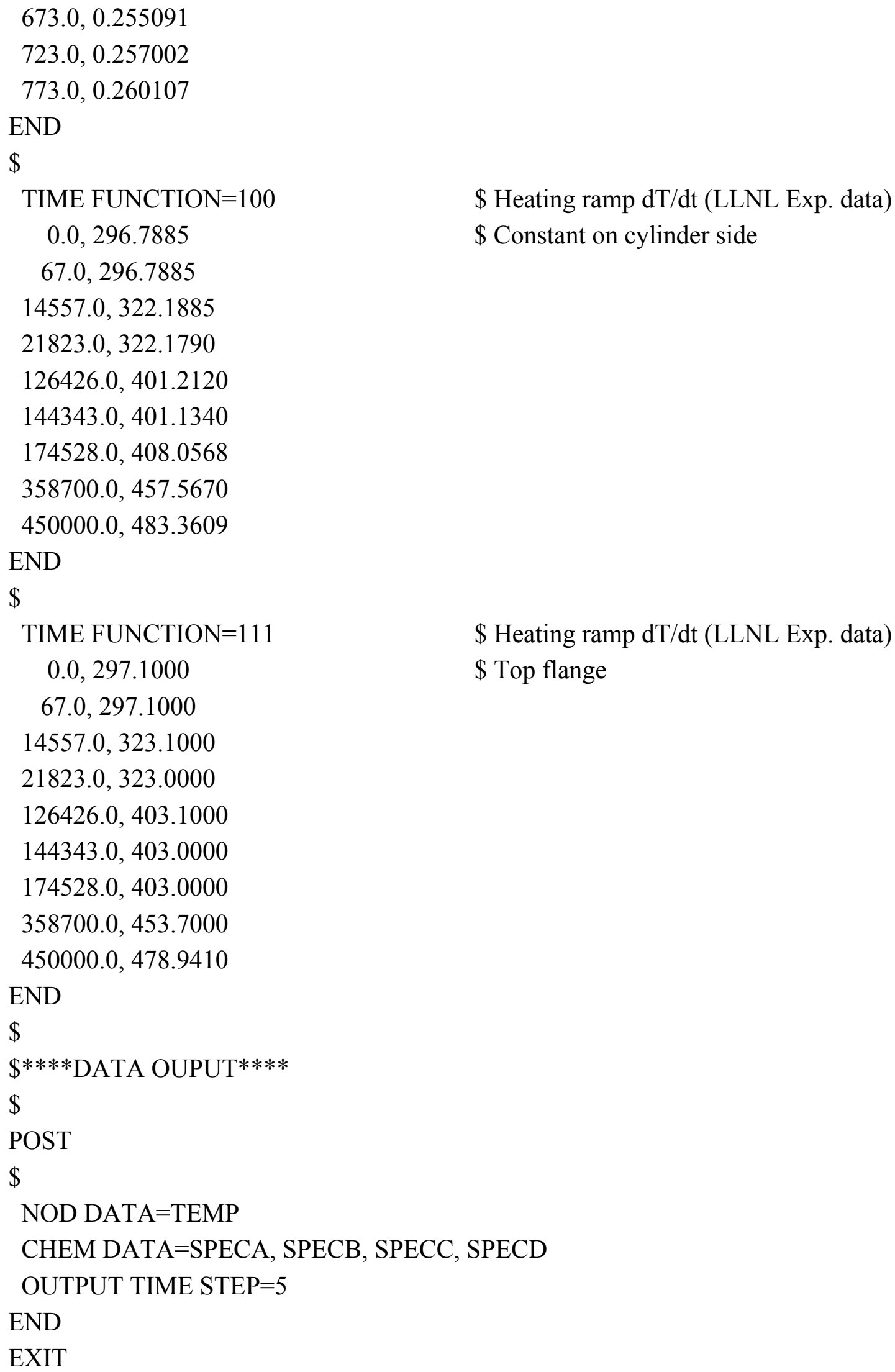

\$ Heating ramp dT/dt (LLNL Exp. data)

\$ Constant on cylinder side

$\$$ Top flange 


\section{A.3. Example of an Input File for the STEX Model Using the Tarver and McGuire Kinetics}

TITLE

STEX with Tarver-McGuire Kinetics

END

$\$$

$\$ * * *$ This is TM1 that has constant average heating on the outer cylinder

$\$$

$\$ * * * *$ MATERIAL DEFINITIONS****

$\$$

MATERIAL, HMX, ISOTROPIC

\$ HMX used for PBX 9501

DENSITY $=1.84$

$\$ \mathrm{~g} / \mathrm{cc}$

$\mathrm{COND}=\mathrm{VFUNC}, 5$

SPECIFIC HEAT=VFUNC, 6

$\$ \mathrm{cal} / \mathrm{cm}-\mathrm{s}-\mathrm{K}$

INIT TEMP $=296.7885$

$\$ \mathrm{cal} / \mathrm{g}-\mathrm{K}$

LAT HEAT $=50.0$

$\$ \mathrm{~K}$

SOL TEMP $=519.0$

$\$ \mathrm{cal} / \mathrm{g}$

LIQ TEMP $=521.0$

$\$ \mathrm{~K}$

$\$ \mathrm{~K}$

PHASE CHANGE

$\$$ delta-HMX to liquid HMX

REACT MIX=4,3,,

SPEC $=$ SPECA, SPECB, SPECC, SPECD

$\$ 4$ species, 3 reactions,

SPEC PHASE, COND, COND, GAS, GAS

$\$$ species in Tarver \& McGuire's Mech.

FRAC COND $=0.0$

INIT CONC $=1,0,0.0 ., 0$.

$\$$ Assumed phase of species

$\$$ Fraction condensed not used

$\$$ Initial conc.

MIN CON,1.E-08,1.E-08,1.E-08,1.E-08

STERIC COEF $=0.0,0.0,0.0$

ACTIVATION ENERGY $=52700,44100,34100$

LPREEX FACT $=48.7,37.5,28.1$

ENERGY REL $=-184.0,+552.0,+2208.0$

CONC EXP, $1=1.0,0.0,0.0$

$\$$ Minimum conc.

$\$$ Steric factors

$\$$ Activation Energies, (7th det. symp., pg 58)

\$ Ln of pre-exponential, (7th det. symp., pg 58)

$\$ \mathrm{cal} / \mathrm{cc}$, heat of react., (7th det. symp., pg 58)

CONC EXP, $2=0.0,1.0,0.0$

$\$ \mathrm{~A}->\mathrm{B} \quad$ A 1100

$\$$ B $->2$ C matrix --> B 0010

CONC EXP, $3=0.0,0.0,2.0$

$\$ 2 \mathrm{C}->\mathrm{D} \quad \mathrm{C} \quad 0 \quad 02$

CONC EXP, $4=0.0,0.0,0.0$

$\$ \quad \mathrm{D} 000$

STOICH COEF, $1=-1.0,+0.0,+0.0$

$\$ \mathrm{dA} / \mathrm{dt}=-\mathrm{r} 1$

STOICH COEF, $2=+1.0,-1.0,+0.0$

$\$ \mathrm{~dB} / \mathrm{dt}=+\mathrm{r} 1-\mathrm{r} 2$ 


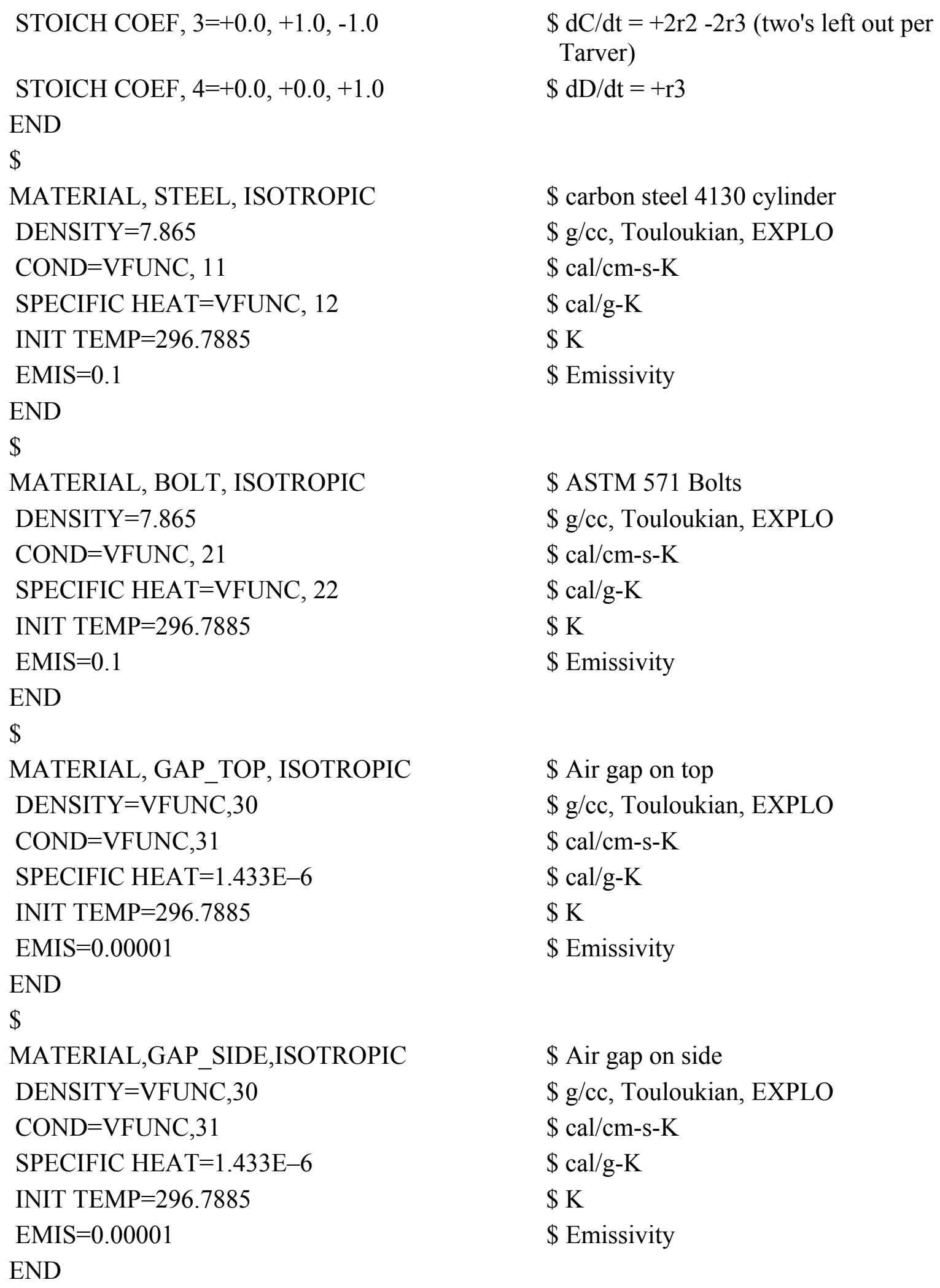

$\$ \mathrm{dC} / \mathrm{dt}=+2 \mathrm{r} 2-2 \mathrm{r} 3$ (two's left out per Tarver)

$\$ \mathrm{dD} / \mathrm{dt}=+\mathrm{r} 3$

\$ carbon steel 4130 cylinder

$\$ \mathrm{~g} / \mathrm{cc}$, Touloukian, EXPLO

$\$ \mathrm{cal} / \mathrm{cm}-\mathrm{s}-\mathrm{K}$

$\$ \mathrm{cal} / \mathrm{g}-\mathrm{K}$

$\$ \mathrm{~K}$

\$ Emissivity

\$ ASTM 571 Bolts

$\$ \mathrm{~g} / \mathrm{cc}$, Touloukian, EXPLO

$\$ \mathrm{cal} / \mathrm{cm}-\mathrm{s}-\mathrm{K}$

$\$ \mathrm{cal} / \mathrm{g}-\mathrm{K}$

$\$ \mathrm{~K}$

\$ Emissivity

\$ Air gap on top

$\$ \mathrm{~g} / \mathrm{cc}$, Touloukian, EXPLO

$\$ \mathrm{cal} / \mathrm{cm}-\mathrm{s}-\mathrm{K}$

$\$ \mathrm{cal} / \mathrm{g}-\mathrm{K}$

$\$ \mathrm{~K}$

\$ Emissivity

\$ Air gap on side
\$ g/cc, Touloukian, EXPLO
\$ cal/cm-s-K
$\$ \mathrm{cal} / \mathrm{g}-\mathrm{K}$
\$ K
\$ Emissivity




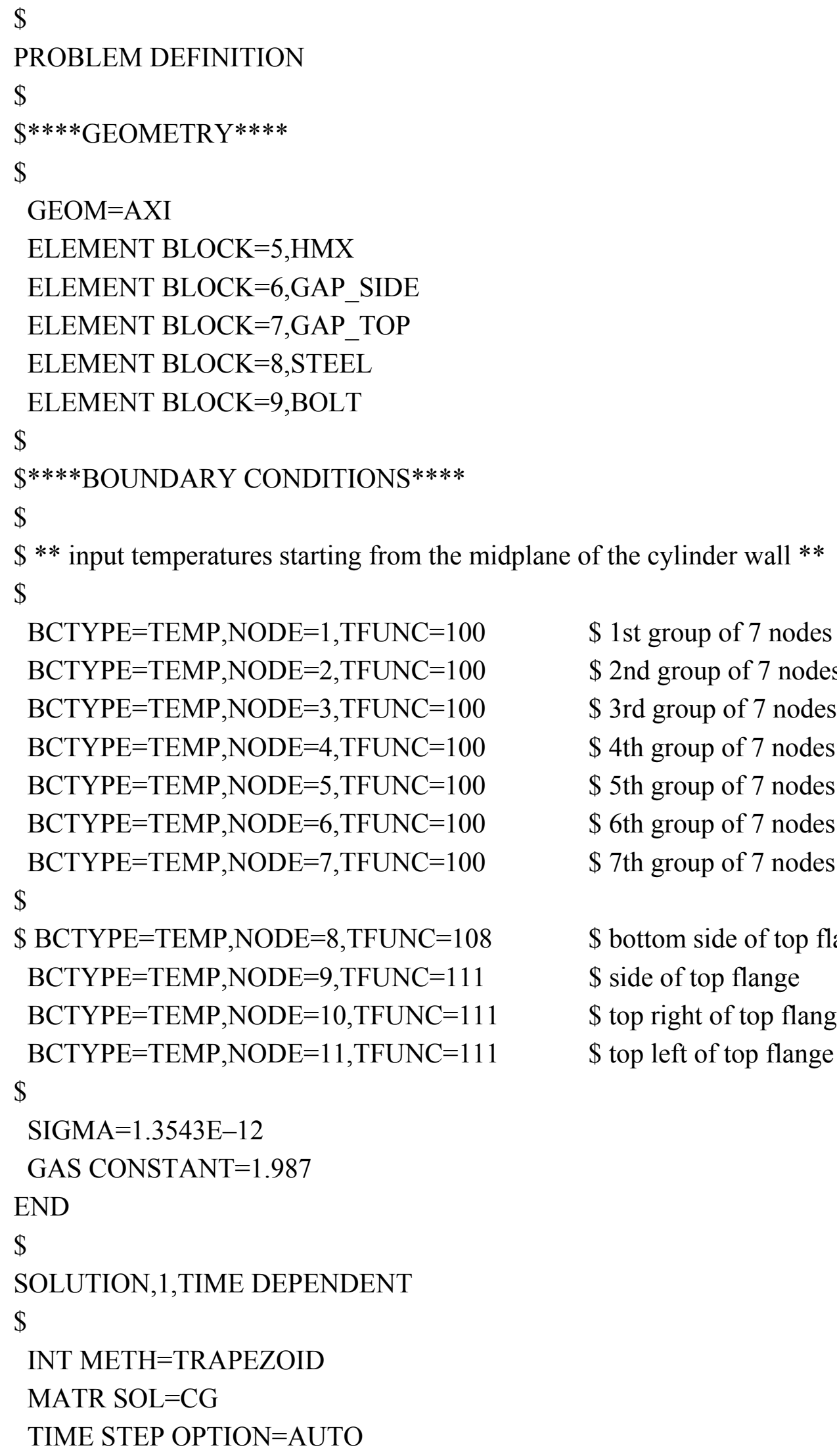




\author{
$\$$ TIME STEP OPTION=FIXED \\ TIME STEP $=0.1$ \\ INIT TIME $=0.0$ \\ FINAL TIME $=500000$ \\ CONV TOL $=1 . E-8$ \\ NUM TIME STEP $=50000$ \\ MAX MATRIX ITER $=10000$ \\ ABS TEMP LIMIT $=700$. \\ END \\ $\$$ \\ $\$ * * *$ FUNCTIONS $* * * *$ \\ $\$$ \\ VAR FUNCTION $=5$ \\ $200.0,1.408800 \mathrm{E}-3$ \\ 293.0, 1.205100E-3 \\ $300.0,1.191035 \mathrm{E}-3$ \\ $350.0,1.095102 \mathrm{E}-3$ \\ $400.0,1.007026 \mathrm{E}-3$ \\ 433.0, 9.52900E-4 \\ $450.0,9.26128 \mathrm{E}-4$ \\ $500.0,8.51826 \mathrm{E}-4$ \\ $550.0,7.83538 \mathrm{E}-4$ \\ $600.0,7.20779 \mathrm{E}-4$ \\ $650.0,6.63161 \mathrm{E}-4$ \\ $700.0,6.10199 \mathrm{E}-4$ \\ $750.0,5.61602 \mathrm{E}-4$ \\ $800.0,5.16885 \mathrm{E}-4$ \\ $850.0,4.75854 \mathrm{E}-4$ \\ 900.0, 4.38121E-4 \\ 950.0, 4.03492E-4 \\ $1000.0,3.82800 \mathrm{E}-4$ \\ $1100.0,3.25513 \mathrm{E}-4$ \\ $1200.0,2.68177 \mathrm{E}-4$ \\ $1300.0,2.28213 \mathrm{E}-4$ \\ 2000.0, 7.79503E-5 \\ END
}

$\$$ Conductivity of HMX, (log interpolation) $\$ \mathrm{cal} / \mathrm{cm}-\mathrm{s}-\mathrm{K}$ 


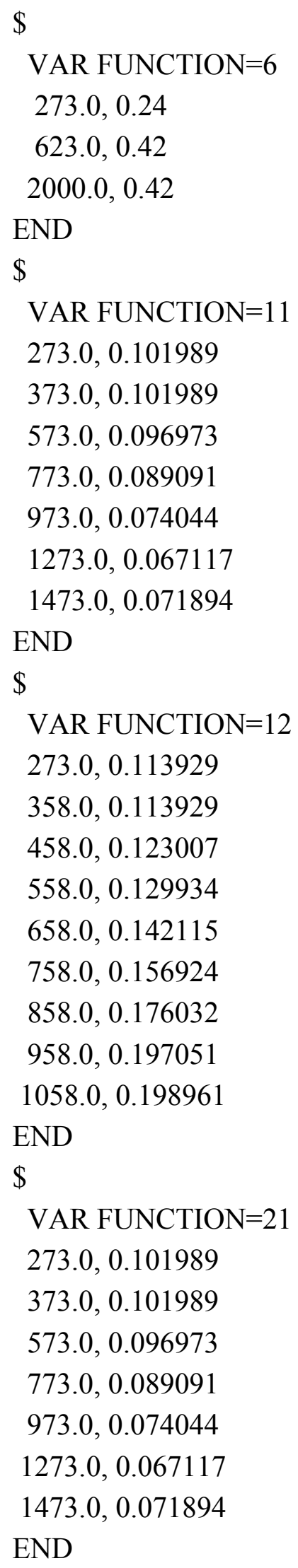

\$ Specific heat of HMX

$\$ \mathrm{cal} / \mathrm{g}-\mathrm{K}$

\$ Conductivity of 4130 steel $\$ \mathrm{cal} / \mathrm{cm}-\mathrm{s}-\mathrm{K}$

\$ www.eFunda.com
\$ Specific heat of 4130 Steel $\$ \mathrm{cal} / \mathrm{g}-\mathrm{K}$

$\$$ www.eFunda.com
\$ Conductivity of $4130 \mathrm{H}$ bolt $\$ \mathrm{cal} / \mathrm{cm}-\mathrm{s}-\mathrm{K}$

\$ www.eFunda.com 
$\$$

VAR FUNCTION $=22$

273.0, 0.113931

358.0, 0.113931

458.0, 0.124918

558.0, 0.129934

658.0, 0.144928

758.0, 0.156924

858.0, 0.176987

958.0, 0.198006

1058.0, 0.199917

END

$\$$

VAR FUNCTION $=30$

273.0, 0.001293

293.0, 0.001205

313.0, 0.001127

333.0, 0.001067

353.0, 0.001000

373.0, 0.000946

393.0, 0.000898

413.0, 0.000854

433.0, 0.000815

453.0, 0.000779

473.0, 0.000746

523.0, 0.000675

573.0, 0.000616

623.0, 0.000566

673.0, 0.000524

723.0, 0.000489

773.0, 0.000460

END

$\$$

VAR FUNCTION $=31$

273.0, 0.000243

393.0, 0.000257

313.0, 0.000271

333.0, 0.000285
$\$$ Specific heat of $4130 \mathrm{H}$ bolt

$\$ \mathrm{cal} / \mathrm{g}-\mathrm{K}$

\$ www.eFunda.com
\$ Density of air gap

$\$ \mathrm{cal} / \mathrm{cm}-\mathrm{s}-\mathrm{K}$

\$ www.eFunda.com
\$ Conductivity of air gap

$\$ \mathrm{cal} / \mathrm{cm}-\mathrm{s}-\mathrm{K}$

\$ www.eFunda.com 


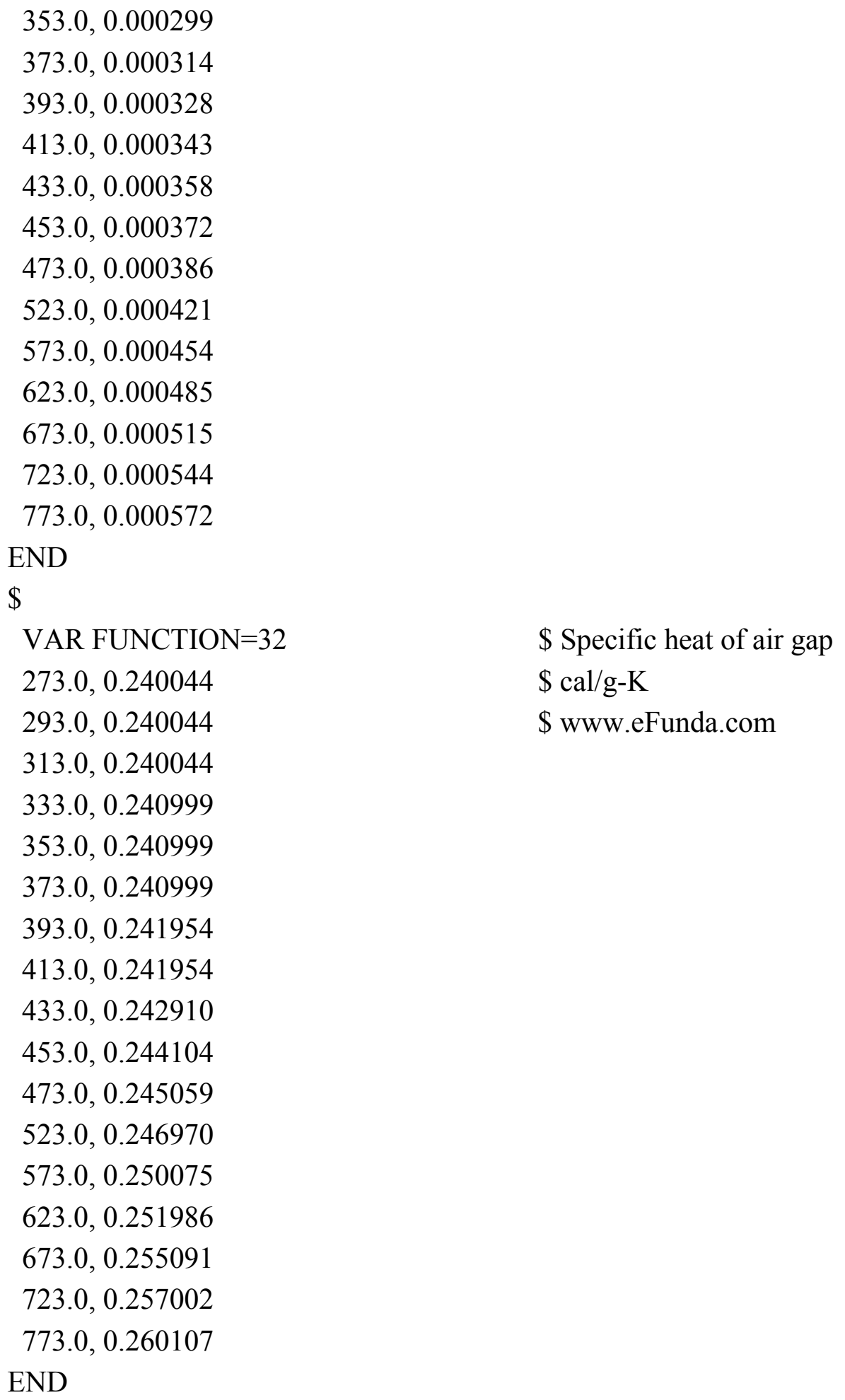

\$ Specific heat of air gap $\$ \mathrm{cal} / \mathrm{g}-\mathrm{K}$

\$ www.eFunda.com 


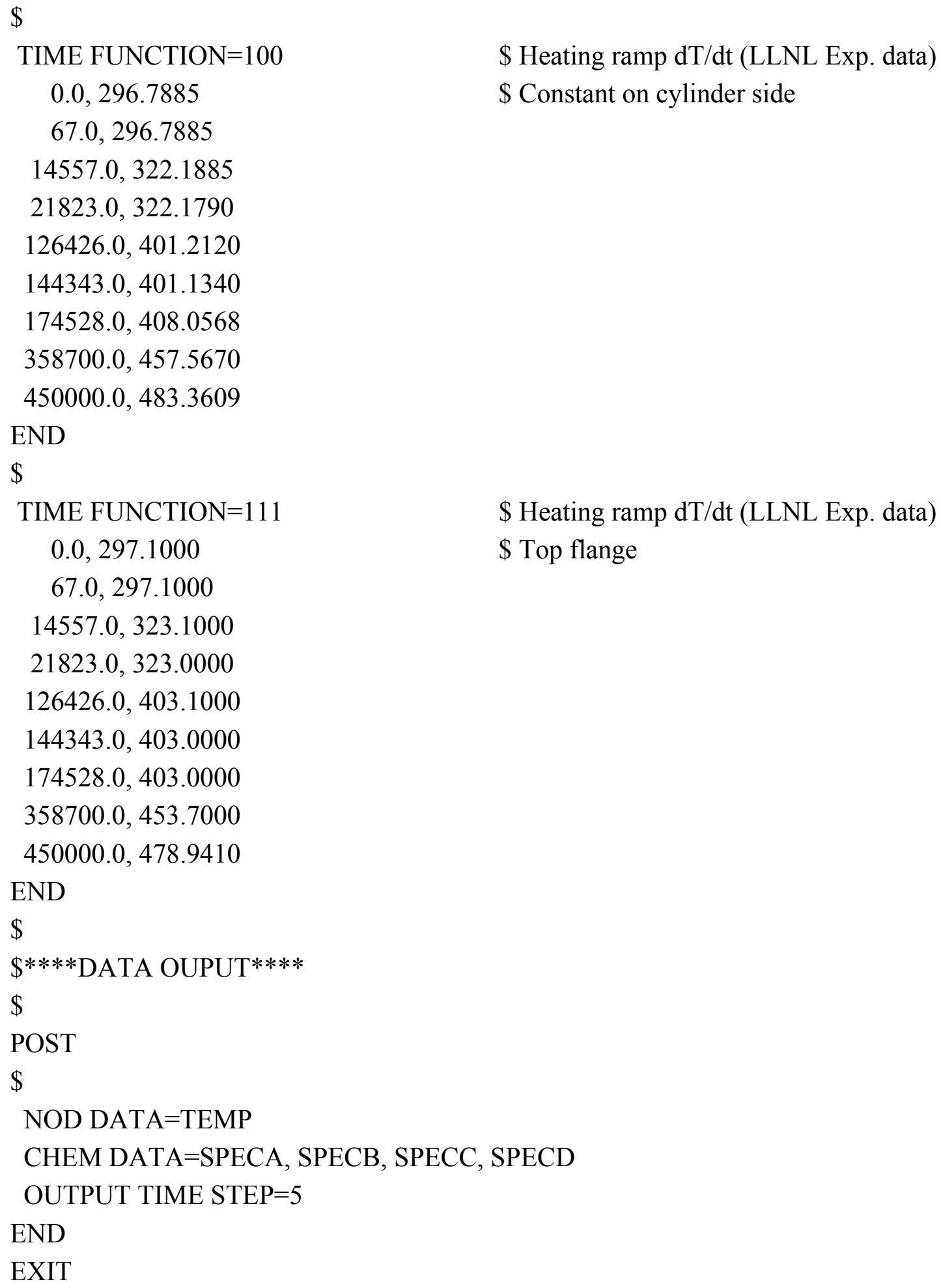

$\$$ Heating ramp dT/dt (LLNL Exp. data)

$\$$ Constant on cylinder side

\$ Heating ramp dT/dt (LLNL Exp. data)

$\$$ Top flange 


\section{A.4. User-Defined Conductivity, USRCON, for the Dickson et al. Kinetics}

C For Coyote4.10 use:

SUBROUTINE USRCON (COND11, COND22, COND33, TEMP, SPEC, XIP, YIP,

* ZIP, NAME, NUMIPT, MXSPEC, NSPEC, M_STAT, TIME,

* $\quad$ KSTEP, RCONST, ICONST)

C For Coyote3 use:

C SUBROUTINE USRCON (COND11, COND22, COND33, TEMP, SPEC, XIP, YIP,

C * ZIP, NAME, NUMIPT, MXSPEC, NSPEC, TIME, KSTEP,

C * RCONST, ICONST)

$\mathrm{C}$

$\mathrm{C} * * * * * * * * * * * * * * * * * * * * * * * * * * * * * * * * * * * * * * * * * * * * * * * * * * * * * * * * * * * * * * * * * * * * * \pi$

$\mathrm{C}$

C Version: \$Id: USRCON.F,v 1.4 1999/08/10 15:09:46 rehogan Exp \$

$\mathrm{C}$

C DESCRIPTION:

C USER SUBROUTINE TO EVALUATE THE CONDUCTIVITY FOR A MATERIAL

C AT THE ELEMENT INTEGRATION POINTS

$\mathrm{C}$

C PARAMETERS:

C COND11 (REAL) - Principal thermal conductivity component in

$\mathrm{C}$ the 11 direction evaluated at the element

C integration points (output)

C COND22 (REAL) - Principal thermal conductivity component in

$\mathrm{C}$ the 22 direction evaluated at the element

C integration points (output)

C COND33 (REAL) - Principal thermal conductivity component in

$\mathrm{C}$ the 33 direction evaluated at the element

C integration points (output)

C TEMP (REAL) - Temperatures at the element integration

$\mathrm{C}$ points (input)

C SPEC (REAL) - Chemical species at the element integration

$\mathrm{C}$ points (input)

C XIP (REAL) - Coordinates for the element integration

C YIP points (input)

C ZIP

C NAME (CHARACTER) - Material name (input) 
C NUMIPT (INTEGER) - Number of element integration points (input)

C MXSPEC (INTEGER) - Maximum number of chemical species (input)

C NSPEC (INTEGER) - Number of chemical species (input)

C M_STAT (INTEGER) - Material temperature status flag (input)

C TIME (REAL) - Current time (input)

C KSTEP (INTEGER) - Current iteration/time step number (input)

C RCONST (REAL) - User constants (input)

C ICONST (INTEGER) - User constants (input)

$\mathrm{C}$

C CALLED BY: ELMKF2, ELMKF3

$\mathrm{C}$

$\mathrm{C}$

$\mathrm{C}$

CHARACTER $* 20$ NAME

DIMENSION COND11(*), COND22(*), COND33(*)

DIMENSION TEMP(*), SPEC(MXSPEC $\left.{ }^{*}\right)$

DIMENSION XIP(*), YIP(*), ZIP(*)

DIMENSION RCONST(*), ICONST $(*)$

$\mathrm{C}$

$\mathrm{C} * * * * * * * * * * * * * * * * * * * * * * * * * * * * * * * * * * * * * * * * * * * * * * * * * * * * * * * * * * * * * * * * * * * *$

$\mathrm{C}$

C USER SUPPLIED FORTRAN CODE TO EVALUATE THE CONDUCTIVITY TENSOR,

C COND11,COND22,COND33

$\mathrm{C}$

C Comment-out the following call when this subroutine is populated

$\mathrm{C}$

C CALL ERROR('USRCON','Attempting to use an empty user subroutine',

$\mathrm{C} * \quad$ ' $, 0,,^{\prime}, 0,,^{\prime}, 0.0,{ }^{\prime},, 0.0$,

$\mathrm{C} * \quad$ 'User failed to provide user subroutine',',', ',1)

$\mathrm{C}$

do $100 \mathrm{n}=1$,numipt

$\operatorname{cond} 11(\mathrm{n})=(\operatorname{spec}(1, \mathrm{n}) *(\operatorname{rconst}(121)+\operatorname{rconst}(122) * \operatorname{temp}(\mathrm{n}))$

$\& \quad+\operatorname{spec}(2, n) *(\operatorname{rconst}(123)+\operatorname{rconst}(124) * \operatorname{temp}(\mathrm{n}))$

$\& \quad+\operatorname{spec}(3, n) *(\operatorname{rconst}(125)+\operatorname{rconst}(126) * \operatorname{temp}(\mathrm{n})))$

if (iconst(10).eq.1) then cond $11(\mathrm{n})=\operatorname{cond} 11(\mathrm{n}) * 1.0 \mathrm{e} 7 / 100$.

elseif (iconst(10).eq.2) then 
cond $11(\mathrm{n})=\operatorname{cond} 11(\mathrm{n})$

elseif (iconst(10).eq.3) then

cond1 $1(\mathrm{n})=\operatorname{cond} 11(\mathrm{n}) / 4.184 / 100$.

else

CALL ERROR('USRCON','set integer user constant \#10 to 1,2, or 3',

* ' ',0,' ',0, ', $, 0.0,,^{\prime}, 0.0$,

* 'to use USRCON', ',', ',1)

endif

$\operatorname{cond} 22(\mathrm{n})=\operatorname{cond} 11(\mathrm{n})$

$\operatorname{cond} 33(\mathrm{n})=\operatorname{cond} 11(\mathrm{n})$

100 continue

$\mathrm{C}$

\section{RETURN}

END 


\section{A.5. User-Defined Specific Heat, USRCP, for the Dickson et al. Kinetics}

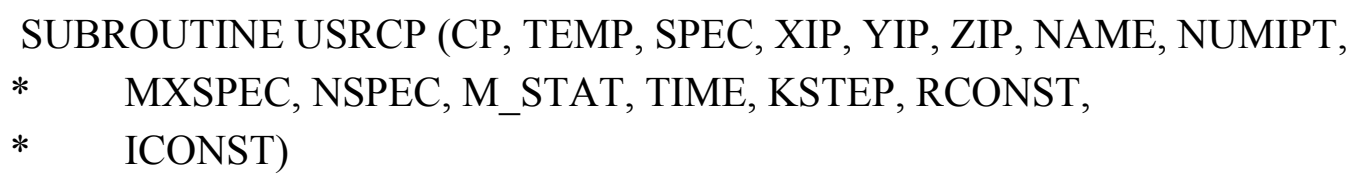

C For Coyote 3 use this

C SUBROUTINE USRCP (CP, TEMP, SPEC, XIP, YIP, ZIP, NAME, NUMIPT,

C * MXSPEC, NSPEC, TIME, KSTEP, RCONST, ICONST)

$\mathrm{C}$

$\mathrm{C} \quad * * * * * * * * * * * * * * * * * * * * * * * * * * * * * * * * * * * * * * * * * * * * * * * * * * * * * * * * * * * * * * * * * *$

$\mathrm{C}$

C Version: \$Id: USRCP.F,v 1.4 1999/08/10 15:09:46 rehogan Exp \$

$\mathrm{C}$

C DESCRIPTION:

C USER SUBROUTINE TO EVALUATE THE SPECIFIC HEAT FOR A MATERIAL

C AT THE ELEMENT INTEGRATION POINTS

$\mathrm{C}$

C PARAMETERS:

C CP (REAL) - Specific heat evaluated at the element

C integration points (output)

C TEMP (REAL) - Temperatures at the element integration

C points (input)

C SPEC (REAL) - Chemical species at the element integration

$\mathrm{C}$ points (input)

C XIP (REAL) - Coordinates for the element integration

C YIP points (input)

C ZIP

C NAME (CHARACTER) - Material name (input)

C NUMIPT (INTEGER) - Number of element integration points (input)

C MXSPEC (INTEGER) - Maximum number of chemical species (input)

C NSPEC (INTEGER) - Number of chemical species (input)

C M_STAT (INTEGER) - Material temperature status flag (input)

C TIME (REAL) - Current time (input)

C KSTEP (INTEGER) - Current iteration/time step number (input)

C RCONST (REAL) - User constants (input)

C ICONST (INTEGER) - User constants (input)

C 


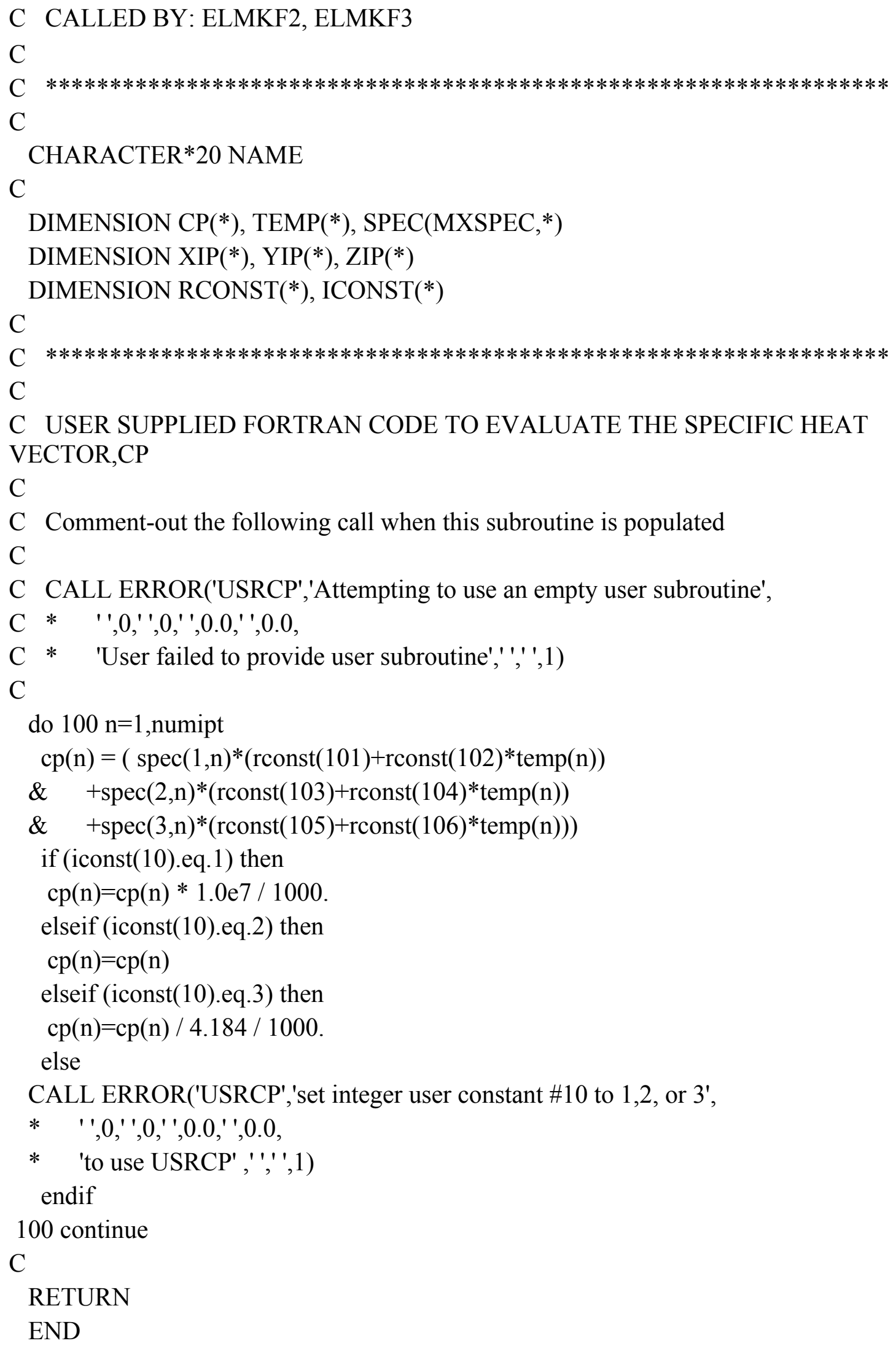




\section{APPENDIX B}

\section{B.1. Thermal Analysis of PBX 9501 and PBX 9407}

\section{Memorandum}

\section{Dynamics Experimentation Division}

To/MS: $\quad$ Pete Pittman, J580

From/MS: $\quad$ Lloyd Davis, C-920

Phone/Fax: $\quad$ 5-3907/Fax 7-0500

Symbol: DX-2:05-096

Date: $\quad$ July 25,2005

Subject: $\quad$ Thermal Analysis of PBX 9501 and PBX 9407

Differential Scanning Calorimetry was performed on PBX 9501 lot HOL-89C-730-010, PBX 9407 lot HOL-79C-565-003, and a 50:50 mixture of these two materials at heating rates of $20,10,5,2,1$, and 0.5 degrees $C$ per minute. A substantial difference in the onset, temperature at maximum heat flux, and temperature of maximum rate acceleration was observed. No indication of chemical incompatibility was expected or observed. Results are summarized below in Table B.1.

Table B.1: Thermal Analysis Results for PBX 9501 and PBX 9407

\begin{tabular}{|c|c|c|c|c|c|c|}
\hline & $20^{\circ} \mathrm{C} / \mathrm{min}$ & $10^{\circ} \mathrm{C} / \mathrm{min}$ & $5^{\circ} \mathrm{C} / \mathrm{min}$ & $2^{\circ} \mathrm{C} / \mathrm{min}$ & $1^{\circ} \mathrm{C} / \mathrm{min}$ & $0.5^{\circ} \mathrm{C} / \mathrm{min}$ \\
\hline PBX 9501 onset & $261.77^{\circ} \mathrm{C}$ & $242.45^{\circ} \mathrm{C}$ & $245.63^{\circ} \mathrm{C}$ & $239.71^{\circ} \mathrm{C}$ & $234.39^{\circ} \mathrm{C}$ & $227.20^{\circ} \mathrm{C}$ \\
\hline PBX 9501 peak & $282.20^{\circ} \mathrm{C}$ & $279.87^{\circ} \mathrm{C}$ & $274.68^{\circ} \mathrm{C}$ & $266.17^{\circ} \mathrm{C}$ & $258.55^{\circ} \mathrm{C}$ & $247.88^{\circ} \mathrm{C}$ \\
\hline PBX 9501 max. slope & $280.37^{\circ} \mathrm{C}$ & $275.92^{\circ} \mathrm{C}$ & $268.86^{\circ} \mathrm{C}$ & $263.42^{\circ} \mathrm{C}$ & $245.92^{\circ} \mathrm{C}$ & $237.29^{\circ} \mathrm{C}$ \\
\hline PBX 9407 onset & $200.84^{\circ} \mathrm{C}$ & $198.35^{\circ} \mathrm{C}$ & $199.00^{\circ} \mathrm{C}$ & $198.27^{\circ} \mathrm{C}$ & $197.54^{\circ} \mathrm{C}$ & $196.53^{\circ} \mathrm{C}$ \\
\hline PBX 9407 peak & $247.77^{\circ} \mathrm{C}$ & $242.26^{\circ} \mathrm{C}$ & $234.63^{\circ} \mathrm{C}$ & $224.85^{\circ} \mathrm{C}$ & $216.19^{\circ} \mathrm{C}$ & $212.90^{\circ} \mathrm{C}$ \\
\hline PBX 9407 max. slope & $223.08^{\circ} \mathrm{C}$ & $215.31^{\circ} \mathrm{C}$ & $210.91^{\circ} \mathrm{C}$ & $198.85^{\circ} \mathrm{C}$ & $197.80^{\circ} \mathrm{C}$ & $197.39^{\circ} \mathrm{C}$ \\
\hline Mixture onset & $225.95^{\circ} \mathrm{C}$ & $202.82^{\circ} \mathrm{C}$ & $193.53^{\circ} \mathrm{C}$ & $186.71^{\circ} \mathrm{C}$ & $189.68^{\circ} \mathrm{C}$ & $189.59^{\circ} \mathrm{C}$ \\
\hline Mixture peak & $277.55^{\circ} \mathrm{C}$ & $272.73^{\circ} \mathrm{C}$ & $263.17^{\circ} \mathrm{C}$ & $244.51^{\circ} \mathrm{C}$ & $231.23^{\circ} \mathrm{C}$ & $221.86^{\circ} \mathrm{C}$ \\
\hline Mixture max. slope & $264.03^{\circ} \mathrm{C}$ & $260.74^{\circ} \mathrm{C}$ & $250.04^{\circ} \mathrm{C}$ & $255.38^{\circ} \mathrm{C}$ & $244.63^{\circ} \mathrm{C}$ & $236.02^{\circ} \mathrm{C}$ \\
\hline
\end{tabular}

Onset temperature is defined as the temperature at which the slope first increases to between 0.01 and $0.011 \mathrm{~W} /\left(\mathrm{g}^{\circ} \mathrm{C}\right)$ in the decomposition of the sample. This value is most relevant to safety considerations. Temperature of maximum slope and peak temperature are dependent on shape of the peak, and as these effects are controlled by chemical kinetics there is some comparative information to be drawn from them, but since sample mass decreases following the onset of decomposition, quantitative use of these values is problematic. 
PBX 9407 decomposition is controlled by a solid-solid phase transition which is superimposed on the melt at higher heating rates. Decomposition follows immediately with melt, and these data show very little dependence of the onset of decomposition on heating rate (only $4^{\circ} \mathrm{C}$ over the range of heating rates studied). PBX 9407 decomposes at substantially lower temperatures than $\mathrm{PBX} 9501 ; 61^{\circ} \mathrm{C}$ lower at a heating rate of $20^{\circ} \mathrm{C} /$ minute, and $31^{\circ} \mathrm{C}$ lower at a heating rate of $0.5^{\circ} \mathrm{C} /$ minute. Close proximity of the temperature of maximum rate to the onset temperature, especially at lower heating rates, indicates that thermal runaway in PBX 9407 will follow immediately after the melt.

PBX 9501 decomposition has been studied extensively by Smilowitz and Henson (C-PCS) and their results are documented in the literature. In these experiments we observe that both the onset of decomposition and the peak temperature varies by $34^{\circ} \mathrm{C}$ over the range of heating rates applied, and the temperature of maximum slope varies by $43^{\circ} \mathrm{C}$ indicating that decomposition is dominated by chemical kinetics.

In decomposition of the mixture of PBX 9501 and PBX 9407 we see the decomposition of each component separately, with a distinct bicameral profile. Onset temperature (except at the fastest heating rates) is slightly depressed relative to pure PBX 9407, while the maximum slope and peak temperatures are dominated by the decomposition of PBX 9501.

When evaluating response of a complex system containing both PBX 9501 and PBX 9407 to thermal stimulus, decomposition of PBX 9407 will be the controlling factor. Within the range of heating rates observed in these experiments, unrestrained decomposition in PBX 9407 will begin near $200^{\circ} \mathrm{C}$ and rapidly involve the PBX 9501 . Failure to consider the effect of this materials presence in a system will overestimate the thermal stability by a substantial margin.

\section{Distribution:}

Pete Pittman

Mike Fletcher

Joe Howard

Armando Vigil 


\section{APPENDIX C}

\section{C.1. STEX Data from the Dickson et al. Kinetics}

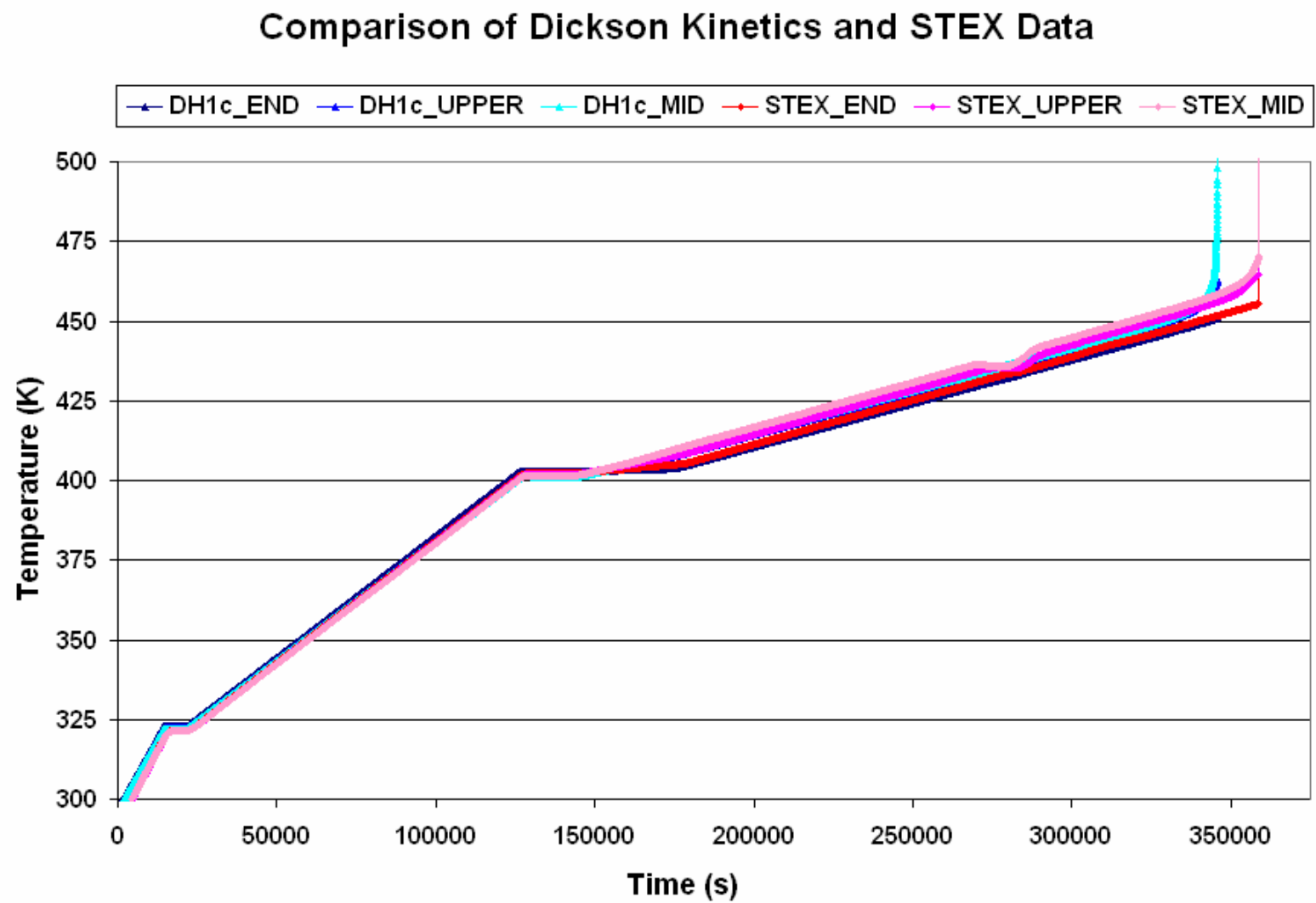

Figure C.1: Comparison between STEX thermocouple data and numerical results from the Dickson et al. kinetics. 


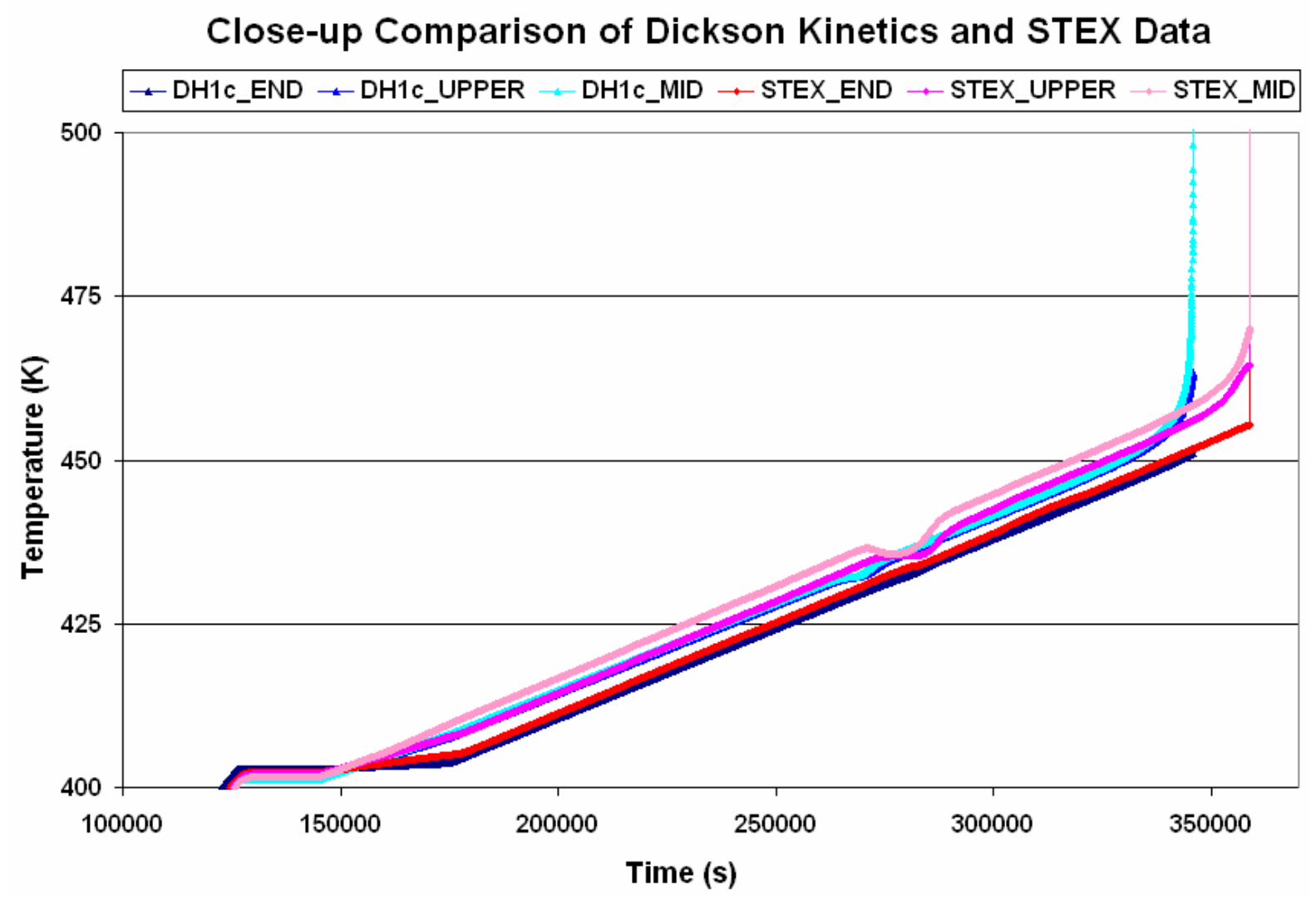

Figure C.2: Close-up comparison of the thermal runaway location for the Dickson et al. kinetics. 


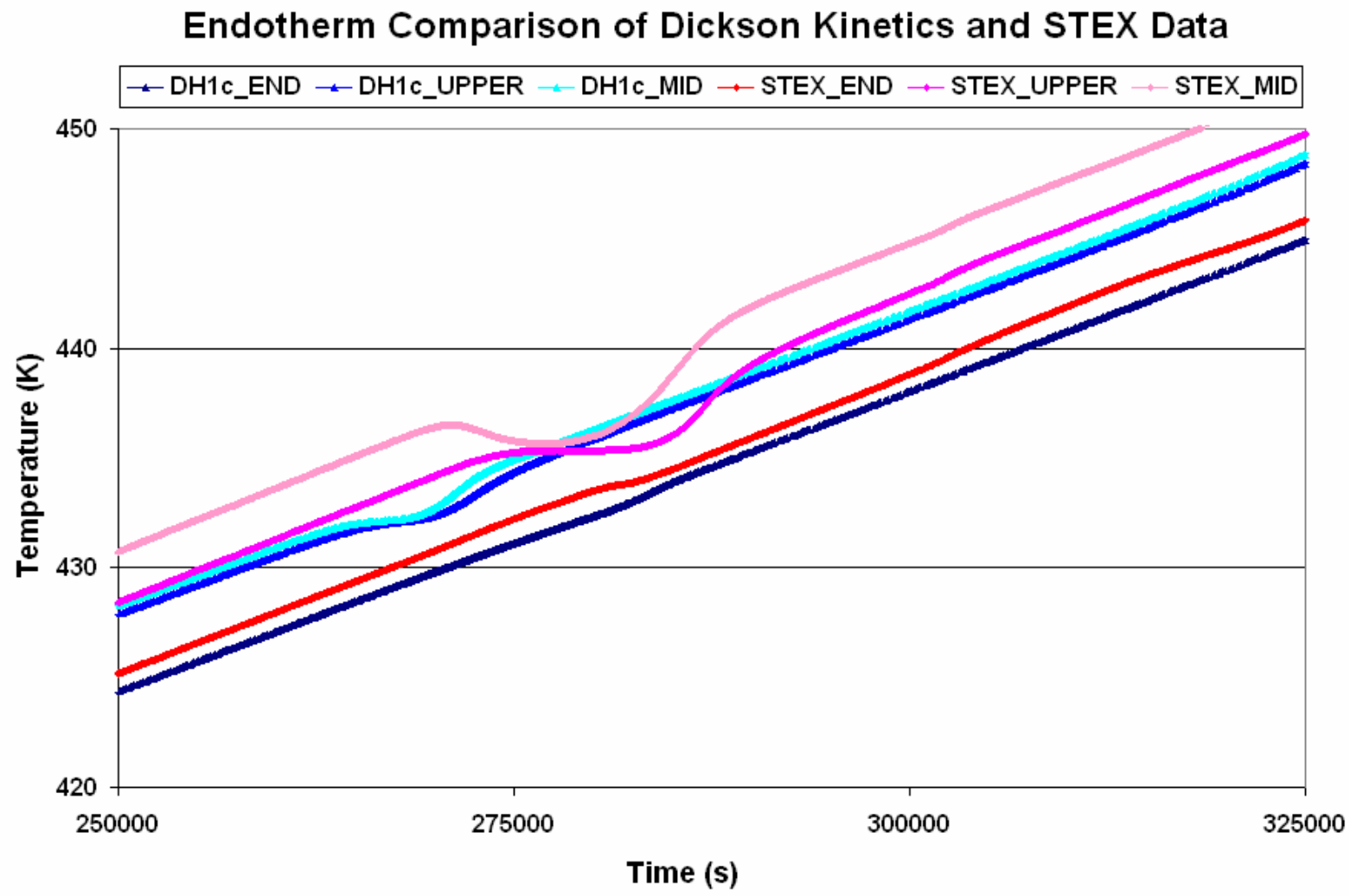

Figure C.3: A comparison of the endothermic phase change seen in the use of the Dickson et al. kinetics. 


\section{C.2. STEX Data from the Jaeger Kinetics}

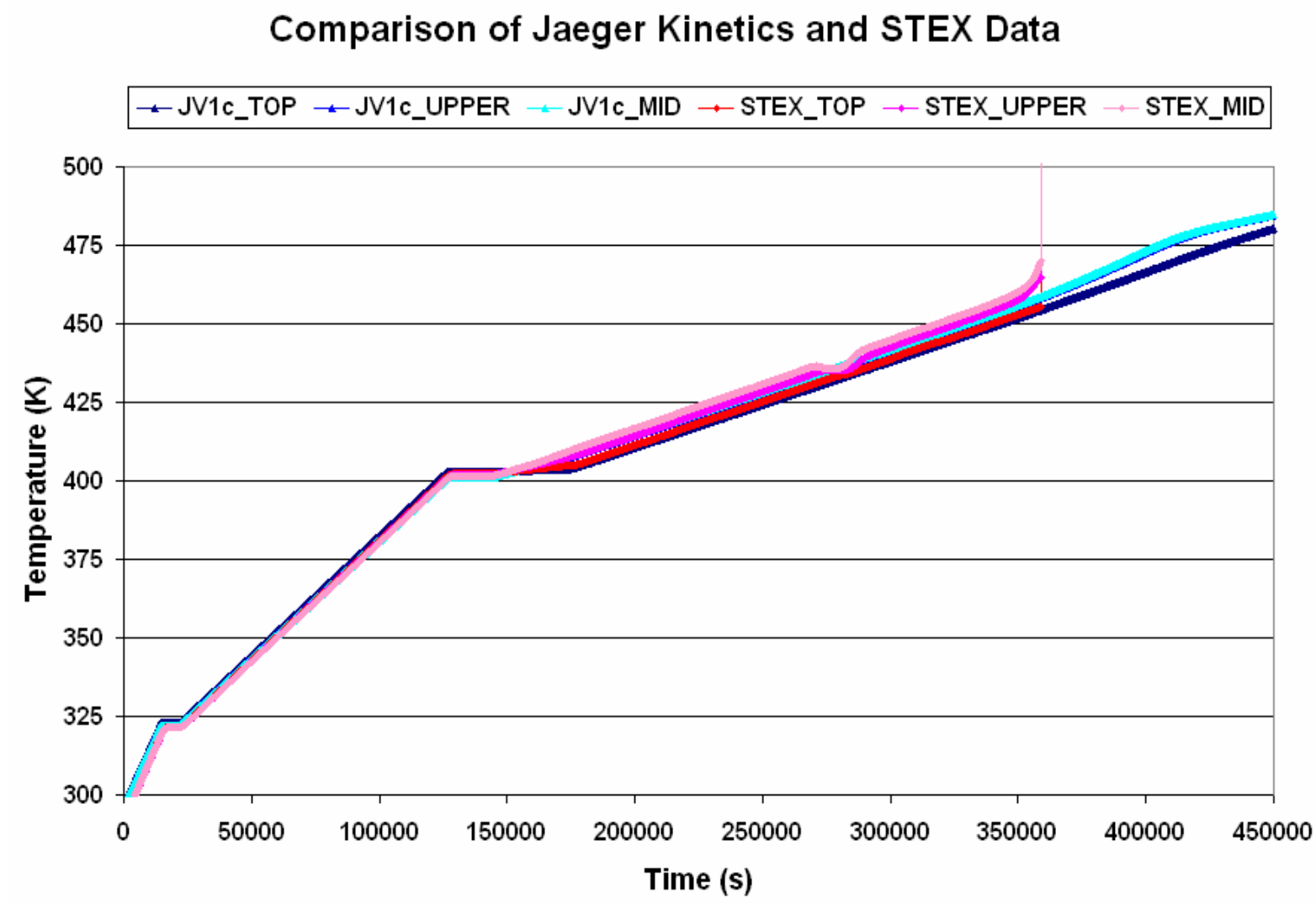

Figure C.4: Comparison between STEX thermocouple data and numerical results from the Jaeger kinetics. 


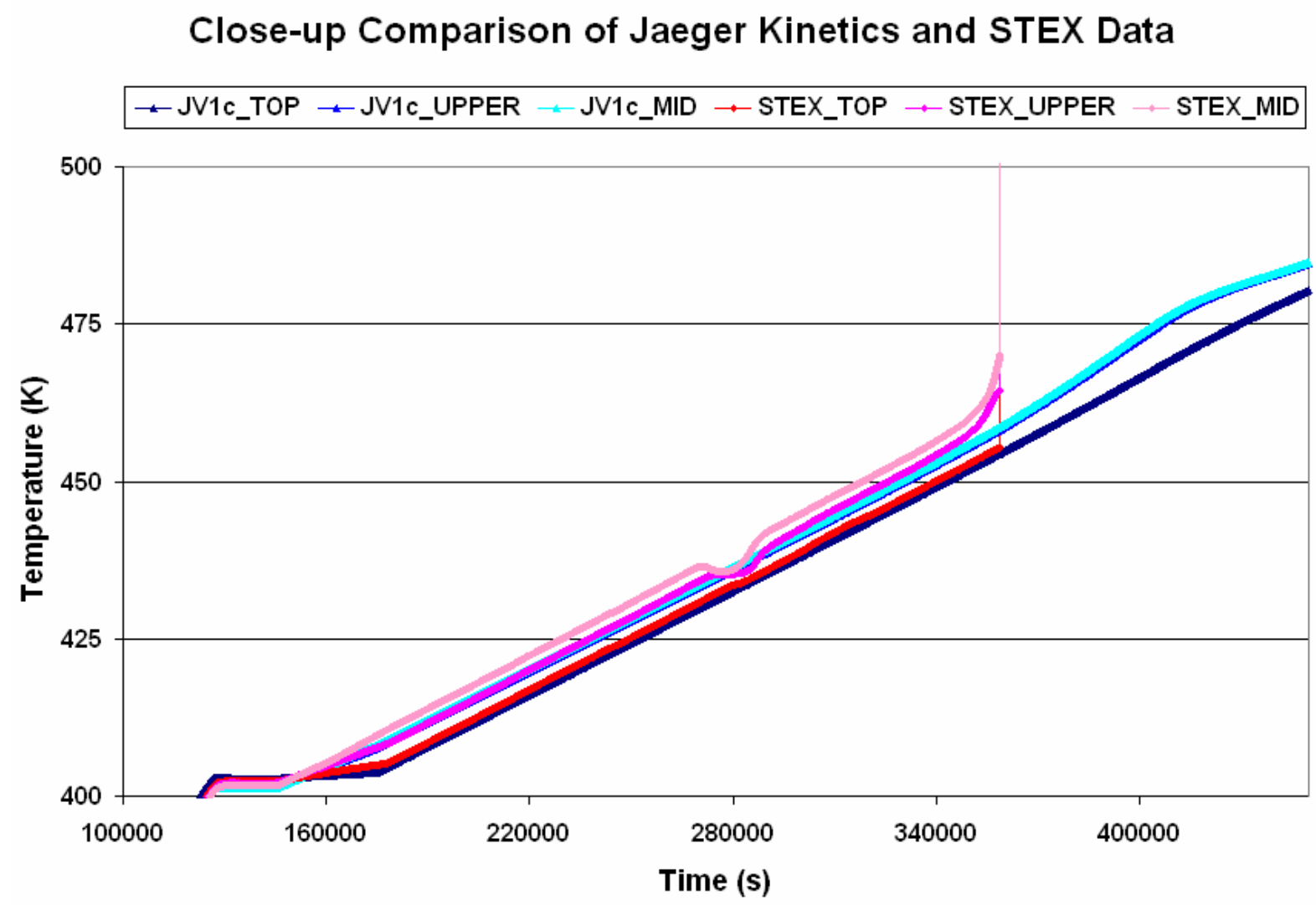

Figure C.5: Close-up comparison of the thermal runaway location for the Jaeger kinetics. 


\section{C.3. STEX Data from the Tarver and McGuire Kinetics}

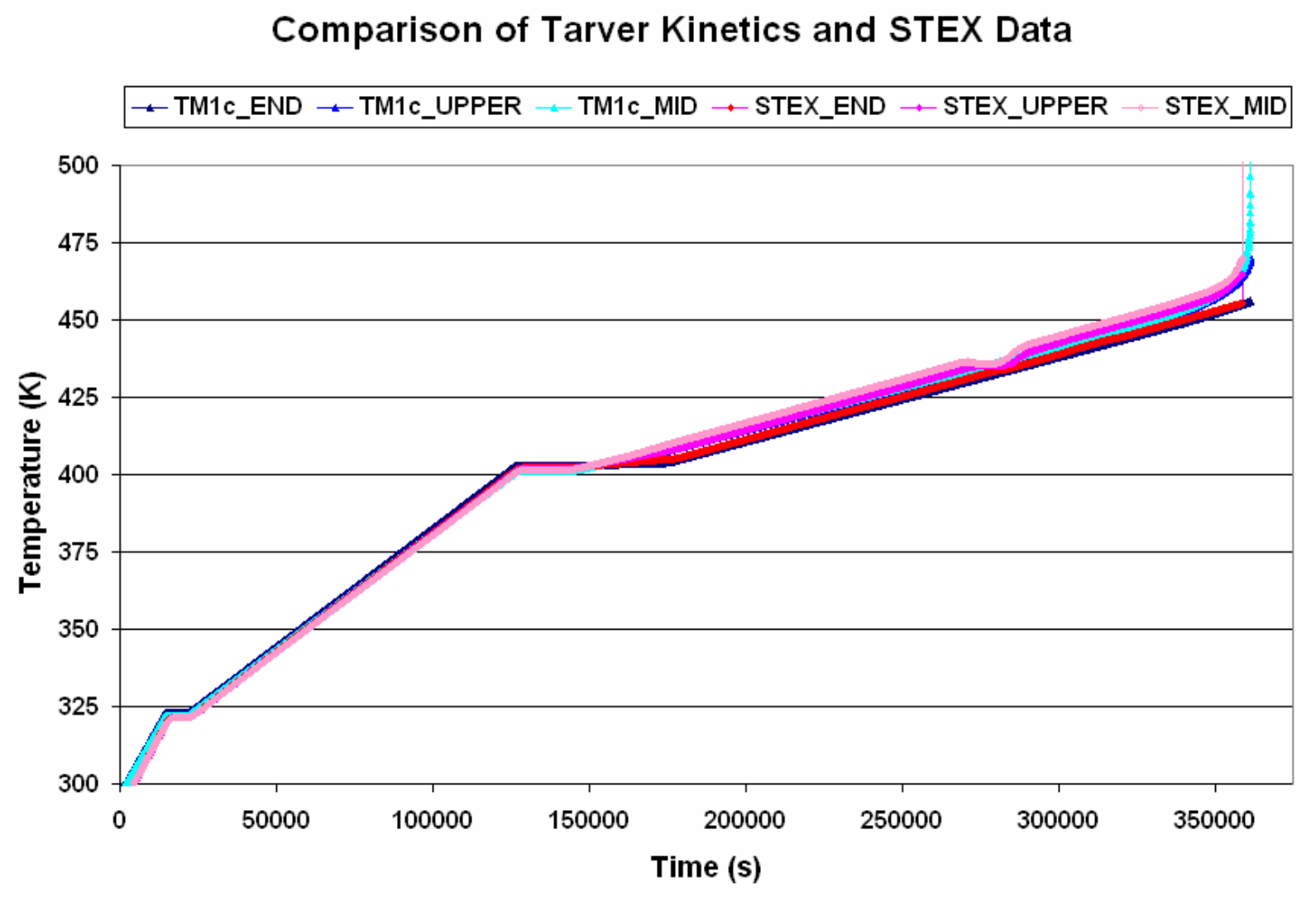

Figure C.6: Comparison between STEX thermocouple data and numerical results from the Tarver kinetics. 


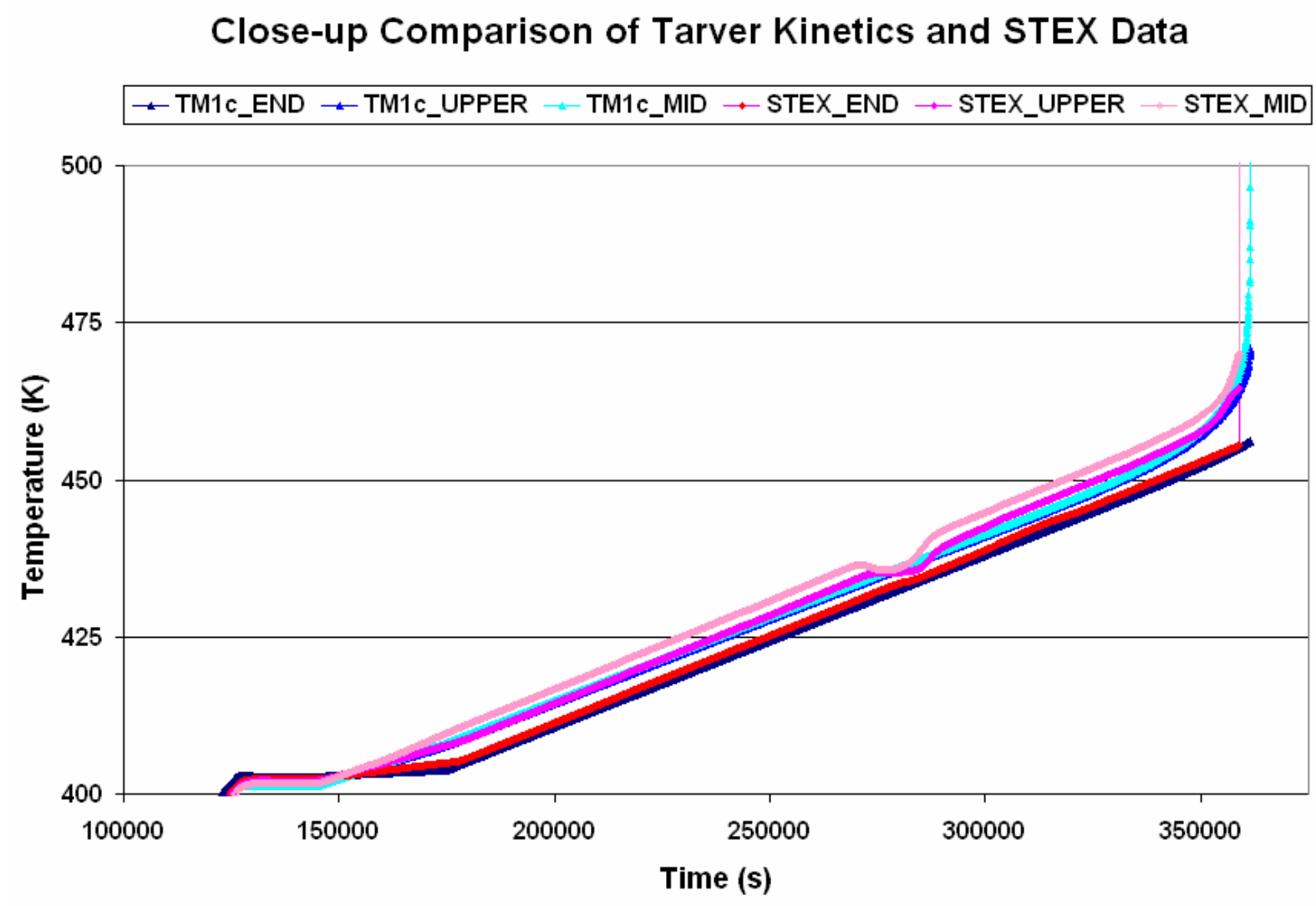

Figure C.7: Close-up comparison of the thermal runaway location for the Tarver kinetics. 



\section{APPENDIX D}

\section{D.1. Results Using the Dickson et al. Kinetics System}

The 16 confined experiments are arranged in ascending order based on the experimental values for ignition time. For the results column, the experimental data are denoted in red, and the numerical results of the FEA analysis are in black. The delta time column is the difference in time between the experimental data and the numerical analysis. The percent error column is a measure of how far the numerical results of the kinetics systems vary from the experimental data.

Table D.1: ODTX results for the 16 confined experiments using Dickson et al. kinetics

\begin{tabular}{|l|c|c|c|}
\hline \multicolumn{3}{|c|}{ Time to Ignition for LLNL ODTX - Confined } \\
\hline \hline & Results & $\boldsymbol{\Delta}$ time & $\%$ Error \\
\hline ODTX 05 Data & 4.80 & & \\
\hline ODTX - TM5 & 6.64 & 1.8 & 38.33 \\
\hline ODTX - TM5a & 6.38 & 1.6 & 32.92 \\
\hline ODTX 16 Data & 6.60 & & \\
\hline ODTX - TM16 & 5.95 & -0.6 & -9.85 \\
\hline ODTX - TM16a & 8.56 & 2.0 & 29.70 \\
\hline ODTX 01 Data & 9.30 & & \\
\hline ODTX - TM01 & 9.34 & 0.0 & 0.43 \\
\hline ODTX - TM01a & 9.41 & 0.1 & 1.18 \\
\hline ODTX 15 Data & 12.60 & & \\
\hline ODTX - TM15 & 10.43 & -2.2 & -17.22 \\
\hline ODTX - TM15a & 9.10 & -3.5 & -27.78 \\
\hline ODTX 06 Data & 18.60 & & \\
\hline ODTX - TM06 & 16.58 & -2.0 & -10.86 \\
\hline
\end{tabular}

D-1 
Table D.1: ODTX results for the 16 confined experiments using Dickson et al. kinetics

\begin{tabular}{|l|c|c|c|}
\hline \multicolumn{3}{|c|}{ Time to Ignition for LLNL ODTX - Confined } \\
\hline \hline & Results & $\boldsymbol{\Delta}$ time & \% Error \\
\hline ODTX - TM06a & 15.55 & -3.1 & -16.40 \\
\hline ODTX 02 Data & 28.50 & & \\
\hline ODTX - TM02 & 31.35 & 2.9 & 10.00 \\
\hline ODTX - TM02a & 26.56 & -1.9 & -6.81 \\
\hline ODTX 14 Data & 47.40 & & \\
\hline ODTX - TM14 & 32.74 & -14.7 & -30.93 \\
\hline ODTX - TM14a & 44.22 & -3.2 & -6.71 \\
\hline ODTX 07 Data & 175.80 & & \\
\hline ODTX - TM07 & 84.11 & -91.7 & -52.16 \\
\hline ODTX - TM07a & 140.99 & -34.8 & -19.80 \\
\hline ODTX 03 Data & 226.20 & & \\
\hline ODTX - TM03 & 40.34 & -185.9 & -82.17 \\
\hline ODTX - TM03a & 123.60 & -102.6 & -45.36 \\
\hline ODTX 12 Data & 249.60 & & \\
\hline ODTX - TM12 & 41.31 & -208.3 & -83.45 \\
\hline ODTX - TM12a & 248.28 & -1.3 & -0.53 \\
\hline ODTX 11 Data & 413.10 & & \\
\hline ODTX - TM11 & 188.45 & -224.7 & -54.38 \\
\hline ODTX - TM11a & 438.90 & 25.8 & 6.25 \\
\hline ODTX 04 Data & 517.80 & & \\
\hline ODTX - TM04 & 218.57 & -299.2 & -57.79 \\
\hline
\end{tabular}

D-2 
Table D.1: ODTX results for the 16 confined experiments using Dickson et al. kinetics

Time to Ignition for LLNL ODTX - Confined

\begin{tabular}{|l|c|c|c|}
\hline \hline & Results & $\Delta$ time & $\%$ Error \\
\hline ODTX - TM04a & 424.31 & -93.5 & -18.06 \\
\hline ODTX 08 Data & 643.50 & & \\
\hline ODTX - TM08 & 610.50 & -33.0 & -5.13 \\
\hline ODTX - TM08a & 643.07 & -0.4 & -0.07 \\
\hline ODTX 10 Data & 1950.60 & & \\
\hline ODTX - TM10 & 54.65 & -1896.0 & -97.20 \\
\hline ODTX - TM10a & 1681.98 & -268.6 & -13.77 \\
\hline ODTX 09 Data & 4351.80 & & \\
\hline ODTX - TM09 & 269.56 & -4082.2 & -93.81 \\
\hline ODTX - TM09a & 4909.66 & 557.9 & 12.82 \\
\hline ODTX 13 Data & 9369.60 & & \\
\hline ODTX - TM13 & N/A & N/A & N/A \\
\hline ODTX - TM13a & N/A & N/A & N/A \\
\hline
\end{tabular}


Table D.2: ODTX results for the 14 unconfined experiments using Dickson et al. kinetics

\begin{tabular}{|l|c|c|c|}
\hline \multicolumn{3}{|c|}{ Time to Ignition for LLNL ODTX - Unconfined } \\
\hline \hline & Results & $\Delta$ time & \% Error \\
\hline ODTX 17 Data & 149.70 & & \\
\hline ODTX - DH17 & 35.57 & -114.1 & -76.24 \\
\hline ODTX - DH17a & 35.68 & -114.0 & -76.17 \\
\hline ODTX 18 Data & 111.00 & & \\
\hline ODTX - DH18 & 18.37 & -92.6 & -83.45 \\
\hline ODTX - DH18a & 17.98 & -93.0 & -83.80 \\
\hline ODTX 19 Data & 208.50 & & \\
\hline ODTX - DH19 & 115.30 & -93.2 & -44.70 \\
\hline ODTX - DH19a & 114.65 & -93.9 & -45.01 \\
\hline ODTX 20 Data & 577.20 & & \\
\hline ODTX - DH20 & 365.05 & -212.2 & -36.76 \\
\hline ODTX - DH20a & 367.55 & -209.7 & -36.32 \\
\hline ODTX 21 Data & 2620.80 & & \\
\hline ODTX - DH21 & 1343.08 & -1277.7 & -48.75 \\
\hline ODTX - DH21a & 1351.86 & -1268.9 & -48.42 \\
\hline ODTX 22 Data & 1061.40 & & \\
\hline ODTX - DH22 & 685.30 & -376.1 & -35.43 \\
\hline ODTX - DH22a & 686.14 & -375.3 & -35.36 \\
\hline ODTX 23 Data & 4990.20 & & \\
\hline ODTX - DH23 & 3546.10 & -1444.1 & -28.94 \\
\hline ODTX - DH23a & 3558.05 & -1432.2 & -28.70 \\
\hline
\end{tabular}


Table D.2: ODTX results for the 14 unconfined experiments using Dickson et al. kinetics

\begin{tabular}{|l|c|c|c|}
\hline \multicolumn{3}{|c|}{ Time to Ignition for LLNL ODTX - Unconfined } \\
\hline \hline & Results & $\boldsymbol{\Delta}$ time & \% Error \\
\hline ODTX 24 Data & 301.20 & & \\
\hline ODTX - DH24 & 220.39 & -80.8 & -26.83 \\
\hline ODTX - DH24a & 220.87 & -80.3 & -26.67 \\
\hline ODTX 25 Data & 176.10 & & \\
\hline ODTX - DH25 & 67.47 & -108.6 & -61.69 \\
\hline ODTX - DH25a & 66.24 & -109.9 & -62.39 \\
\hline ODTX 26 Data & 9950.10 & & \\
\hline ODTX - DH26 & 9968.61 & 18.5 & 0.19 \\
\hline ODTX - DH26a & 9986.06 & 36.0 & 0.36 \\
\hline ODTX 27 Data & 90.90 & & \\
\hline ODTX - DH27 & 25.11 & -65.8 & -72.38 \\
\hline ODTX - DH27a & 24.48 & -66.4 & -73.07 \\
\hline ODTX 28 Data & 99.90 & & \\
\hline ODTX - DH28 & 27.32 & -72.6 & -72.65 \\
\hline ODTX - DH28a & 27.09 & -72.8 & -72.88 \\
\hline ODTX 29 Data & 95.10 & & \\
\hline ODTX - DH29 & 19.71 & -75.4 & -79.27 \\
\hline ODTX - DH29a & 17.95 & -77.2 & -81.13 \\
\hline ODTX 30 Data & 12.90 & & \\
\hline ODTX - DH30 & 9.54 & -3.4 & -26.05 \\
\hline ODTX - DH30a & 9.00 & -3.9 & -30.23 \\
\hline
\end{tabular}


Table D.3: ODTX results for the 10 aged experiments using Dickson et al. kinetics

\begin{tabular}{|c|c|c|c|}
\hline \multicolumn{4}{|c|}{ Time to Ignition for LLNL ODTX - Aged } \\
\hline & Results & $\Delta$ time & $\%$ Error \\
\hline ODTX 31 Data & 294.60 & & \\
\hline ODTX - DH31 & 206.24 & -88.4 & -29.99 \\
\hline ODTX - DH31a & 208.22 & -86.4 & -29.32 \\
\hline ODTX 32 Data & 126.60 & & \\
\hline ODTX - DH32 & 64.06 & -62.5 & -49.40 \\
\hline ODTX - DH32a & 60.45 & -66.2 & -52.25 \\
\hline ODTX 33 Data & 14.10 & & \\
\hline ODTX - DH33 & 17.88 & 3.8 & 26.81 \\
\hline ODTX - DH33a & 19.42 & 5.3 & 37.73 \\
\hline ODTX 34 Data & 824.70 & & \\
\hline ODTX - DH34 & 671.20 & -153.5 & -18.61 \\
\hline ODTX - DH34a & 671.16 & -153.5 & -18.62 \\
\hline ODTX 35 Data & 1885.80 & & \\
\hline ODTX - DH35 & 1391.64 & -494.2 & -26.20 \\
\hline ODTX - DH35a & 1402.79 & -483.0 & -25.61 \\
\hline ODTX 36 Data & 2909.10 & & \\
\hline ODTX - DH36 & 2304.50 & -604.6 & -20.78 \\
\hline ODTX - DH36a & 2316.80 & -592.3 & -20.36 \\
\hline ODTX 37 Data & 3896.10 & & \\
\hline ODTX - DH37 & 3649.96 & -246.1 & -6.32 \\
\hline
\end{tabular}

D-6 
Table D.3: ODTX results for the 10 aged experiments using Dickson et al. kinetics

\begin{tabular}{|l|c|c|c|}
\hline \multicolumn{4}{|c|}{ Time to Ignition for LLNL ODTX - Aged } \\
\hline \hline & Results & $\Delta$ time & \% Error \\
\hline ODTX - DH37a & 3658.19 & -237.9 & -6.11 \\
\hline ODTX 38 Data & 1584.30 & & \\
\hline ODTX - DH38 & 1307.60 & -276.7 & -17.47 \\
\hline ODTX - DH38a & 1312.31 & -272.0 & -17.17 \\
\hline ODTX 39 Data & 21255.60 & & \\
\hline ODTX - DH39 & 40088.60 & 18833.0 & 88.60 \\
\hline ODTX - DH29a & 40126.50 & 18870.9 & 88.78 \\
\hline ODTX 40 Data & 9345.60 & & \\
\hline ODTX - DH40 & 12672.10 & 3326.5 & 35.59 \\
\hline ODTX - DH40a & 12701.50 & 3355.9 & 35.91 \\
\hline
\end{tabular}




\section{D.2. Results Using the Jaeger Kinetics System}

The 16 confined experiments are arranged in ascending order, based on the experimental values for ignition time. The values shown in the tables below follow the same format as defined in section D.1.

Table D.4: ODTX results for the 16 confined experiments using Jaeger kinetics

\begin{tabular}{|c|c|c|c|}
\hline \multicolumn{4}{|c|}{ Time to Ignition for LLNL ODTX - Confined } \\
\hline & Results & $\Delta$ time & $\%$ Error \\
\hline ODTX 05 Data & 4.80 & & \\
\hline ODTX - JV5 & 3.88 & -0.9 & -19.17 \\
\hline ODTX - JV5a & 3.93 & -0.9 & -18.13 \\
\hline ODTX 16 Data & 6.60 & & \\
\hline ODTX - JV16 & 6.55 & 0.0 & -0.76 \\
\hline ODTX - JV16a & 8.70 & 2.1 & 31.82 \\
\hline ODTX 01 Data & 9.30 & & \\
\hline ODTX - JV01 & 30.53 & 21.2 & 228.28 \\
\hline ODTX - JV01a & 30.98 & 21.7 & 233.12 \\
\hline ODTX 15 Data & 12.60 & & \\
\hline ODTX - JV15 & 9.39 & -3.2 & -25.48 \\
\hline ODTX - JV15a & 8.81 & -3.8 & -30.08 \\
\hline ODTX 06 Data & 18.60 & & \\
\hline ODTX - JV06 & 12.08 & -6.5 & -35.05 \\
\hline ODTX - JV06a & 14.68 & -3.9 & -21.08 \\
\hline ODTX 02 Data & 28.50 & & \\
\hline ODTX - JV02 & 25.32 & -3.2 & -11.16 \\
\hline
\end{tabular}

D-8 
Table D.4: ODTX results for the 16 confined experiments using Jaeger kinetics

\begin{tabular}{|l|c|c|c|}
\hline \multicolumn{3}{|c|}{ Time to Ignition for LLNL ODTX - Confined } \\
\hline \hline & Results & $\Delta$ time & \% Error \\
\hline ODTX - DH02a & 25.45 & -3.1 & -10.70 \\
\hline ODTX 14 Data & 47.90 & & \\
\hline ODTX - JV14 & 20.10 & -27.8 & -58.04 \\
\hline ODTX - JV14a & 20.86 & -27.0 & -56.45 \\
\hline ODTX 07 Data & 175.80 & & \\
\hline ODTX - JV07 & 67.28 & -108.5 & -61.73 \\
\hline ODTX - JV07a & 81.94 & -93.9 & -53.39 \\
\hline ODTX 03 Data & 226.20 & & \\
\hline ODTX - JV03 & 67.02 & -159.2 & -70.37 \\
\hline ODTX - JV03a & 85.02 & -141.2 & -62.41 \\
\hline ODTX 12 Data & 249.60 & & \\
\hline ODTX - JV12 & 88.63 & -161.0 & -64.49 \\
\hline ODTX - JV12a & 99.89 & -149.7 & -59.98 \\
\hline ODTX 11 Data & 413.10 & & \\
\hline ODTX - JV11 & 134.22 & -278.9 & -67.51 \\
\hline ODTX - JV11a & 129.01 & -284.1 & -68.77 \\
\hline ODTX 04 Data & 517.80 & & \\
\hline ODTX - JV04 & 128.30 & -389.5 & -75.22 \\
\hline ODTX - JV04a & 132.06 & -385.7 & -74.50 \\
\hline ODTX 08 Data & 643.50 & & \\
\hline ODTX - JV08 & 170.78 & -472.7 & -73.46 \\
\hline
\end{tabular}

D-9 
Table D.4: ODTX results for the 16 confined experiments using Jaeger kinetics

\begin{tabular}{|l|c|c|c|}
\hline \multicolumn{3}{|c|}{ Time to Ignition for LLNL ODTX - Confined } \\
\hline \hline & Results & $\Delta$ time & $\%$ Error \\
\hline ODTX - JV08a & 166.02 & -477.5 & -74.20 \\
\hline ODTX 10 Data & 1950.60 & & \\
\hline ODTX - JV10 & 332.73 & -1617.9 & -82.94 \\
\hline ODTX - JV10a & 320.06 & -1630.5 & -83.59 \\
\hline ODTX 09 Data & 4351.80 & & \\
\hline ODTX - JV09 & N/A & N/A & N/A \\
\hline ODTX - JV09a & N/A & N/A & N/A \\
\hline ODTX 13 Data & 9369.60 & & \\
\hline ODTX - JV13 & N/A & N/A & N/A \\
\hline ODTX - JV13a & N/A & N/A & N/A \\
\hline
\end{tabular}


Table D.5: ODTX results for the 14 unconfined experiments using Jaeger kinetics

\begin{tabular}{|l|c|c|c|}
\hline \multicolumn{3}{|c|}{ Time to Ignition for LLNL ODTX - Unconfined } \\
\hline \hline & Results & $\boldsymbol{\Delta}$ time & $\%$ Error \\
\hline ODTX 17 Data & 149.70 & & \\
\hline ODTX - JV17 & 16.68 & -133.0 & -88.86 \\
\hline ODTX - JV17a & 22.78 & -126.9 & -84.78 \\
\hline ODTX 18 Data & 111.00 & & \\
\hline ODTX - JV18 & 13.87 & -97.1 & -87.50 \\
\hline ODTX - JV18a & 9.01 & -102.0 & -91.88 \\
\hline ODTX 19 Data & 208.50 & & \\
\hline ODTX - JV19 & 52.13 & -156.4 & -75.00 \\
\hline ODTX - JV19a & 73.94 & -134.6 & -64.54 \\
\hline ODTX 20 Data & 577.20 & & \\
\hline ODTX - JV20 & 132.85 & -444.4 & -76.98 \\
\hline ODTX - JV20a & 136.06 & -441.1 & -76.43 \\
\hline ODTX 21 Data & 2620.80 & & \\
\hline ODTX - JV21 & 379.94 & -2240.9 & -85.50 \\
\hline ODTX - JV21a & 349.11 & -2271.7 & -86.68 \\
\hline ODTX 22 Data & 1061.40 & & \\
\hline ODTX - JV22 & 207.38 & -854.0 & -80.46 \\
\hline ODTX - JV22a & 200.30 & -861.1 & -81.13 \\
\hline ODTX 23 Data & 4990.20 & & \\
\hline ODTX - JV23 & $\mathrm{N} / \mathrm{A}$ & $\mathrm{N} / \mathrm{A}$ & $\mathrm{N} / \mathrm{A}$ \\
\hline ODTX - JV23a & $\mathrm{N} / \mathrm{A}$ & $\mathrm{N} / \mathrm{A}$ & $\mathrm{N} / \mathrm{A}$ \\
\hline
\end{tabular}


Table D.5: ODTX results for the 14 unconfined experiments using Jaeger kinetics

\begin{tabular}{|l|c|c|c|}
\hline \multicolumn{3}{|c|}{ Time to Ignition for LLNL ODTX - Unconfined } \\
\hline \hline & Results & $\boldsymbol{\Delta}$ time & \% Error \\
\hline ODTX 24 Data & 301.20 & & \\
\hline ODTX - JV24 & 98.40 & -202.8 & -67.33 \\
\hline ODTX - JV24a & 94.97 & -206.2 & -68.47 \\
\hline ODTX 25 Data & 176.10 & & \\
\hline ODTX - JV25 & 32.45 & -143.7 & -81.57 \\
\hline ODTX - JV25a & 38.91 & -137.2 & -77.90 \\
\hline ODTX 26 Data & 9950.10 & & \\
\hline ODTX - JV26 & N/A & N/A & N/A \\
\hline ODTX - JV26a & N/A & N/A & N/A \\
\hline ODTX 27 Data & 90.90 & & \\
\hline ODTX - JV27 & 11.18 & -79.7 & -87.70 \\
\hline ODTX - JV27a & 12.61 & -78.3 & -86.13 \\
\hline ODTX 28 Data & 99.90 & & \\
\hline ODTX - JV28 & 13.29 & -86.6 & -86.70 \\
\hline ODTX - JV28a & 13.76 & -86.1 & -86.23 \\
\hline ODTX 29 Data & 95.10 & & \\
\hline ODTX - JV29 & 10.09 & -85.0 & -89.39 \\
\hline ODTX - JV29a & 12.39 & -82.7 & -86.97 \\
\hline ODTX 30 Data & 12.90 & & \\
\hline ODTX - JV30 & 5.28 & -7.6 & -59.07 \\
\hline ODTX - JV30a & 4.79 & -8.1 & -62.87 \\
\hline
\end{tabular}


Table D.6: ODTX results for the 10 aged experiments using Jaeger kinetics

\begin{tabular}{|c|c|c|c|}
\hline \multicolumn{4}{|c|}{ Time to Ignition for LLNL ODTX - Aged } \\
\hline & Results & $\Delta$ time & $\%$ Error \\
\hline ODTX 31 Data & 294.60 & & \\
\hline ODTX - JV31 & 95.23 & -199.4 & -67.67 \\
\hline ODTX - JV31a & 104.02 & -190.6 & -64.69 \\
\hline ODTX 32 Data & 126.60 & & \\
\hline ODTX - JV32 & 24.76 & -101.8 & -80.44 \\
\hline ODTX - JV32a & 35.97 & -90.6 & -71.59 \\
\hline ODTX 33 Data & 14.10 & & \\
\hline ODTX - JV33 & 11.26 & -2.8 & -20.14 \\
\hline ODTX - JV33a & 15.06 & 1.0 & 6.81 \\
\hline ODTX 34 Data & 824.70 & & \\
\hline ODTX - JV34 & 202.82 & -621.9 & -75.41 \\
\hline ODTX - JV34a & 202.07 & -622.6 & -75.50 \\
\hline ODTX 35 Data & 1885.80 & & \\
\hline ODTX - JV35 & 382.94 & -1502.9 & -79.69 \\
\hline ODTX - JV35a & 359.09 & -1526.7 & -80.96 \\
\hline ODTX 36 Data & 2909.10 & & \\
\hline ODTX - JV36 & N/A & $\mathrm{N} / \mathrm{A}$ & N/A \\
\hline ODTX - JV36a & N/A & N/A & $\mathrm{N} / \mathrm{A}$ \\
\hline ODTX 37 Data & 3896.10 & & \\
\hline ODTX - JV37 & N/A & $\mathrm{N} / \mathrm{A}$ & $\mathrm{N} / \mathrm{A}$ \\
\hline
\end{tabular}

D-13 
Table D.6: ODTX results for the 10 aged experiments using Jaeger kinetics

\begin{tabular}{|l|c|c|c|}
\hline \multicolumn{4}{|c|}{ Time to Ignition for LLNL ODTX - Aged } \\
\hline \hline & Results & ( time & $\%$ Error \\
\hline ODTX - JV37a & N/A & N/A & N/A \\
\hline ODTX 38 Data & 1584.30 & & \\
\hline ODTX - JV38 & 359.71 & -1224.6 & -77.30 \\
\hline ODTX - JV38a & 335.10 & -1249.2 & -78.85 \\
\hline ODTX 39 Data & 21255.60 & & \\
\hline ODTX - JV39 & N/A & N/A & N/A \\
\hline ODTX - JV29a & N/A & N/A & N/A \\
\hline ODTX 40 Data & 9345.60 & & \\
\hline ODTX - JV40 & N/A & N/A & N/A \\
\hline ODTX - JV40a & N/A & N/A & N/A \\
\hline
\end{tabular}




\section{D.3. Results Using the Tarver \& McGuire Kinetics System}

The 16 confined experiments are arranged in ascending order, based on the experimental values for ignition time. The values shown in the tables below follow the same format as defined in section D.1.

Table D.7: ODTX results for the 16 confined experiments using Tarver \& McGuire kinetics

\begin{tabular}{|l|c|c|c|}
\hline \multicolumn{3}{|c|}{ Time to Ignition for LLNL ODTX - Confined } \\
\hline \hline & Results & $\Delta$ time & $\%$ Error \\
\hline ODTX 05 Data & 4.80 & & \\
\hline ODTX - TM5 & 6.64 & 1.8 & 38.33 \\
\hline ODTX - TM5a & 6.38 & 1.6 & 32.92 \\
\hline ODTX 16 Data & 6.60 & & \\
\hline ODTX - TM16 & 5.95 & -0.6 & -9.85 \\
\hline ODTX - TM16a & 8.56 & 2.0 & 29.70 \\
\hline ODTX 01 Data & 9.30 & & \\
\hline ODTX - TM01 & 9.34 & 0.0 & 0.43 \\
\hline ODTX - TM01a & 9.41 & 0.1 & 1.18 \\
\hline ODTX 15 Data & 12.60 & & \\
\hline ODTX - TM15 & 10.43 & -2.2 & -17.22 \\
\hline ODTX - TM15a & 9.10 & -3.5 & -27.78 \\
\hline ODTX 06 Data & 18.60 & & \\
\hline ODTX - TM06 & 16.58 & -2.0 & -10.86 \\
\hline ODTX - TM06a & 15.55 & -3.1 & -16.40 \\
\hline ODTX 02 Data & 28.50 & & \\
\hline ODTX - TM02 & 31.35 & 2.9 & 10.00 \\
\hline
\end{tabular}

D-15 
Table D.7: ODTX results for the 16 confined experiments using Tarver \& McGuire kinetics

\begin{tabular}{|l|c|c|c|}
\hline \multicolumn{3}{|c|}{ Time to Ignition for LLNL ODTX - Confined } \\
\hline \hline & Results & $\Delta$ time & $\%$ Error \\
\hline ODTX - TM02a & 26.56 & -1.9 & -6.81 \\
\hline ODTX 14 Data & 47.40 & & \\
\hline ODTX - TM14 & 32.74 & -14.7 & -30.93 \\
\hline ODTX - TM14a & 44.22 & -3.2 & -6.71 \\
\hline ODTX 07 Data & 175.80 & & \\
\hline ODTX - TM07 & 84.11 & -91.7 & -52.16 \\
\hline ODTX - TM07a & 140.99 & -34.8 & -19.80 \\
\hline ODTX 03 Data & 226.20 & & \\
\hline ODTX - TM03 & 40.34 & -185.9 & -82.17 \\
\hline ODTX - TM03a & 123.60 & -102.6 & -45.36 \\
\hline ODTX 12 Data & 249.60 & & \\
\hline ODTX - TM12 & 41.31 & -208.3 & -83.45 \\
\hline ODTX - TM12a & 248.28 & -1.3 & -0.53 \\
\hline ODTX 11 Data & 413.10 & & \\
\hline ODTX - TM11 & 188.45 & -224.7 & -54.38 \\
\hline ODTX - TM11a & 438.90 & 25.8 & 6.25 \\
\hline ODTX 04 Data & 517.80 & & \\
\hline ODTX - TM04 & 218.57 & -299.2 & -57.79 \\
\hline ODTX - TM04a & 424.31 & -93.5 & -18.06 \\
\hline ODTX 08 Data & 643.50 & & \\
\hline ODTX - TM08 & 610.50 & -33.0 & -5.13 \\
\hline
\end{tabular}

D-16 
Table D.7: ODTX results for the 16 confined experiments using Tarver \& McGuire kinetics

\begin{tabular}{|l|c|c|c|}
\hline \multicolumn{4}{|c|}{ Time to Ignition for LLNL ODTX - Confined } \\
\hline \hline & Results & $\Delta$ time & $\%$ Error \\
\hline ODTX - TM08a & 643.07 & -0.4 & -0.07 \\
\hline ODTX 10 Data & 1950.60 & & \\
\hline ODTX - TM10 & 54.65 & -1896.0 & -97.20 \\
\hline ODTX - TM10a & 1681.98 & -268.6 & -13.77 \\
\hline ODTX 09 Data & 4351.80 & & \\
\hline ODTX - TM09 & 269.56 & -4082.2 & -93.81 \\
\hline ODTX - TM09a & 4909.66 & 557.9 & 12.82 \\
\hline ODTX 13 Data & 9369.60 & & \\
\hline ODTX - TM13 & N/A & N/A & N/A \\
\hline ODTX - TM13a & N/A & N/A & N/A \\
\hline
\end{tabular}


Table D.8: ODTX results for the 14 unconfined experiments using Tarver \& McGuire kinetics

\begin{tabular}{|l|c|c|c|}
\hline \multicolumn{3}{|c|}{ Time to Ignition for LLNL ODTX - Unconfined } \\
\hline \hline & Results & $\Delta$ time & $\%$ Error \\
\hline ODTX 17 Data & 149.70 & & \\
\hline ODTX - TM17 & 13.33 & -136.4 & -91.10 \\
\hline ODTX - TM17a & 38.80 & -110.9 & -74.08 \\
\hline ODTX 18 Data & 111.00 & & \\
\hline ODTX - TM18 & 10.20 & -100.8 & -90.81 \\
\hline ODTX - TM18a & 12.64 & -98.4 & -88.61 \\
\hline ODTX 19 Data & 208.50 & & \\
\hline ODTX - TM19 & 47.82 & -160.7 & -77.06 \\
\hline ODTX - TM19a & 125.70 & -82.8 & -39.71 \\
\hline ODTX 20 Data & 577.20 & & \\
\hline ODTX - TM20 & 405.21 & -172.0 & -29.80 \\
\hline ODTX - TM20a & 430.63 & -146.6 & -25.39 \\
\hline ODTX 21 Data & 2620.80 & & \\
\hline ODTX - TM21 & 186.08 & -2434.7 & -92.90 \\
\hline ODTX - TM21a & 1739.70 & -881.1 & -33.62 \\
\hline ODTX 22 Data & 1061.40 & & \\
\hline ODTX - TM22 & 877.80 & -183.6 & -17.30 \\
\hline ODTX - TM22a & 885.83 & -175.6 & -16.54 \\
\hline ODTX 23 Data & 4990.20 & & \\
\hline ODTX - TM23 & 502.43 & -4487.8 & -89.93 \\
\hline ODTX - TM23a & 5051.25 & 61.1 & 1.22 \\
\hline
\end{tabular}


Table D.8: ODTX results for the 14 unconfined experiments using Tarver $\&$ McGuire kinetics

\begin{tabular}{|l|c|c|c|}
\hline \multicolumn{4}{|c|}{ Time to Ignition for LLNL ODTX - Unconfined } \\
\hline \hline & Results & $\boldsymbol{\Delta}$ time & $\%$ Error \\
\hline ODTX 24 Data & 301.20 & & \\
\hline ODTX - TM24 & 241.29 & -59.9 & -19.89 \\
\hline ODTX - TM24a & 277.95 & -23.3 & -7.72 \\
\hline ODTX 25 Data & 176.10 & & \\
\hline ODTX - TM25 & 29.97 & -146.1 & -82.98 \\
\hline ODTX - TM25a & 32.18 & -143.9 & -81.73 \\
\hline ODTX 26 Data & 9950.10 & & \\
\hline ODTX - TM26 & N/A & N/A & N/A \\
\hline ODTX - TM26a & N/A & N/A & N/A \\
\hline ODTX 27 Data & 90.90 & & \\
\hline ODTX - TM27 & 16.68 & -74.2 & -81.65 \\
\hline ODTX - TM27a & 22.50 & -68.4 & -75.25 \\
\hline ODTX 28 Data & 99.90 & & \\
\hline ODTX - TM28 & 9.51 & -90.4 & -90.48 \\
\hline ODTX - TM28a & 21.75 & -78.2 & -78.23 \\
\hline ODTX 29 Data & 95.10 & & \\
\hline ODTX - TM29 & 9.51 & -85.6 & -90.00 \\
\hline ODTX - TM29a & 12.45 & -82.7 & -86.91 \\
\hline ODTX 30 Data & 12.90 & & \\
\hline ODTX - TM30 & 6.38 & -6.5 & -50.54 \\
\hline ODTX - TM30a & 5.99 & -6.9 & -53.57 \\
\hline
\end{tabular}


Table D.9: ODTX results for the 10 aged experiments using Tarver \& McGuire kinetics

\begin{tabular}{|c|c|c|c|}
\hline \multicolumn{4}{|c|}{ Time to Ignition for LLNL ODTX - Aged } \\
\hline \hline & Results & $\boldsymbol{\Delta}$ time & \% Error \\
\hline ODTX 31 Data & 294.60 & & \\
\hline ODTX - TM31 & 195.59 & -99.0 & -33.61 \\
\hline ODTX - TM31a & 245.58 & -49.0 & -16.64 \\
\hline ODTX 32 Data & 126.60 & & \\
\hline ODTX - TM32 & 47.25 & -79.4 & -62.68 \\
\hline ODTX - TM32a & 52.67 & -73.9 & -58.40 \\
\hline ODTX 33 Data & 14.10 & & \\
\hline ODTX - TM33 & 11.19 & -2.9 & -20.64 \\
\hline ODTX - TM33a & 13.21 & -0.9 & -6.31 \\
\hline ODTX 34 Data & 824.70 & & \\
\hline ODTX - TM34 & 804.79 & -19.9 & -2.41 \\
\hline ODTX - TM34a & 858.88 & 34.2 & 4.14 \\
\hline ODTX 35 Data & 1885.80 & & \\
\hline ODTX - TM35 & 55.06 & -1830.7 & -97.08 \\
\hline ODTX - TM35a & 1817.35 & -68.5 & -3.63 \\
\hline ODTX 36 Data & 2909.10 & & \\
\hline ODTX - TM36 & 2880.15 & -28.9 & -1.00 \\
\hline ODTX - TM36a & 3033.25 & 124.2 & 4.27 \\
\hline ODTX 37 Data & 3896.10 & & \\
\hline ODTX - TM37 & 5180.52 & 1284.4 & 32.97 \\
\hline ODTX - TM37a & 5213.52 & 1317.4 & 33.81 \\
\hline
\end{tabular}

D-20 
Table D.9: ODTX results for the 10 aged experiments using Tarver \& McGuire kinetics

\begin{tabular}{|c|c|c|c|}
\hline \multicolumn{4}{|c|}{ Time to Ignition for LLNL ODTX - Aged } \\
\hline \hline & Results & $\Delta$ time & \% Error \\
\hline ODTX 38 Data & 1584.30 & & \\
\hline ODTX - TM38 & 533.04 & -1051.3 & -66.35 \\
\hline ODTX - TM38a & 1706.25 & 122.0 & 7.70 \\
\hline ODTX 39 Data & 21255.60 & & \\
\hline ODTX - TM39 & N/A & N/A & N/A \\
\hline ODTX - TM29a & N/A & N/A & N/A \\
\hline ODTX 40 Data & 9345.60 & & \\
\hline ODTX - TM40 & N/A & N/A & N/A \\
\hline ODTX - TM40a & N/A & N/A & N/A \\
\hline
\end{tabular}





\section{APPENDIX E}

\section{E.1. Unconfined Sphere Data Using the Dickson et al. Kinetics}

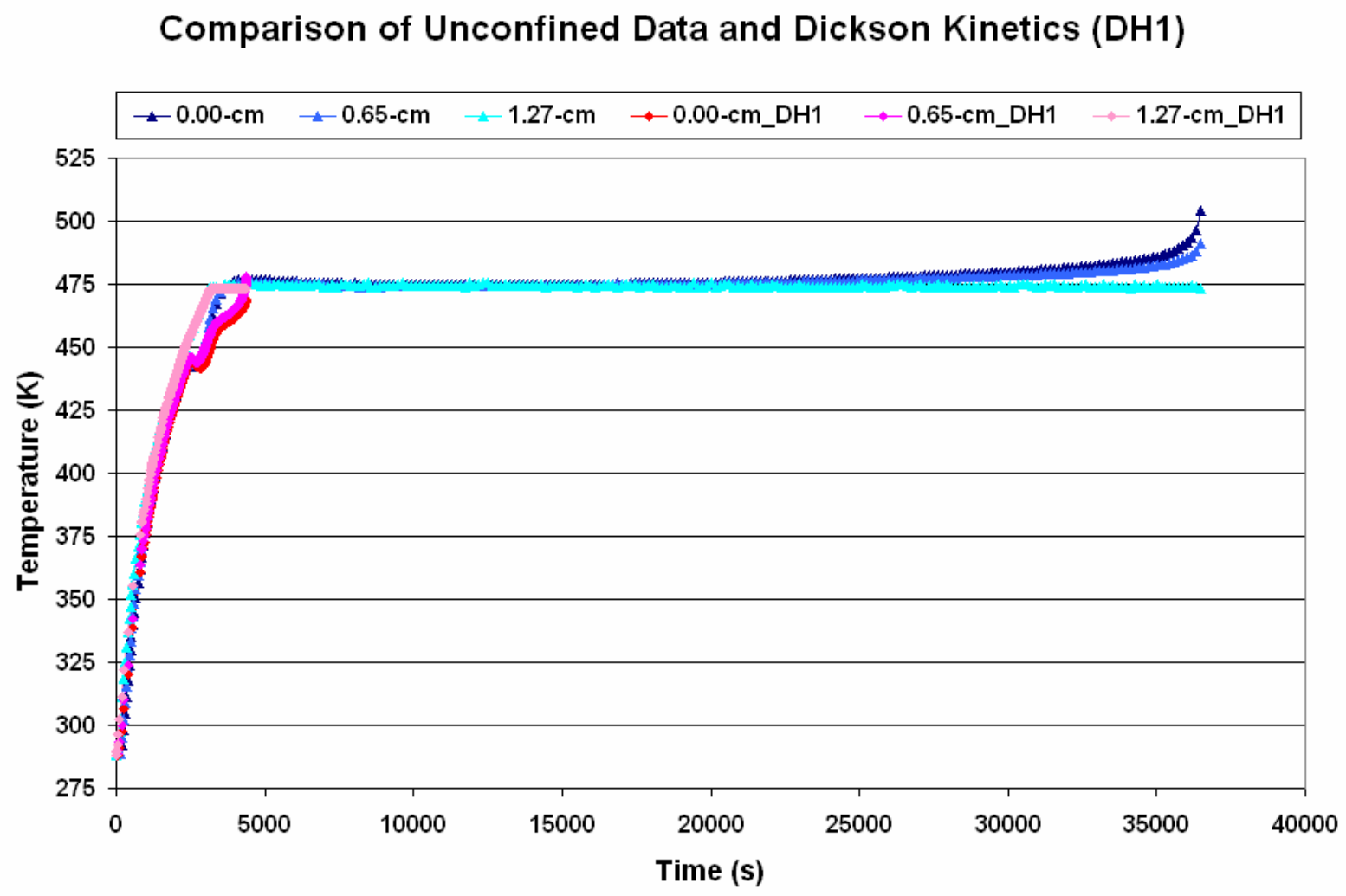

Figure E.1: Comparison of the thermocouple data and the numerical results of the Dickson et al. kinetics for Experiment 1.

The Dickson et al. kinetics could not solve for the conditions present in Experiment 2. An error of quadrature for $\mathrm{CV}$ failed to converge was reported. The reason given for this failure is due to an inability for the kinetics solver to resolve a value for the internal energy in a particular element. 


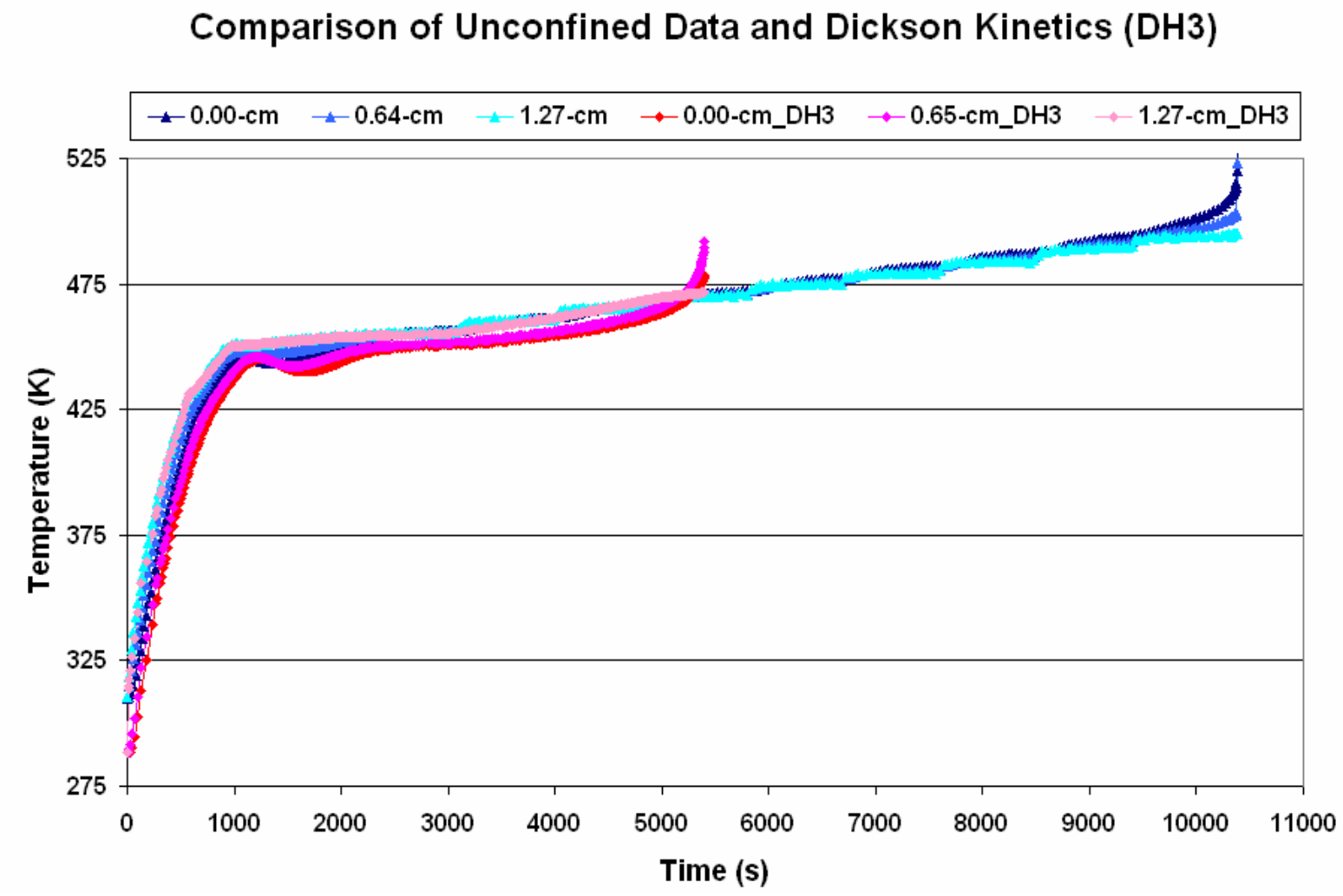

Figure E.2: Comparison of the thermocouple data and the numerical results of the Dickson et al. kinetics for Experiment 3. 


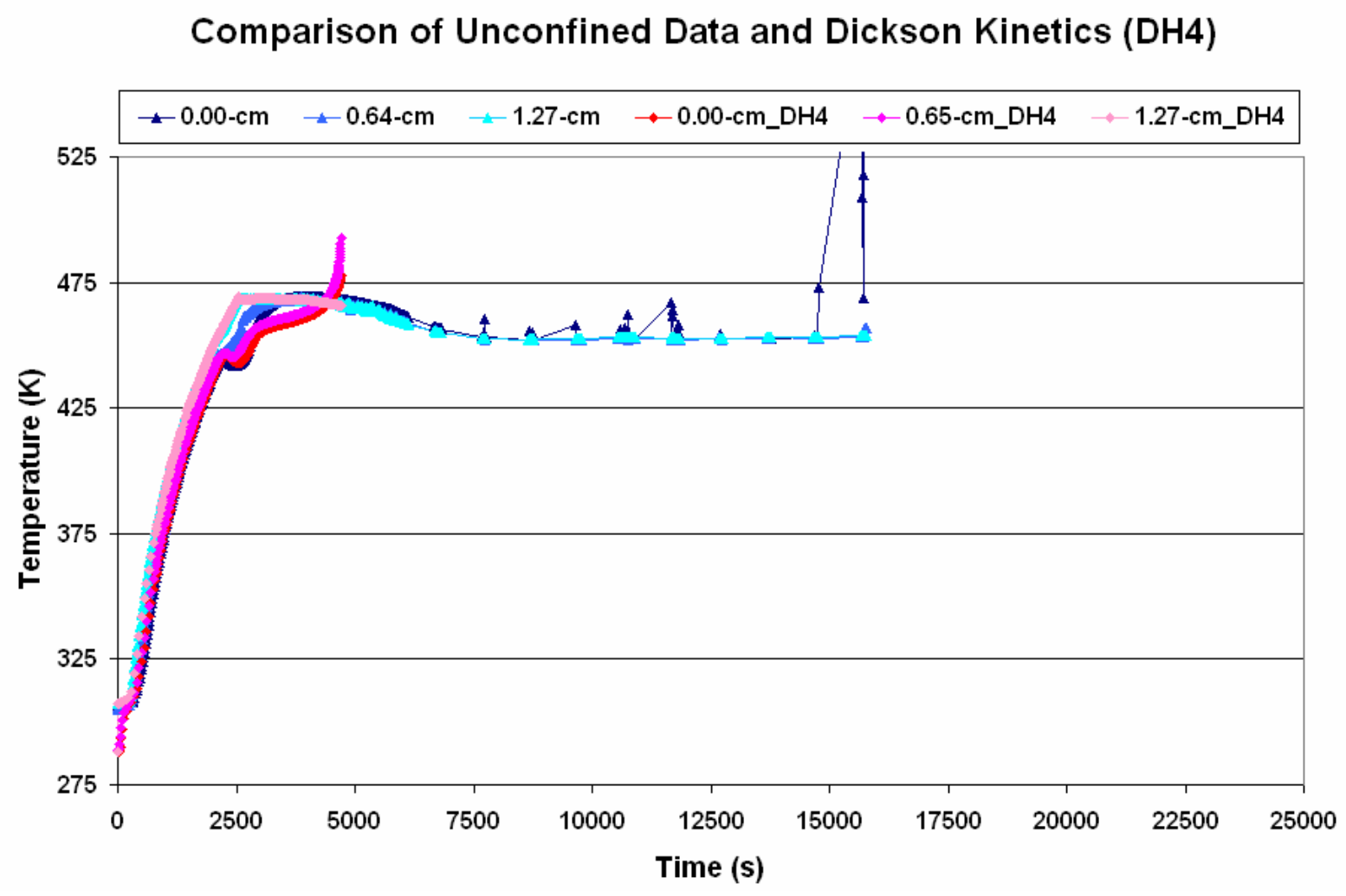

Figure E.3: Comparison of the thermocouple data and the numerical results of the Dickson et al. kinetics for Experiment 4. 


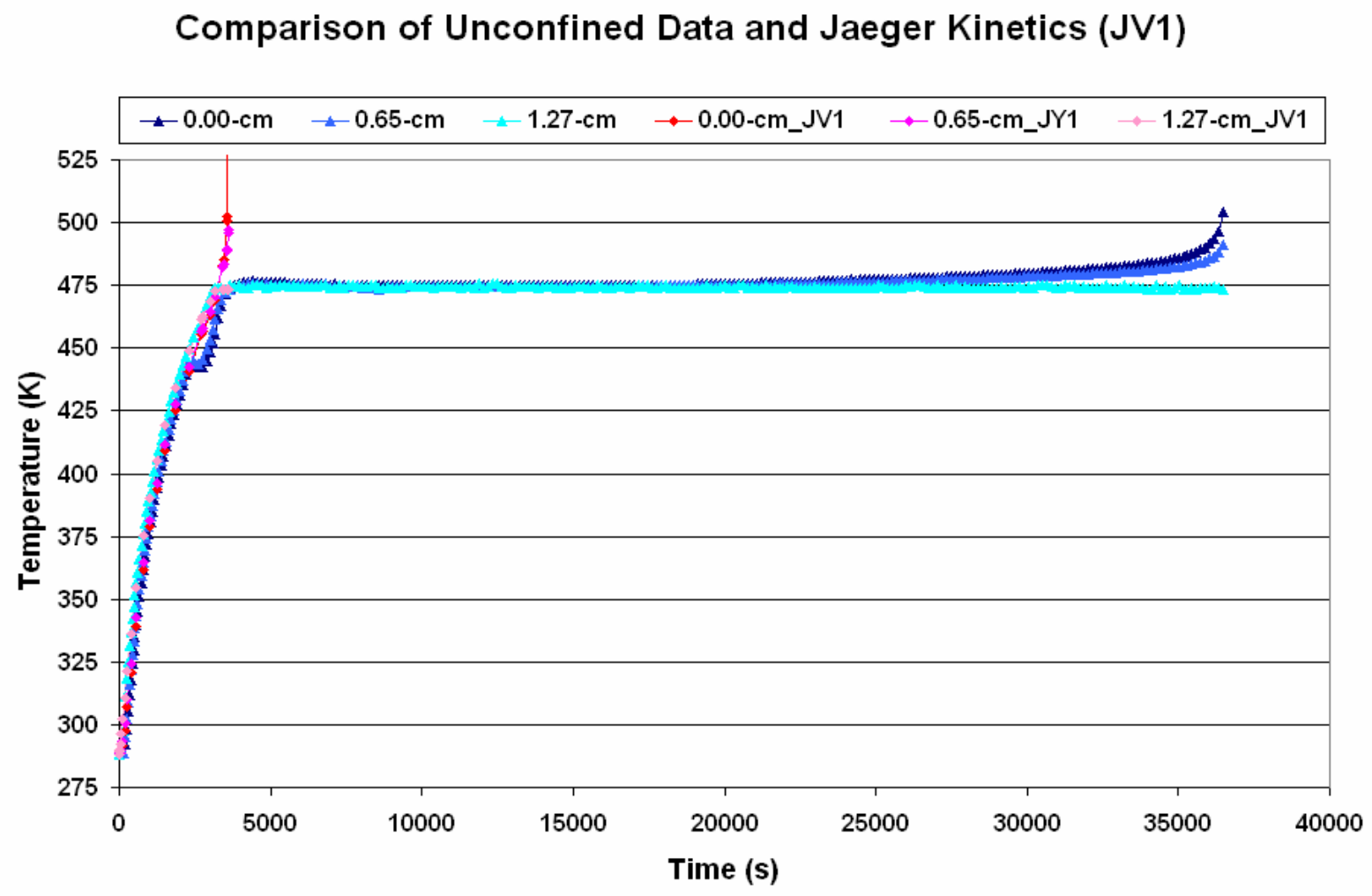

Figure E.4: Comparison of the thermocouple data and the numerical results of the Jaeger kinetics for Experiment 1. 


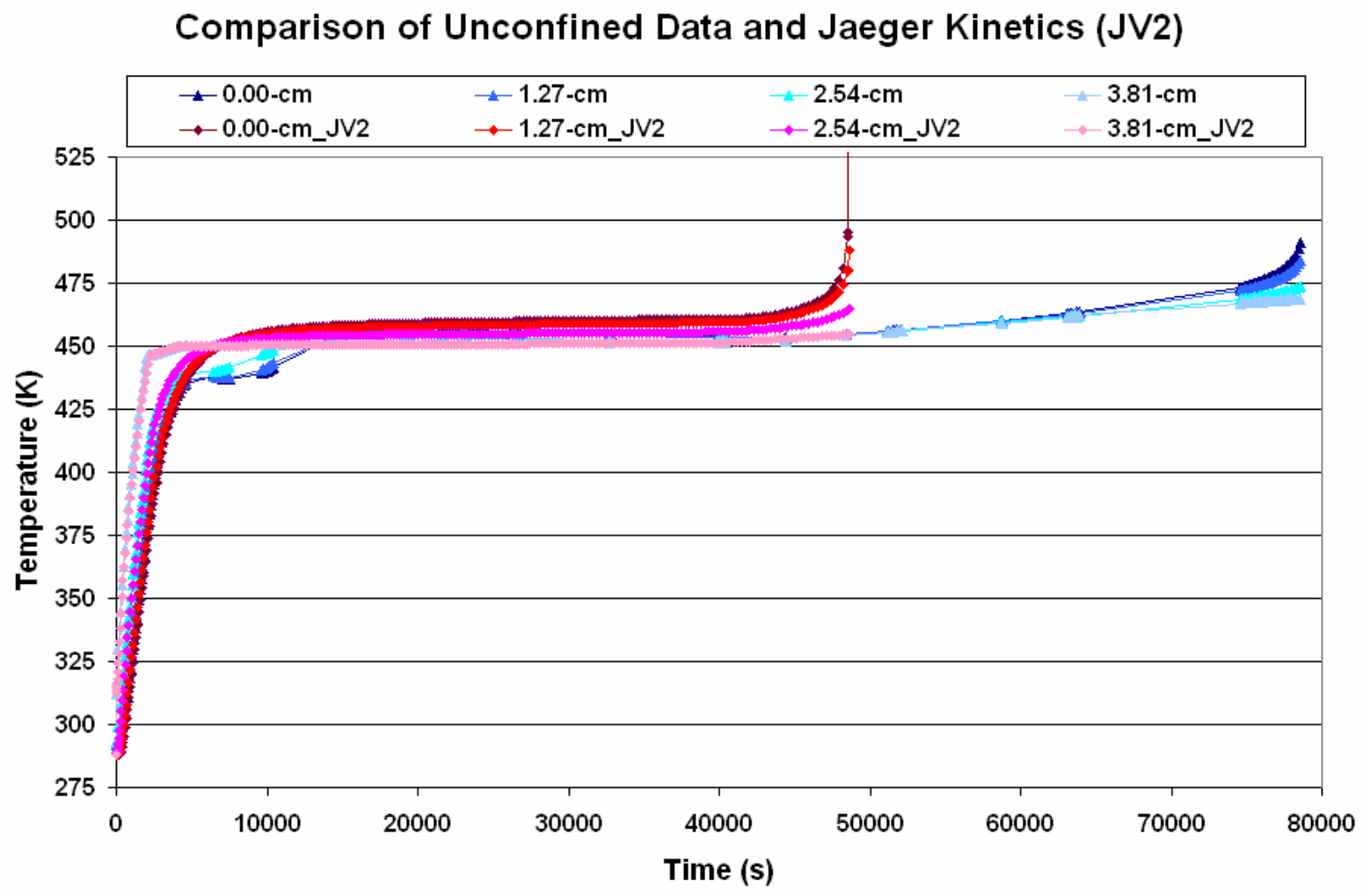

Figure E.5: Comparison of the thermocouple data and the numerical results of the Jaeger kinetics for Experiment 2. 


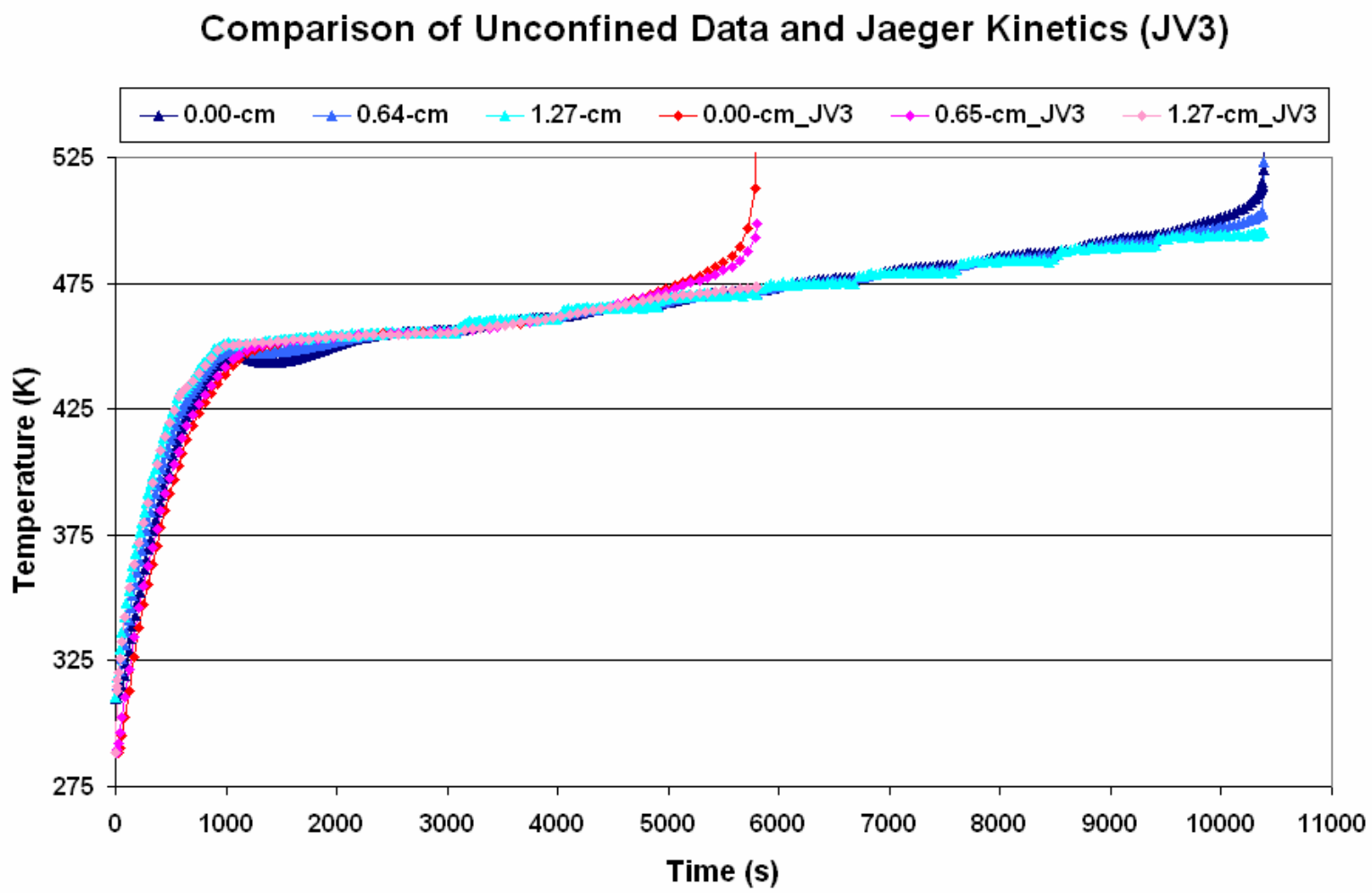

Figure E.6: Comparison of the thermocouple data and the numerical results of the Jaeger kinetics for Experiment 3. 


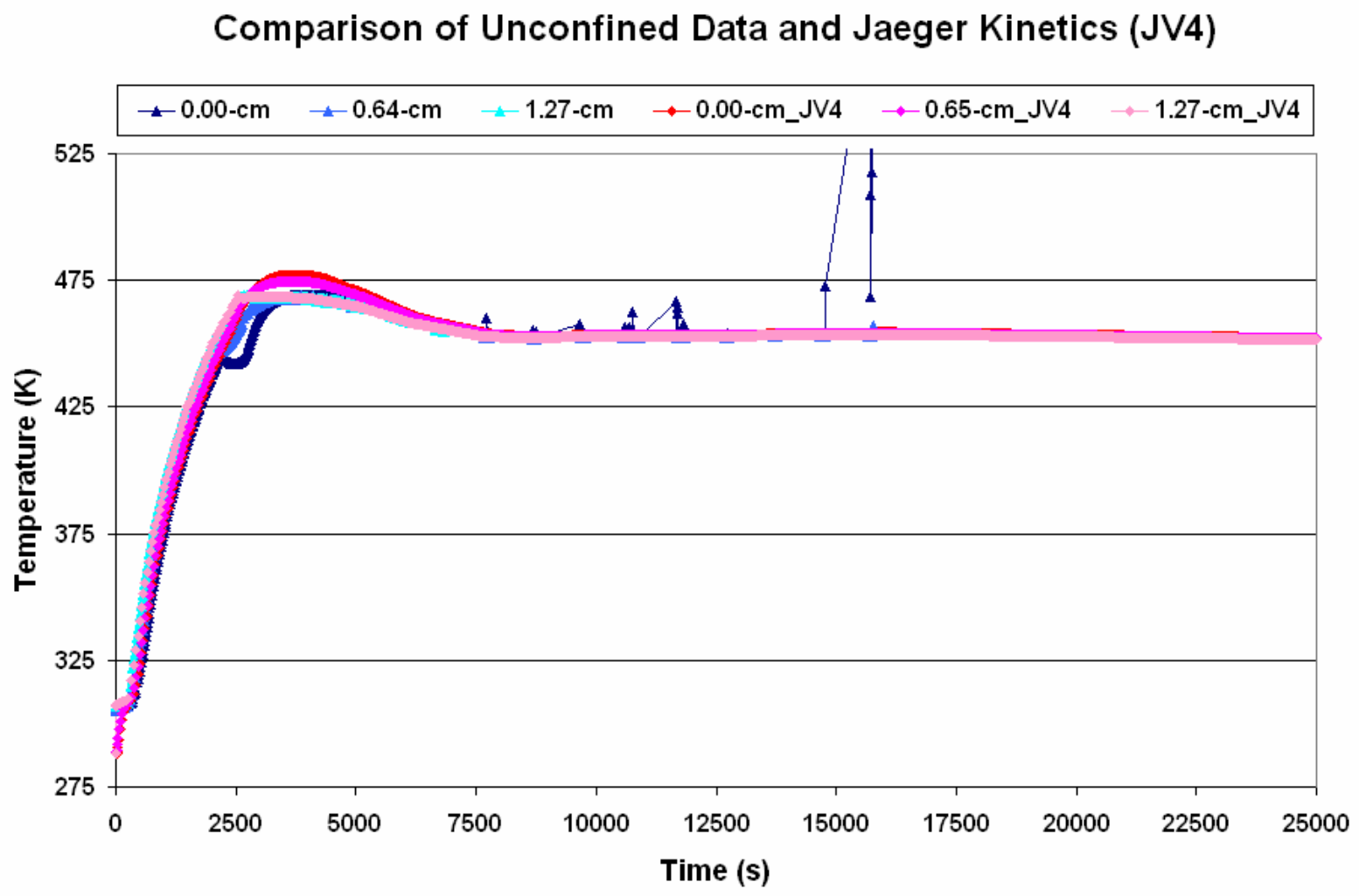

Figure E.7: Comparison of the thermocouple data and the numerical results of the Jaeger kinetics for Experiment 4. 


\section{Comparison of Unconfined Data and Tarver Kinetics (TM1)}

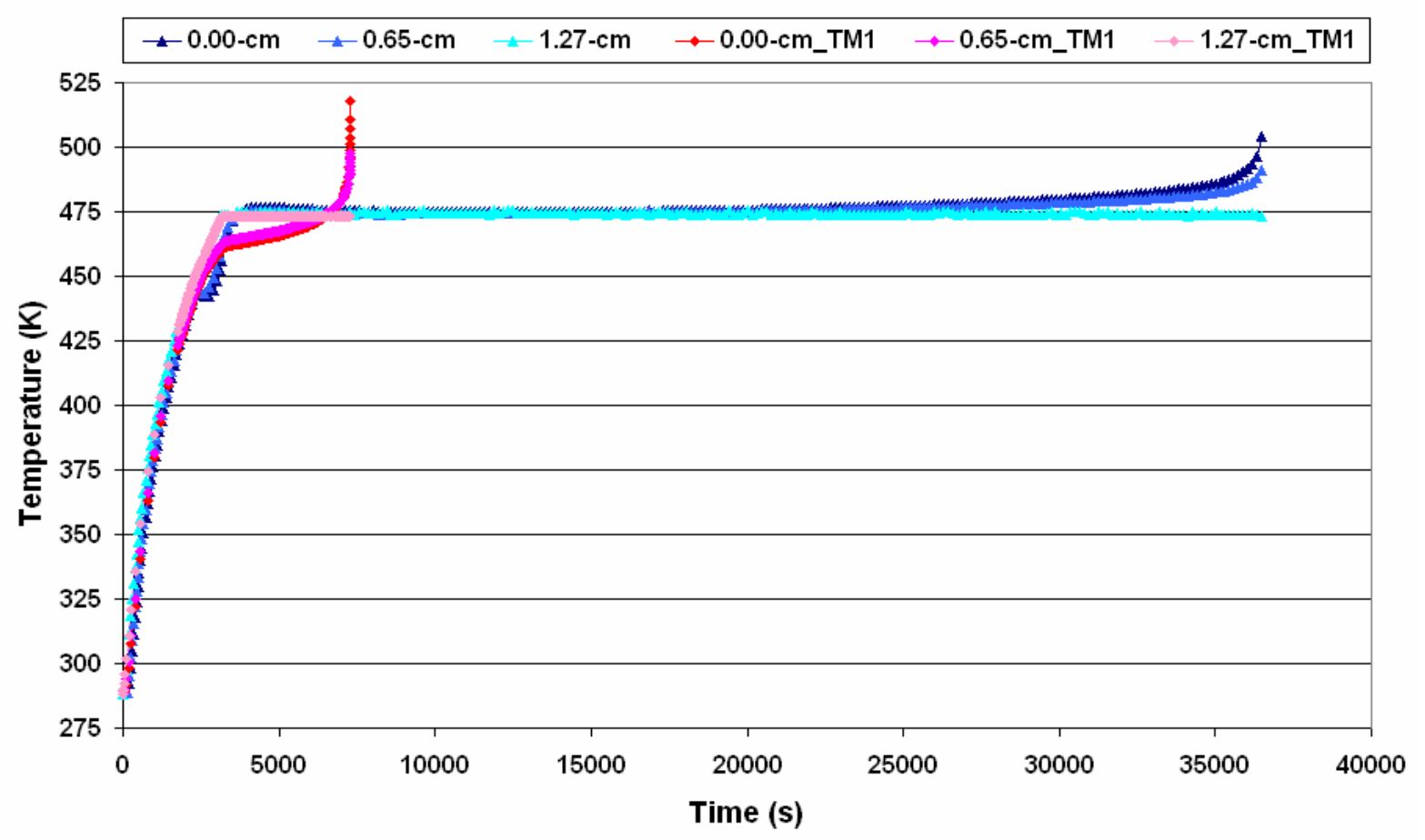

Figure E.8: Comparison of the thermocouple data and the numerical results of the Tarver kinetics for Experiment 1. 


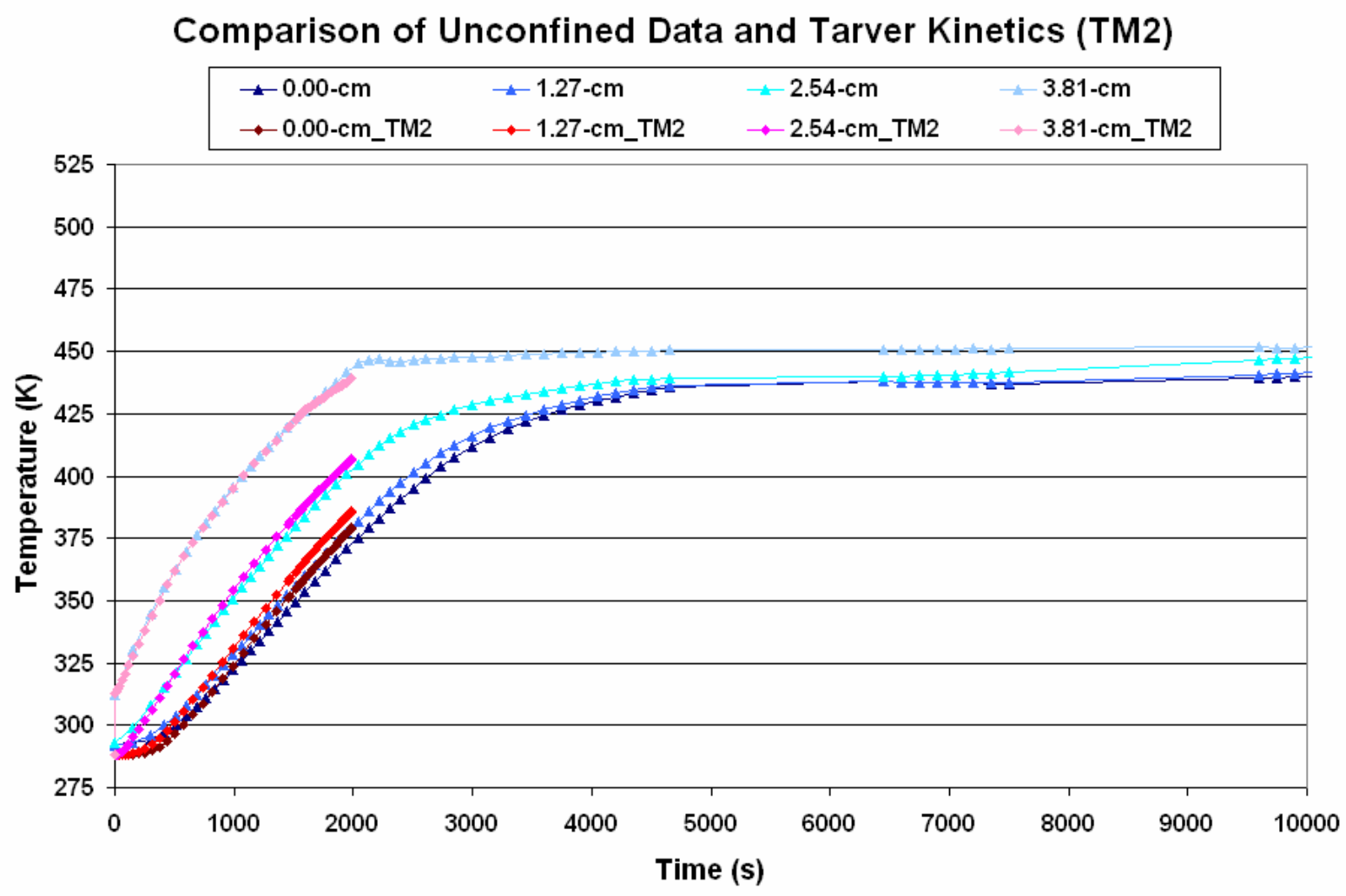

Figure E.9: Comparison of the thermocouple data and the numerical results of the Tarver kinetics for Experiment 2. 


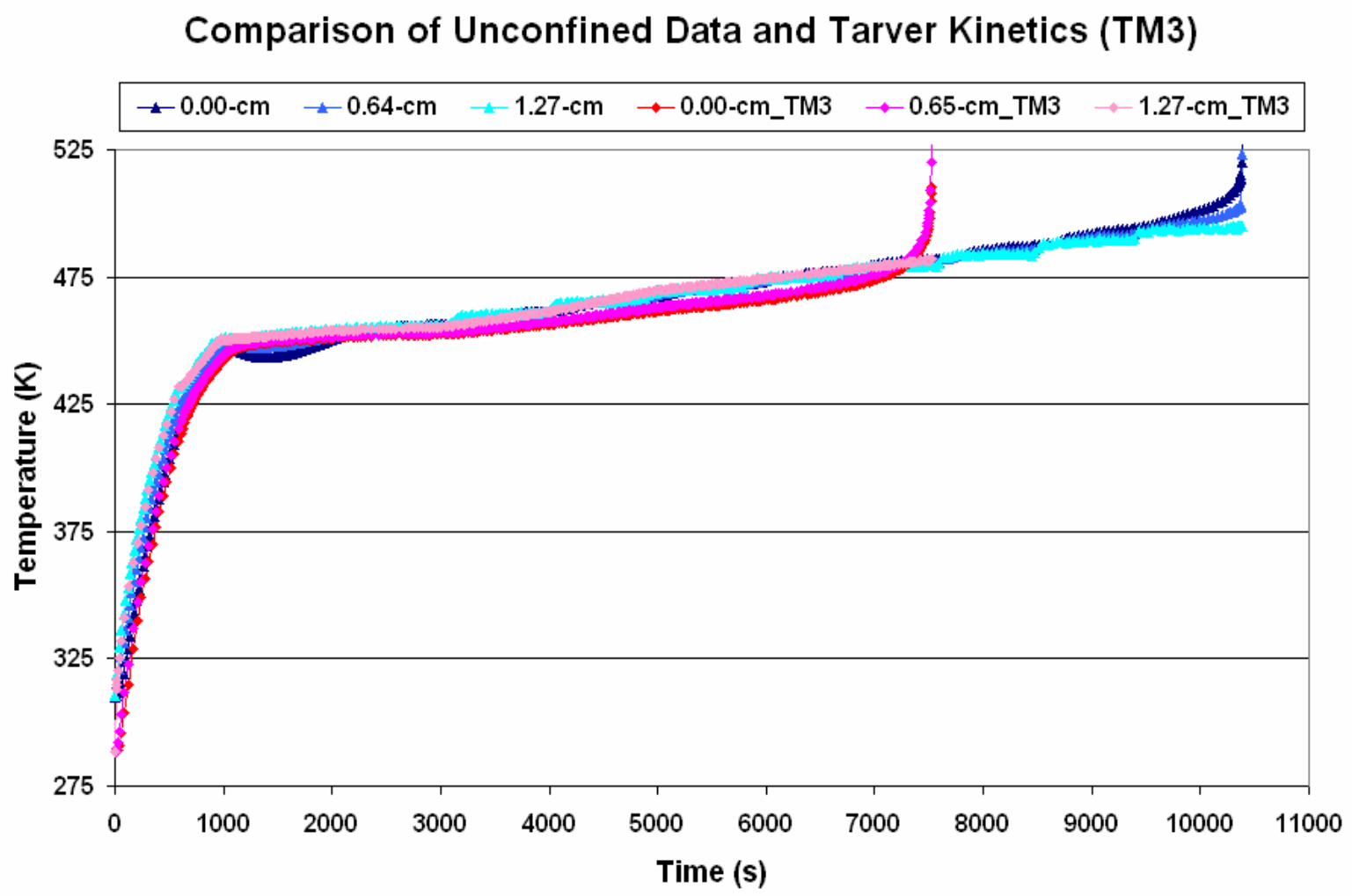

Figure E.10: Comparison of the thermocouple data and the numerical results of the Tarver kinetics for Experiment 3. 


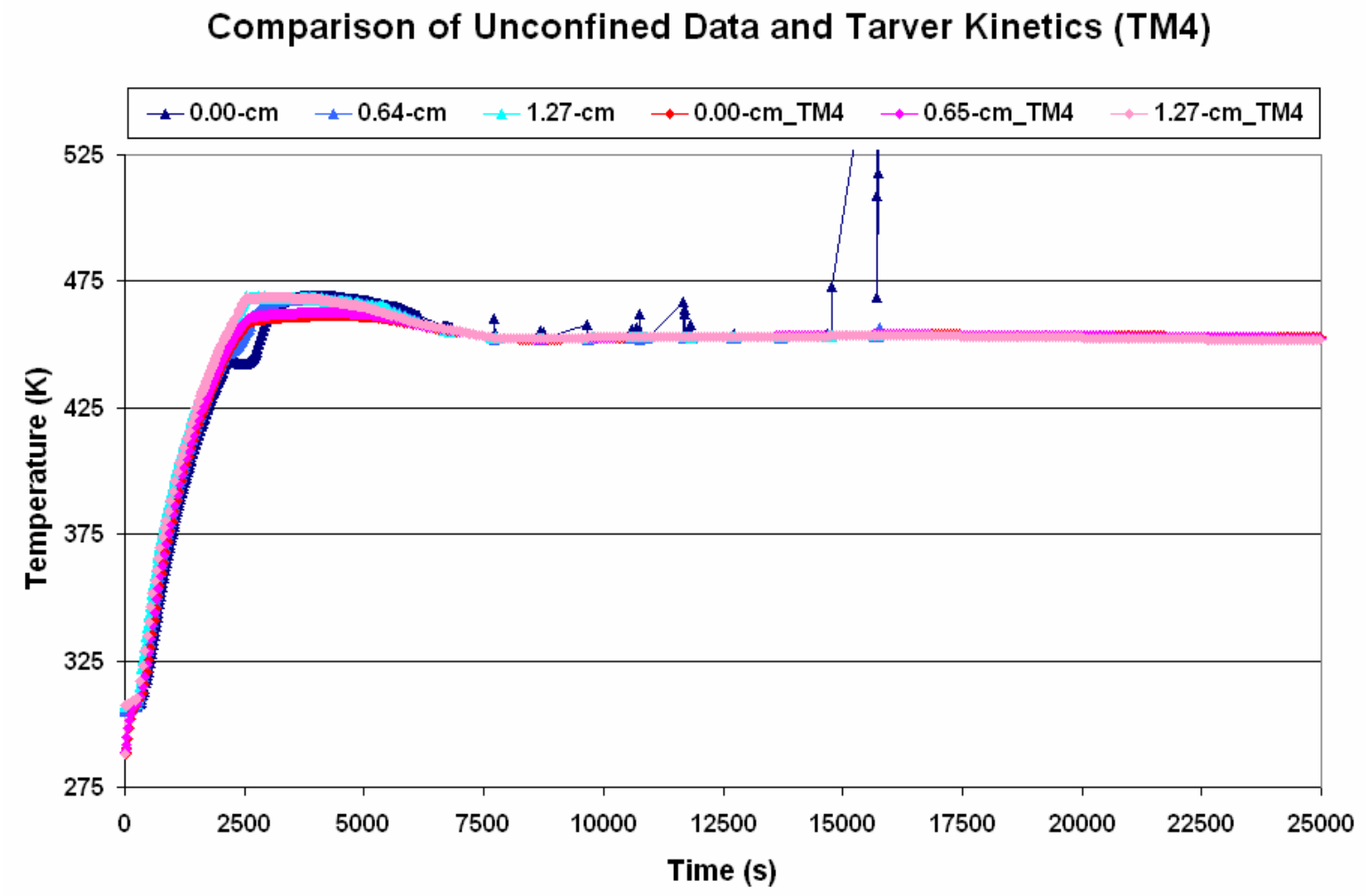

Figure E.11: Comparison of the thermocouple data and the numerical results of the Tarver kinetics for Experiment 4. 



\section{REFERENCES}

1. Robertson, A. J. B.; The Thermal Decomposition of Pentaerythritol Tetranitrate, Nitroglycerin, Ethylenediamine Dinitrate and Ammonium Nitrate. Journal of the Society of Chemical Industry-London; 1948; v. 67, no. 6, pp. 221-224

2. Henkin, H.; McGill, R.; Rates of Explosive Decomposition of Explosives - Experimental and Theoretical Kinetic Study as a Function of Temperature. Industrial and Engineering Chemistry; 1952; v. 44, no. 6, pp. 1391-1395

3. Zinn, J.; Mader, C. L.; Thermal Initiation of Explosives. Journal of Applied Physics; Feb 1960; v. 31, no. 2, pp. 322-328

4. Zinn, J.; Rogers, R. N.; Thermal Initiation of Explosives. Journal of Physical Chemistry; 1962; v. 66, no. 12, pp. 2646-2653

5. Rogers, R. N.; Smith, L. C.; Estimation of Preexponential Factor from Thermal Decomposition Curve of an Unweighed Sample. Analytical Chemistry; 1967; v. 39, no. 8, pp. 1024-1025

6. Rogers, R. N.; Simplified Determination of Rate Constants by Scanning Calorimetry. Analytical Chemistry; 1972; v. 44, no. 7, pp.1336-1337

7. Jaeger, Dwight L.; Thermal Response of Spherical Explosive Charges Subjected to External Heating. Los Alamos Scientific Laboratory, Aug. 1980 (LA-8332)

8. McGuire, R.R.; Tarver, C. M.; Chemical Decomposition Models for the Thermal Explosion of Confined HMX, TATB, RDX, and TNT Explosives. Lawrence Livermore National Laboratory, March 26, 1981 (UCRL-84986)

9. Dickson, P. M.; Asay, B. W.; Henson, B. F.; Fugard, C. S.; Wong, J.; Measurement of Phase Change and Thermal Decomposition Kinetics Using the Los Alamos Radial Cookoff Test. Los Alamos National Laboratory, 1999 (LA-UR-99-3272)

10. Gartling, David K.; Hogan, Roy E.; Glass, Michael W.; COYOTE - A Finite Element Computer Program for Nonlinear Heat Conduction Problems: Part I-Theoretical Background. Sandia National Laboratory, Dec. 2001; Version 4.25, pp. 3-13

11. Wardell, J. F.; Maienschein, J. L.; The Scaled Thermal Explosion Experiment. Twelfth Symposium (International) on Detonation, Aug. 11-16, 2002; San Diego, CA; Lawrence Livermore National Laboratory 
12. Catalano, E.; McGuire, R.; Lee, E. L.; Wrenn, E.; Ornellas, D.; Walton, J.; The Thermal Decomposition and Reaction of Confined Explosives. Sixth Symposium (International) on Detonation, 1976, Office of Naval Research, ACR-221, Coronado, CA; pp. 214-223

13. Popolato, A.; Ruminer, J. J.; Vigil, A. S.; Kernodle, N. K.; Jaeger, D. L.; Thermal Response of Explosives Subjected to External Heating. Los Alamos Scientific Laboratory, Feb. 1979 (LA-7667-MS)

14. Atwood, A. I.; Curran, P. O.; Bui, D. T.; Boggs, T. L.; Energetic Material Response in a Cookoff Model Validation Experiment. Naval Air Warfare Center Weapons Division

15. Wardell, Jeffrey; correspondence with Lawrence Livermore National Laboratory, Experiments from Jan. 2002

16. Curran, Pat; correspondence with Naval Air Warfare Center Weapons Division, Experiments from Nov. 2001

17. Aviles-Ramos, Cuauhtémoc, Three-Dimensional Finite Element Simulations of the LANL Large Scale Annular Cookoff Experiments Designated as Shot 5, Shot 6, and Shot 8, Los Alamos National Laboratory, 2004 (LA-UR-04-2870)

18. Gartling, David K.; Hogan, Roy E.; Glass, Michael W.; COYOTE - A Finite Element Computer Program for Nonlinear Heat Conduction Problems: Part I - User's Manual. Sandia National Laboratory; Dec. 2001; Version 4.25, pp. 167-170

19. Davis, Lloyd; Thermal Analysis of PBX 9501 and PBX 9407, memorandum DX-2:05-096 to Pete Pittman, Los Alamos National Laboratory, July 2005 
This report has been reproduced directly from the best available copy. It is available electronically on the Web (http://www.doe.gov/bridge).

Copies are available for sale to U.S. Department of Energy employees and contractors from:

Office of Scientific and Technical Information

P.O. Box 62

Oak Ridge, TN 37831

(865) 576-8401

Copies are available for sale to the public from: National Technical Information Service

U.S. Department of Commerce

5285 Port Royal Road

Springfield, VA 22161

(800) 553-6847 
- Los Alamos NATIONAL LABORATORY

EST.1943 